\title{
Working time arrangements, work-family conflict, and fatigue
}

Citation for published version (APA):

Jansen, N. W. H. (2003). Working time arrangements, work-family conflict, and fatigue. [Doctoral Thesis, Maastricht University]. Datawyse / Universitaire Pers Maastricht. https://doi.org/10.26481/dis.20031219nj

Document status and date:

Published: 01/01/2003

DOI:

10.26481/dis.20031219nj

Document Version:

Publisher's PDF, also known as Version of record

\section{Please check the document version of this publication:}

- A submitted manuscript is the version of the article upon submission and before peer-review. There can be important differences between the submitted version and the official published version of record.

People interested in the research are advised to contact the author for the final version of the publication, or visit the DOI to the publisher's website.

- The final author version and the galley proof are versions of the publication after peer review.

- The final published version features the final layout of the paper including the volume, issue and page numbers.

Link to publication

\footnotetext{
General rights rights.

- You may freely distribute the URL identifying the publication in the public portal. please follow below link for the End User Agreement:

www.umlib.nl/taverne-license

Take down policy

If you believe that this document breaches copyright please contact us at:

repository@maastrichtuniversity.nl

providing details and we will investigate your claim.
}

Copyright and moral rights for the publications made accessible in the public portal are retained by the authors and/or other copyright owners and it is a condition of accessing publications that users recognise and abide by the legal requirements associated with these

- Users may download and print one copy of any publication from the public portal for the purpose of private study or research.

- You may not further distribute the material or use it for any profit-making activity or commercial gain

If the publication is distributed under the terms of Article $25 \mathrm{fa}$ of the Dutch Copyright Act, indicated by the "Taverne" license above, 
WORKING TIME ARRANGEMENTS,

WORK-FAMILY CONFLICT, AND FATIGUE 
ISBN 90-5278-396-9

Lay-out: Marliese Saya | Nicole Jansen, Epidemiologie, Universiteit Maastricht Cover: Robert Frings | Nicole Jansen

Production: Datawyse | Universitaire Pers Maastricht

(c) 2003, N.W.H. Jansen

All rights reserved. No part of this thesis may be reproduced or transmitted in any form or by any means, electronic or mechanical, including photocopying, recording or any information storage or retrieval system, without permission in writing from the author, or, when appropriate, from the publishers of the publications. 


\title{
WORKING TIME ARRANGEMENTS, WORK-FAMILY CONFLICT, AND FATIGUE
}

\author{
PROEFSCHRIFT
}

ter verkrijging van de graad van doctor aan de Universiteit Maastricht, op gezag van de Rector Magnificus,

Prof. dr. A.C. Nieuwenhuijzen Kruseman, volgens het besluit van het College van Decanen, in het openbaar te verdedigen op vrijdag 19 december 2003 om 14.00 uur

dloor

Nicole Wilhelmina Hendrika Jansen

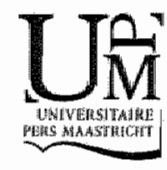




\section{Promotores}

Prof. dr. ir. P.A. van den Brand

Prof dr. F.J.N. Nijhuis

\section{Co-promotor}

Dr.ing. H. Kant

\section{Beoordelingscommissie}

Prof. dr. J. van Eijk (voorzitter)

Prof. dr. F.J.H. van Dijk (Coronel Instituut voor Arbeid, Milieu en Gezondheid/ Universiteit van Amsterdam)

Dr. J.A. Landeweerd

Prof. dr. T.F. Meijman (Rijksuniversiteit Groningen)

Prof. dr. N. de Vries

The Maastricht Cohort Study is part of the Netherlands concerted research action on "Fatigue at Work" granted by the Netherlands Organization for Scientific Research (NWO). The study presented in this thesis was supported by the Netherlands Organization for Scientific Research (NWO grant no. 580-02.201).

The study presented in this thesis was performed at the Care and Public Health Research Institute (Caphri), which participates in the Netherlands School of Primary Care Research (accredited by the Royal Dutch Academy of Sciences (KNAW)). 
Voor miln auders 



\section{CONTENTS}

1 Introduction

2 Need for recovery in the working population:

Description and associations, with fatigue and psychological distress

$3 \quad$ Need for recovery from work: Evaluating short-term effects

of working hours, patterns and schedules

$4 \quad$ Work schedules and fatigue: A prospective cohort study

5 Direction of shift rotation in three-shift workers in relation to psychological health and work-family conflict

6 Prevalence of common infections among employees in different work schedules

7 Antecedents and consequences of work-family conflict: A prospective cohort study

8 Impact of working time arrangements on work-home interference among Dutch employees

9 Work-family conflict as a risk factor for sickness absence

10

$$
\text { Epilogue }
$$

Surnmary

Samenvatting

Dankwoord

About the author 

Introduction 
The way working time arrangements are designed nowadays is largely influenced by historical developments. Towards the end of the nineteenth century the industrial and economic expansion made many people move from the countryside to live in the fast growing and overcrowded cities to work in the factories. They were no longer selfsupporting but became dependent on an employer. Both men and women, and even young children were employed in the factories. Working in the factories was low paid. with poor working conditions, where employees had to work long hours under appalling circumstances. A 16-hour working day was no exception. In some companies people even had to work for 24 hours in succession. As noted by Wohl in his description of public health in Victorian Britain" and further illustrated by Mclvor," ${ }^{3}$ "for industrial workers the working day meant early starts, long hours, and often physically demanding labor conditions that would have challenged even the strongest constitutions. To start work at 6 am, perhaps after walking through sleet and rain, and to continue at it all day in overheated, draughty, or ill-ventilated workrooms meant for many a slow process of physical decline or a life lived continuously on the brink of exhaustion. For those workers already weakened by the insidious effects of the urban and domestic emvironment, working conditions could literally mean the difference between life and death". The poor working conditions of these workers became of ever greater concern and called for active interference. In Europe, the actual beginning of government intervention and legal labor protection of workers can be dated back to the last quarter of the nineteenth century. In the Netherlands this process started with the intraduction of Van Houten's Child labor law in $1874^{1,4}$ that prohibited working for children under age twelve, with the exception of agricultural work and domestic chores. Since then many labor laws followed and also the labor inspection was introduced to check compliance with the law.

In the Netherlands, the labor law from 1919 is particularly noteworthy "which pursued reduced working hours and for the first time drew attention to mental health and well being of workers. By limiting working hours of employees, the labor law from 1919 aimed at preventing excessive fatigue on the one hand, and at providing workers with a sufficient amount of time for personal growth and relaxation, also in the interest of the family and society. "This attention for mental health and well being has been part of all following labor laws, including the European framework directive on health and safety at work of $1989(89 / 391 / \mathrm{EEC})^{5}$ and the Dutch Occupational Health and Safety Act of $1998_{2}{ }^{6}$ in which safety, health and well being of employees are regulated.

\section{RECENT TRENDS IN WORK AND THE DIVISION OF HOUSEHOLD AND LABOR}

Due to labor legislation many unhealthy physical, chemical, ergonomic and biological exposures in the work situation have been eliminated or substantially reduced, as have the accompanying diseases. In the last decades, however, other features and changes with regard to work appeared, that might affect employee health and well being as well. These changes have primarily occurred in three related domains, concerning working time arrangements, job content and the division of household and labor. 


\section{Changes in working time arrangements}

With regard to working hours, in the twentieth century considerable reductions in working time emerged. Where employees worked about 48 hours a week in 1960 , a contractual working week of 36 to 38 hours a week is now very common in the Netherlands. ${ }^{7}$ The latter is mainly organized, however, as actually working 40 hours per week, providing employees with more leisure days during the year. Working time is no longer automatically organized on a weekly or annual basis, but a more flexible approach is being adopted. Not only are working hours spread over all days of the week and all hours of the day, there are also flexible patterns within time schedules, with $24 \%$ of European workers reporting fluctuating weekly work schedules and $41 \%$ reporting fluctuating daily work schedules. ${ }^{3}$ Many work situations also require frequent overtime work due to tight deadines, understaffing or emergency contingencies. ${ }^{\text {th }}$ The reorganization of working time arrangements in recent decades is partly due to advances in technology and industry, but is mainly driven by employer's demands for greater flexibility in work schedules to cover extended operating or opening hours, predictable peaks in labor demand at different parts of the day, week, or year as well as less predictable requirements for additional cover due to market uncertainty. ${ }^{10,1 \%}$

Working time arrangements can be distinguished in several categories. One distinction is between day work generally indicating working hours between seven am and seven pm, and shift work. Shift work can be defined as work, which includes working outside the normal working hours. Most shift work includes working nights. Shift work schedules can further be divided in discontinuous (two-shift), semi-continuous (three-shift), continuous (four-, five- and six-shift), and irregular work schedules. Figure 1 presents examples of a

\begin{tabular}{|c|c|c|c|c|c|c|c|}
\hline & \multicolumn{7}{|c|}{ Two-shiff work } \\
\hline Week & Mo & Tu & We & Th & $\mathrm{Fr}$ & $\mathrm{Sa}$ & Su: \\
\hline 1 & $M$ & $M$ & $M$ & $M$ & $M$ & 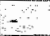 & 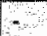 \\
\hline \multirow[t]{2}{*}{2} & $E$ & $E$ & $E$ & $\mathrm{E}$ & $E$ & 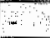 & 8 \\
\hline & \multicolumn{7}{|c|}{ Thee-shift work } \\
\hline Weak & Mo & $\mathrm{Tu}$ & We & Th & $\mathrm{Fr}$ & Sa & Su \\
\hline 1 & M & $M$ & $\mathrm{M}$ & M & $M$ & 2 & + \\
\hline 2 & $\mathrm{M}$ & $N$ & $\mathbb{N}$ & $N$ & $N$ & 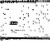 & 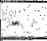 \\
\hline \multirow[t]{2}{*}{3} & $E$ & $E$ & $E$ & $E$ & $E$ & 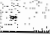 & 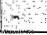 \\
\hline & \multicolumn{7}{|c|}{ Four-shiff worlt } \\
\hline Woek & Mo & Tu & We & Th & $\mathrm{Fr}$ & $\mathrm{Sa}$ & Su \\
\hline 1 & $M$ & $M$ & $M$ & $M$ & $M$ & $M$ & $\mathrm{M}$ \\
\hline 2 & - & $=$ & $E$ & $E$ & $E$ & $E$ & $E$ \\
\hline 3 & $E$ & $E$ & - & - & $N$ & $\mathrm{~N}$ & $\mathrm{~N}$ \\
\hline \multirow[t]{2}{*}{4} & $\mathbb{N}$ & $\mathrm{N}$ & $\mathbb{N}$ & $\mathbb{N}$ & $\therefore$ & 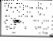 & - \\
\hline & \multicolumn{7}{|c|}{ Five-shiff work } \\
\hline Week & Mo & Tu & We & Th & $\mathrm{Fr}$ & $\mathrm{Sa}$ & Su \\
\hline 1 & - & - & $M$ & $M$ & $M$ & - & + \\
\hline 2 & $\mathrm{~N}$ & $\mathbb{N}$ & $\mathrm{N}$ & $\mathbb{N}$ & - & 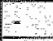 & 3 \\
\hline 3 & $E$ & $\mathrm{E}$ & $E$ & - & - & $M$ & $\mathrm{M}$ \\
\hline 4 & $M$ & $M$ & $\therefore$ & - & $\mathbb{N}$ & $\mathrm{N}$ & $\mathrm{N}$ \\
\hline 5 & - & 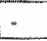 & - & $E$ & $E$ & $E$ & $E$ \\
\hline
\end{tabular}

Figure 1 Examples of schedules in two-shift, three-shift, four-shiff and five-shift work - Day off, $M=$ Morning shift $N=$ Night shife, $E=$ Evening shift 
shift schedule for a team in two-shift, three-shift, four-shift and five-shift work. Studies have shown that shift work is amongst others associated with cardiovascular diseases, ${ }^{12}$ ${ }^{16}$ gastrointestinal diseases, ${ }^{17.20}$ and sleep-wake disorders. ${ }^{18.21 .22}$ Athough shift work has frequently been shown to have detrimental effects on the health of employees, shift work is still becoming increasingly prevalent in contemporary life. ${ }^{23} .24$ Nowadays, about one in five workers in Europe are employed in shift work involving night work. As presented in Figure 2, the proportion of employees employed in shift work involving night work, in the Dutch labor force has slightly increased in the period of 1992 to 2000 .

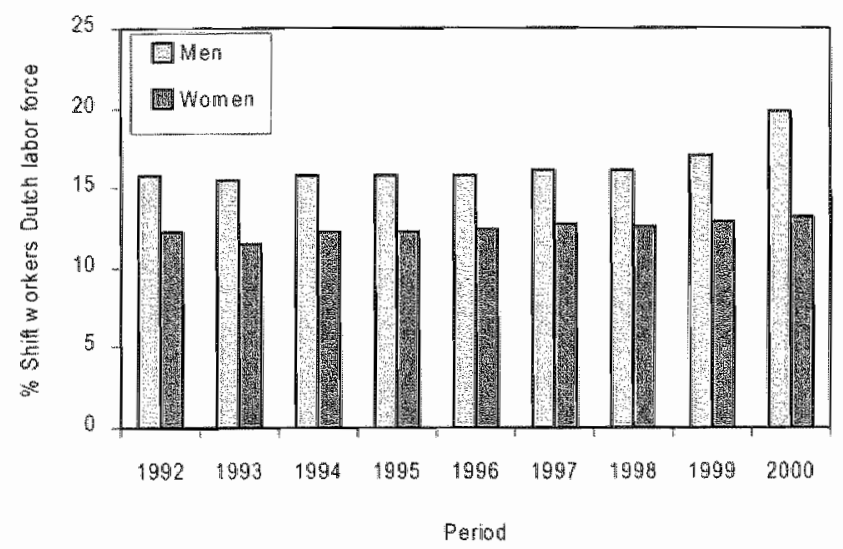

Figure 2 Employees inwolved in shift work (\%) in the Netherlands ( $1992-2000)$

Source: Central Bureau of Statistics, Voorburgitheerten, The Netherlands, 2002

\section{Changes in job content}

The past decades have seen striking developments and changes in the job content of employees. Quantitative and qualitative demands at work are high. Largely, work has changed from manual to mental in nature. Nowadays, for many employees, work primarily poses mental and emotional demands. ${ }^{25}$ A steady increase in workload has been reported. European surveys have shown continuing increases in work intensity and job demands, ${ }^{26}$ whereas job control remained stable between 1995 and 2000 , as reported in the Third European Survey on working conditions. ${ }^{27}$ Results from the Danish Work Environment Cohort Study showed that while low job control slightly decreased in the period of 1990 to 2000 , this decline in job control was fully explained by labor force changes. ${ }^{28}$ More is expected from employees in terms of efficiency, performance, and continuous wocational retraining and in-service training are warranted. ${ }^{29}$ More than half of the respondents in the European Survey on working conditions reported working at very high speed for at least one quarter of their time in 2000 and one in four reported working al high speed all the time or almost all the time. Almost two in three workers had to contend with tight deadiines for at least one quarter of their time in $2000{ }^{27}$ The intensified demands and stable control between 1995 and 2000 suggest that the 
prevalence of job strain has continued to increase in Europe, which should be considered an alarming trend with a potentially dramatic impact on health. ${ }^{26}$

\section{Changes in the division of household and labor}

Apart from these changes in the structure of working time arrangements and changes in job content, that can impact on workers' health, there have been striking alterations in the composition of the labor force and role patterns between men and women as well. Whereas labor force participation of men has remained relatively stable, recent decades have known a remarkable increase in women's employment in the Netherlands (Figure 3).

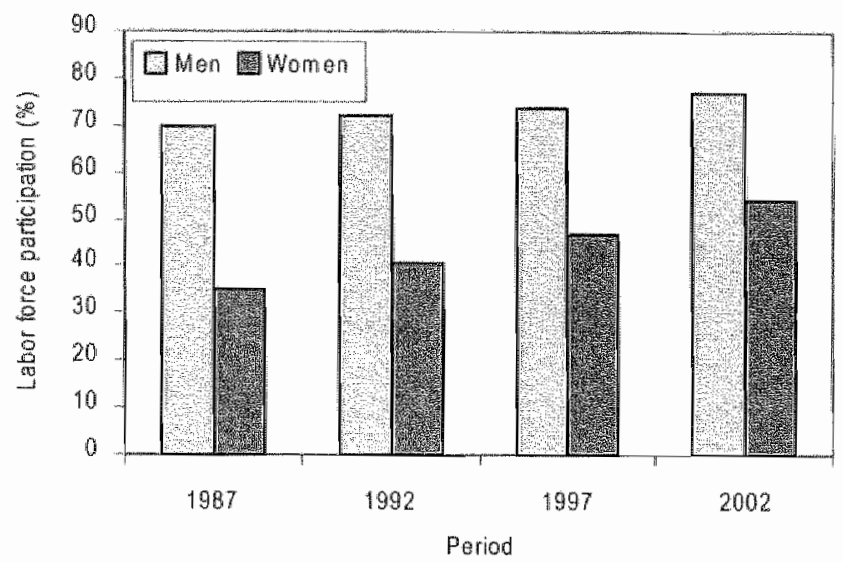

Figure 3 Labor force participation (\%) of men and women in the Nethertands (1987-2002) Source: Ceniral Bureau of Statistics, Voorburghteerlen, 蚆e Netherlands, 2002

Consequently, there has been a large social shift from male breadwinner families to dual-eamer couples and single-parent households. Figure 4 shows the distribution of fulltime and partime work among couples in the Netherlands over the period 1992 to 2001. As presented in Figure 4, the proportion of single-earner couples where the worker is employed fulltime is gradually decreasing in this period, whereas the proportion of dual-earner couples where both partners work partime, as well as the proportion of dualearner couples where one partner works fulltime and the other parttime have increased in this period. Similarly, the proportion of single-earner couples where the breadwinner works partime has increased as well. lin the Netherlands, the so-called one-and-a-half earner model is especially popular, where men are usually fulltime workers and the women partime workers. In 2000, $18.9 \%$ of the male and $67.3 \%$ of the female active workforce worked less than 35 hours a week. ${ }^{30}$ 


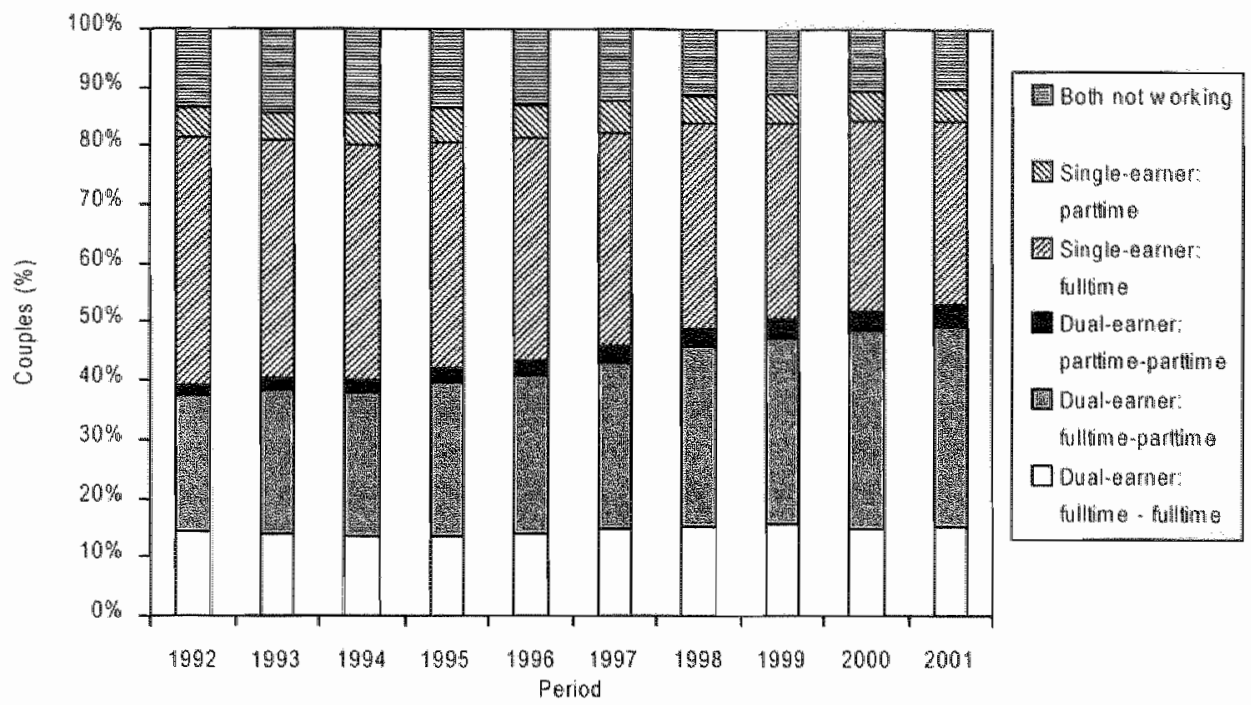

Figure 4 Distribution of working hours anong couples in the Netherlands (1992-2001)

Source: Central Bureau of Statistics, Voorburg/Heerlen, the Netherlands, 2002

The increase in the number of working women also influences the allocation of men's time. In the traditional male breadwinner model men were, as a matter of speaking, fully available for work outside the home. In a dual-earner family, that availlability is far more restricted. $^{31}$ So far, however, task divisions in the household have not changed substantially between men and women. In all European countries, women spend on average more hours on household tasks than their husbands do, regardless of the number of hours they work outside the home. ${ }^{32}$ To facilitate employees' abilities to combine caring tasks at home with paid jobs elsewhere, provisions are needed, such as childcare facilities, partime work, flexible working hours, or possibilities for parental leave. ${ }^{31}$ Although working time arrangements may facilitate the reconciliation of work and family life in some ways, it is also conceivable that certain characteristics of working time arrangements may have a negative impact on the ability to adequately combine work and familly life.

\section{CONSEQUENCES OF THE TRENDS IN WORK AND THE DIVISION OF HOUSEHOLD AND LABOR}

Effects of the described changes in working time arrangements, job content and the division of household and labor may develop on several domains. One of these domains can be found in fatigue. Working time arrangements for example will provide employees to a large extent with the actual time and timing to recover from their working day. Insufficient recovery from work may result in increased fatigue. Fatigue is a prominent 
issue in Europe. According to a study among 21,500 European employees, fatigue belongs to the most common work-related health problems." In the Netherlands specifically, the prevalence of fatigue was $22 \%$ in a cohort study of 12,095 Dutch employees. These high levels of fatigue may partly explain why mismatches between work and employees are increasingly manifested in psychosomatic diseases and psychological dysfunctioning, where fatigue often thas a large share.

A. second domain could be made up by the reconciliation of work and family life. The rapid changes in the domains of work and caring tasks have resulted in more and more people struggling to combine work with family matters. The developments with regard to working time arrangements, where overtime work for instance poses high extensive demands for the worker, may result in a time conflict for finetuning work and familly life. Furthermore, the trends with regard to the job content, posing intensified demands for example with regard to working with tight deadlines, may result in having too few energy left for dealing with family matters.

In this thesis the main focus will be on the impact of various aspects of working time arrangements on fatigue related outcomes on the one hand and on the (in)ability of employees to adequately combine work and family on the other. Working time arrangements are in essence modifiable factors that can be subject to change when necessary or requested. When working time arrangements prove to be important factors affecting fatigue and the combining of work and family, working time arrangements could constitute clear utilizable tools for the prevention or reduction of fatigue among employees and for facilitating an adequate work-family balance.

\section{WORKING TIME ARRANGEMENTS AND FATIGUE}

When studying the effects of working lime arrangements on fatigue, it is important to note that we view fatigue, in line with Lewis and Wessely, ${ }^{34}$ as a continuum ranging from mild, frequent complaints seen in the community to the severe, disabling fatigue characteristics of burnout, overstrain or chronic fatigue syndrome. Therefore, in the present thesis, we will include different fatigue related outcomes. Need for recovery from work ${ }^{35-37}$ was defined as the need to recuperate from work-induced fatigue, primarily experienced after a day of work. The concept involves the intensity of work-induced fatigue, both mentally and physically, as well as the time period required to return to a normal or prestressor level of functioning. Repeated insufficient recovery from workinduced fatigue is seen as the start of a vicious circle where extra effort has to be exerted at the beginning of every new working period to rebalance the suboptimal psycho-physiological state, and to prevent performance breakdown. ${ }^{36,38}$ Need for recovery is considered relevant as a mediating or moderating characteristic in the etiology of prolonged fatigue. ${ }^{39}$ Prolonged fatigue is not easily reversible in the short-term and not task-specific, ${ }^{40}$ and the compensating mechanisms that were useful in reducing acute fatigue are no longer effective. ${ }^{41}$ Prolonged fatigue affects the individual's performance in the work and home setting and may lead to sick leave and work disability. ${ }^{42,43}$ 
Working too many shifts in succession, having too short a period of rest in between two shifts, working frequent overtime, or having to sacrifice days off, can all have a strong negative impact on the opportunity to recover from fatigue at work. ${ }^{4}$ Some studies have already revealed that long working hours are associated with poor psychological health. ${ }^{45,46}$ As regards work schedules, various studies have demonstrated that shift workers generally report more fatigue than day workers. ${ }^{22.47}$ in a study by Rosa et al. ${ }^{49}$ it was found that perceived muscular fatigue increased more quickly across the night shifts compared with day shifts. Accumulated fatigue across consecutive workdays was illustrated in a study by Schroeder et all." where progressive increases in choice reaction time were apparent across a 5-day week of 8-hour shifts and a 4-day week of 10-hour shifts in air traffic control specialists. Fatigue might accumulate and build up over time, for example in work schedules with too short resting periods between the shifts, which do not allow employees to completely recover. It is hypothesized that shift work will be associated with higher fatigue levels over time as compared to day work and that within day work overtime work and long working hours will be associated with higher fatigue levels as well.

When studying the role of working time arrangements in fatigue related outcomes, the impact of other work-related factors should be taken into account. Work-related factors such as psychological job demands, physical and emotional demands, are important risk factors for prolonged fatigue. ${ }^{50}$ Moreover job demands often differ between shift workers and day workers ${ }^{54}$ as well as between fulltime and parttime workers. ${ }^{52}$

\section{WORKING TIME ARRANGEMENTS AND COMBINING WORK AND FAMILY LIFE}

The challenge of adequately balancing work and family has drawn increased attention in public debate, governmental policy and research. As regards combining work and family life, in this thesis the main focus will be on those employees who are unable to combine work and family life adequately, or experience work-family conflict. Work-family conflict is defined as a perception of insufficient energy and/or time to successfully perform work and family roles. ${ }^{53}$

Whereas the amount of time demanded by work and the pattern or timing of work within the day are among the most obvious ways in which work can affect family life, and although working hours and work schedules are in essence modifiable factors that can be subject to change when necessary or requested, the role of specific characteristics of working time arrangements in combining work and family life is relatively unknown. For example, employees involved in shift work or those who work long hours may experience considerable disruption of family and social activities, because many of these rhythms of the general population are oriented around the day. ${ }^{54}$ It is therefore hypothesized that work-family conflict may be higher among shift workers as compared to day workers. With regard to day workers specifically, subgroups may be defined with increased risks of work-family conflict. Many employees, mainly women, often change from fullime to parttime jobs at one point during their career because of an incapability to combine work 
and family life adequately. ${ }^{\text {sis }}$ Hence, partime work could be used as a coping strategy to meet conflicting claims on time and availability and to reconcile family and work. ${ }^{31}$ It is hypothesized that partime work is associlated with less work-family conflict as compared to fultume work. Further, in many cases, work hours and schedules vary from week to week and are not posted far enough in advance to enable employees to plan ahead and this unpredictability may interfere with the employee's ability to make commitments. ${ }^{56}$ Apart from the distinction between fultime and partime workers in day work, it is hypothesized that other characteristics of working time arrangements, such as flexible working hours, control over working hours and predictability of working hours are associated with less work-family conflict.

\section{WORK-FAMILY CONFLICT AND FATIGUE}

Work-family conflict itself may have important implications for mental health "because those employees who are struggling to combine work and family life probably have less time available to recuperate from their carefully planned and hectic day, causing fatigue levels to accumulate and build up over time. It is hypothesized that work-family conflict is associated with increased fatigue over time. Several outcomes have already been associated with work-family conflict. Allen et al. ${ }^{57}$ revilewed consequences of work-family conflict, with examples being job dissatisfaction, job burnout, turnover, psychological distress, depression, life dissatisfaction, and marital dissatisfaction. Most research on the consequences of work-family conflict so far, however, has been cross-sectional in nature, and therefore the direction of influence is difficult to interpret. Hence, a need exists for longitudinal studies to examine prospective relationships between work-family conflict and mental health related outcomes, such as fatigue.

Other consequences of work-family conflict could be reflected in increased absenteeism of employees. In a study by Goff et al. ${ }^{5 B}$ it was found that lless work-family conflict was related to lower levels of absenteeism. When the demands of work and family are incompatible, and for example demands at horme such as taking care for sick children can neither be delayed nor ignored, employee absence is likely ${ }^{59}$ and may constitute a way to (temporarily) cope with the situation. It is therefore hypothesized that employees repoiting work-family conflict may be at greater risk for sickness absenteeism. There is only limited information available on a possible relationship between work-family conflict and employee absenteeism. Perhaps more companies and organizations could be convinced to implement strategies and programs designed to reduce work-family conflict if there was more evidence that work-family conflict may impact on these economic bottom-line indicators. ${ }^{5 ?}$

\section{AIM OF STUDY}

Obviously, working time arrangements constitute characteristics of work that can be subject to change when necessary or requested. If specific characteristics of working time arrangements prove to be strongly related to fatigue and/or work-family conflict 
among employees, then working time arrangements might constitute important starting points for the prevention and/or reduction of these outcomes. Therefore, the relationship between working time arrangements and work-family conflict, as well as the relationship between working time arrangements and fatigue will constitute the main focus of the present thesis. Furthermore, becauise those employees who report work-family' conflict might be at greater risk for future fatigue, the relationship between work-family conflict and fatigue will be subject of study as well. The possible relations between working time arrangements, work-family conflict and fatigue resulted in the development of a conceptual model, which is shown in Figure 5. This conceptual model served as the basis for the different studies described in this thesis.

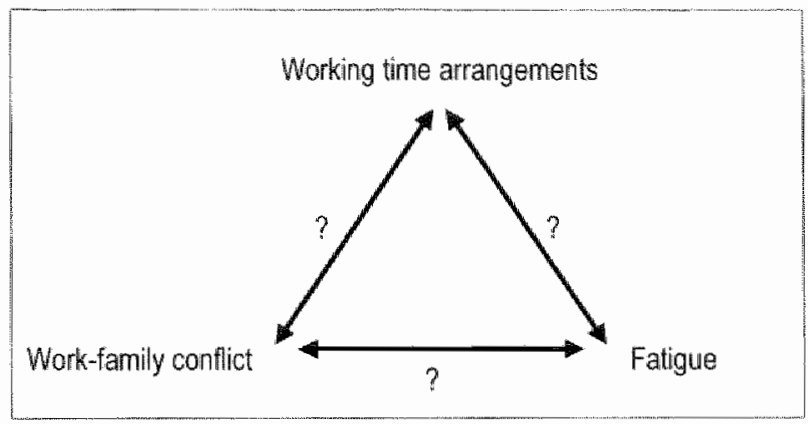

Figure 5 Conceptual model of possible relationships. between working time arrangements, work-family contict and fatigue

The following research questions were formulated from this model:

1. What is the relationship between working time arrangements and fatigue related outcomes?

2. What is the relationship between working time arrangements and work-family conflict?

3. What is the relationship between work-family conflict and fatigue related outcomes?

\section{Methods}

\section{Requirements study design and population}

To examine the complex relationship between working time arrangements, work-family conflict and fatigue adequately, several requirements concerning study design and study population should be fulfilled.

First, a large and helerogeneous study population is required, because this would allow stuldying the effects of various characteristics of working time arrangements, and would ensure variation in risk factors and outcome variables. Second, a longitudinal design is necessary to gain insight in causal relations. It is likely that different components of working time arrangements, such as overtime work and shift work for example, show a different time course of cause and effect. Furthermore, one specific exposure measure 
may show different courses of cause and effect as well. depending on the outcomes under study. This would require repeated measurements of both the exposure and outcome variables over time. However, when the exposure is relatively stable over time, for example in the case of shift work, both cross-sectional and longitudinal designs might be suitable. Cross-sectional studies provide insight into the accumulated effects of working thrne arrangements at the time of study and may reflect the length of exposure. Longitudinal studies, on the other hand, can provide insight into the time sequence between working time arrangements and the onset of work-family conflict and/or fatigue and study exposure before effect. Furthermore, prospective studies enable to study the impact of changes in working time arrangements on work-family conflict and fatiguerelated outcomes. Finally, prospective studies also allow investigating reciprocal effects, that is, to explore the possibility that employees who experience high levels of fatigue and/or work-family conflict, may adjust their working hours or work schedules as a means to reduce fatigue or work-family conflict.

In this thesis the large-scale prospective Maastricht Cohort Study on "Fatigue at Work" will be used as a sampling frame for the separate studies. Depending on the specific research question, a cross-sectional and/or longitudinal design will be used.

\section{Maastricht Cohort Study on "Fatigue at Work"}

\section{Design}

The Maastricht Cohort Study on "Fatigue at Work" was started in 1998. The ultimate goal of this study was to identify risk factors in the etiology and course of prolonged fatigue in the working population and to develop preventive measures and treatments that can be used in occupational health settings. 39,60 In this cohort study, employees from 45 different companies were followed for three years by means of nine self-administered questionnaires at four-monthly intervals. Once a year employees received an extensive questionnaire with items on work and nonwork related factors, demographics and health factors, as well as on fatigue and work-family conflict. Twice a year employees received a short questionnaire that captured mainly outcome measures.

\section{Study population}

In May 1998, a total of 26,978 employees from 45 companies received a letter at home, inviting participation, and the self-administered baseline questionnaire. A reminder was sent out after two weeks. Altogether, 12,161 employees completed and returned the baseline questionnaire (response rate of $45 \%$ ). Sixty-six questionnaires were excluded from analysis due to technical reasons or because inclusion criteria were not met. The baseline (To) cohort consisted of 8840 (73\%) men and 3255 (27\%) women. All employees who returned the baseline questionnaire (T0) received the wo short questionnaires $T 1$ in September 1998 (response rate $87.6 \%, n=10,592$ ) and $T 2$ in January 1999 (response rate $84.9 \%, n=10,270$ ) as well. Employees who returned the baseline questionnaire and at least one of the short questionnaires (T1 and/or T2) received the extensive questionnaire $\mathrm{T} 3$ in May 1999 (response rate $79.8 \%, n=9655$ ). Employees returning the T3 questionnaire also received the short questionnaires T4 in September 1999 (response rate $74.0 \%, \mathrm{n}=8956$ ) and $\mathrm{T} 5$ in January 2000 (response rate 
$71.9 \%, n=8692)$. Employees who returned the questionnaire at $T 3$ and at least one of the consecutive short questionnaires (T4 and/or $T 5$ ) also received the extensive questionnaire $T 6$ in May 2000 (response rate $66.7 \%, n=8070$ ). Employees returning the T6 questionnaire also received the short questionnaire $T 7$ in September 2000 (response rate $63,3 \%, n=7662$ ) and the final T8 questionnaire in January 2001 (response rate $61,9 \%, n=7482$ ). Furthermore, sickness absence data in the period of 1998 to 2004 were collected through record linkages to company sickness absence and work disability registry systems.

\section{Characteristics of working time arrangements in the Maastricht Cohort Study}

The baseline questionnaire included 32 questions on working time arrangements, which enabled us to describe in detail the work schedules and working hours employees were engaged in. With regard to working time arrangements several categorizations could be made. Our first distinction was between work schedules and working hours. With regard to work schedules, employees were asked whether they were involved in day work only. or whether they were employed in two-shift, three-shift, four-shift, five-shift, or irregular shift work, or whether they warked exclusively evenings or nights. As regards working hours, employees were asked for their average working hours per day and per week, days per week, overtime work and changes in working hours and working days. Of course working hours and work schedules are very interrelated to one another, implying that when studying work schedules comparable working hours should be considered and vice versa. Apart from work schedules and working hours other characteristics of working time arrangements were discerned. In this respect one could think of characteristics reflecting control and predictability of working hours, such as flexible working hours, the ability to take a day off when wanted and familiarity with the work roster in advance.

\section{OUTLINE THESIS}

To address the specific research questions that were formulated in this chapter, we first wanted more insight in the relationship between the different fatigue related outcomes that were included in the cohort study. Chapter 2 provides a description of need for recovery from work in the working population, in which comparisons are made with other concepts such as fatigue and psychological distress.

To study the relationship between working time arrangements and fatigue-related outcomes several studies were conducted. In Chapter 3 , the cross-sectional relation between working time arrangements and need for recovery from work is addressed, in which the associations between need for recovery and working hours, working patterns and work schedules are described. Chapter 4 presents the results of a study on the course of fatigue among day workers and three-shift, five-shift and irregular shift workers over 32 months of follow-up. This chapter further describes fatigue levels among shift workers prior and atter changing to day work. Chapter 5 constitutes a refinement of the concept of work schedules and addresses the effects of shift rotation in three-shift workers on amongst others need for recovery from work, fatigue and work-family conflict. 
Moreover, the impact of need for recovery, fatigue and work-familly conflict as predictors of quitting shift work is addressed.

Because fatigue is also related to common infections and since a few studies have already explored depressed immune function in relation to shift work, the relation between work schedules and the prevalence of common infections is studied as well. Chapter 6 is concerned with the prevalence of common infections, such as common cold, flu-like illiness and gastroenteritis, among employees involved in different work schedules.

Several studies were carried out to gain more insight in the relationship between predictors and outcomes of work-family conflict. Chapter 7 describes the prevalence and cumulative incidence of work-family conflict among employees. Furthermore, a wide range of risk factors at baseline, both in the work and private situation, for work-family conflict after one year of follow-up are addressed. In Chapter 7 " consequences of workfamily conflict, in terms of need for recovery from work and fatigue are explored as well to obtain more insight in the relationship between work-family conflict and fatigue-related outcomes. Chapter 8 reports the relationship between various aspects of working time arrangements and work-home interference. Chapter 8 further addresses whether employees experiencing work-home interference have a higher probability of changing work hours. Chapter 9 describes the role of work-family conflict as a risk factor for sickness absenteeism.

Finally in Chapter 10, the Epilogue, the overall vallue of our studies and findings above and beyond the studies conducted are described and discussed. Strengths and weaknesses of the studies are described and implications for the prevention af fatigue and work-family conflict are addressed. Furthermore, propositions are made for moving the focus from effects on the individual level to the family and societal level.

\section{REFERENCES}

1. Burger GCE Gerritsen WB, De Groot J, Kuiper JP, Ziehuis RL. Arbeids- en bedriffsgeneeskunde. Leiden: Stenfert Kroese; 1974.

2. Wohl AS. Endangered lives: Public health in Victorian Britaim. Cambridge: Harvard University Press; 1983.

3. Mclvor AJ. Employers, the government, and industrial fatigue in Britain, 1890-1918. Brit $\mathrm{J}$ Ind Med 1987;44(11):724-32.

4. Van Houten S. Voorstel van wet van den heer van Houten, strekkende om overmatigen arbeid en verwaarloozing van kindleren tegen te gaam. Nederlandsche Staats-courant 1873:113:1 3.

5. EEC European Directive $89 / 391 / E E C$ EED. On the introduction of measures to encourage improvements in the health and safety of workers at work. Official Journal of the European Communities 1989:L-183.

6. Staatsblad 1999. Wet van 18 maart 1999, houdende bepalingen ter verbetering van de arbeidsomstandigheden (Arbeidsomstandighedenwet 1998). Den Haag: Sdu Uitgevers; 1999.

7. Central Bureau of Statistics. Labor History. Working hours per week (1960-1993). Voorburg/Heerlen: Central Bureau of Statistics; 2003.

8. Bosch G. Working time: tendencies and emerging issues. Int Labour Rev 1999:138(2):131-49.

9. Merllie $\mathbb{D}_{\text {. Paoli }} \mathrm{P}$. Ten years of working conditions in the European Union. Dublin: European Foundation for the Improvement of Living and Working Conditions; 2001. 
10. Sparks K, Faragher B, Cooper CL. Well-being and occupational health in the 21 st century workplace. J Occup Organ Psych 2001:74(4):489-509.

11. OECD. Implementing the OECD jobs strategy: Assessing performance and policy. Paris: OECD; 1999.

12. Bøggild $H$, Knutsson A. Shift work, risk factors and cardiowascular disease. Scand d Work Environ Health $1999 ; 25(2): 85-99$

13. Knutsson A. Akerstedt T, Jonsson BG, Orth-Gomer K. Increased risk of ischaemic heart disease in shift workers. Lancet 1986;ii:89-92.

14. Tenkanen L, Sjöblom T, Kalimo R, Alikoski T. Härmä M. Shift work, occupation and coronary heart disease over 6 years of follow-up in the Helsinki Heart Study. Scand J Work Environ Health 1997;23(4):257-65.

15. Kristensen TS. Cardiovascullar diseases and the work environment. A critical review of the epidemiologic literature on nonchemical factors. Scand J Work Environ Health 1989;15(3):16579.

16. Van Amelswoort $L P G M_{n}$ Schouten $E G$. Maan $A C$. Swenne KA, Kak FJ. Changes in frequency of premature complexes and heart rate variability rellated to shift work. Occup Environ Med 2001:58(10):678-81.

17. Tüchsen $F$, Jeppesen $H J$, Bach $E$. Employment status, non-daytime work and gastric ulcer in men. Int J Epidemiol 1994;23(2):365-70.

18. Angersbach $D$, Knauth $P$, Loskant $H$, Karvonen MiJ, Undeutsch K, Rutenfranz J. A retrospective cohort study comparing complaints and diseases in day and shift workers. Int Arch Occup Environ Health 1980;45(2):127-40.

19. Costa $G$. The impact of shift and night work on health. Appl Ergon 1996;27(1):9-16.

20. Harrington JM. Shift work and health. A critical review of the literature on working hours. Ann Acad Med Singap 1994;23(5):699-705.

21. Härmä M, Tenkanen L, Sjöblom T, Alikaski T, Heinsalmi $P$. Combined effects of shift work and life-style on the prevalence of insominia, sleep deprivation and daytime sleepiness. Scand J Work Envirom Health 1998:24(4):300-7.

22. Akerstedt T. Psychological and psychophysiological effects of shift work. Scand $J$ Work Environ Health 1990;16(Suppl 1):67-73.

23. Smith CS, Robie C, Folkard S, Barton J, Macdonald I, Smith L, et al. A process model of shiftwork and health. J Occup Health Psychol 1999;4(3):207-18.

24. Härmä M. New work times are here - are we ready? Scand J Work Environ Health 1998;24(Suppl 3):3-6.

25. Kompier MAJ. The psychosacial work environment and health - what do we know and where should we go? Scand J Work Environ Health 2002;28(1):1-4.

26. Landsbergis PA. The changing organization of work and the safety and health of working people: A commentary. J Occup Environ Med 2003,45(1):61-72.

27. Paoli P. Merllié D. Third European Survey on Working Conditions, Dublin: European Foundation for the Improvement of Living and Warking Conditions; 2001.

28. Burr $H$, Bjorner JB, Kristensen TS, Tüchsen $F$, Bach $E$. Trends in the Danish work environment 1990-2000 and their associations with labor force changes. Submitted for publication.

29. Ester $P$, Vinken $H$. Van later zorg. Verwachtingen wan Nederlanders over arbeid, zorg en wrijetijd in de $21 e$ eeuw [Of later concem. Expectations of the Dutch population about work, care, and leisure in the 21st century]. Den Haag: Service Centrum Uitgevers; 2000.

30. Central Bureau of Statistics. Statistisch Jaarboek 2003 [Statistical yearbook 2003]. Voorburg/Heerlen: Centraal Bureau voor de Statistiek; 2003.

31. Van Doorne-Huiskes J. Den Dulk L, Schippers J. Work-family arrangements in the context of welfare states. In: Den Dulk L, Van Daorne-Huiskes J, Schippers J, editors. Work-family arrangements in Europe. Amsterdam: Thela Thesis; 1999.

32. Van Doorne-Huliskes J. The unpaid work of mothers and housewives in different types of

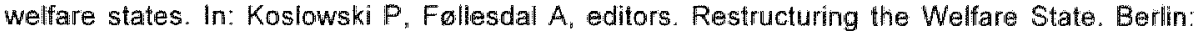
Springer; 1996 . p. $202 \times 21$. 
33. Buthrann U, Kant IJ, Kasl S, Beutiskens M, Van den Brandt P. Fatigue and psychologica distress in the working population: Psychometrics, prevalence, and correlates. I Psychosom Res $2002 ; 52(6): 445-52$

34. Lewis G. Wessely S. The epidemiology of fiatigue: more questions than answers. I Epidemiol Community Health $1992 ; 46(2), 92-7$.

35. Brown 10. Dritor fatigue. Hum Factors 1994;36(2):298-314.

36. Meiman T. Mentale belasting en werkstresis. Een arbeidspsychologische benadering. [Mental strain and workstress. An $1 / 10$ psychology approach. Assen/Maastricht: Van Gorcum; 1989.

37. Sturter JK, Frings-Dresen MHW, Van der Beek A. Meijman TF. The relation between workinduced neuroendocrine reactivity and recowery, subjective need for recowery, and health status. J Psychosom Res 2001;50(1) 29-37.

38. Van der Beek AJ, Meijman TF, Frings-Dresen MH, Kuiper JI. Kuiper S. Lorry drivers' work stress evaluated by catecholamines excreted in urine. Occup Environ Med 1995:52(7):464-9.

39. Kant 1J, Beurskens A.JMM, Schröer CAP, Wijhuis FJN, Van Schayck CP, Van den Elzen H, et al. De Mastrichtse Cohort Studie naar langdurige psychische vermoeidheid in de arbeidssituatie [The Mastricht Cohort Study on fatigue at work]. TEV 2000;8(8):226-32.

40. Meliman T, Schaufeli W. Psychische vermoeidheid en arbeid; Ontwikkelingen in de A\&Opsychologie [Mental fatigue and work. Developments in Work and Organizational Psychology]. Psycholoog $1996,31(6), 236-41$.

41. Meijman TF. Over vermoeidheid: arbeidspsychologische studies naar belewing wan belasingseffecten. [Fatigue: studies on the perception of workload effects]. Amsterdam: University of Amsterdam; 1991.

42. Schröer CAP. De toename wan arbeidsongeschktheid wegens psychische aandoeningen [The increase of work disability due to mental disorders]. TBV 1997:5(1):16-23.

43. Van Amelsvoort LPGM, Kant IJ, Beurskenis A.JHM, Schroer CAP, Swaen GMH. Fatigue as a predictor of work disability. Occup Enivifon Med 2002;59(10):712-3.

44. De Vries-Griever AHG. Evenwicht tussen werkdruk en herstel bij afwijkende werktijden. Uitgangspunten voor dienstroosterplanning [Balancing work load and recovery in deviating working hours. Basic principles of rota planning]. Groningen/Utrecht: Nationaal Ziekenhuisinstituut; 1992.

45. Borg $V$, Kristensen TS. Psychosocial work environment and mentall health among travelling salespeople. Work Stress 1999;13(2):132-43.

46. Sparks K, Cooper $C$, Fried $Y$, Shirom A. The effects of hours of work on health: A meta analytic rewiew. J Occup Organ Psych 1997;70(4):391-408.

47. Akerstedt T. Sleepiness as a consequence of shift work. Sleep 1988:11(1):17-34

40. Rosa $\mathrm{RR}_{\text {, Bonnet } M H}$, Cole LL. Work schedule and task factors in upper extremity fatigue. Hum Factors 1998;40(1):150-8.

49. Schroeder D. Rosa RR, Witt A. Some effects of 8 -versus 10 -hour work schedules on the test performancelelertness of air traffic control specialists. Int J Ind Ergonom 1998:21:307-21.

50. Bultmann U, Kant IJ, Van den Brandt PA, KasI SV. Psychosocial work characteristics as risk factors for the onset of fatigue aind psychological distress: Prospective results from the Maastricht Cohort Study. Psychol Med 2002,32(2):333445

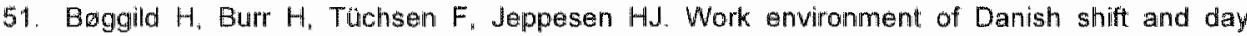
workers. Sciand J Work Envitron Health 2001;27(2):97-105.

52. Bamett RC, Gareis KC. Reduced thours employment: The relationship between difficulty of trademoffs and quality of life. Work Occupat 2000;27(2):168m.87

53. Grandey AA, Cropanzano R. The Conservation Of Resoluces model applied to work-family conflict and strain. I Vocat Behav 1999;54(2):350-70.

54. Herrington JM. Health effects of shift work and extended hours of work. Occup Enwiron Med $2001: 58: 68-72$

55. Koopmans 1, Stavenuiter MMs. Meer werken, minder zorgen. Arbeid en zorg in wetgeving en CAO's [More working. less caring. Work and care in legislation and collective labor agreaments]. Breukelen: NYFER; 1999

56. Barnett RC. Toward a review and reconceptuallization of the work/familly literature. Genet Soc Gen Psych Monograph 1998; 124(2); 125-82 
57. Allen TD. Herst DEL. Bruck CS, Sutton M. Consequences associated with work-to-family conflict: A review and agenda for future research. J Occup Health Psychol 2000; $5(2), 278-308$.

58. Goff S. Mount MK, Jamison RL. Employer supported child care, workfamily conffict, and absenteeism: A field study. Pers Psychol 1990,43(4),793-809.

59. Barling 4 , MacEwen KE, Kelloway EK, Higginbottom SF. Predictors and outcomes of eldercare-based interrole conflict. Psychol Aging 1994:9(3):391-7.

60. Kant IJ, Bültmann U, Schrôer CAP. Beurskens AJHM, Van Amelsvoort LPGM, Swaen GMH. An epidemialogical approach to study fatigue in the working population: The Maastricht Cohort Study. Cocup Environ Med 2003;60(Suppl 1) 32-9. 


\section{Need for recovery in the working population: Description and associations with fatigue and psychological distress}

Nicole WH Jansen ${ }^{7}$

$1 \mathrm{Wmert}$ Kant $^{1}$

Piet A van den Brandt ${ }^{1}$

TDepartment of Epidemiology, Maastricht University, Maastricht, The Netherlands 


\section{ABSTRACT}

This study examined the concept of need for recovery, that is the need to recuperate from work-induced fatigue, experienced after a day of work. The study explored the relationship between need for recovery from work, prolonged fatigue, and psychological distress in the working population. A cross-sectional study was carried out. Data of the Maastricht Cohort Study on "Fatigue at Work" were used $(n=12,095)$. Some degree of need for recovery was found in nearly all employees. Need for recovery from work was associated with demographic, work-related and health factors. Principal Components Analysis revealed obvious separation between need for recovery items and both fatigue items and psychological distress items, supporting the notion that need for recovery, fatigue, and psychological distress represent different underlying concepts. Although need for recovery, fatigue, and psychological distress were frequently comorbid, they also clearly occurred as separate entities. 


\section{INTRODUCTION}

One of the most important factors infuencing the physical and mental condition of an employee, and thus his or her ability to cope with work, is the degree to which employees are able to recover from fatigue and stress at work. "Recovery can be defined as the period of time that an individual needs to return to a normall or prestressor level of functioning following the termination of a stressor. ${ }^{2}$ In line with this definition, the work-induced stressor levell and subsequent recovery are determined by many workrelated factors such as workload, ${ }^{3,4}$ overtime work, ${ }^{4}$ and deviating working hours." Returning to a normal or prestressor level of functioning after work is influenced by numerous individual factors, such as coping strategies ${ }^{5}$ and health status and private situation. ${ }^{6}$ Besides work-related factors and individual characteristics, the actual period of time available to recover from work is important. It has been suggested that the time required to recover from a stressor may be a better measure of the severity of stress and a better predictor of the likelihood of long-term chronic effects than the immediate response to a stressor. ${ }^{\pi}$

In line with these findings on recovery "the concept of need for recovery from work was introduced, ${ }^{8-10}$ which was defined as the need to recuperate from work-induced fatigue, primarily experienced after a day of work. The concept involves the intensity of workinduced fatigue, both mentally and physically, as well as the time period required to return to a normal or prestressor level of functioning. A related concept to recovery was introduced by Glass and Singer, ${ }^{11}$ who demonstrated that the outcome of exposure to prolonged stress, such as that experienced at work, may be best observed in various effects, including irritability, that occur after exposure to the stressor is terminated. ${ }^{12}$ This "postwork irritability" is for example recognizable by feelings of wanted to be left alone for a while after work, or being bothered by noises around you, ${ }^{12}$ feelings that appear similar to the need for recovery after work. High levels of postwork irritability or need for recovery can result in unfavorable implications on the quallity of life after work and can jeopardize the chances of employees to unwind and relax after work. ${ }^{12}$ Repeated insufficient recovery from work-induced fatigue is seen as the start of a vicious circle where extra effort has to be exerted at the beginning of every new working period to rebalance the suboptimal psycho-physiological state, and to prevent performance breakdown. 9.13 The accumulated fatigue from repeated insufficient recovery is related to health problems, ${ }^{9.13}$ and sick leave and work disability. ${ }^{14}$ Need for recovery is considered relevant as a mediating or moderating characteristic in the etiology of fatigue. ${ }^{415}$ Lewis and Wessely ${ }^{16}$ argued that fatigue should not be regarded as a discrete disorder, but as a continuum ranging from mild, frequent complaints seen in the community to the severe, disabling fatigue characteristics of bumout, overstrain or chronic fatigue syndrome. Perhaps need for recovery should be located at the very beginning of this continuum, constituting a possible precursor of prolonged fatigue or psychological distress. If so, then need for recovery could be used to study the onset of fatigue and subsequent sick lleave in general and to investigate the effects of different work and rest schedules in particular. However, so far the relationship between need for recovery and other concepts, like prolonged fatigue and psychological distress, is relatively unknown. 
The purpose of this study was to further gain insight into the concept of need for recovery and to explore its relationship with outcomes, such as prolonged fatigue and psychological distress, in the working population. In 1998, a large-scale prospective cohort study on "Fatigue at Work" was started in the Netherlands. ${ }^{15.17}$ In this Maastricht Cohort Study, the employee's need for recovery consititutes one of the outcome parameters. The Need for Recovery scale was derived from an existing Dutch questionnaire on psychosocial job demands and job stress (VBBA) ${ }^{18}$ and represents short-term effects of a day of work.

First, a description of need for recovery from work in the Maastricht Cohort Study was made, including the association between need for recovery and demographic, workrelated and health factors. Second, the scale was compared with instruments representing prolonged fatigue and psychological distress, the Checklist Individual Strength, and the General Health Questionnaire-12, respectively.

\section{METHODS}

\section{Study population}

For the purpose of this study the data at baseline from the Maastricht Cohort Study were used. The Maastricht Cohort Study surveys a large heterogeneous population of employees from 45 different companies and organizations and follows them for three years. ${ }^{15,17}$ Companies were invited by the researchers to participate in the study. Invitation was based on company size and sector/trade to establish a representation of the Dutch working population. The baseline questionnaire was mailed to the employees in May 1998. Inclusion criteria were age 18-65 years and a minimum employment of $50 \%$. Temporary employees were excluded because they generally change jobs frequently. ${ }^{15}$ At baseline, both exposure and outcome are measured on an individual level by means of a self-administered questionnaire, which covers about 220 questions on work, private situation, individual characteristics, need for recovery, fatigue, and psychological distress. The response rate was $45 \%$. Altogether 12,161 employees responded to the baseline questionnaire. A total of 66 questionnaires were excluded from analysis because of technical reasons or because inclusion criteria were not met, resulting in a final study population of 8840 men and 3255 women $(n=12,095)$. Nonresponse analyses yielded no significant differences between respondents and monrespondents regarding demographic characteristics. Nonrespondents were somewhat less likely to report fatigue complaints, sick leave, and difficulties in work execution. Further details about the baseline questionnaire and nonresponse analyses have been reported elsewhere. ${ }^{15,19,20}$

\section{Measures}

Need for recovery

The Need for Recovery scale was derived from an existing Dutch questionnaire on the Experience and Assessment of work (VBBA). ${ }^{18,21}$ The scale contains 11 dichotomous items, representing short-term effects of a day of work. All variables were recoded in 
such a way that higher scores meant "more complaints", in other words more need for recovery. The total score ranges from $0-100$. The Cronbach 's $\alpha$ of the entre scale is 0.78. There is no existing cutoff point for the scale to classify "cases" with very high scores on the scale. Therefore, in the present study the upper quartile was used to define a contrast between employees. with and without considerable need for recovery from work.

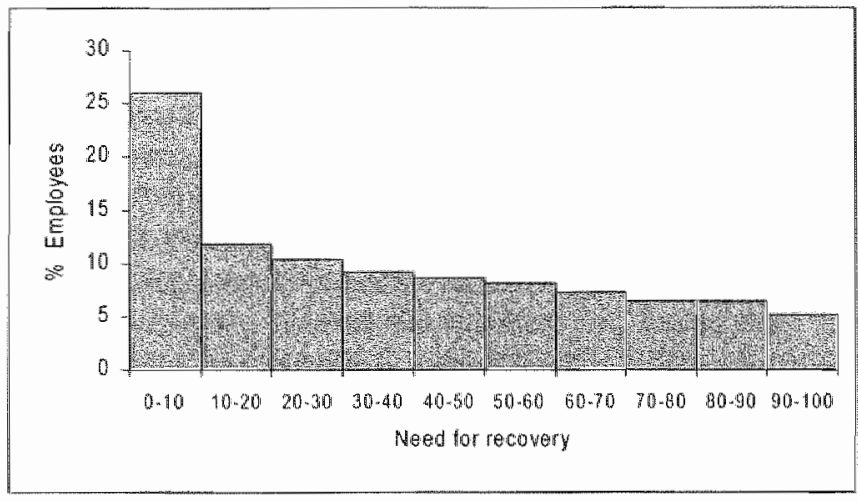

Figure 1 Need for recovery from work

\section{Checklist Individual Strength (CIS)}

The CIS was used to measure prolonged fatigue. The CIS is a 20-item questionnaire developed to measure several aspects of prolonged fatigue. Whereas the items of the Need for Recovery scale are concerned with the recuperation period after one day of work and represent short-term effects, the items of the CIS represent prolonged fatigue asking employees how they felt during the past two weeks. The CIS is a self-report instrument consisting of four factors: subjective experience of fatigue, concentration. motivation, and physical activity level. Items of the Need for Recovery scale, in contrast, are related to the time spent after work in terms of recuperation need. Items of the CIS are scored on seven-point Likert scales. Higher scores indicate a higher degree of fatigue, more concentration problems, reduced motivation, or less activity. A composite CIS-total score, ranging from 20-140, can be constructed by adding the individual's scores on the four factors. The psychometric properties of the CIS are good. ${ }^{22}$ Based on receiver operating characteristic analysis, a CIS-total cutoff point of $>76$ was derived for use in the working population. ${ }^{23}$ Employees scoring $>76$ were designated as probable cases of prolonged fatigue.

\section{General Health Questionnaire (GHQ-12)}

Psychological distress was measured by the 12-item General Health Questionnaire, which was developed as a screening instrument for detecting minor psychiatric disorders. ${ }^{24.25}$ The four-point response scale can be scored in different ways. The $\mathrm{GHO}$ method $(0,0,1,1)$ was developed to identify individuals reporting sufficient psychological distress to be identified as probable cases of minor psychiatric disorder. The total number of times a person indicates that his or her psychological state is worse than 
usual is totalled, giving a scale score ranging from $D$ to 12 . The total score is used for case classification. In this study, a threshold of $3 / 4$ was used to classify cases, that is subjects sconing adverse on 4 or more of the 12 items were designated as probable cases of minor psychiatric disarder. In the second scoring method, the Likert scoring method, a value of $0,1,2$, or 3 is assigned to each response category and summed across all 12 items giving a continuous distribution of the total score ranging from 0 to 36. In the present study, both scoring methods were used.

\section{Demographic and health factors}

Information on gender, age, and educational level was obtained through answers to the respective questions in the questionnaire. Age was divided into five categories (see Table 1). Educational level was divided into seven categories (see Table 1). The questionnaire also included questions about the presence of long-term diseases and the self-rated general health status, adapted from the SF-36, which is a widely used generic health status measure. ${ }^{26}$ The general health status item was scored on a five-point scale (see Table 2).

\section{Work-related factors}

In this study, work-related factors included decision latitude, psychological job demands, and the experience of strenuous work. Decision latitude was assessed with a validated Dutch version of the Job Content Questionnaire using the scale Decision Latitude. ${ }^{27.28}$ To determine the level of psychological job demands a validated Dutch version of the Psychological Job Demands scaie of the Job Content Questionnaire ${ }^{27,28}$ was used. For each scale, the total score was calculated by adding the responses to the items. The total score was then divided into tertiles, resulting in low, medium, and high levels of psychological job demands or decision latitude. A dichotomous item from a Dutch questionnaire on Work and Health (VAG) ${ }^{29}$ rated the experience of strenuous work.

\section{Statistical analyses}

Missing data on the Need for Recovery scale on more than four items resulted in excluding the complete scale from analysis. Sum scores with missing data on four or less items were calculated by dividing the score by the number of completed items. Missing data on the subscales "subjective fatigue" (two items). "motivation" (one item) and "concentration" (one item) of the CIS questionnaires were replaced with the means of the specific scale. CIS questionnaires containing more than four missing items were excluded from analysis. Missing data in GHU-12 questionnaires on three or less items were replaced with the item's means. Missing data on more than three items were excluded from further analysis.

Principal Components Analysis (PCA) was used to extract factors, the direct oblimin procedure to rotate factors, and the eigen value greater-than-one criterion was used to determine the number of factors. Further statistical procedures included Pearson correlation coefficients. Because the distribution of need for recovery was skewed to the left, Poisson regression analysis was the most adequate way to test statistical significant differences between the groups. In all analyses, differences were considered to be 
statistically significant at $p<0.05$. Statistical analyses were performed with both the SPSS-package for Windows $9.0^{30}$ and SAS. ${ }^{34}$

\section{RESULTS}

\section{Need for recovery from work}

The overall mean score of need for recovery in the total study population was 38.13 $(S D=26.90)$. As shown in Figure 1, need for recovery showed a continuous distribution with no cutoff point or rarity and some degree of need for recovery was found in nearly all employees. The distribution was skewed to the left.

Men reported a slightly higher need for recovery from work in comparison with women ( $p$ $<0.001$ ) (see Table 1). With respect to age, the highest need for recovery was found among subjects aged $46-55$ years. Poisson regression analysis indicated that employees aged 46-55 years scored higher on need for recovery than employees aged 36-45 years $(p<0.05)$. Employees aged $26-35$ years reported a significantly lower need for recovery than employees aged 36-45 years $(p<0.05)$. Concerning educational level (see Table 1), need for recovery from work showed a curvilinear relationship with higher need for recovery in the lower and higher educational levels. Poisson regression analysis revealed that employees who only completed primary school or lower vocational school reported a significantly higher need for recovery than employees who completed intermediate vocational school $(\rho<0.001)$.

Table 1 Need for recovery from work: Associations with demographic variables

\begin{tabular}{|c|c|c|c|c|c|}
\hline Variable & Need for recovery $(M)$ & SD & dif & $n$ & $\%$ Total Study \\
\hline Total study & 38.13 & 26.90 & & 12,015 & 100 \\
\hline \multicolumn{6}{|l|}{ Gender } \\
\hline Male & $38.82^{\text {क* }}$ & 27.19 & 1 & 8788 & 73 \\
\hline female: & 36.25 & 26.00 & & 3227 & 27 \\
\hline \multicolumn{6}{|l|}{ Age } \\
\hline$\leq 25$ years & 38.17 & 25.17 & 4 & 485 & 4 \\
\hline 26.35 years & $36.75^{*}$ & 25.80 & & 3026 & 25 \\
\hline $36-45$ years & 38.14 & 26.86 & & 4508 & 38 \\
\hline $46-55$ years & $39.51^{*}$ & 27.93 & & 3489 & 29 \\
\hline$\geq 56$ years & 36.66 & 27.60 & & 507 & 4 \\
\hline \multicolumn{6}{|l|}{ Highest educattional level } \\
\hline Primary school & $43.73^{* *}$ & 30.35 & 6 & 517 & 4 \\
\hline Lower vocational school & $40.24^{* *}$ & 28.15 & & 1815 & 16 \\
\hline Lower secondary school & 37.73 & 27.28 & & 1516 & 13 \\
\hline Intermediale wocational schoo|s & 36.59 & 26.40 & & 2780 & 24 \\
\hline Secondary school & 37.20 & 26.51 & & 1003 & 9 \\
\hline Higher vocational school & 37.69 & 26.16 & & 2694 & 23 \\
\hline Universily & 38.08 & 25,45 & & 1332 & 11 \\
\hline
\end{tabular}

"Reference group

$* p<0.05 * * * 0<0.001$ 
As presented in Table 2, employees reporting a long-term disease ( $n=2818$ ) showed a substantial higher need for recovery after work $(\rho<0.001)$ than employees not reporting a long-term disease. Concerning self-rated general health status, employees rating their health status as moderate or bad, reported the highest need for recovery. As shown in Table 2, employees with low psychological job demands reported substantially lower levels of need for recovery $(\rho<0.001)$ compared to employees experiencing medium psychological job demands. High psychological job demands resulted in substantial and significant higher levels of need for recovery $(\rho<0.001)$ compared to employees experiencing medium levels of psychological job demands. Employees reporting low decision latitude reported significantly more need for recovery than employees with medium levels of psychological job demands $(p<0.001)$. Employees experiencing their work as very strenuous reported a substantial higher need for recovery $(\rho<0.001)$ than employees experiencing their work not as very strenuous.

Table 2 Need for recowery fron work: Associations with health factors and work-related factors

\begin{tabular}{|c|c|c|c|c|c|}
\hline Variable & Need for recowery (M) & 50 & $d f$ & n & $\%$ Total Study \\
\hline Total study & 38.13 & 26.90 & & 12,015 & 100 \\
\hline \multicolumn{6}{|c|}{ Long-term disease } \\
\hline Yes & 46.84 & 27.76 & 1 & 2818 & 24 \\
\hline Not & 35.04 & 25.85 & & 8860 & 76 \\
\hline \multicolumn{6}{|c|}{ General health status } \\
\hline Excellent & $24,35 *$ & 20.43 & 4 & 1136 & 9 \\
\hline Very good & $27.64^{4-* x}$ & 22.20 & & 2641 & 22 \\
\hline Good: & 39.26 & 26.31 & & 6395 & 54 \\
\hline Moderate & $57.84^{k * x}$ & 25.91 & & 1638 & 14 \\
\hline Bad & $66.18^{\text {nin }}$ & 25.51 & & 121 & 1 \\
\hline \multicolumn{6}{|c|}{ Psychological job demands } \\
\hline Low & $27.08^{-2 \cdot}$ & 22.81 & 2 & 3763 & 32 \\
\hline Medium & 37.50 & 25.93 & & 3793 & 33 \\
\hline High & $49: 04^{.7 x}$ & 26.99 & & 413 & 35 \\
\hline \multicolumn{6}{|l|}{ Decision latifude } \\
\hline Low & $44.11^{\text {m+ }}$ & 28.34 & 2 & 3607 & 31 \\
\hline Medium & 35.79 & 26.28 & & 3735 & 31 \\
\hline High & 35.34 & 25.40 & & 4543 & 38 \\
\hline \multicolumn{6}{|l|}{ Strenuous work } \\
\hline Yes & $48.77^{* * *}$ & 27.29 & 1 & 3082 & 26 \\
\hline No & 34.46 & 25.77 & & 8861 & 74 \\
\hline
\end{tabular}

$p<0.001$

\section{Associations of need for recovery with fatigue and psychological distress}

Based on the total study population, the overall mean values of the Need for Recovery scale, $\mathrm{CIS}$, and $\mathrm{GHQ}-12$ (Likert-scoring) were $38.13(\mathrm{SD}=26.90), 57.19(\mathrm{SD}=23.69)$ and $11.61(\mathrm{SD}=5.36)$, respectively. The Pearson correlation coefficient between need for recovery and $\mathrm{CIS}$ and $\mathrm{GHQ}-12$ was $0.63(n=11,790 ; p<0.001)$ and $0.48(n=11,909 ; p<$ 0.001 ), respectively 
As presented in Table 3, cases classified by the Need for Recovery scale and cases classified by the CIS and GHQ-12 can both be overlapping and exclusive. Of the employees, $38 \%(n=828)$ reported significant need for recovery, fatigue, and psychologicall distress. When regarding caseness however, $25 \%$ of the employees with significant need for recovery $(n=544)$ reported significant need for recovery alone. without fatigue and psychological distress.

Table 3 Comparison of "cases" of need for recovery from: work, failgue and psychological distress

\begin{tabular}{|c|c|c|c|c|}
\hline & Total (n) & Need for recovery + & $\mathrm{ClS}+$ & GHQ $12+$ \\
\hline Need for recovery + & 2189 & $2189(100 \%)$ & $1.293(59 \%)$ & $1139(52 \%)$ \\
\hline $\operatorname{cis}+$ & 2595 & $1293(50 \%$ & $2595(100 / 2)$ & $1473(57 \%)$ \\
\hline \multirow[t]{2}{*}{$\mathrm{GHQ}-12+$} & 2746 & $1139(41 \%)$ & $1473(54 \%)$ & $2746(100 \%)$ \\
\hline & & Need for recovery + & $C: 5+$ & $\mathrm{GHQ}-12+$ \\
\hline Total (n) & & 2189 & 2595 & 2746 \\
\hline Need for recovery - & & - & $1284(49 \%)$ & $1592(58 \%)$ \\
\hline CIS - & & $850(39 \%)$ & - & $1218(44 \%)$ \\
\hline $\mathrm{CHO}-12-$ & & $1214(55 \%)$ & $1100(42 \%)$ & - \\
\hline
\end{tabular}

"Row totals of cases are not equal to $100 \%$, due to missing values and overiapping beween instruments"

Need for recovery $=$ considerable need for recovery

$\mathrm{CIS+}=$ fatigue case

$\mathrm{GHO}-12+=$ psychologicall distress case

Need for recovery $=$ no considarable need for recowery

CIS- $=$ no fatigue case

$\mathrm{GHQ}-12-=$ no psychological distress case

\section{Principal Components analysis}

The Need for Recovery scale was examined, using PCA. Selection of the number of factors was based on the eigen value-greater-than one criterion and the use of the scree test. These criteria indicated a one-factor model for need for recovery that accounted for $46.7 \%$ of the total variance (eigen value $=5.13$ ).

PCA of the CIS yielded four factors in a population of patients with chronic fatigue syndrome, ${ }^{22}$ which was replicated in the present study. To compare the Need for Recovery scale and the CIS, the 11 need for recovery items and the 20 CIS items were analyzed in a PCA with oblique rotation. Setting an eigen value greater-than-one and the scree test as criterions for retaining components, PCA yielded five factors (see Table 4). The first factor accounted for $39.3 \%$ of the variance and consisted of the eight subjective fatigue items of the $\mathrm{ClS}$ and one motivation item. The second factor explained $8.4 \%$ of the variance and captured the three reduced-activity items of the CIS. The third factor accounted for $5.3 \%$ of the variance and consisted of 10 out of 11 items from the Need for Recovery scale. The fourth factor explained $4.3 \%$ of the variance and consisted of the five concentration items of the CIS. Finally, the fifth factor accounted for $3.6 \%$ of the variance and consisted of three out of four reduced motivation items of the CIS. In this five-factor solution no substantial cross-loading was observed. Double-foading was operationalized as secondary loadings of 0.40 or greater. In this five-factor solution one double-loading item was observed (see Table 4). 
Table 4. Five-factor solutian affer direct oblimin rotation

\begin{tabular}{|c|c|c|c|c|c|}
\hline Need for Recovery Scale & Factor 1 & Factor 2 & Factor 3 & Factor 4 & Factor 5 \\
\hline 1. Ifind ithard to relax at he end of a working day & .04 & .08 & .54 & .36 & 11 \\
\hline 2. Ait the end of a working dan I am really reeling worrout & .25 & .01 & .67 & .06 & .12 \\
\hline 3. My job causes me to feel rather exhausted at the end of & & 02 & 69 & 06 & 14 \\
\hline 4. Gernerally speaking. I'm still foelling fresh after supper & 20 & .03 & .56 & .12 & 02 \\
\hline $\begin{array}{l}\text { 5. Generally speaking, I am able to relax only on a second } \\
\text { day off }\end{array}$ & .11 & .02 & .62 & .00 & .01 \\
\hline $\begin{array}{l}\text { 6. Thave trouble concentrating in the hours off after my } \\
\text { working day }\end{array}$ & .09 & .03 & .53 & 36 & .05 \\
\hline $\begin{array}{l}\text { 7. Ifind it hard to show interest in other people when I just } \\
\text { came hore from work }\end{array}$ & .2 & 05 & .69 & 10 & .18 \\
\hline $\begin{array}{l}\text { 8. In general it lakes me over an hour lo feet fully recovered } \\
\text { after work }\end{array}$ & .04 & .04 & .77 & .04 & .02 \\
\hline $\begin{array}{l}\text { 9. When I get hom people should leave me alone for some } \\
\text { lime }\end{array}$ & .14 & .03 & .70 & .01 & .12 \\
\hline $\begin{array}{l}\text { 10. After a working day I am often too tired to stari other } \\
\text { activities }\end{array}$ & .22 & .08 & .62 & .03 & .04 \\
\hline $\begin{array}{l}\text { 11. During the lasl part of the working day l cannot oplimally } \\
\text { pertorm rry job because of fatigue sometimes }\end{array}$ & .09 & .04 & .29 & .31 & .15 \\
\hline
\end{tabular}

Checklist individual strength (CIS)

\begin{tabular}{|c|c|c|c|c|c|}
\hline 1. Ifoelfita & $.7 n$ & 02 & .66 & .09 & .18 \\
\hline 2. I feel very actives & .51 & .12 & .06 & 04 & 40 \\
\hline 3. Thinking requiles effort & .12 & .10 & .02 & .69 & .02 \\
\hline 4. Physically I feel exhausted & .72 & .05 & .09 & .11 & .04 \\
\hline 5. I feel like doing ath kind of nice things & 17 & .02 & .10 & .01 & .73 \\
\hline 6. I leel tireda & .75 & .10 & .11 & .10 & .01 \\
\hline 7. I do quite a lot wilhin a day & .00 & .87 & .04 & .09 & .06 \\
\hline 8. When I am doing something, I can concentrate quite wellc & .03 & .14 & .02 & .74 & .08 \\
\hline 9. lteel weakta & .68 & .08 & .06 & 16 & .01 \\
\hline 10. I don't do much duning the dayt & .03 & .86 & .04 & .06 & .09 \\
\hline 11. I can concentrate well & .03 & .09 & .04 & .78 & .10 \\
\hline 12. I freel restede: & .63 & .04 & 14 & 13 & .15 \\
\hline 13. Thave trouble concentrating. & 10 & .01 & .01 & .76 & .04 \\
\hline 14. Physically / an in a bad conditions & .78 & .11 & .04 & .01 & 01 \\
\hline 15. I am full of plang & .05 & .04 & .01 & .03 & .79 \\
\hline 16. I am lired very quicklya & .69 & .10 & .07 & .11 & .03 \\
\hline 17. I thave a low output & .14 & .60 & .04 & .21 & .02 \\
\hline 18. I foel no desire to do anything & 27 & .17 & .13 & .17 & .39 \\
\hline 19. My thoughts easly wander & .03 & .09 & .02 & .73 & .03 \\
\hline 20. Phys cally / feel in a good shapea & .76 & .07 & .04 & 02 & .13 \\
\hline
\end{tabular}

Bold numbers indicate the lactor to which each item was assigned/highest factor loading

"Subjective experience of faligue item (Cls)

b Reduced motiwation item (CIS)

a Reduced concentrathon item (CIS)

"Reduced acliwity item (CIS)

To investigate whether ineed for recovery and CIS really assess two different underlying concepts, the need for recovery and CIS items were analyzed in a two-factor solution (see Table 5). The first and second factor accounted for $39.3 \%$ and $8.4 \%$ of the variance, respectively. In this two-factor solution, the first factor captured all need for recovery items and all subjective fatigue items of the CIS. The second factor captured all other CIS items. One double-loading item was observed in these CIS-items (see Table 5). All 
subjective fatigue items from the CIS crossloaded with factor 4. Therefore, the subjective fatigue and need for recovery items were jointly analyzed in PCA, indicating a two-factor solution. The first factor captured all need for recovery thems, the second factor captured all subjective fatigue items. No cross-loading or double-loading items were observed.

The Need for Recovery scale and the CIS use different response formats. Therefore, the possibility exists that the observed factors are simply response scale factors. To investi-

Table 5. Two-factor solution afler direct oblimin rotation

\begin{tabular}{|c|c|c|}
\hline Need for Reoovery Scale & Factor 1 & Faclor 2 \\
\hline Ifind it thard to relax at the end of a working day & .62 & 03 \\
\hline At the end of a working day I am really feeling worny-out & .81 & .14 \\
\hline My job causes me to feell rather exhausted at the end of a working day & .81 & 17 \\
\hline Generally speaking. I'm still feeling fresh after supper & .73 & .06 \\
\hline Generally speaking, I am able to relax only on a second day off & .69 & .07 \\
\hline I have trouble concentrating in the hours off after my working day & .53 & .16 \\
\hline I find it hard to show interest in other people when I just came home from work & .56 & .02 \\
\hline In genaral, it takes ma over an hour to feel fully recowered afler work & 77 & .12 \\
\hline When I get home, people should leave me alone for some time & .61 & .07 \\
\hline 10. After a working day 1 am often too tired to slart other activites & .73 & .01 \\
\hline $\begin{array}{l}\text { 11. During the last part of the working day I cannot optimally perform my job because } \\
\text { of fatigue sometimes }\end{array}$ & .37 & .17 \\
\hline
\end{tabular}

Checklist Individual Strength (CHS)

1. Ifeel fita

2. I feel very activeb 38

3. Thinking requires effort

$42 \quad .47$

4. Physically I feel exhausted

$.20 \quad .49$

5. I feel like doing all kind of nice things $\mathrm{s}^{\mathrm{b}}$

$59 \quad .23$

6. If feel tireda

7. I do quite a lot within a day

8. When I am doing something I can concentrate quite wello

$30 \quad .36$

9. I ferl weak

10. I don ti do much during the day

11. I can concentrate well

$.65 \quad .22$

12. Ifeel resteda:

$.30 \quad .69$

13. I have troubie concentrating

$.05 \quad .71$

14. Physically 1 am in a bad condition

$.52 \quad .38$

15. I am full of plans:

16. I am lired very quick:y $y^{\star}$

17. I have a low output

$.15 \quad .73$

18. I feel no desire to do anything

$.09 \quad .72$

19. Hy thoughts easily wander

20. Physically I feel in a good shapea

$.17 \quad 60$

$.47 \quad .36$

Bold numbers indicate the factor to which each item was assigned/highest factor loading

* Subjective experience of fatigue item (CIS)

r Reduced moivation item (CIS)

CRoduced concentration ifem (CIS)

- Reduced activity item (CIS) 
gate this possibility, the response scale of the CIS was reduced to dichotomous items. Values 1,2 and 3 of the seven-point Likert scale were replaced by value 1 . The middle value (4) was recoded as a missing value, since it can not be categorized in a dichotomized scale. Values 5,6 , and 7 were replaced by value 0 . Using this revised scoring method, PCA revealed similar factors as previously abtained with regard to the five-factor model. The two-factor model however yielded a stronger separation between the need for recovery items and the CIS items when using this revised scoring method.

Explorative PCA of the GHQ-12 revealed two factors, replicating the findings of earlier studies in different populations. ${ }^{32.33}$ To compare the Need for Recovery scale and the GHQ-12, the need for recovery items and the GHQ-12 items were analyzed in a PCA with oblique rotation. A three-factor solution was indicated. The first factor explained $34.7 \%$ of the variance and consisted of nine GHQ-12 items. The second factor explained $12.7 \%$ of the variance and consisted of the 11 need for recovery items. The third factor accounted for $4.6 \%$ of the variance and consisted of three GHQ-12 items. No doubleloading or cross-loading items were observed.

To investigate whether need for recovery and psychological distress actually represent two different underlying concepts, the need for recovery and GHQ-12 items were analyzed in a two-factor solution. The first factor accounted for $34.7 \%$ of the variance and consisted of the $12 \mathrm{GHQ}-12$ items. The second factor explained $12.7 \%$ of the variance and consisted of the 11 need for recovery items. No double-loading or crossloading items were observed.

The Need for Recovery scale and the GHQ-12 also use different response formats. To investigate the possibility of response scale factors, the response scale of the GHQ was reduced to dichotomous variables, using the $\mathrm{GHQ}$ method $(0,0,1,1)$. Using this revised scoring method, PCA revealed similar factors as previously obtained.

\section{Discussion}

In this study, the concept of need for recovery in the working population was explored. In addition, the association between need for recovery from work, fatigue and psychological distress in the working population was reported.

The distribution of need for recovery showed no cutoff point or rarity and some degree of need for recovery from work was found in nearly all employees. The overall mean level of need for recovery was higher than that found in a study by Sluiter et al. ${ }^{10}$ However, the sample size in the study by Sluiter et al. was relatively small compared to the sample size in the present study. The skewed distribution of need for recovery is comparable to what others have found, and which is not unusual for a scale measuring symptoms. ${ }^{34}$ Regarding fatigue, some degree of fatigue was present in almost every employee in the Maastricht Cohort Study, ${ }^{19}$ which is in line with other studies examining fatigue in the general population and primary care. ${ }^{35.36}$ The overall mean score of psychological distress is also comparable to other studies. ${ }^{37}$ These findings were obtained by participants of 45 different companies. Our response rate of $45 \%$ raises the question of a 
possible selective response. A nonresponse analysis revealed that nonrespondents were somewhat less likely to report fatigue complaints, sick leave, and difficulties in work execution. Therefore, the observed prevalence of fatigue in this study could be a slight overestimation and it is therefore likely that the prevalences of need for recovery and psychological distress could also be slightly overestimated. However, we argue that these potential overestimations have not affected the presented associations between need for recovery and demographic, health, and work-related factors, because overestimation probably will not have influenced the distribution of need for recovery in the cohort.

Need for recovery from work was higher in men than in women. However, because the difference was that small, significance findings may be due to sample size. Need for recovery was higher in the higher age groups, as others have found. "Need for recovery was highest in the group of employees who only completed primary school and lowest in the group of employees who completed intermediate vocational school. In a study by Van Veldhoven and Broersen, ${ }^{34}$ it was found that need for recovery increased with increasing educational level. In the present study, need for recovery increased when employees completed intermediate vocational school or more. However, the differences in need for recovery with increasing educational level were not statistically significant. These different findings between the two studies can possibly be explained by different operationalizations of categories of educational level or by differences in the composition of the study population. Furthermore, when interpreting the association between need for recovery and educational level one has to keep in mind that within one group of educational level different aspects of job position and content of work may be represented. Thus, when regarding demographic factors associated with need for recovery, one has to consider that these associations are infuenced by many other factors, such as work-related and nonwork-related factors and the private situation.

Employees reporting a long-term disease showed a substantial higher need for recovery from work than employees not reporting a long-term disease. Concerning self-rated general health status, employees rating their health status as "moderate" or "bad", reported the highest need for recovery. These findings support the notion that health status plays an important role in need for recovery. Employees with low psychological job demands reported substantially lower levels of need for recovery compared to employees experiencing medium psychological job demands. High psychological job demands resulted in substantially more need for recovery. Employees reporting low decision latitude had a significantly higher need for recovery than employees with medium levels of psychological job demands, suggesting that the concept of need for recovery may be applicable to recovery from different work-related stressors. Another study also revealed that employees reporting more job demands also reported more need for recovery after work. ${ }^{10}$ Employees experiencing their work as very strenuous reported a substantial higher need for recovery compared with those experiencing their work as not very strenuous. Although need for recovery seems to be associated with health status and subjective work experience, one should be cautious when interpreting these results, because both exposure and effect are assessed in a cross-sectional study. in which cause and effect are difficult to separate. 
To date, there are no existing cutoff points for classifying cases with a marked need for recovery from work, putting them at risk for future health problems. Therefore, in the present study the upper quartile was used to define a contrast between employees with and without considerable need for recovery, which so far appeared to be a good method because the distribution of need for recovery in the cohort covered the whole range of the scale and showed no cutoff point or rarities. However, definition and validation of a cutoff point for need for recovery is needed for actual classification of cases.

An association between need for recovery from work, fatigue, and psychological distress in the working population was observed regarding overlapping cases. In the present study, $59 \%$ of the employees reporting significant need for recovery also reported fatigue, even as $52 \%$ of the employees reporting considerable need for recovery also reported psychological distress. Of course, similar items used in the three instruments can explain some degree of overlap. Other studies ${ }^{19,38}$ found an association between fatigue and psychological distress as well. When regarding caseness, need for recovery alone was still reported by $25 \%$ of the employees. Thus, although need for recovery, fatigue, and psychological distress were frequently comorbid, they also clearly occurred as separate entities.

PCA indicated a distinction between need for recovery and prolonged fatigue. Of interest are the CIS items relating to subjective fatigue, which are demonstrated in the two-factor solution to be strongly related to both the need for recovery factor and the subjective fatigue factor. The presence of these subjective fatigue CIS items in a primarily based need for recovery factor is not unexpected, as they represent the subjective experience of fatigue, as opposed to the other CIS items which are more concerned with concentration, motivation and activity aspects of fatigue. Classification as a "fatigue case" "however, depends on scoring on more dimensions than simply the dimension general fatigue.

When forcing the need for recovery items and $\mathrm{GHQ}-12$ items in a two-factor model, the items of the two instruments were clearly separated, which supports the notion of different underlying concepts. A step beyond the scope of the present findings concerns longitudinal research. If longitudinal investigations in the future are able to discriminate further between the concepts of need for recovery, fatigue, and psychological distress, perhaps it will be possible to put the three concepts on a continuum, starting with need for recovery, followed by fatigue and/or psycholagical distress. So far, directly associating need for recovery and psychological distress seems a bridge too far. In another study ${ }^{19}$ fatigue and psychological distress were fairly well associated. Perhaps need for recovery should be considered as a precursor of prolonged fatigue in the working environment, in which need for recovery represents the more acute effects of a day of work and fatigue, as assessed by the CIS, representing the more prolonged effects. On the other hand, it may as well be so that prolonged fatigue lowers the resistance against daily workloads, and consecutively, increases the need for recovery during time.

When regarding the concept of need for recovery from work, working time arrangements are of interest, because working time arrangements provide employees the actual time to 
recover from work. Perhaps need for recovery could constitute a good measure when studying the effects of working time arrangements in the short lerm.

Our findings confirm that need for recovery is related to several work-related factors, demographic factors, as well as to health status. This study shows that need for recovery, fatigue, and psychological distress are frequently comorbid. However, evidence of different underlying concepts was also found. Whether or not these three "conditions" also occur at different periods in time has to be examined further and requires a longitudinal approach. Longitudinal research also has to clarify whether employees with a high need for recovery are at risk for future health problems, including prolonged fatigue and sick leave. If this proves to be the case, then need for recovery could be an important tool for early detection of employees at risk for prolonged fatigue in the work environment.

\section{ACKNOWLEDGEMENTS}

This study is prart of the Maastricht Cohort Study, which is granted by the Netherlands Organization for Scientific Research (NWO grant no. 580-02.201).

\section{REFERENCES}

1. De Vries-Griever AHG. Evenwicht tussen werkdruk en herstel bij afwijkende werktijden. Uitgangspunten voor dienstroosterplanning [Balancing work load and recovery in deviating working hours. Basic principles of rota planning]. Groningen/Utrecht: Nationaal Ziekenhuisinstituut; 1992.

2. Craig $A_{4}$ Cooper RE. Symptoms of acute and chronic fatigue. Im: Smith AP, Jones DM, editors. Handbook of human performance. London: Harcourt Brace Jovanovich; 1992. p. 289-339.

3. Milosevic S. Drivers" fatigue studies. Ergonomics 1997;40(3):381-9.

4. Saito K. Measurement of fatigue in industries. Ind Health 1999;37(2):134-42.

5. Wessely $S$. Chronic fatigue and myalgia syndromes. In: Sartorius N, Goldberg D, editors. Psychological disorders in general medical settings. Goettingen, Germany: Hogrefe \& Huber Publishers; 1990. p. 82-97

6. Galambos NL. Walters BJ. Work hours, schedule inflexibility, and stress in dual-earner spouses. Can J Beh Sci 1992;24(3):290-302

7. Depue RA, Monroe SM. Conceptualization and measurement of human disorder in life stress research: The problem of chronic disturbance. Psychol Bull 1986;99(1):36-51.

8. Brown $\|$ D. Driver fatigue. Hum Factors 1994;36(2):298-314.

9. Meijman T. Mentale belasting en werkstress. Een arbeidspsychologische benadiering. [Mental strain and workstress. An $1 / O$ psychology approach]. Assen/Maastricht: Van Gorcum; 1989

10. Sluiter JK, Frings-Dresen MHW, Van der Beek AJ, Meilman TF. The relation between workinduced neuroendocrine reactivity and recovery, subjective need for recovery, and health status. J Psychosom Res 2001:50:29-37.

11. Glass DC. Singer JE. Urban stress: Experiments on noise and social stressors. New Vork Academic Press: 1972.

12. Melamed S. Bruhis $S$. The effects of chronic industrial noise exposure on urinary cortisol, fatigue and irritability: a controlled field experiment. $\mathbb{J}$ Occup Environ Med 1996:38(3):252-6.

13. Van der Beek. Ad, Meijman TF. Frings-Dresen MH, Kuiper J, Kuiper S. Lorry drivers' work stress evaluated by catecholamines excreted in urine. Occup Environ Med 1995;52(7):464-9.

14. Schröer CAP. De toename van arbeidsongeschiktheid wegens psychische aandoeningen [The increase of work disability due to mental disorders]. TBV 1997:5(1):16-23, 
15. Kant U, Eeurskens AJHM, Schöer CAP, Nijhus FuM, Van Schayck CP, Van den Elzen HJ, et ar. De Maastrichse Cohort Studie naar langdurige psychische vermoeidheid in de arbeidssituatie [The Maastricht Cohort Study on falligue at work]. TBV 2000;8(8):226-32

16. Lewis $\mathrm{G}$. Messely 5 . The epidemiology of fatigue: more questions than answers. J Epidemiol Commun $1992,46(2), 92-7$.

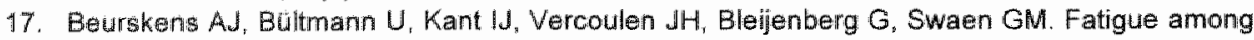
working people: validity of a questionnaire measure. Occup Environ Med $2000 ; 57(5): 353-7$

18. Var Veldhoven M, Meiman TF. Het meten van psychosocialle arbeidsbelasting met een Wragenlifst: de vragentijst beleving en beoondeling van de arbeid (VBBA) The measurement of psychosocial job demands with a questonnaire (VBBA)]. Amsterdam: NIA; 1994.

19. Bultmann U. Kant IJ, Kasl S, Beurskens A, Van den Brandt P. Fatigue and psychological distress in the working population: Psychometrics, prevalence, and correlates. J Psychosom Res 2002,52(6):445-52

20. Janssen $N$, Nighuis FJN, Beurskens. A.JHM. The Maastricht cohort study on fatigue at work: mon-response aralysis in a health survey. Manulscript submitted.

21. Slutter JK, Van der Beek AJ, Frings-Dresen MHW. The influence of work characteristics on the need for recovery and experienced health: A study on coach drivers. Ergionomics $1999 ; 42(4): 573-83$

22. Vercoullen JH, Swanink $C M$. Fennis JF, Galama JM. Van der Meer $\Perp W, ~ B l e i j e n b e r g ~ G$. Dimensional assessment of chronic fatigue syndrome. J Psychosom Res 1994,38(5),383-92.

23. Bultmann $U$, De Vries M, Beurskens AJlHM, Blejenberg G, Vercoulen JHMM, Kant IJ. Measurement of prolonged fatigue at work in the Maastricht Cohort Study: Determination of a cutoff point. J Occup Health Psychol 2000;5(4):411-6

24. Goldberg DP, Williams. P. The user's guide to the General Health Questionmaire. Windsor NFER-Mlsolson; 1991

25. Koeter MWJ Ormel J. General Health Questionnaire, Handleiding Nederlandse bewerking [General Health Questionnaire, Manual Dutch version]. Lisse: Swets \& Zeitlinger; 1991.

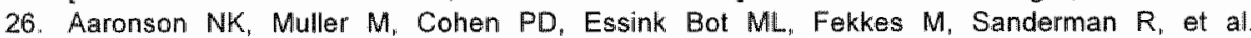
Translation, validation, and norming of the Dutch language version of the SF-36 Health Survey in community and chronic disease populations. J Clin Epidemiol 1998;51(11):1055-68.

27. Houtman I. Relliability and validity of the Dutch version of the Karasek Job Content Questionnaire. In: NOSHIAPA conference on Stress, Work, and Health. Washington , DC: APA; 1995.

28. Karasek RA. The Job Content Questionnaire and User's Guide (version 1.1). Los Angelles: Department of Industrial and Systems Engineering. University of Southern California; 1985

29. Grundemann RWM, Smulders PWG, De Winter CR. Handleiding Vragentijst Arbeid en Gezondheid [Manual, Questionnaire on work and health] Lisse: Swets \& Zeitllinger; 1993.

30. SPSS. Base 9.0 for Windows User's Quide. Chicago: SPSS Inc.; 1998.

31. SAS Institute. SAS version 6.12 Cary, North Carolima: SAS Institute; 1989.

32. Politi PL. Piccinelli M. Wilkinson G. Reliability, validity and factor structure of the 12-item General Heailth Questionnaire among young malles in ltaly. Acta Psychiat Scand $1994 ; 90(6): 432-7$.

33. Schmitz N, Kruse J. Tress W. Psychometric properties of the General Health Questionnaire (GHQ-12) in a German primary care sample. Acta Psychiat Scand 1999;100(6):462 8.

34. Van Veldhowen M. Broersen JPJ. Psychosociale arbeidsbelasting en werkstress in Nederland [Psychosocial work pressure and jobstress in the Netherlands]. Amsterdam: $S K B ; 1999$.

35. David A, Pelosi A, McDonald E. Stephens D, Ledger D. Rathbone R, et al. Tired, weak, or in need of rest: fatigue among general practice attenders. Brit Med J 1990;301(6762):1199-202.

36. Loge $\mathrm{JH}$. Ekaberg $\mathrm{O}$. Kaasa $\mathrm{S}$. Fatigue in the generai Norwegian popullation: Normative data and assaciations. J Psychosom Res 1998,45(1):53-65.

37. MoCabe CJ, Thomas KJ, Brazier JE, Coleman P. Measuring the mental health status of a population: a comparison of the GHQ-12 and the SF-36 (MHH-5). Brit J Psychiat $1996 ; 169(4): 516-21$

38. Kirk KM, Hickle IB, Martin NG. Fatigue as related to anxiety and depression in a communitybased sample of twins aged over 50. Soc Psych Psych Epid 1999;34(2):85-90 


\section{Need for recovery from work: Evaluating short-term effects of working hours, patterns and schedules}

Nicole WH Jansen"

IJmert Kant ${ }^{1}$

Ludovic GPM van Amelsvoort ${ }^{1}$

Frans JN Nijhuis ${ }^{2}$

Plet A van den Brandt ${ }^{1}$

'Department of Epidemiology, Maastricht University , Maastricht, The Netherlands ${ }^{2}$ Department of Health Orglanization, Policy and Economics, Maastricht University, Maastricht, The Netherlands 


\section{ABSTRACT}

In this paper working hours, patterns and work schedules of employees were evaluated in terms of need for recovery from work. Self-administered questionnaire data from employees of the Maastricht Cohort Study on "Fatigue at Work" $(n=12,095)$ were used. Poisson regression analyses and multivariate logistic regression analyses revealed that higher working hours a day and working hours a week generally went together with more need for recovery from work. Overtime work was particularly associated with higher need for recovery from work in both genders. Both male and female three-shift or irregular shift workers had higher odds of elevated need for recovery compared to day workers. When additionally controlling for work-related factors, need for recovery levels among shift workers substantially lowered. This study clearly showed that working hours and schedules are associated with need for recovery from work, with different associations for men and women. Especially the associations between work schedulies and need for recovery from work were very interrelated with other work-related factors. Future studies could further investigate the possibility that shift work might function as a proxy of other work-pelated factors that explain the different levels in need for recovery from work, or that job demands are perceived higher among shift workers and may therefore lead to more need for recovery from work. 


\section{INTRODUCTION}

Due to economic, technological, and social changes in the past decade, a 24 hour organization of the workplace is now widespread. ${ }^{1}$ This requires the workforce to adapt to many different forms of work schedules including flexible working hours and irregular shifts. Recent studies show that not only shift work but also flexible working conditions, even within day work, can have a negative impact on health and well being. ${ }^{2}$

There are several concepts and mechanisms how working hours and schedules could influence the workers health and well being. ${ }^{3}$ First, biological disruption to physiological processes, including the sleep-wake cycle. ${ }^{45}$ Second, the impairment of physical health and psychological well being ${ }^{6}$ and third the disruption of domestic and social life. ${ }^{7,8}$

Another interesting way in which working hours and schedules can have an impact on employees concerns the concept of need for recovery from work. ${ }^{9-13}$ Need for recovery from work was defined as the need to recuperate from work-induced fatigue, primarily experienced after a day of work. The concept involves the intensity of work-induced fatigue, both mentally and physically, as well as the time period required to return to a normal or prestressor level of functioning. ${ }^{13}$ Feelings of temporary overload after work or need for recovery can be recognized in the off-work situation by feelings of "wanting to be left alone for a while after work", or "being able to relax only on a second day off". 12,14 Recovery from a work-induced stressor level is determined by many work-related factors such as work load, ${ }^{15.15}$ overtime work, ${ }^{16}$ deviating working hours ${ }^{17}$ and by individual factors, such as coping strategies, ${ }_{1}^{18}$ health status and private situation. ${ }^{19}$ De VriesGriever $^{17}$ reported that the degree to which employees are able to recover from fatigue and stress at work is one of the most important factors influencing the physical and mental condition of an employee.

Besides work-related factors and individual characteristics, the actual time window, that is duration as well as timing, available to recover from work is important. Therefore, work-rest schedules are of great importance, since working time arrangements determine the actual time and timing to recover from work. Working too many shifts in succession, having too short a period of rest in between two shifts, or having to sacrifice days off "can all have a strong negative impact on the opportunity to recover from fatigue at work. ${ }^{17}$ Thus, in recovery from occupationally exerted efforts time seems to be a crucial variable. ${ }^{9,15}$ Van Veldhoven and Meijman ${ }^{10}$ found that working in shift systems required more effort and time to recover than working in day shifts. Since need for recowery reflects both the effects of work and the recovery time, need for recovery from work may be an interesting tool for assessing the short-term effects of work-rest schedules. It was hypothesized that daytime working employees who work many hours a week, will report more need for recovery compared to employees working less hours a week. It was also hypothesized that shift workers would report more need for recovery from work compared to day workers. Further, need for recovery from work may be different for men and women, because of different types of jobs occupied by men and women and because men and women often occupy different roles in the private situation. 
When studying the role of working time arrangements, other work-related factors have to be taken into accourt. As regards work schedules, strong differences between day and shift workers in other work conditions have been reported. ${ }^{20}$ The possibility exists that shift work could act as a proxy for other work-related risk factors, ${ }^{20}$ thus emphasizing the need to control for differences in the work environment when examining working time arrangements. One approach to potential confounding with regard to shift work is to include measures of perceived job characteristics in the analysis of shift work effecits. ${ }^{21}$

The present study was designed to (1) describe the magnitude of associations between working hours / patterns and need for recovery from work with regard to exclusively day workers, (2) to investigate differences in the level of need for recovery from work between four types of work schedules (day work, three-shift, five-shift and irregular shift work), with comparable working hours a week and (3) to study the impact of other workrelated factors in the association between working time arrangements and need for recovery from work.

\section{Methods}

\section{Study population}

This study is part of the Maastricht Cohort Study on "Fatigue at Work", capturing employees from 45 different companies and organizations, which were followed by means of self-administered questionnaires. ${ }^{14,22}$ Data from the baseline questionnaire were used for the present cross-sectional study. The baseline questionnaire was sent in May 1998. A reminder was sent out after two weeks. After six weeks a brief nonresponse questionnaire was sent to a random subsample of 600 nonrespondents. Nonresponse analyses yielded no significant differences between respondents and nonrespondents regarding demographic characteristics. Nonrespondents were somewhat less likely to report difficulties in work execution. fatigue complaints, and sick leave. Altogether, 12,161 employees completed and returned the baseline questionnaire (response rate of $45 \%$ ). Sixty-six questionnaires were excluded from analysis due to technical reasons or because inclusion criteria were not met. The baseline cohort consists of $8840(73 \%)$ men and $3255(27 \%)$ women. For the present study further selections were made from this baseline cohort. Included were men and women, aged 18.65 years, with a minimum employment of $50 \%$, that is working at least $50 \%$ of the contractual working hours of a fulltime job in the company. Temporary employees were excluded since they generally change jobs frequently. For the present study further exclusion criteria were having multiple jobs, being absent from work at the time of completing the questionnaire and not having completely resumed work after a period of sick leave. Three different subpopulations were selected from the totall cohort. First, to study the effects of working hours and patterns, only employees involved in day work were selected constituting population $A$ ( $n=5170$ ). Second, to study the effects of work schedules, only employees working in day shift, three-shift, or irregular shifts were selected. In order to make the work schedule groups comparable with regard to working hours, only employees with a warking week of $36-40$ hours were selected. Although the working hours then were 
similar between work schedule groups, differences in other work-related factors between employees with different work schedules are often large. In general, day workers have a higher educational level compared to shift workers and educational level is often seen as a proxy of job content. Therefore, we further selected in population $B$ only those employees whose highest educational level was intermediate vocational or lower, in order to try to keep the differences in work-related factors between the different schedules somewhat smaller. These selection criteria resulted in population $B(n=2167)$. Since employees working five-shift systems generally have a working weelk comprising 26-35 hours a third study population had to be constructed, population $C \quad(n=815)$. Population C captured five-shift workers and a reference group of day workers with a 26 . 35 hour working week. Again, only employees whose maximum educational level was intermediate vocational or lower were selected. Descriptive characteristics of subpopulations $A, B$ and $C$ are presented in Table 1

Table 1 Descriptiwe characteristics of study population $A, B$ and $C$

\begin{tabular}{|c|c|c|c|c|c|c|c|c|}
\hline & \multirow{2}{*}{$\begin{array}{c}\begin{array}{c}\text { Sludy } \\
\text { population A }\end{array} \\
\text { Day work }\end{array}$} & \multicolumn{4}{|c|}{ Study population B } & \multicolumn{3}{|c|}{ Studly populalion C } \\
\hline & & $\begin{array}{l}\text { Day } \\
\text { work }\end{array}$ & $\begin{array}{l}\text { Threes shift } \\
\text { work }\end{array}$ & $\begin{array}{l}\text { liregular } \\
\text { shift work }\end{array}$ & p value & Day work & $\begin{array}{l}\text { Five-shift } \\
\text { work }\end{array}$ & p valta \\
\hline n (number of organizations) & $5170(45)$ & $\begin{array}{l}1287 \\
(43)\end{array}$ & $590(15)$ & $290(21)$ & & $184(32)$ & $631(6)$ & \\
\hline Gender $\%$ female & 31.9 & 19.7 & 6.6 & 21.4 & 0.000 & 81.5 & 4.9 & 0.000 \\
\hline Agle mean $(S D)$ & $\begin{array}{l}42.37 \\
(8.85)\end{array}$ & $\begin{array}{l}44.48 \\
(8.44)\end{array}$ & $\begin{array}{r}36.43 \\
(8.35)\end{array}$ & $\begin{array}{l}38.61 \\
(8.78)\end{array}$ & 0.000 & $\begin{array}{r}40.91 \\
(9.60)\end{array}$ & $\begin{array}{l}37.58 \\
(8.40)\end{array}$ & 0.000 \\
\hline Highest educational level \% & & & & & 0.000 & & & 0.000 \\
\hline Primary school & 2.3 & 6.2 & 10.7 & 7.2 & & 4.9 & 7.0 & \\
\hline Lower wocational & 3.0 & 19.6 & 45.1 & 36.6 & & 19.0 & 32.3 & \\
\hline Lower secondary & 12.3 & 26.6 & 15.6 & 22.8 & & 33.2 & 20,9 & \\
\hline Intermediate vocational & 19.5 & 47.6 & 28.6 & 33.4 & & 42.9 & 39.8 & \\
\hline Secondary & 11.3 & - & - & - & & - & - & \\
\hline Higher vocational & 31.2 & - & - & $=$ & & $=$ & - & \\
\hline Uniwersity & 15.4 & $\approx$ & . & - & & $\therefore$ & - & \\
\hline Long-term disease \% & 22.4 & 27.4 & 23.1 & 230 & 0.076 & 26.6 & 178 & 0.010 \\
\hline Physical dernand ing work \% & 10.7 & 17.3 & 48.6 & 76.0 & 0.000 & 24.0 & 33.1 & 0.020 \\
\hline $\begin{array}{l}\text { Psychological job demands } \\
(12-48)^{\text {t" }}(\mathrm{SD})\end{array}$ & $\begin{array}{r}32.66 \\
(5.49)\end{array}$ & $\begin{array}{l}32.36 \\
(5.54)\end{array}$ & $\begin{array}{l}34.26 \\
(5.95)\end{array}$ & $\begin{array}{r}34.30 \\
(5.63)\end{array}$ & 0.000 & $\begin{array}{r}31.93 \\
(5.57)\end{array}$ & $\begin{array}{l}31.57 \\
(5.49)\end{array}$ & 0.439 \\
\hline $\begin{array}{l}\text { Denision latude } \\
(24-96)^{-1}(\mathrm{SO})\end{array}$ & $\begin{array}{r}73.49 \\
(10.30)\end{array}$ & $\begin{array}{r}71.36 \\
(9.89)\end{array}$ & $\begin{array}{r}65.13 \\
(13.57)\end{array}$ & $\begin{array}{r}67.48 \\
(11.41)\end{array}$ & 0.000 & $\begin{array}{r}69.11 \\
(10.32)\end{array}$ & $\begin{array}{r}68.29 \\
(11.31)\end{array}$ & 0.379 \\
\hline $\begin{array}{l}\text { Emolional demands } \\
(0-5)^{*}(\mathrm{SD})\end{array}$ & $\begin{array}{r}0.86 \\
(1.11) \\
\end{array}$ & $\begin{array}{r}0.91 \\
(1.11)\end{array}$ & $\begin{array}{r}1.45 \\
(1.36)\end{array}$ & $\begin{array}{r}1.79 \\
(1.44) \\
\end{array}$ & 0.000 & $\begin{array}{r}1.13 \\
(1.23)\end{array}$ & $\begin{array}{r}1.06 \\
(1.15) \\
\end{array}$ & 0.495 \\
\hline
\end{tabular}

* Scalle range

\section{The questionnaire}

The questionnaire of the Maastricht Cohort Study captured amongst others information on working time arrangements, work characteristics, demographics, health factors and need for recovery from work. 
The Need for Recovery scale was derived from the Dutch questionnaire Experilence and Assessment of Work (VBBA), a scale widely used in the Netherlands. "114.23 The scale contains 11 dichotomous items, concerning the recuperation period after one day of work. Examples of items are "I find it hard to relax at the end of a working day" and "My job causes me to feel rather exhausted at the end of a working day". ${ }^{21.13}$ All variables were recoded in such a way that higher scores meant "more complaints", in other words more need for recovery. Missing data on the Need for Recovery scale on more than four items resulted in excluding the subject from analysis. Sum scores with missing data on four or less litems were calculated by dividing the score by the number of completed ltems. The recoded total score ranges from 0 to 100 . The Cronbach's alpha of the entire scale is 0.78 . To indicate employees with low and high levels of need for recovery the lower and upper quartile were used respectively.

The baseline questionnaire included 32 questions on working time arrangements, which enabled us to adequately describe the working hours, patterns, in terms of working days a week, and work schedules employees were engaged in. Regarding working hours and patterns employees were asked for their working hours a day. working hours a week, and working days a week (Table 2) that not include overtime work. Overtime work was assessed separately by asking employees if they worked overtime frequently and whether or not they experienced overtime work as troublesome. Regarding work schedules, employees were asked whether they worked irregular shifts, two-, three-, four-, or five-shift work, exclusively evening work, exclusively night work, or whether they worked daytime only. Because of too sample size in some work schedule groups, in the present study only day shift, three-shift, five-shift and irregular shift workers were included for investigating differences between the schedules. In the present study threeshift work, also referred to as $3 \times 8$ semi-continuous shift work, involves a 24-hour production from Monday through Friday carried out by three teams of employees. generally working eight-hour shifts. In three-shift work, teams are switched as a rule every week. Five-shift work involves full continuous shift work, spread over seven days including five alternating teams, generally working eight-hour shifts. Employees working irregular shifts are involved in frequently deviating work hours, which can vary substantially every week. The direction of the shifts (clockwise "counter clockwise) varied between the companies. As shown in Table 1, there are differences in the number of organizations representing a type of work schedule. Employees working in day shifts were well distributed over 45 different organizations. With regard to three-shift systems, the majority of employees $(88.1 \%)$ stemmed from a large automobille factory. In five-shift systems, the majority of employees originated from companies in the paper industry or from a microelectronics company. In irregular shift systems, $52.4 \%$ of the employees stemmed from a postal services company.

When investiglating associations between working time arrangements and need for recovery in the working population, other work-related factors are of interest. Therefore, we included measures regarding the experience of several demands at work. A Dutch version of the Job Content Questionnaire (JCQ) was used to measure psychological job demands and decision latitude. ${ }^{24,25}$ Decision latitude (Cronbach"s alpha 0.81) was measured by the sum of two subscales: skill discretion and decision authority. 
Psychological job demands were assessed by the sum of five items (Cronbach's alpha 0.69). Physical demands were measured using a dichotomous item of the Dutch Questionnaire on Work and Health (VAG). ${ }^{26}$ The level of emotional demanding work was assessed using a five item scale (Cronbach's alpha 0.60) consisting of two items of the Questionnaire Experience and Assessment of Work (VBBA), ${ }^{10}$ two items of the Questionnaire on Work and Health $(\mathrm{VAG})^{26}$ and one self-formulated item.

Information on age, gender and the presence of a long-term disease was obtained through self-report in the baseline questionnaire. The type of longuterm disease was inventoried as well, with examples such as heart condition, rheumatism, diabetes and protracted back pain. The presence of a long-term disease was related to higher need for recovery levels in an earlier study. "In addition, having a long-term disease may also influence the choice or ability to work a certain number of working hours a week. Therefore, it is important to control for the presence of a long-term disease as well.

\section{Statistical analysis}

Two different analysis methods were used. First, since need for recovery in the study population showed a Poisson distribution, Poisson regression analysis was used to investigate the relationship between working time arrangements and need for recovery as a continuous variable, controlled for age, presence of a long-term disease, psychological job demands, decision latitude, physical demands and emotional demands of work. Second, multiple logistic regression analyses were performed to compare the relationship between working time arrangements and need for recovery in two contrasting groups, representing high (upper quartile) and low (lower quartile) need for recovery respectively, controlled for age, presence of a long-term disease, psychological job demands, decision latitude, physical demands and emotional demands of work. All analyses were conducted for men and women separately. Further statistical procedures included Chi-square tests, independent samples T-tests and ANOVAs. P values of $5 \%$ or less were considered significant. Analyses were conducted with SPSS $^{2 \pi}$ and SAS. ${ }^{28}$

\section{RESULTS}

\section{Need for recovery from work}

In the total study population at baseline, the mean total score on need for recovery was 37.09 (SD=26.43), the lower and upper quartile were 9.09 and 54.55 respectively, after excluding those employees who were absent from work, and those who had not completely resumed work after a period of sick leave. In sub population $A$, the mean total score on need for recovery was $34.43(S D=25.48), 38.40(S D=27.17)$ in study population $B$ and $35.13(S D=26.10)$ in population $C$. The total score of need for recovery was skewed to the left in all study populations, indicating that the majority of employees reported low levels of need for recovery from work. 


\section{Working hours, patterns and need for recovery from work}

Because the presence of a long-term disease was found to be highly associated with need for recovery in an earlier study. ${ }^{13}$ we first studied the prevalences of long-term diseases in the different distinguished groups of working hours in Table 1. For men, the prevalence of a long-term disease ranged from $17.6 \%$ for men working over 40 hours per week to $70 \%$ for men who worked $\leq 25$ hours per week. As regards examples of the types of long-term diseases, men working $\leq 25$ hours more frequently reported having a heart condition $(\rho<0.001)$, protracted back complaints $(\rho<0.001)$ and psychological problems $(\rho<0.001)$ compared to men working over 25 hours a week. The extreme high prevalence of a long-term disease was only observed in the group of men working $\leq 25$ hours per week and to a lesser extent $(56.6 \%)$ among those men working $\leq 6$ hours per day. For women, the range was much smaller, that is the presence of a long-term disease ranged from $18.7 \%$ for women working $9-10$ hours per day to $25 \%$ for women working $\leq 7$ hours per day. These findings emphasize the need to control for the presence of a long-term disease in the relationship between working hours and need for recovery.

Table 2 Need for recovery for different working hours and patterns in day working employees

\begin{tabular}{|c|c|c|c|c|c|c|}
\hline \multirow[t]{2}{*}{ Variable } & \multicolumn{3}{|c|}{ Need for recovery } & \multicolumn{3}{|c|}{ Need for recovery } \\
\hline & Mena & Men $^{0}$ & $n$ & Womena & Women & $n$ \\
\hline \multicolumn{7}{|c|}{ Working hours a week } \\
\hline$\leq 25$ & 37.27 & $39.19^{*}$ & 51 & $26.70^{* * k}$ & $25.75^{\text {kik }}$ & 6.42 \\
\hline $26-35$ & 33.10 & 34.18 & 146 & 34.10 & 31.97 & 334 \\
\hline $36-40$ & 33.68 & 32.80 & 2392 & 35.68 & 34.66 & 573 \\
\hline$>40$ & $37.85^{* * * 1}$ & $35.14^{* t}$ & 921 & 39.53 & 35.43 & 87 \\
\hline \multicolumn{7}{|c|}{ Frequent overtime work } \\
\hline Yas & $38.39^{* \text { *ix }}$ & $34.99^{* * \times *}$ & 1518 & $35.63^{* \pm * t}$ & 32.15 & 580 \\
\hline No & 32.19 & 32.09 & 1995 & 29.97 & 30.06 & 1062 \\
\hline \multicolumn{7}{|c|}{ Owertime work troublesome } \\
\hline Yos & $51.36^{\text {thit }}$ & $45.01^{* * *}$ & 217 & $48.31^{* * * *}$ & $43.00^{2 * *}$ & 132 \\
\hline Not & 35.53 & 35.24 & 1266 & 31.65 & 31.71 & 428 \\
\hline \multicolumn{7}{|c|}{ Working hours a day } \\
\hline$\leq 6$ & 34.39 & 34.89 & 79 & $23.98^{* \ldots}$ & $22.72^{*+1+2}$ & 473 \\
\hline 7 & $37.77^{*}$ & 34.15 & 175 & 36.01 & 33.50 & 149 \\
\hline 8 & 33.46 & 32.59 & 2636 & 34.62 & 34.03 & 927 \\
\hline $9-10$ & $39.6 \|^{* * * x}$ & $35.8 .5 *$ & 606 & $40.66^{*}$ & 35.80 & 78 \\
\hline \multicolumn{7}{|c|}{ Working days a week } \\
\hline$\leq 3$ & 33.24 & 37.70 & 16 & $29.15^{*}$ & 28.84 & 304 \\
\hline 4 & 31.71 & 32.30 & 140 & 33.16 & 30.81 & 365 \\
\hline 5 & 35.05 & 33.27 & 3366 & 32.47 & 30.93 & 979 \\
\hline
\end{tabular}

Adjusted values of need for recovery were extracted from the regression formula. Therefore no slandard deviations can be presented.

"p<0.05," $" p<0.01$, *

"Controlled for age and long-tern disease

- Controlled for age and long-term disease, physical demands, enotional demands, psychological job demands and decision latitude

- Reference groups 
Poisson regression analysis revealed differences in need for recovery regarding different working hours a day, a week, and regarding overtime work, when adjusting for demographic and health factors (Table 2). As shown in Table 2 , more working hours a week resulted in a higher need for recowery from work in women. In men, a different pattern was observed, suggesting curvilinearity. Men with a 25-hour working week or less showed higher but nonsignificant levels of need for recovery compared to traditionally 36-40 hours/week workers. Men working over 40 hours a week reported significantly higher levels of need for recovery compared to 36-40 hours/week workers. Women working $\leq 25$ hours a week reported substantial and significantly lower levels of need for recovery compared to women working the traditional 36-40 hour working week. The size of this group of women working $\leq 25$ hours a week allowed us to refine the association between working hours a week and need for recovery. These data are not shown in Table 2. When women worked $\leq 16$ hours a week $(n=62)$ the adjusted mean level of need for recovery was 17.36, when we controlled for age and the presence of a long-term disease and 15.20 when we additionally controlled for work-related factors. These results were statistically significant different from the reference group of women working 36-40 hours per week.

Frequent overtime work was associated with a substantially higher need for recovery in both genders. When overtime work was reported as troublesome in employees with frequent overtime, even higher levels of need for recovery were reported.

With regard to the number of working hours per day, women working six or less hours a day reported significantly lower levels of need for recovery, compared to women working eight hours a day. The size of this group of women working six hours a day or less allowed us to refine the association between working hours a day and need for recovery. These data are not shown in Table 2. When women worked less than four hours a day $(n=36)$, the adjusted mean level of need for recovery was 16.73 , when we controlled for age and the presence of a long-term disease, and 12.92 when we additionally corrected for work-related factors. These results were statistically significant different from the reference group of women working eight hours per dlay. Working nine or ten thours a day was associated with significanlly higher levels of need for recovery compared to working eight hours a day in both genders.

As regards the pattern of working days a week, Poisson regression analysis yielded nonsignificant associations between the number of working days a week and need for recovery in men. In women, however, working three days or less a week was associated with a significantly lower need for recovery compared to female employees working five days a week.

As shown in Table 2, the continuous scores of need for recovery from work were additionally controlled for other work-related factors in a second step. Overall, similar trends appeared, although in general the levels of need for recovery from work were somewhat lower in magnitude.

Table 3 shows the results of logistic regression analyses regarding differences in working hours, patterns and need for recovery dichotomized in low and high need for recovery from work. Working 25 hours a week or less was clearly associated with a lower odds of elevated levels of need for recovery in women (OR $0.34 ; \mathrm{Cl} 0.24-0.50$ ) but not in men (OR 1.33; $\mathrm{Cl} 0.62-2.85$ ) compared to employees working $36-40$ hours a 
week. Workirig over 40 hours a week was associated with a higher odds of elevated levels of need for recovery only in men (OR 1.65; $\mathrm{Cl} 1.31-2.07$ ).

Frequent overtime workers reported significantly more need for recovery (OR $2.05 ; \mathrm{Cl}$ 1.67-2.52 for men and OR 1.86; $\mathrm{Cl} 1.36-2.55$ for women), especially when overtime work was considered to be troublesome (OR $6.61 ; \mathrm{Cl} 3.86-11.30$ for men and OR $7.24 ; \mathrm{Cl}$ 3.66 14.30 for women).

Regarding working hours a day working six or less hours a day decreased the odds of high levels of need for recovery compared to employees working eight hours a day only in women (OR $0.23 ; \mathrm{Cl} 0.15-0.34$ ) after controlling for age and the presence of a longterm disease. Working seven hours a day was in men associated with a higher odds of need for recovery compared to employees working eight hours a day (OR 1.66, $\mathrm{Cl} 1.06$ 2.59). Working nine or ten hours a day was associated with a higher odds of elevated levels of need for recovery in both genders (OR 2.09; $\mathrm{Cl} 1.61-2.70$ for men, OR $2.21 ; \mathrm{Cl}$ 1.09-4.47 for women). As shown in Table 3, the odds ratios for need for recovery from work were additionally controlled for other work-related factors in a second step. In general, similar trends appeared, although in most cases the ORs were somewhat lower in magnitude or became nonsignificant.

Table 3 Working hours, patterns, demographic and health factors and job demands associated with the odds ratio (OR) of elevated need "or recovery (upper ws lower quartile). (95\% $\mathrm{Cl}=95 \%$ confidence interval)

\begin{tabular}{|c|c|c|c|c|c|c|}
\hline \multirow[t]{2}{*}{ Variable } & \multicolumn{3}{|c|}{ Men } & \multicolumn{3}{|c|}{ Women } \\
\hline & OR $(95 \% \mathrm{C})$ & $O R^{\circ}(95 \% \mathrm{Cl})$ & $n$ & $\mathrm{OR}^{\mathrm{a}}(95 \% \mathrm{Cl})$ & $\mathrm{OR}(95 \% \mathrm{CH})$ & $n$ \\
\hline \multicolumn{7}{|c|}{ Working hours a week } \\
\hline$\leq 25$ & $1.33(0.62-2.85)$ & $2.37(0.97-5.82)$ & $5 \pi$ & $0.34(0.24 \times 0.50)$ & $0.26(0.16-0.41)$ & 642 \\
\hline $26-35$ & $0.83(0.49-1.39)$ & $1.10(0.60-2.03)$ & 146 & $0.94(0.62-1.42)$ & $0.74(0.45-1.22)$ & 334 \\
\hline $36-40=$ & 1 & 1 & 2392 & 1 & 1 & 573 \\
\hline$>40$ & $1.65(1.31-2.07)$ & $1.44(1.10-1.90)$ & 921 & $1.73(0.82-3,67)$ & $0.97(0.39-2.45)$ & 87 \\
\hline \multicolumn{7}{|c|}{ Frequent overtime work } \\
\hline Yes & $2.05(1.67-2.52)$ & $1.59(1.17-1.04)$ & 1518 & $1.86(1.36-2.55)$ & $1.49(0.80-1.77)$ & 580 \\
\hline $\mathrm{No}^{\mathrm{in}}$ & 1 & 1 & 4995 & 1 & 4 & 1062 \\
\hline \multicolumn{7}{|c|}{ Owertime work tratblesome } \\
\hline Yes & $6.61(3.86-11.30)$ & $4.80(2.64-8.73)$ & 217 & $7.24(3.66 \cdot 14.30)$ & $5.54(2.52-12.19)$ & 132 \\
\hline No: & 1 & 1 & 1266 & 1 & 1 & 428 \\
\hline \multicolumn{7}{|c|}{ Working hours a day } \\
\hline$\leq 6$ & $1.10(0.56-2.16)$ & $4.38(0.62-3.06)$ & 79 & $0.23(0.15-0.34)$ & $0.13(0.07 \times 0.21)$ & 473 \\
\hline 7 & $1.66(1.06-2.59)$ & $1.25(0.72-2.19)$ & 175 & $1.14(0.65-1.98)$ & $0.84(0.41-1.70)$ & 149 \\
\hline 8 & 1 & 1 & 2636 & 1 & 1 & 927 \\
\hline $9-10$ & $2.09(1.61-2.70)$ & $1.65(1.21-2.25)$ & 606 & $2.21(1.09-4.47)$ & $1.56(0.66 \times 3.72)$ & 78 \\
\hline \multicolumn{7}{|c|}{ Working days a week } \\
\hline$\leq 3$ & $1.12(0.24-5.20)$ & $3.19(0.55-18.33)$ & 16 & $0.72(0.47-1.10)$ & $0.84(0.50-1.39)$ & 304 \\
\hline 4 & $0.65(0.39-1.08)$ & $0.75(0.42-1.36)$ & 140 & $1.08(0.75 * 1.56)$ & $1.10(0.71-1.70)$ & 365 \\
\hline $5^{n}$ & 1 & 1 & 3366 & 1 & 1 & 979 \\
\hline
\end{tabular}




\section{Work schedules and need for recovery from work}

To investigate the association between work schedules and need for recovery. subpopulations $B$ and $C$ were used. As presented in Table 4, Poisson regression analysis revealed that need for recovery was highest among three-shift workers and irregular shift workers in both genders, when we controlled for age and the presence of a long-term disease. Although the different work schedule groups in these populations were comparable with regard to working hours and had the same restriction with respect to the highest educational level, differences in work-related factors remained. As shown in Table 1, the percentage of physical demands was highest in irregular shift workers $(76 \%)$ and lowest in day workers (17.3\%). Psychological job demands were highest in irregular shift workers $(M=34.30, S D=5.63)$ and three-shift workers $(M=34.26, S D=5.95)$. The highest decision latitude was observed among day workers working $36-40$ hours a week ( $M=71.36, S D=9.89)$. Irregular shift workers reported the highest emotional demands $(M=1.79, S D=1.44)$. Since work-related demands differed across the work schedule groups, even after the reported selection in educational level, we also corrected for these factors. When correcting for work-related factors, only the difference in need for recovery between male three-shift workers and male day workers remained statistically significant.

Table 4 Need for recovery from work in different work schedules with a $26-35$ or $36-40$ hour woiking week

\begin{tabular}{|c|c|c|c|c|c|c|c|}
\hline & \multirow[t]{2}{*}{ Variable } & \multicolumn{3}{|c|}{ Need for tecovery } & \multicolumn{3}{|c|}{ Need for lecovery } \\
\hline & & Men' & Ment & 7 & Womenti & Woment & $\mathrm{m}$ \\
\hline \multirow[t]{3}{*}{36.40 hr/wk } & Day worke & 33.01 & 34.91 & 1033 & 33.08 & 35.58 & 254 \\
\hline & Three-shift work & $44.31^{* * * n}$ & $37.83^{\mathrm{d}}$ & 551 & $46.96^{*}$ & 34.26 & 39 \\
\hline & Irregular shift work & 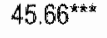 & 35.46 & 228 & $42.76^{\star}$ & 35.70 & 62 \\
\hline \multirow[t]{2}{*}{$26-35 \mathrm{hr} / \mathrm{wk}$} & Day work & 27.10 & 29.96 & 34 & 31.27 & 30.64 & 150 \\
\hline & Five-shift work & 35.30 & 34.80 & 600 & 35.37 & 37.00 & 31 \\
\hline
\end{tabular}

Adjusted walues of need for recovery were exlracted from the regression formula. Therefore no stand ard deviatong can be presented.

" $p<0.05 . * p<0.01$, *i* $p<0.001$

a Controlled for age and long-term disease

- Controlled for age, long-term disease, physical demands, emotional demands, psychological job demands and decision latitude

- Reterence group

Table 5 presents the results of the logistic regression analyses regarding the association between work schedules and need for recovery in two contrasting groups, representing high and low need for recovery from work. When controlling for agle and the presence of a long-term disease, working in shift systems was clearly associated with a higher odds of elevated levels of need for recovery compared to day workers with a 36-40 hour working week. In particular, male three-shift workers and male irregular shift workers had substantial higher odds of elevated need for recovery (OR 3.66; CI 2.56-5.24 and OR 4.17; Cl 2.64-6.59 respectively) compared to male day workers. Female three-shift workers had over fourfold higher odds of elevated need for recovery compared to female 
day workers (OR 4.70; Cl 1.67-13.22). Women working irregular shift systems had over twofold higher odds of elevated need for recovery (OR 2.52; Cl 1.01-6.30) compared to female day workers. In both genders, working in a five-shift system was not associated with higher odds of elevated need for recovery compared to working day time in a 26-35 hour working week.

After riultivariate adjustments for age, long-term disease, decision latitude, psychological job demands, physical and emotional demands, only the odds ratio for elevated need for recovery for male three-shift workers versus male day workers was statistically significant (OR 1.73 ; Cll 1.11-2.86).

Table 5 Shift work, demographic and health lactois and job demands associated with the odds ratio (OR) of need for ecovery (upper quartile). $195 \% \mathrm{Cl}=95 \%$ confidence interval)

\begin{tabular}{|c|c|c|c|c|c|c|}
\hline \multirow[t]{2}{*}{ Variable } & \multicolumn{3}{|c|}{ Men } & \multicolumn{3}{|c|}{ Women } \\
\hline & ORa $(95 \% \mathrm{Cl})$ & OR $(95 \% \mathrm{C})$ & $n$ & $\mathrm{OR}^{2}(95 \% \mathrm{Cl})$ & OR $(95 \%$ Cl $)$ & $n$ \\
\hline \multicolumn{7}{|l|}{$36-40$ hrivk } \\
\hline Day worke & 1 & 1 & 1033 & 1 & 1 & 254 \\
\hline Three shiff work & $3.66(2.56-5.24)$ & $1.78(1.11-2.86)$ & 551 & $4.70(1.67-13.22)$ & $1.04(0.24-4.45)$ & 39 \\
\hline Iregular shith work & 4. $17(2.64-6.59)$ & $0.96(0.51-1.79)$ & 228 & $2.52(1.01-6.30)$ & $0.84(0.20-3.48)$ & 62 \\
\hline \multicolumn{7}{|l|}{$26-35$ mrhak } \\
\hline Day wrorkc & 1 & 1 & 34 & 1 & 1 & 150 \\
\hline Five-shift work & $3.41(0.99-11.77)$ & $2.41(0.53-10.96)$ & 600 & $1.01(0.29-3.51)$ & $0.42(0.07-2.63)$ & 31 \\
\hline
\end{tabular}

\section{DISCUSSION}

In this study we examined the association between working hours, patterns, work schedules and need for recovery for men and women separattely. The study showed that high working hours a day and high working hours a week generally went together with a higher need for recovery, confirming our hypothesis that day workers with many working hours a week report more need for recovery from work compared to employees working less hours a week. Extension of the working day, in terms of overtime work, was particularly associated with more need for recovery in both men and women. Interestingly, also important differences in need for recovery between men and women with regard to working hours were observed. Differences in need for recovery between men and women were highest in the groups of employees with partime jobs. It was found that men with a small parttime job ( $\leq 25$ hours per week) generally reported higher levels of need for recovery compared to fulltime workers, whereas women with a small partime job generally reported lower need for recovery levels compared to fulltime workers. Compared to men working $>25$ hours a week, the men working $\leq 25$ hours had a substantially higher prevalence of a long-term disease. In women, the presence of a long-term disease was not significantly related to their specific working hours. Because the existing differences in the presence of a long-term disease between the men in these 
Wwo groups were that substantial, the adjustment for the presence of a long-term disease could be insufficient, and therefore residual confounding may exist. In addition, the possibility exists that the type of long-term disease is more severe among the male parttime workers as compared to male fulltime workers with a long-term disease. Further, it is also possible that male fulltime workers remaining to work fulltime even with a long-term disease had more possibilities to adjust their activities at work to their heath status. Hence, men who are unable to work long hours, for example due to health status. may have reduced their working hours in order to cope better with their work.

Working hours, expressed as working hours per day or per week, showed much stronger associations with need for recovery in contrast to the pattern of working days a week, probably reflecting the fact that the pattern of days a week can be made up by different working hours a day and different working hours a week between employees.

When controlling for age and the presence of a long-term disease a strong association was also found regarding the relationship between work schedules and need for recovery, confirming our hypothesis that shift workers would report more need for recovery compared to day workers. Van Veldhoven and Meijman ${ }^{10}$ also found that working in shift systems required more effort and recovery than working in day shifts. In the present study three-shift workers and irregular shift workers reported the highest need for recovery from work. Although, due to the selections made in the present study. the overall hours worked were similar as in day work, three-shift workers additionally have only two (weekend) days available to adjust and recuperate from their shift and switch to a new shift cycle. The traditional weekly change of shifts, as for example seen in three-shift work, is often reported to be the worst solution. ${ }^{29,30}$ Others have also found that recovery from a shift did not occur by the end of the first rest day but might have occurred only by the end of the second rest day. ${ }^{31}$ Too short a period of recuperation time could be an explanation for the high levels of need for recovery observed in these groups. A limitation of the study was that the majority of three-shift workers originated from one company. This company, a large automobile factory had recently switched from a twowshift system to the present three-shift system. Adaptation to another shift. system could perhaps result in higher levels of need for recovery as well.

Variations and alterations in the structure of irregullar shift rosters may have a substantial impact on subjective health. The irregularity in working hours and consequent irregularity and lack of control over recovery time from work can probably explain part of the high levels of need for recovery observed in irregular shift workers.

Parkes $^{21}$ reported that the findings from shift work studies might be distorted if the sample includes a variety of occupational groups and the effects of job differences ane not controlled. Occupation, however, is only a very crude index of working conditions because conditions may be quite different within the same occupational domain/job title, ${ }^{32.33}$ which enforces the need to control for stress at work. ${ }^{34}$ It was reported, for example, that employees working in an irregular three-shift system indicated more shift work stress compared to employees working in regular shifts. ${ }^{35}$ Moreover, Sluiter ef al. ${ }^{12}$ found that subjects who reported more job demands also reported more need for 
recovery from work. Therefore, we controlled for several work-related factors, such as decision latitude, psychological job demands, physical and emotional demands. When controlling for these work-related factors, similar trends in need for recovery were observed for working hours, although the levels of need for recovery were somewhat lower in magnitude. Work schedules, in contrast, showed nonsignifficant associations with need for recovery from work after adjustments for work-relaled factors, with the exception of three-shift work in men. Work-related factors such as demands at work were very interrelated with work schedules and appeared to explain part of the differences in need for recovery. This raises questions to the specific contribution of work schedules and work-related factors to different need for recovery levels. It may be that shilit work has been acting as a proxy for objective differences in other work environment factors between shift and day workers and that these differences were responsible for the findingls. In addition, work-related demands could be a proxy for shift work as well. By correcting for these work-related factors, the effects of work schedules are largely erased, which would indicate that, except for three-shift work, there was no significant contribution of work schedules in explaining need for recovery levels. However, the possibility exists that shift workers subjectively perceive their work as more demanding as compared to day workers. In that case, adjustment for job characteristics may lead to over-control and thus could lead to underestimation of the observed associations, which would imply that the specific contribution of shift work in explaining need for recovery levels would actually be higher than indicated after the multivariate adjustments for workrelated factors.

With regard to the comparison of day workers and shift workers a possible healthy worker effect has to be taken into account as well, because a selection could take place, in which only those employees start working shifts or remain in shift work who are able to withstand the effects that accompany shift work. A healthy worker effect would probably have resulted in an underestimation of the true levels of need for recovery from work among the work schedules.

We used the Need for Recovery scale to assess need for recovery in a working population. To date, there are no existing cutoff points for classifying employees with a marked need for recovery, putting them at risk for future health problems. Therefore, the upper and lower quartile were used to define a contrast between employees with and without a considerable need for recovery, which so far appeared to be a good method since the distribution of need for recovery in the cohort covered the whole range of the scale and showed no cutoff point or rarities. Definition and validation of a cutoff point for need for recovery, however, is needed for actual classification of cases.

Our study had the advantage of a relatively large sample. Inevitably, however, the crosssectional nature of the study imposes limitations on causal interpretation of the findings. Additionally, with a cross-sectional design the effects of a change in working hours on need for recovery levels for example, can not be studied adequately.

In this study the primary focus was on the association between working time arrangements and need for recovery, controlled for work-related factors. However, also 
individual differences in various personal, social, and environmental factors will allmost centainly moderate the impact of a shift schedule ${ }^{136}$ as well as the levels of need for recovery. Factors outside the work situation, such as home responsibilities and interference with familial roles can also be major contributing factors to the problems experienced by shift workers. Incomplete unwinding after work in female managers was found in a study by Frankenhaeuser et al. ${ }^{37}$ They concluded that the total workload, i.e., the combination of job and home demands, was responsible for the results. Time for recovery is usually taken during the free days after shifts (38), which can interfere with other activities undlertaken during leisure time, such as meeting friends and relatives for instance. ${ }^{36}$ Possibly, demanding factors in the home environment in combination with demanding work factors result in elevated levels of need for recovery from work. Therefore, in future studies, also the work-family interface has to be taken into account. Although it was already found that need for recovery was associated with health status in the Maastricht Cohort Study, ${ }^{13}$ as well as in a study of caach drivers, ${ }^{11}$ longitudinal analyses are needed to investigate whether need for recovery can be considered a precursor of prolonged fatigue and sick leave in the course of time. If so, then the instrument can be used to evaluate the effects of working time arrangements in the short-term and to detect employees at risk for future prolonged fatigue in the long-term.

\section{CONCLUSIONS}

Need for recovery from work was strongly associated with both working hours and work schedules. As regards working hours, extension of the working day, in terms of overtime work, was particularly associated with higher need for recovery from work. Considerable gender differences in the associations between working hours and need for recovery were observed. Especially the asisociations between work schedules and need for recovery from work depended strongly on the differences in work demands between day and shift workers. Future studies could further investigate the possibility that shift work might function as a proxy of other work-related factors that explain the different levels in need for recovery from work, or that job demands are perceived higher among shift workers and may therefore lead to more need for recovery from work.

\section{ACKNOWLEDGEMENTS}

The Maastricht Cohort Study is part of the Netherlands concerted research action on "Fatigue at Work" granted by the Netherlands Organization for Scientific Research. The present study was supported by grant no. 580.02.201 from the Netherlands Organization for Scientific Research.

\section{REFERENCES}

1. Smith L. Folkard S. Tucker P, Macdonald !. Work shift duration: A, review comparing elght hour and 12 hour shift systems. Occup Environ Med 1998;55:217-29. 
2. Martens MFJ, Nihuis FJM, Van Boxtel MPJ, Knottnerus JA. Flexible work schedules and mertal and physical health. A study of a working population with non-traditional working hours. J Organ Behav 1999;20(1):35-46.

3. Smith L. Macdonald I. Folkand $S$. Tucker $P$. Industrial shift systems. Appl Ergon $1998: 29(4): 273-80$.

4. Akerstedt T. Psychological and psychophysiological effects of shift work. Scand J Work Environ Health 1990;16 Suppl 1:67-73.

5. Hărmá M, Tenkanen $L_{i}$ Sjöblom $T$, Alikaski $T$, Heinsalmi $P$. Combined effects of shift work and lifemstyle on the prevalence of insomnia, sleep deprivation and daytime sleepiness. Scand $J$ Wark Environ Health $1998 ; 24(4): 300-7$.

6. Bohle $P$. Tilley AJ. The impact of night work an psychological well-being. Erganomics 1989;32(9):1089-99.

7. Monk TH, Folkard S. Making shift work tolerable. London/Washington: Taylor \& Francis: 1992.

8. Walker J. Social problems of shiftwork. In: Folkard $S_{4}$ Monk TH, eds. Hours of work. Temporal factors in work-scheduling. New York: John Wiley \& Sons; 1985. p. 211-25.

9. Meijman T. Mentale belasting en werkstress. Een arbeidspsychologische benadering. [Mental strain and workstress. An 1/O psychology approach]. Assen/Maastricht: Van Gorcum; 1989.

10. Van Veldhoven M, Meliman TF. Het meten van psychosociale arbeidsbelasting met een vragenlijst: de wragenlijst beleving en beoordeling van de arbeid (VBBA) [The measurement of pisychosocial job demands with a questionnaire (VBBA)]. Amsterdam: NIA: 1994.

11. Sluiter JK, Van der Beek AJ, Frings-Dresen MHVW. The influence of work characteristics on the need for recovery and experienced health: $A$ study on coach drivers. Ergonomics $1999: 42(4): 573-83$.

12. Sluiter JK, Frings-Dresen MHW, Van der Beek A.J, Meijman TF. The relation between workinduced neuroendocrine reactivity and recovery, subjective need for recovery, and health status. J Psychosom Res 2001;50:29-37.

13. Jansen NWH, Kant IJ, Van den Brandt PA. Need for recovery in the working population: description and associations with fatigue and psychological distress. Int $\Downarrow$ Behav Med 2002;9(4):322-40.

14. Beurskens AJ, Bültmann U, Kant IJ, Vercowlen JH, Bleijenberg $G$, Swaen GM. Fatigue among working people: validity of a questionnaire measure. Occup Environ Med 2000;57(5):353-7.

15. Milosevic S. Drivers' fatigue studies. Ergonomics 1997;40(3):381-9.

16. Saito K. Measurement of fatigue in industries. Ind Health 1999;37(2):134-42.

17. De Vries-Griever AHG. Evemwicht tussen werkdruk en herstel bij afwijkende werktijden. Uitgangspunten voor dienstroosterplanning [Balancing work laad and recovery in deviating working hours. Basic principles of rota planning]. Groningen/Utrecht: Nationaal Ziekenhuisinstituut: 1992.

18. Wessely S. Chronic fatigue and myalgia syndromes. In: Sartorius N. Goldberg D, eds. Psychological disorders in general medical settings. Goettingen. Germany: Hogrefe \& Huber Publishers; 1990. p. 82-97.

19. Galembos NL. Walters BJ. Work hours, schedule inflexibility, and stress in dual-earner spouses, Can J Beh Sci 1992;24(3);290-302.

20. Baggild $H$, Burr $H$, Tüchsen $F$, Jeppesen $H J$. Work environment of Danish shift and day workers. Scand J Work Environ Health 2001;27(2):97-105.

21. Parkes KR. Shiftwork, job type, and the work environment as joint predictors of health-related outcomes. J Occup Health Psychol 1999:4(3):256-68

22. Kant IJ, Beurskens AJHM, Schröer CAP, Nijhuis FJN, Van Schayck CP, Van den Elzen HJ, et al. De Maastrichtse Cohort Studie naar langdurige psychische vermoeidheid in de arbeidssituatie [The Maastricht Cohort Study on fatigue at work]. TBV 2000;8(8):226-32.

23. De Croon EM, Blonk RWB, Van der Beek AJ, Frings-Dresen MHW. The trucker strain monitor: an accupation-specific questionnaire measuring psychological job strain. Int Arch Occup Enveron Health 2001:74:429-36.

24. Houtman 1. Reliability and validity of the Dutch version of the Karasek Job Content Questionnaire. In: NIOSH/APA conference on Stress, Work, and Health; 1995; Washington. DC 1995. 
25. Karasek RA. The Job Content Questionnaire and User's Guide (version 1.1). Los Angeles: Department of Industrial and Systems Engineering. Uniwersity of Southern Califomia: 1985.

26. Gründemann RWM, Smulders PWG, De Winter CR. Handleiding Vragenlijst Arbeid en Gezondheid [Manual, Questionnaire on work and health]. Lisse: Swets \& Zeittinger; 1993.

27. SPSS. Base 9.0 for Windows User's Guide. Chicago: SPSS Inc: 4998.

28. SAS Institute. SAS version 6.12. Cary, North Carolina: SAS Institute; 1989.

29. Knauth $P$. Designing better shift systems. Appl Ergon 1996;27(1):39-44.

30. Knauth $\mathbb{P}$. The design of shift systems. Ergonomics 1993;36(1-3):15-28.

31. Totterdell P, Spelten E, Smith L, Barton J, Folkard S. Recovery from work shifts: How long does it take? J Appl Psychol 1995;80(1):43-57.

32. Frieling $E$. Die Arbeitsplatzanalyse als Grundlage der Eignungsdiagnostik. Beiträge zur Eignungsdiagnostik. Bem: Huber; 1977.

33. Bültmann $U$, Kant $U$, Van Amelsvoort LGPM, Varn den Brandt PA, KasI SV. Differences in fatigue and psychological distress across occupations: The Maastricht Cohort Study of Fatigue at Work. J Occup Environ Med 2001;43:976-83.

34. Frese $M$, Semmer N. Shiftwork, stress, and psychosomatic complaints: a comparison between workers in different shiftwork schedules, non-shiftworkers, and former shiftworkers. Ergonomics 1986;29(1):99-114.

35. Olsson $K_{n}$ Kandolin I. Kauppinen Toropainen $K$. Stress and coping strategies of three-sihift workers. Trav Humain 1990;53(2):175-88.

36. Härmä M. Individual differences in tolerance to shiftwork: a review. Ergonomics 1993;36(13):101-9.

37. Frankenhaeuser $M$, Lundberg $U$, Fredrikson $M$, Melin $B$, Tuomisto M, Myrsten AL, et al. Stress on and off the job as related to sex and occupational status in white-collar workers. J Organ Behav 1989; 10(4):321-46.

38. Fischer FM, Moreno CR de C, Fernandez R de $L$, Berwerth A, Coffani dos Santos AM, Bruni A de C. Day- and shiftworkers' leisure time. Ergonomics 1993;36(1-3);43-9. 


\section{Work schedules and fatigue: A prospective cohort study}

Nicole WH Jansen ${ }^{1}$

Ludovic GPM van Amelsvoort ${ }^{1}$

Tage S Kristensen ${ }^{2}$

Piet A van den Brandt ${ }^{1}$

IJmert Kant ${ }^{11}$

"Department of Epidemiology, Maastricht University, Maastricht, The Netherlands

${ }^{2}$ National Institute of Occupational Health, Copenhagen, Denmark 


\section{ABSTRACT}

Aims: (1) To describe the prevalence of fatigue among employees in different work schedules (day work, three-shift, five-shift, and irregular shift work); (2) to investigate whether different work schedules are related to increasing fatigue over time, while taking into account job titie and job characteristics; and (3) to study fatigue among shift workers changing to day work.

Melhods: Data from nine consecutive four-monthly self-administered questionnaires from the Maastricht Cohort Study on "Fatigue at work" (n=12,095) were used with 32 months of follow-up. Day and shift workers were matched on job title.

Results: The prevalence of fatigue was $18.1 \%$ in day workers, $28.6 \%$ in three-shift. $23.7 \%$ in five-shift, and $19.1 \%$ in irregular shift workers. For three-shift and five-shift workers substantial higher fatigue levels were observed compared to day workers at baseline measurement. In the course of fatigue over the 32 months of follow-up there were only small and insignificant differences between employees in different work schedules. However, among employees fatigued at baseline, fatigue levels decreased faster over time among five-shift workers compared to fatigued day workers. Shift. workers changing to day work reported substantially higher fatigue levels prior to change, compared to those remaining in shift work.

Conclusions: Substantial differences in fatigue existed between day and shift workers. However, as no considerable differences in the course of fatigue were found, these differences have probably developed within a limited time span after starting in a shift work job. Further, evidence was found that fatigue could be an important reason for quitting shift work and moving to day work. Finally, in the relation between work schedules and fatigue, perceived job characteristics might play an important role. 


\section{INTRODUCTION}

Although shift work has frequently been shown to have detrimental effects on the health of employees, it is becoming increasingly prevalent in contemporary life. ${ }^{1,2}$ Studies have shown that shift workers have an increased risk of cardiovascular disease, ${ }^{3.7}$ gastrointestinal disease, ${ }^{6-11}$ and reduced well being. "Shift work has also been associated with fatigue, ${ }^{2.12-14}$ and fatigue is frequently cited as a major cause of shift work intolerance. ${ }^{11}$ In many studies on shift work and fatigue, fatigue is defined and operationalized in different ways, for example in terms of increased sleepiness ${ }^{12.15}$ and reduced allertness. ${ }^{16-18}$ in studies of schedluled long work shifts, performance decrements in both work-related tasks and laboratory-type behavioral tests, significant sleep loss and increased subjective sleepiness have been reported. ${ }^{19}$ In our study, fatigue is seen as a subjective sensation with cognitive and behavioral components. Furthermore, we will only deal with fatigue persistent over a period of several days, also called prolonged fatigue. Prolonged fatigue is not easily reversible in the short-term and is not task specific $^{20}$; furthermore the compensating mechanisms that were useful in reducing acute fatigue are no longer effective. ${ }^{21}$ This prolonged fatigue, further referred to as fatigue, affects the individual's performance in the work and home setting and may lead to sick leave and work disability. ${ }^{22}$ Little is known, however, about the course of fatigue over time among employees in different work schedules. More knowledge concerning the relation between work schedules and fatigue could have important consequences for employee health and implications for designing better shift systems.

Problems with shift work are most often attributed to the assumption that employees are being required to do the opposite of what their sleep-wake rhythm would predict, that is, to stay awake during the night and to sleep during the day., ${ }^{1,18}$ Since sleep is more efficient during the night and work is often more fatiguing during the night, ${ }^{23}$ considerable differences in the course and accumulation of fatigue between day and shift workers may exist. Van Vellohoven and Meijman, ${ }^{24}$ for example, found that working in shift systems required more effort and time to recower than working in day shifts. Further, important differences may also exist in the levels and course of fatigue among employees involved in different types of shift work. Working too many shifts in succession, having too short a period of rest in between two shifts, or having to sacrifice days off, can all have a strong negative impact on the opportunity to recover from fatigue at work ${ }^{25}$ and constitute characteristics of work schedules that often vary substantially between different shift work types. Fatigue might accumulate and build up over time, for example in work schedules with too short resting periods between the shifts, which do not allow employees to completely recover and thus cause fatigue levels to increase over time. For 12-hour shifts for example, there seems to be a build up of fatigue over the period of work. ${ }^{26}$ Other work schedules may be related to accumulated fatigue as well. in threeshift work, for example, employees in general have only two weekend days available to recuperate and switch to a new shift cycle. Five-shift workers generally work fewer hours a week compared to three-shift workers, providing them with more opportunities to recover from fatigue at work. For irregular shift workers, the unpredictability in timing of work and rest periods could be specifically related to fatigue. Therefore, as reported by Rosa, ${ }^{27}$ fatigue experienced by employees will be a function of the number of hours 
worked, the timing of work in the 24-hour day (that is, what shift is worked), how many work shifts occur before a rest day, ${ }^{2 g}$ how many rest days are taken before return to work, how much rest is taken during the shift and between consecutive work shifts, and how variable the timing of the shift is.

Furthemore, fatigue is strongly influenced by other job characteristics, such as psychological job dernands, decision latitude, and emotional and physical demands. ${ }^{29}$ Job characteristics often differ substantially between day and shift workers. ${ }^{30}$ Crosssectional analyses on the data of the Maastricht Cohort Study on "Fatigue at Work" revealed that the association between work schedules and need for recovery from work was also strongly influenced by other job characteristics, such as, for example, psychological job demands and physical demands. ${ }^{31.32}$ Hence, as reported by Rosa ${ }^{27}$ work schedules and workload factors need to be examined in combination to obtain a realistic picture of the effects of shift work on fatigue. Approaches to potential confounding with regard to shift work are to include measures of perceived job characteristics in the analysis of shift work effects ${ }^{33}$ and/or use occupation as a matching variable in the analyses. As work scheduling is superimposed on many other qualities of the workplace that may affect health and well being. control subjects who are doing the same jab, but on a different work schedule, are vital. ${ }^{3.4}$ In the present study job title will be used as a matching variable for comparing shift workers and day workers. In addition. adjustments will be made regarding perceived job characteristics. We hypothesized that shift work would be associated with a stronger accumulation of fatigue over time compared to day work. To elucidate whether work schedules actually go together with a different course of fatigue over time, prospective studies are a prerequisite. In this study we used 32 months of follow-up data from the Maastricht Cohort Study on "Fatigue at Work": (1) to describe the prevalence of fatigue among employees in different work schedules (three-shift work, five-shift work, irregular shift work, day work); (2) to investigate whether different work schedules are related to increasing fatigue levels over time, while taking into account job title and perceived job characteristics" and (3) to study fatigue among shift workers changing to day work during follow-up.

\section{METHODS}

\section{Study population}

This study is part of the prospective Maastricht Cohort Study on "Fatigue at Work", 35,36 in which employees from 45 different companies were followed by means of nine selfadministered questionnaires at four-monthly intervals. Once a year employees received an extensive questionnaire with items on work and nonwork-related factors, demographics, and health factors, as well as on fatigue. Twice a year employees. received a short questionnaire, capturing mainly outcome measures. For the present study all nine consecutive questionnaires were used. In May 1998, a total of 26,978 employees from 45 companies and organizations received a letter at home, inviting participation, and the self-administered baseline questionnaire. A reminder was sent out after two weeks. After six weeks a brief nonresponse questionnaire was sent to a 
random subsample of 600 nonrespondents. Nonresponse analyses yielded no significant differences between respondents and nonrespondents regarding demographic characteristics. Nonrespondents were somewhat less likely to report difficulties in work execution, fatigue complaints, and sick leave. Altogether, 12,161 employees completed and returned the first questionnaire (response rate of $45 \%$ ). Sixty-six questionnaires were excluded from analysis because of technical reasons or because inclusion criteria were not met. The first measurement in May 1998 will further be referred to as the baseline. The baseline (TO) cohort consisted of $8840(73 \%)$ men and $3255(27 \%)$ women, aged 18-65 years. All employees who returned the baseline questionnaire (TO) also received the two short questionnaires T1 in September 1998 (response rate $87.6 \%$, $n=10.592$ ) and $T 2$ in January 1999 (response rate $84.9 \%, n=10,270$ ) as well. Employees who retumed the baseline questionnaire and at least one of the short questionnaires (T1 and/or T2) received the extensive questionnaire T3 in May 1999 (response rate $79.8 \%$, $\mathrm{n}=9655$ ). Employees returning the $\mathrm{T} 3$ questionnaire also received the short questionnaires T4 in September 1999 (response rate $74.0 \%, n=8956$ ) and $T 5$ in January 2000 (response rate $71.9 \%, n=8692$ ). Employees who returned the questionnaire at $T 3$ and at least one of the consecutive short questionnaires (T4 and/or T5) also received the extensive questionnaire T6 in May 2000 (response rate $66.7 \%, n=8070$ ). Employees returning the T6 questionnaire also received the short questionnaire $T 7$ in September (response rate $63,3 \%, n=7662$ ) and the final T8 questionnaire in January 2001 (response rate $61,9 \%, n=7482$ ).

Included in the present study were men and women, who worked three-shifts, five-shifts, irregular shifts or who were involved exclusively in day work. We included only employees with a working week of at least 26 hours/week to establish more comparable working hours between day and shift workers. Temporary employees were excluded since they generally change jobs frequently. Further exclusion criteria were being absent from work at the time of completing the baseline questionnaire and not having completely resumed work after a period of sick leave at baseline. Also excluded were those employees with multiple jobs, since we had no information on working time arrangements and content of the other job.

The two questions "What is your job in the companylorganization?" and "What is your most important task?" were used to assess an employee's job title in the current job. The responses to these open-ended questions were used by trained coders to assign a job title, with a five-digit code, based on The Netherlands Standard Classification of Occupations $1992 .^{37}$ From the employees, 88 did not indicate their function or most important task. These employees were excluded from further analyses. At first measurement in May 1998, our study population captured 687 different job titles. ${ }^{38}$ Job tille was used to match the employees in the different work schedule groups, that is, for example, for employees working three-shift systems, a reference group of day workers with similar job title was matched. The minimum number of employees within one job title was two employees per shift type.

Employees reporting to have switched to another work schedule at any point during the 32 months follow-up were excluded from the multilevel analyses ( $n=68$ for day workers, 
$n=158$ for three-shift workers, $n=181$ for five-shift workers, and $n=96$ for iregular shif workers). With regard to the shift workers who changed to day work explicitly, however, separate subanalyses were performed concerning demagraphics and fatigue.

For the comparison of three-shift workers with day workers, 34 job titles were identifed $(n=494$ for three-shift workers, $n=675$ for day workers). Examples of job titles both in day work and three-shift work were production planner, operator, and assembler of vehicles. For comparing five-shift workers and matched day workers, 47 job titles were identified $(n=663$ for five-shift workers, $n=1284$ for day workers). Examples of job titles both in day work and fve-shift work were machine operator, maintenance electrician, and controller or tester electric-machinery. Regarding irregular shift workers and matched day workers, 19 job titles were identified ( $n=161$ for irregular shift workers, $n=206$ for day workers), for example mailman, enrolled nurse, and daycare worker/care taker of the elderly or mentally handicapped.

\section{Measures}

\section{Work schedules}

The questionnaire included 32 questions on working time arrangements, which enabled us to exactly select the work schedules employees were engaged in. A check among a sample of the cohort yielled that the information given by the emplayees corresponded with the company records on work schedules. In our study the term shift work is used for a work schedule, which includes night work. In the present study only day work, threesinift, five-shift, or irregular shift workers were included for investigating differences between the schedules. The direction of the shifts (clockwise, countercllockwise) varied between the companies. Figure 1 presents examples of a shift schedule for a team in three-shift as well as for a team in five-shift work. In the present study three-shiff work, also referred to as $3 \times 8$ semi-continuous shift work, involves a 24-hour production from

\begin{tabular}{|c|c|c|c|c|c|c|c|}
\hline \multirow[b]{2}{*}{ Week } & \multicolumn{7}{|c|}{ Thee shiff work } \\
\hline & Mo & Tu & We & Thi & $\mathrm{Fr}$ & $\mathrm{Sa}$ & Su \\
\hline 1 & $M$ & $M$ & $M$ & M & M & - & - \\
\hline 2 & N & $\mathbb{N}$ & $N$ & $\mathbb{N}$ & $\mathrm{N}$ & 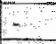 & 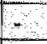 \\
\hline \multirow[t]{2}{*}{3} & $E$ & $E$ & $\mathbb{E}$ & $E$ & $E$ & 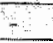 & 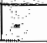 \\
\hline & \multicolumn{7}{|c|}{ Five-shift work } \\
\hline Week & Mo & $\mathrm{Tu}$ & We & Th & $\mathrm{Fr}$ & Sa & Su \\
\hline 1 & - & $\therefore$ & $M$ & $\mathrm{M}$ & $M$ & 3 & 4 \\
\hline 2 & $M$ & $\mathrm{~N}$ & $\mathrm{~N}$ & $\mathrm{~N}$ & - & +2 & 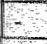 \\
\hline 3 & $E$ & $E$ & $E$ & 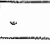 & - & M & $\mathrm{M}$ \\
\hline 4 & $M$ & $M$ & - & - & $\mathrm{N}$ & $N$ & N \\
\hline 5 & - & - & - & $E$ & $E$ & $E$ & $E$ \\
\hline
\end{tabular}

Figure f Examples of schedules in three-sint and five-shift work - = Day off, $M=$ Morring shift, $N=$ Night shift, $E=$ Evening shift 
Monday through Friday carried out by three teams of employees, generally working eight-hour shifts. In three-shift work, teams are switched as a rule every week. Five-shift work involves full continuous shift work, spread over seven days including five alternating teams, generally working eight-hour shifts. Only employees with a working week of at least 26 hours/week were selected to establish more comparable working hours between day and shift workers. Concerning actual working hours per week, the vast majority of five-shift workers worked 26-35 hours a week, whereas three-shift work generally comprised 36-40 hours a week. Employees working irregular shifts are involved in frequently deviating work hours, which can vary substantially every week, in the present study with a range from at least 26 hours to over 40 hours per week. For irregular shifts we included only those employees reporting frequent night work within their shift. The vast majority of day workers averaged $36-40$ hours a week, with a range of 26 hours to over 40 hours per week.

\section{Fatigue}

The Checklist Individual Strength (CIS) was used to measure fatigue. ${ }^{3940}$ The CIS is a 20-item questionnaire developed to measure several aspects of fatigue, asking employees how they felt during the past two weeks. The CIS is a self-report instrument consisting of four components, identified through factor analyses ${ }^{39}$ : subjective experience of fatigue (eight items), concentration (five items), motivation (four items), and physical activity level (three items). The Cronbach's alpha of the total scale is 0.93 . CIS items are scored on seven-point Likert scales. Higher scores indicate a higher degree of fatigue, more concentration problems, reduced motivation, or less activity. A composite C/S-totall score, ranging from 20 to 140 , is constructed by adding the individual's scores on the four factors in order to capture both the subjective sensation of fatigue as well as the reduction in functioning in terms of reduced concentration, motivation, and activity level. Missing data were treated on an individual level. Missing data on the subscales "subjective fatigue" (two of eight items missing at most), "motivation" (one of four items missing at most), and "concentration" (one of five items missing at most) of the CIS questionnaires were replaced with the means of the specific scale. CIS questionnaires containing more than four missing items were excluded from analysis. For case classification a cutoff point of CIS total $>76$ was used, with all those scoring $>76$ designated as probable fatigue cases. This cutoff was established in $a$ separate pilot study by means of defined samples with differences in fatigue level. ${ }^{41}$

\section{Work enviromment}

Decision latitude was assessed with the Dutch version of the Job Content Questionnaire using the scale Decision Latitude (Cronbach's alpha 0.81), consisting of the two subscales Decision Authority and Skill Discretion. ${ }^{42,43}$ To determine the level of psychological job demands the Dutch version of the Psychological Job Demands scale of the Job Comtent Questionnaire ${ }^{42.43}$ was used (Cronbach's alpha 0.69). The experience of physically demanding work was rated using an item of the Dutch questionnaire on Work and Health (VAG). ${ }^{44}$ The level of emotionally demanding work was assessed using a five item scale (Cronbach's alpha 0.60 ) consisting of two items of the Questionnaire on the Experience and Assessment of Work (VBBA), ${ }^{24}$ wo items of the Questionnaire on Work and Health (VAG) ${ }^{44}$ and one self-formulated item. 


\section{Demographic and health factors}

Information on age, gender, educational level, employment history, and the presence of a long-term disease was obtained through self-report in the baseline questionnaire. Data on employment history in the present work schedule were completely available for shift workers only.

\section{Statistical analysis}

Each type of shift work (three-shift, five-shift and irregular shift work) was compared with a reference group of day workers in similar job titles. We conducted multilevel analysis of a three-level structure, with repeated measurements over time (level 1), in which the individual employees (level 2) were nested within job titles (level 3) by using SAS proc mixed models. To take into account the possibility that the course of fatigue may be different in different occupations we entered the interaction variable Job tifle $x$ Time in every analysis. These multilevel analyses were able to control for selective dropouts. A confirmation that our model was robust was established by investigating whether leaving out specific jobs influenced the results, in which no significant changes appeared. In a first step the calculated betas were adjusted for age, gender, and the presence of a longterm disease. In a second step, the betas were additionally adjusted for psychological job demands, decision latifude, and emotional and physical demands, which in separate analyses were shown to contribute independently to a significant change of the model. Additionally independent samples T-tests and Chi-square tests were used to test univariate differences between the employees in different types of shift work versus day work. All procedures were performed using SPSS for Windows release 9.0.0. and SAS release 8.02 .

\section{REsULtS}

Table 1 presents descriptive characteristics of the study population betore matching on job title. The percentage of women involved in three- and five-shift work was significantly lower compared to day work, whereas the percentage of women was significantly higher in irregular shith work compared to day work. Shift workers were younger in age compared to day workers and had on average received a lower education. Data on employment hisiory in the present schedule were avallable only for shift workers, revealing that most three-shift workers worked five years or less in the present work schedule, whereas the majority of irregular shift workers had been involved in shift work for more than 15 years. With regard to job characteristics substantial differences emerged between the employees in different work schedules. For example, the percentage of employees reporting their work to be physically demanding was significantly higher in all types of shift work compared to day work. The prevalence of employees reporting a long-term disease did not differ significantly between the work schedules. Compared to day work, the prevalence of fatigue was substantially higher in most shift work groups, with three-shift workers reporting the highest prevalence $(28.6 \%)$. 
Table 1 Descipive characteristics of the study population

\begin{tabular}{|c|c|c|c|c|}
\hline & Day work? & Theres-shift & Five-shift & Irregular shift \\
\hline n (number of arganizations) & $4582(45)$ & $729(17)$ & $930(10)$ & $321(24)$ \\
\hline Gender \% temale & 21.9 & $8.8^{* 6 \times}$ & $5.3^{* *+8}$ & $30.5^{\mathrm{*} * \mathrm{x}}$ \\
\hline Agle mean (SD) & $42.56(8.88)$ & $35.77^{*+8}(8.59)$ & $37.94^{4 * 1}(8.59)$ & $37.90^{0 * * *}(8.72)$ \\
\hline $\begin{array}{l}\text { Highest educational level \% } \\
\text { Primany school } \\
\text { Lower vocational } \\
\text { Lower secondany } \\
\text { Intermediate vocational } \\
\text { Seconday } \\
\text { Higher vocational } \\
\text { University }\end{array}$ & $\begin{array}{l}2.1 \\
7.4 \\
10.5 \\
19.3 \\
11.1 \\
32.6 \\
17.0\end{array}$ & $\begin{array}{l}9.5 \\
40.7 \\
14.3 \\
26.2 \\
4.9 \\
4.2 \\
0.2\end{array}$ & $\begin{array}{l}* * * 1 \\
7.6 \\
30.0 \\
16.5 \\
33.8 \\
5.6 \\
5.5 \\
1.0\end{array}$ & $\begin{array}{l}* * 2 \\
5.2 \\
26.2 \\
21.4 \\
33.0 \\
4.9 \\
9.1 \\
0.2\end{array}$ \\
\hline $\begin{array}{l}\text { Employment hisiony } \\
\qquad \begin{array}{c}\leq 5 y \\
6-10 y \\
11-15 y \\
>15 y\end{array}\end{array}$ & & $\begin{array}{l}78.4 \\
5.3 \\
5.5 \\
10.8\end{array}$ & $\begin{array}{l}30.5 \\
23.3 \\
23.4 \\
22.8\end{array}$ & $\begin{array}{l}26.1 \\
17.6 \\
14.5 \\
41.8\end{array}$ \\
\hline Plysically demanding work \% & 9.0 & $48.5^{5 x+1}$ & $33.4^{* * *}$ & $73.3^{* * *}$ \\
\hline $\begin{array}{l}\text { Psychological job demands } \\
(12-48) \text { (SD) }\end{array}$ & $32.87(5.46)$ & $34.42^{*+* * * 13)}(6.13)$ & $32.15^{+2 \times}(5.68)$ & $34.52^{* * *}(5.85)$ \\
\hline Decision lalitude (24-96) (SD) & $74.44(10.02)$ & $6.5 .08^{* \text { tind }}(13.62)$ & $68.11^{m * *}(11.47)$ & $68.11 *(11.64)$ \\
\hline Emotional demands $(0-5)^{*}$ (SD) & $0.83(1.09)$ & $1.53^{* * 4 \times}(1.44)$ & $1.17^{16+6}(1.23)$ & $1.93^{* * *}(1.42)$ \\
\hline Long-tem disease \% & 211 & 228 & 19.4 & 24.8 \\
\hline $\begin{array}{l}\text { Fatigue } \\
\text { Mean (20-140) (SD) } \\
\text { Cases \% (CIS-total score > 76) }\end{array}$ & $\begin{array}{l}54.87(21.84) \\
18.1\end{array}$ & 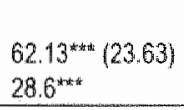 & $\begin{array}{l}58.35^{\text {w******}}(23.72) \\
23.7^{\text {t*x: }}\end{array}$ & $\begin{array}{l}55.46(22.11) \\
19.1\end{array}$ \\
\hline
\end{tabular}

Significant difference with day work: $p<0.01$; $p<0.004$

t Scale range

* Reference group for all three types of shift work

Data awailable for shift workers only

Since substantial differences existed in the work-related factors between day and shift workers (Table 1), we matched the day and shift workers on job title in all further analyses. Table 2 presents the results of the multilevel analyses for fatigue by work schedule. As Table 2 shows, at baseline measurement in May 1998, the CIS-total score of three-shift workers was 7.83 points higher compared to day workers, when controlled for age, gender, and the presence of a long-term disease. Furthermore, for five-shift workers a significant difference with day workers in CIS-total score (6.30 points) was observed at first measurement. Regarding irregular shift work, only nonsignificant results were obtained, with smaller differences in fatigue levels between day and irregular shift workers at baseline. The variable "Course of fatigue within day work" represents the estimated average change in CIS-total score among day workers every four months over the total observation period of 32 months. The CIS-total score increased over time but this increase was not statistically significant. As for every type of shift work different occupation matched day workers were selected, insignificant differences in betas between the day workers can be observed. The variable "Course of fatigue within shift work" indicates the estimated average change in CIS-total score among the different 
types of shift workers per four months over the total observation period of 32 months. The CIS-total scores for all types of shift workers increased as well, but this increase in fatigue over time in shift workers was not significantly higher compared to day workers. In a second step the betas were additionally adjusted for several job characteristics. resulting in a substantial decrease of the difference in fatigue score between the day and shift workers at baseline measurement, in which all distinguished job characteristics contributed significantly.

Table 2 Fatigue over lime by work schedule

\begin{tabular}{|c|c|c|c|c|c|c|}
\hline & \multicolumn{2}{|c|}{ Three-stinte work } & \multicolumn{2}{|c|}{ Five-shitt work } & \multicolumn{2}{|c|}{ Irregtular shift work } \\
\hline & $\beta^{i}$ & 98 & $\beta^{+4}$ & $\beta$ & $\beta^{1 t}$ & $\beta$ 闻 \\
\hline Basetirte differencet & $7.83^{*}$ & 1.70 & $6.30 *$ & 227 & 4.60 & -2.39 \\
\hline Course of fatigue within day wort: & 0.06 & -0.01 & 0.71 & 0.87 & .48 & 1.43 \\
\hline Course of tatigue within shith works & 0.11 & 0.17 & 0.46 & 0.64 & 1.42 & 1.49 \\
\hline
\end{tabular}

fror every shiff type the reference group consisted or cay workers with comparable job titles

$p<0,001$

4 Difference in CIS-total score beween day $(0$ ) wersus shitt work type 11 ) al baseline measuremen! (May 1998 )

* Change of fatigue over lime in day workers per four months

5. Change of fatigue over time in shift workers per four months

1. Adjusted lor age, gender, and long-term disease

自 Additionally adjusted for psychologic al job demands, decision latitude, and emotional and physical demands

The course of fatigue might be different in employees already designated as probable fatigue cases at baseline. Table 3 presents the results of the course of fatigue in different work schedules among employees designated as probable fatigue cases at baseline, that is employees reporting a CIS-total score of $>76$. The same criteria for matching on job title were applied as described in the Method section, resulting for the comparison of three-shift workers with day workers in six job titles $(n=33$ for three-shift workers, $n=41$ for day workers). For comparing five-shift workers and matched day workers, eight job titles were identified ( $n=61$ for five-shift workers, $n=45$ for day workers). The course of fatigue among fatigued employees working in irregular shifts could not be studied because of a too small sample size of the fatigued group. As Table 3 shows, there were differences in the CIS-total score between fatigued day and shift workers at baseline. although these were not statistically significant. The decrease in baseline difference of CISutotal score between day and shift workers after controlling for perceived job characteristics was less pronounced compared to the differences in Table 2. In threeshift workers, physical demands mainly contributed to the decrease of the beta "Baseline difference". In contrast to fatigued day workers, the CIS-total score in fatigued five-shift workers decreased significantly more over time after controlling for confounding factors.

A separate analysis was conducted to study the role of employment history in the relation between work schedultes and fatigue. We were not able to compare the exposure time to shift work with the years spent in day work, because of missing data, especially in the day workers group. Therefore, we decided to study the role of job tenure within shift work specifically, in which the category of employees with over 15 years of shift work experience was treated as a reference group. These analyses could be 
conducted in five-shift work only, since only in fiwe-shift work were all four distinguished categories well represented. We pertormed multilevel analyses, in which we compared fatigue levels in four categories of job tenure in five-shift work. Employees involved in five-shift work for $0-5$ years, 6-10 years, or 11-15 years were compared with workers with a job tenure of over 15 years in five-shift work. In these analyses only nonsignificant results were obtained, although there seemed to be a trend that the employees with the lowest job tenure ( $0-5$ years in five-shift work) reported the highest fatigue levels at baseline.

Table 3 Course of fatigue by work schedule among employees latigued at baseline:

\begin{tabular}{|c|c|c|c|c|}
\hline & \multicolumn{2}{|c|}{ Threa-shift work } & \multicolumn{2}{|c|}{ Five-shift work } \\
\hline & $\beta !$ & B & $B 17$ & $\beta !$ \\
\hline Baseline differencet & 3.75 & 1.78 & 7.14 & 5.23 \\
\hline Course of fatigue within day work" & -0.13 & .0 .17 & 0.03 & .0 .02 \\
\hline Course of fatigue within shill works & 0.16 & 0.21 & $-2.07^{*}$ & $.2 .11^{*}$ \\
\hline
\end{tabular}

For ewery shift type the reference group consisted of day workers with comparable job titles

* $p<0.05$

4 Difference in CIS-lotal score between day (0) wersus shiffurch type (1) all baseline measurement (May 1998)

1: Change of fatigue ower time in day workers per four months

s. Change of fatigue ower time in shitt workers per four months

it Adjusted for age, gender, and lang-tem disease

Additionaly adjusted for psychological job demands, decision latiltude, and emotional and physical demands

As described in the Methods section, employees who switched from work schedule at any point during the 32 months of follow-up were excluded from the multilevel analyses. We did, however, make a comparison between those shift workers (including three-shift workers, five-shift workers, and irregular shift workers) who changed explicitly to day work at one point during the follow-up period $(n=150)$ and the shift workers remaining in the same work schedule $(n=444)$ during the total observation period. Only employees with complete data were included. Shift workers changing to day work generally received a somewhat higher educiation $(0<0.05)$ compared to those remaining in shift work. No significant differences were observed with respect to gender, age and the presence of a long-term disease. Regarding fatigue, on average six months prior to the change from shift to day work, shift workers scored 9.4 points higher on the CIS $(p<0.001)$ compared to those remaining in shift work. On average two months prior to this change, employees scored on average 6.7 points higher on the CIS $(p<0.01)$ compared to those remaining in shift work. From just after the change until on average six months after the change to day work, employees reported no significant differences in fatigue levels compared to those remaining in shift work.

\section{DISCUSSION}

The present study found that fatigue was significantly more prevalent among three- and five-shift workers compared to day workers. At baseline substantial differences in fatigue existed among the employees in different work schedules, which significantly decreased 
after controlling for job characteristics. In the time course of fatigue there were only minor differences between employees in different work schedules. In fatigued employees. however, the level of fatigue decreased significantly faster over time among five-shift workers compared to day workers. Shift workers changing to day work reported significant higher fatigue levels prior to their change compared to those remaining in shift work.

A comparison of the obserwed prevalences of fatigue with other studies is difficult because most studies used different definitions and operationalizations of fatigue. Various studies have demonstrated, however, that shift workers generally report more fatigue than day workers. ${ }^{12.15}$ In a study by Rosa and colleagues, ${ }^{45}$ it was found that perceived muscular fatigue increased more quickly across the night shifts compared with day shifts. Accumulated fatigue across consecutive workdays was illustrated in a study by Schroeder and colleagues, ${ }^{46}$ where progressive increases in choice reaction time were apparent across a five-day week of eight-hour shifts and a four-day week of 10 hour shifts in air traffic control specialists. Ansberg and colleagues ${ }^{47}$ reported that fatigue, in terms of lack of energy and physical exertion, tended to accumulate during night shifts.

To our knowledge, this is the first study to examine the relation between various work schedules and the course of fatigue over a relatively long follow-up period. Although fatigue did not significantly increase over time in neither shift nor day workers, shift work clearly sustained the higher levels of fatigue that already existed between day and shift workers. No indication of further accumulation of fatigue over time was found. The possibility exists that the effects of shift work on fatigue develop very quickly after starting to work in a shift work jab, for which some indications were found when comparing fatigue levels in different categories of years of shift work experience among five-shift workers. As regards fatigue status, in employees fatigued at baseline, the fatigue levels over time decreased significantly faster in five-shift workers compared to day workers. Between fatigued day and three-shift workers no significant difference in change of fatigue over time was observed. It is possible that five-shift workers who were unable to cope with the fatigue accompanying their shift work have already left shift work Compared to five-shift workers, three-shift workers generally were lower educated, which could make it more difficult for them to change jobs. In addition, compared to three-shift workers, five-shift workers have a working week comprising fewer hours, providing them with more opportunities to recover from their work and prevent fatigue from further accumulation. Three-shift workers generally only have two (weekend) days available to recuperate and switch to a new shift cycle. The traditional weekly change of shifts, as for example seen in three-shift work, is often reported to be the worst solution. ${ }^{26,48}$

When studying the relation between work schedules and fatigue, the role of actual working hours in day work versus shift work has to be acknowledged. To reduce the potential confounding effect of working hours in the relation between work schedules and fatigue. we made a selection on working hours in this study, that is, we selected only those employees who reported to work at least 26 hours per week. For the comparison 
of day work and five-shift work, the day workers may be somewhat at disadwantage with regard to working hours. Day workers could be somewhat more fatigued as a result of higher average working hours per week as compared to five-shift work, which may have resulted in an underestimation of the effects of five-shift work.

Besides time needed for recovery, sleep deficits could be an explanation for differences in fatigue levels between the day and shift workers in general. When there are several night shifts in a row there is likely to be a bigger cumulative sleep deficit towards the end of a span of night shifts, ${ }^{49.50}$ whereas after a single night shift (or two night shifts) the sleep deficit can be compensated at once. ${ }^{46}$ Accumulated sleep debt could also constitute an explanation why shift work sustains higher fatigue levels among employees.

Although matching on job title was important for comparison of employees in different schedules but with similar job characteristics and educational level, the adjustment for job characteristics still decreased the association between work schedules and fatigue substantially. Apparently, compared to day workers, shift workers perceive these job characteristics, such as physical demands, as far more demanding. possibly since they are fighting their sleep, or that job demands in similar jobs actually are more demanding when performed in shift work compared to day work. Another possibility is that shift workers experienced their jobs as more demanding because they were more fatigued. We are aware that adjustment for job characteristics may therefore lead to over-control

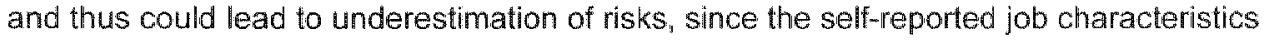
may be associated with fatigue because of the problem of common method variance. We therefore assume that the relatively crude results, only adjusted for age. gender, and long-term disease, are more likely to represent the actual effect of shift work and reflect the differences in fatigue levels employees in different work schedules actually encounter. However, to disentangle possible mechanisms linking work schedules to fatigue over time, the analyses with adjustments for job characteristics provided important additional information. In the different groups of day workers the trends of fatigue over time varied, reflecting the fact that these groups of day workers were made up by employees with very different job titles and hence other job demands accompanying their work. This study dealt with work schedules, the role of percelved job characteristics, and the course of fatigue only. However, other factors could also be considered, such as individual characteristics, work-family conflict, and social pressures, which could influence the relationship between work schedules and fatigue as well

When interpreting the results of this study, several methodological issues should be considered. Since the Maastricht Cohort Study does not constitute a representative sample of the Dutch working population, the study population within the different work schedules does not reflect a representation of the employees involved in these work. schedules in general and by matching on occupation any representativeness is even worse. However, studying the effects of different types of shift work does not require a representative sample, and as a broad range of occupations was still present we do consider the effects likely to be present in most shift work jobs. No misclassification of work schedules took place, since the questionnaire captured precise questions on 
working time arrangements, enabling us to specifically select the work schedules employees are involved in. Furthermore, the information in the questionnaire on work schedules was checked with the company records on work schedules. Another issue is that our study captured employees already involved in shift work for several years. The same is true for day workers. In this respect our first measurement is not a true baseline measurement. With regard to shift work, it is well known that different selection processes take place. Because of self-selection and pre-job medical examinations, primary selection processes could have led to differences between the day and shift workers. With experienced shift workers we may have a self-selected and robust group of employees who are either more able or more determined to adapt. ${ }^{34}$ Because of secondary selection processes and by excluding those employees who changed their work schedule at one point during our follow-up an underestimation of the observed levels and course of fatigue over time may have resulted. The lower mean age and the larger dropout of the shift workers compared to the day workers clearly point in this direction. We did, however, have a unique opportunity to study whether fatigue could be a reason for quitting shift work and moving to day work. Indeed, compared to those remaining in shift work, employees who changed from shift to day work reported substantially higher fatigue levels on average six months prior to changing to day work. On average two months prior to changing to day work employees also scored higher on fatigue, although the fatigue levels were somewhat lower compared to six months prior to change. Possibly at this point, employees had already decided to change work schedules or had already found a future job in day work, resulting in lower fatigue levels because of the prospect of leaving their shift work job.

Although selection processes certainly played their part in this study, it did provide new insights on several aspects. The hypothesis that shift work is associated with a higher prevalence of fatigue certainly seems justified. Over time shift work seems to sustain the higher fatigue levels observed in shift workers compared to day workers. Fatigue is frequently cited as a major cause of shift work intolerance, "11 and this study actually provided evidence that fatigue could be an important reason for quitting shift work. Furthermore, in the relation between work schedules and fatigue, perceived job characteristics may play an important role, which should also be considered in future studies on the effects of shift work. The present study aimed at the course of fatigue over time. We did not capture the onset and time span during which the large differences in fatigue levels between day and shift workers have developed. This time period has probably taken place before our baseline measurement, and has most likelly occurred in the first time period after starting to work in a shift work job. Future studies on work schedules and fatigue should aim at this onset of the different levels in fatigue observed among employees involved in different work schedules, ideally requiring a cohort of employees starting to work in a shift work job.

\section{ACKNOWLEDGEMENTS}

The Maastricht Cohort Study is part of the Netherlands concerted research action on "Fatigue at work" granted by the Netherlands Organization for Scientific Research. The 
present study was supported by grant no. 580-02.201 from the Netheriands Organization for Scientific Research.

\section{REFERENCES}

1. Smith CS, Robie C, Folkard S, Barton J, Macdonald I. Smith L, et al. A process model of shiftwork and health. J Occup Health Psychol 1999;4(3):207-18.

2. Härma M. New work times are here - are we ready? Scand J Work Enwiron Health 1998:24 (Suppl 3) 3-6.

3. Bøggild $H$, Knutsson A. Shift work, risk factors and cardiovascular disease. Scand J Work Environ Health 1999;25(2):85-99.

4. Knutsson $A$, Akerstedt $T$, Jonsson $B G_{*}$ Orth-Gomer $K$. Increased risk of ischaemic heart disease in shift workers. Lancet 1986;8498(2):89-92.

5. Tenkanen L, Sjöblom T, Kalimo R, Alikoski T, Härmä M. Shift work, occupation and coronary heart disease over 6 years of follow-up in the Helsinki Heart Study. Scand $J$ Work Environ Health 1997;23(4):257-65.

6. Kristensen TS. Cardiovascular diseases and the work environiment. A critical review of the epidemiologic literature on nonchemical factors. Scand J Work Environ Health 1989;15(3):16579.

7. Van Amelswoort LPGM, Schouten EG, Maan AC, Swenne KA, Kok FJ. Changes in frequency of premature complexes and heart rate variability related to shift work. Occup Environ Med 2001;58:678-81.

8. Tüchsen $F$, Jeppesen $H_{J}$, Bach E. Employment status, non-daytime work and gastric ulcer in men. Int J Epidemiol 1994:23:365-70.

9. Angersbach $D$, Knauth $P$, Loskant $H$, Karvonem $M J$, Undeutsch $K$, Rutenfranz J. A retrospective cohort study comparing complaints and diseases in day and shift workers. Int Arch Occup Environ Health 1980;45:127-40

10. Costa G. The impact of shift and night work on health. Appl Ergon 1996:27(1):9-16.

11. Harrington JM. Shift work and health. A critical review of the literature on working hours. Ann Acad Med Singap 1994;23(5):699-705.

12. Akerstedt T. Sleepiness as a consequence of shift work. Sleep 1988;11(1):17-34.

13. Smith L, Folkard $S$, Tucker $P$, Macdonald I. Work shift duration: A review comparing eight hour and 12 hour shift systems. Occup Environ Med 1998;55:217-29.

14. Ono $Y$. Watanabe $S$, Kaneko $S$, Matsumoto $K$, Miayo M. Working hours and fatigue of Japanese flight attendants (FA). J Hum Ergal 1991;20(2):155-64.

15. Akerstedt T. Psychological and psychophysiological effects of shift work. Scand J Work Environ Health 1990;16(Suppl 1):67-73.

16. Rosa RR. Performance, alertmess, and sleep after $3.5 \mathrm{yrs}$ of $12 \mathrm{~h}$ shifts: A follow-up study. Work Stress 1991;5(2):107-16.

17. Rosa RR. Performance and alertness on $8 \mathrm{~h}$ and $12 \mathrm{~h}$ rotating shifts at a natural gas utility. Ergonomics 1993:36(10):1177-93

18. Tucker $P$. Barton J, Folkard $S$. Comparisoin of eight and 12 hour shifts: impacts on health. wellbeing, and alertness during the shift. Occup Environ Med 1996;53(11):767-72.

19. Rosa RR: Extended workshifts and excessive fatigue. J Sleep Res 1995:4(Suppl 2):51-6.

20. Meijman $T$. Schaufeli $W$. Psychische vermoeidheid en arbeid; Ontwikkelingen in de A\&Opsychollogie [Mental fatigue and work. Developments in Work and Organizational Psychology]. Psycholoog 1996; 31(6):236-41.

21. Meijman TF. Over vermoeidheid: arbeidspsychologische studies naar beleving van belastingseffecten. [Fatigue: studies on the perception of workload affects]. Amsterdam: University of Amsterdam; 1991.

22. Schröer CAP. De toename van arbeidsongeschiktheid wegens psychische aandoeningen [The increase of work disability due to mental disorders]. TBV 1997;5(1):16-23. 
23. Vespa $S$. Wyile $D$. Mitter Mt, Shuitz $T$. Study of commercial vehicle driver rest periods and recovery of perfomance in an operational environment. In: Hartley $\mathrm{L}$, ed. Managing fatigue in transportation. Oxford: Pergamon; 1998. p. $119-65$.

24. Van Veldhoven $M$. Mejiman TF. Het meten van psychiosociale arbeidsbelasting met een wragenlijst: de vragenlilst beleving en beoordeling van de arbeid (VBBA) [The measurement of psychosocial job demands with a questionnaire (VBBA)]. Amsterdam: NIA, 1994.

25. De Vhies-Griever AHG. Evenwichi tussen werkdrulk en herstel bij afwijkende werktijden. Uitgangspunten voor dienstroosterplanning [Balancing work load and recovery in deviating working hours. Basic principles of rota planning]. Groningen/Utrecht: Nationaal Ziekenhuisinstituut; 1992

26. Knauth $P$. The design of shift systems. Ergonomics 1993;36(1-3):15-28.

27. Rosa RR. Examining work schedules for fatigue: It's not just hours of work. In: Hancock PA, Desmond PA, eds. Siress, workload and fatigue. Mahwah: Lawrence Erlbaum Associates; 2001. p. 513-28.

28. Smith L. Macdonald H. Folkard S, Tucker P. Industrial shift systems. Appl Ergon $1998 ; 29(4): 273-80$.

29. Buittmann U, Kant IJ, Van den Brandt PA, KasI SV. Psychosocial work characteristics as risk factors for the onset of fatigue and psychological distress: Prospective results from the Maastricht Cohort Study. Psychol Med 2002;32:333-45.

30. Bøggild $H$, Burr $H$, Tüchsen $F$, Jeppesen $H J$. Work environment of Danish shift and day workers. Scand J Work Environ Health 2001;27(2):97-105.

31. Jansen NW, Kant IJ. Need for recovery related to working time arrangements: results from the Maastricht Cohort Study on faligue at work. Int J Behav Med 2000;7(Suppl 3):S9.

32. Jansen NWH, Kant IJ, Niijhuis FJN, Van den Brandt PA. Work schedules as risk factors for need for recovery and fatigue: Results from the Maastricht Cohort Study after one year followup. Shiftwork International Newsletter $2001 ; 18(1): 5.2$

33. Parkes KR. Shiftwork, job type, and the work environment as joint predictors of health-related outcomes. J Occup Health Psychol 1999;4(3):256-68.

34. Bohle P. Tilley AJ. The impact of night work on psychological well-being. Ergonomics $1989 ; 32(9): 1089-99$

35. Kant IJ, Bültmann U, Schröer CAP, Beurskens AJHM, Van Amelsvoort LPGM, Swaen GMH. An epidemiological approach to study fatigue in the working population: The Maastricht Cohort Study. Occup Environ Med. lin press.

36. Kant HJ, Beurskens A.JHM, Schroer CAP, Nijhuis FJN, Van Schayck CP, Van den Elzen HIJ, et al. De Maastrichtse Cohort Studie naar langdurige psychische vermoeidheid in de arbeidssituatie [The Maastricht Cohor Study on fatigue at work]. TBV 2000;8(8):226-32.

37. Central Bureau of Statistics. Standaard Beroepenclassificatie 1992 [The Netherlands Standard Classification of Occupations 1992]. 's Gravenhage: SDU/uitgeverij; 1993.

38. Bültmann U, Kant IJ, Van Amelsvoort LGPM Van den Brandt PA, Kas! SV. Differences in fatigue and psychollogical distress across occupations: The Maastricht Cohort Study of Fatigue at Work. J Occup Environ Med 2001;43:976-83.

39. Vercoulen JH, Swanink CM. Fennis JF, Galama JM, Van der Meer JW, Bleijenberg $G$ Dimensional assessment of chronic fatigue syndrome. J Psychosom Res 1994;38(5):383-92.

40. Beurskens $A J$, Bültmann $U$, Kant $I J$, Vercoulen JH, Bleljeniberg $G$, Swaen GM. Fatigule among working people: vallidity of a questionnaire measure. Occup Environ Med 2000; $57(5): 353-7$.

41. Bültmann U, De Vries $M$, Beurskens AJHM, Bleijenberg $G$, Vercoulen JHMM, Kant $Y$. Measurement of prolonged fatigue at work in the Maastricht Cohort Study: Determination of a cutoff point, J Occup Health Psychol 2000;5(4):411-6.

42. Houtman 1. Reliability and validity of the Dutch version of the Karasek Job Content Questionnaire. In: NIOSHIAPA conference on Stress, Work, and Health; Washington, DC: APA; 1995

43. Karasek RA. The Job Content Questionnaire and User's Guide (version 1.1). Los Angeles: Department of Industrial and Systems Engineering, University of Southern California; 1985

44. Grundemann RWM. Smulders PWG, De Winter CR. Handleiding Vragenlijst Arbeid en Gezondheid [Manual, Questionnaire on work and health]. Lisse: Swets \& Zeitlinger; 1993. 
45. Rasa RR, Bonnet MH, Cole LL. Work schedule and task factors in upper-extremity fatigue. Hum Factors $1998 ; 40(1): 150-8$

46. Schroeder D, Rosa RR, Witt A. Some effects of 8- versus 10-hour work schedules on the test performancelalertness of air traffic control specialists. Int J Ind Ergonom 1998;21:307-21.

47. Ansberg $E$, Kecklund $G$, Akerstedt $T$, Gamberale $F$. Shiftwork and different dimensions of fatigue. Int J Ind Ergonom 2000;26:457-65.

48. Knauth P. Designing better shift systems. Appl Ergon 1996;27(1):39-44.

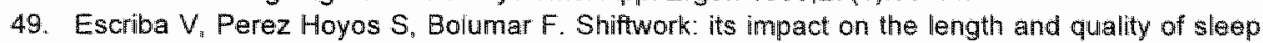
among nurses of the Valencian region in Spain. Int Arch Occup Environ Health $1992 ; 64(2): 125-9$.

50. Foret $\mathrm{J}$, Benoit $\mathrm{O}$. Shiftwork: the level of adjustment to schedule reversal assessed by a sleep study. Waking Sleeping 1978;2:107-12.

51. Van Amelswoort LPGM. Cardiovascular risk profile in shift workers. Cardiac control, biological and lifestyle risk factors [dissertation]. Wageningen: Wageningen University; 2000. 


\section{Direction of shift rotation in three-shift workers in relation to psychological health and work-family conflict}

Ludovic GPM van Amelsvoort ${ }^{1}$

Nicole WH Jansen"

Gerard MH Swaen

Plel A van den Brandt"

IJmert Kant ${ }^{1}$

"Department of Epidemiology, Maastricht University, Maastricht, The Netherlands 


\section{ABSTRACT}

Introduction: The aim of the present study was to investigate whether the direction of shift rotation in three-shift workers was related to need for recovery, fatigue, sleep quality work-family conflict and leisure time.

Methods: Data of the Maastricht Cohort Study were used $(n=12,095)$, with 32 months of follow-up, among which 95 workers in forward and 681 workers in backward rotating three-shift work. Cross-sectional as well as Iongitudinal analyses were performed.

Results: A backward rotating schedule was prospectively related to increased need for recovery (Relative Risk ( $R R$ ) 2.88; Confidence Interval (CI) 1.06-7.81) and poor general health (RR 3.21 ; $\mathrm{Cl} 1.32-7.83$ ) as compared with employees in a forward rotating schedule. Adjustment for demographic and health variables, and characteristics of the work environment did not alter these relations considerably. Furthermore, a forward rotating schedule was prospectively related to less work-family conflict and better sleep quality over the 32 months of follow-up. Finally, high levels of fatigue, need for recovery as well as poor sleep quality, poor general health, insufficient leisure time and workfamily conflict at first measurement were alssociated with an increased risk of leaving shift work during follow-up.

Conclusions: Optimization of shift work schedules, in terms of shift rotation, seems a promising method to decrease the negative impact accompanying shift work. Future studies should investigate whether the present findings for three-shift workers are applicable to other shift work schedules as well. Further, this study clearly illustrates the existence of secondary selection processes in shift workers, thereby emphasizing the complexity of valid shift work research. 


\section{INTRODUCTION}

A considerable and still increasing part of the working population works outside normal working hours. Within the European Union, 19\% of the workforce, or well over 31 million persons work at least one night per month. ${ }^{1,2}$ Most of these workers work in shifts. Generally, shift work can be defined as work, which includes working outside the normal working hours. Most shift work includes working nights. Many different shift work schedules can be distinguished. Shift work schedules can roughly be divided in discontinuous (wo-shift), semi-continuous (three-shift), continuous (four-, five- and sixshift), and irregular work schedules. Shift and night work have been associated with considerable negative impacts on health and well being. Effects on cardiovascular ${ }^{3-7}$ and gastrointestinal health, ${ }^{8,9}$ obesity, ${ }^{10.11}$ the metabolic syndrome, ${ }^{12}$ sleepiness, ${ }^{13}$ need for recovery from work, ${ }^{14}$ fatigue, ${ }^{15-19}$ accidents, ${ }^{8}$ and well being ${ }^{20}$ have been reported.

To decrease the potential adverse health effects of shift work "application of healthier shift systems has been suggested ${ }^{16,21-23}$ One of the possibilities within three-, four-, five-, or six-shift work is the choice for forward or backward rotation of shift schedules. Several studies have reported on different health effects of forward versus backward rotating shift schedules. A shift system which first moves from morning shift to evening shift and then to night shift has a forward rotation (also called phase delay or clockwise rotation). The counter clockwise rotation (night to evening to morning shifts) is called backward rotation or phase advance. ${ }^{24}$ We will further refer to backward and forward rotation. Already in 1982 Czeisler et al. ${ }^{21}$ reported that by adapting from backward to forward rotation the health index score increased favorably. Compared to forward rotating shift systems, backward rotating shift systems have further been associated with poorer physical and psychological health, including chronic fatigue, ${ }^{16}$ a more unfavorable cardiac autonomic control, ${ }^{25}$ and adverse changes in self-rated health, duration and quality of sleep, systolic blood pressure and serum glucose, uric acid and triglyceride levels. ${ }^{26}$ Following shift workers who changed from a backward to a forward rotating system, and from slow to rapid rotation, Knauth \& Kiesswetter ${ }^{27}$ reported a reduction in sleep difficulties associated with the night shift. Three related factors exist favoring forward rotation over backward rotation. ${ }^{28}$ First, the cyclic period of the endogenous circadian rhythm runs slightly longer than 24 hours if allowed to free-run, or oscillate without respect to external time cues. Second, with respect to the clock it is easier to delay sleep onset through voluntary activity than to advance it. Third, forward rotating schedules often allow more than 24 hours of free time before rotating to the new shift, providing more opportunities for rest and sleep.

Although fatigue and need for recovery from work can be regarded as important indicators for adverse (psychological) health effects of shift work, ${ }^{14,18}$ they have not been extensively investigated. Prolonged fatigue affects the worker's performance in the work and home setting. It is related to increased accident risk ${ }^{29}$ and may lead to sick leave and work disability. ${ }^{30}$ Rosa suggested that backwards rotating work schedules could produce more fatigue than those rotating in a forward direction. ${ }^{28}$ Only two studies on fatigue ${ }^{16,31}$ and no studies on need for recovery from work, and the direction of shift rotation have been found. The intervention study by Barton et al. ${ }^{32}$ in which a group of 
120 workers changed from a forward to a backwards-rotating schedule was studied, showed little charges during the intervention. Only the number of sleep difficutties increased during backwards rotation but the reported social disruption decreased. Tucker et al. reported results from a cross-sectional comparison between forward and backward rotation. They found a small favorable effect of backward rotation on sleep duration but not on alerness and chronic fatigue.

An argument frequently mentioned by shift workers against a change of shift schedule rotation from backward to forward rotation is the apparent decrease in leisure time and possible increase in conflict beween work and family life. Work-family conflict among shift workers is often thought to arise because shift work involves working and living patferns diverging from community rhythms of social, recreational and domestic activity. ${ }^{33.34}$ Unfortunately, surprisingly little studies on these outcomes have been conducted. In an earlier study, we found that shift workers reported a higher risk of workfamily conflict compared to day workers. Work-family conflict is a perception of insufficient energy and time to successfully combine work and family roles. ${ }^{3 \hat{6}}$ Backward and forward rotating systems result in a different pattern of leisure time between consecutive shifts. In this respect the direction of rotation may be related to work-farnily conflict as well.

Improvements in the design of shift schedules could help to reduce the negative effects accompanying shift work and prevent employees from leaving shift work. If the direction of rotation proves to be related to levels of need for recovery, fatigue and the occurrence of work-family conflict among shift workers, then companies would have a clear utilizable tool to reduce fatigue-related outcomes and work-family conflict among shift workers. The aim of the present study was to investigate whether the direction of rotation in threeshift work was related to need for recovery, fatigue, sleep quality, work-family conflict and leisure time. Furthermore, it was investigated if these (health) outcomes were prospectively related to leaving shift work over time. Data from the Maastricht Cohort Study on "Fatigue at Work" were used to assess the aims both in a cross-sectional and longitudinal design.

\section{METHOdS}

\section{Study population}

For the current study data from the Maastricht Cohort Study on "Fatigue at Work" were used. This study has been described in detail elsewhere. ${ }^{37.38}$ In short, this prospective study was established in May 1998 and had a baseline response rate of $45 \%$. In total, 12,140 workers, employed by 45 different companies, mostly located in the southern part of the Netherlands, were followed for 32 months. For the present study, exclusion criteria were being absent from work at the time of completing the baseline questionnaire and not having completely resumed work after a period of sick leave at baseline. Also excluded were those employees with multiple jobs, since we had no information on working time arrangements and content of the additional job. 
This sudy focused on male three-shift workers only because of small numbers in the other shift schedule groups and the low number of female shift workers in the cohort. Five-shift workers were excluded because of incomparability between workers in forwards and backward rotating schedules with regard to job title and social economic status. This resulted in a final study population at baseline of 776 three-shift workers, capturing 95 workers in forward rotation and 681 workers in backward rotation. To study the prospective relationship between direction of rotation and the outcomes we used the available data after 32 months of follow-up. The response rates at the eight consecutive time points have been described elsewhere. ${ }^{18,38}$ For the longitudinal analyses, employees who received a retirement pension or stopped working in a three-shift schedule job were not considered to be at risk of becoming a case any more and were therefore excluded from the analysis. Because contrasting results were observed between the cross-sectional and longitudinal analyses, additional analyses were performed to assess whether baseline levels of the main outcome variables were related to a higher risk of leaving shift work. Also for these analyses, subjects leaving shift work due to early retirement were excluded.

\section{Measures}

\section{Work schedules}

The baseline questionnaire included 32 questions on working time arrangements, which enabled us to describe in detail the work schedules employees were engaged in. Information on direction of shift rotation was gathered through the company records on work schedules. In the present study three-shift work, also referred to as $3 \times 8$ semicontinuous shift work, involves a continuous 24-hour production from Monday through Friday carried out by three teams of employees, generally working 8-hour shifts. In threeshift work, teams are switched as a rule every week. This means that they work five morning, evening or night shifts in a row. The precise start and end times of the different shifts were different for the different participating companies. However, as a rulle, in the Netherlands the start of the morning shift is between 6:00 and 8:00, evening shift between 1400 and $16: 00$ and night shift between $22: 00$ and 24:00. Three-shift work generally comprises 36 to 40 working hours a week. The majority of three-shift workers in the present study were employed in the paper and automobile industry.

\section{Need for recovery from work}

Need for recovery was assessed using a 11 item subscale of the VBBA (Dutch questionnaire on Experience and Assessment of Work) ${ }^{39-41}$ with questions like "I find it hard to relax at the end of a working day" and "When I get home, people should leave me alone for some time". An average score was calculated ranging from 0 to 100 . Need for recovery from work was measured every four months. There is no existing cultuff point for the scale to classify "cases" with very high scores on the scale. Therefore, in the present study the upper quartile of the score in the entire cohort study was used to define a contrast between employees with considerable need for recovery from work (upper quartile) versus employees with a lower need for recovery from work (lowest three quartiles). 


\section{Fatigue}

In our study, fatigue is seen as a subjective sensation with cognitive and behavioral components. Furthermore, we will only deal with fatigue persistent over a period of several days, also called prolonged fatigue. Fatigue was measured with the 20 -item selfreported Checkist Individual Strength (CIS), which has been described extensively elsewhere. ${ }^{42.43}$ A composite CIS total score, ranging from 20 to 140 , is calculated by adding all individual scores. For clasification of fatigue cases the cutoff point of CIS total -76 was used. ${ }^{43}$ Fatigue was measured every four months.

\section{Sheep quality}

Sleep quality was assessed using one self formulated question: "Did you sleep well during the last four months" with the pre-coded answer categories "never", "sometimes", "mostly" and "always". We defined a poor sleep qually for respondents reporting "never" or "sometimes". This item was queried every four months.

\section{General health status}

The self-rated general health was inventoried by one item, adapted from the SF-36. which is a widely used generic health status measure. This item was scored on a fivepoint scale and measured every four months. Poor generall health was defined as scoring "moderate" or "bad".

\section{Work and home interaction}

To measure work-family conflict the following item was used: "Are you able to adequately combine work and family life?". Further, employees were asked if they felt they had sufficient leisure time, besides work and family life. The response to these selfformulated items was yes/no. These items were measured once a year.

\section{Confounding factors}

Demographics and health factors. Data on age, gender, educational level, having to take care for dependent children, living with a partner and the presence of a long-term disease, were collected at baseline.

Work-related factors. Overtime work, flexible working hours and years of work experience in the current shift schedule were assessed through self-report in the questionnaire. Psychological demands and decision latitude were assessed using the Dutch version of the selfadministered Job Content Questionnaire (JCQ) ${ }^{45.46}$ Social support was assessed by two scales of the JCQ, that is supervisor support and coworker support, each consisting of four items. The response options varied from "strongly disagree" to "strongly agree" on a four-point scale. To assess whether employees perceived their work as physically demanding, one item of the Dutch questionnaire on Work and Health (VAG) ${ }^{47}$ was used.

\section{Statistical analyses}

Independent samples T-tests and Chi-square tests were used to test univariate differences between the groups of employees with different direction of rotation. Multivariate survival analyses using Cox regression were performed in three steps to 
prospectively examine the role of direction of shift rotation, measured at baseline in 1998 (TO), in the onset of the different outcomes over time. For need for recovery from work. fatigue, sleep quality, and general health status we modeled the time to first "caseness" at $T 1, T 2, T 3, T 4, T 5, T 6, T 7$ or T8. Because work-family conflict and leisure time were queried once a year, for these analyses we modeled the time at T3, and T6 only. In these analyses, all prevalent cases from the involved dependent variable at baseline (TO) were excluded. In a first step, crude relative risks (RRs) and $95 \%$ Confidence Intervals (CIS) were calculated. In a second step, adjustments were made for age, educational level and the presence of a long-term disease. We additionally adjusted the RRs for years of shift work experience, psychological job demands, decision latitude, coworker and supervisor social support, physical demands and overtime work in a third step. In the two analyses in which no incident cases occurred in one of the two groups the RR was calculated by replacing the zero cases with one case and calculating a Taylor series $95 \% \mathrm{Cl}$. In these two instances no further adjustment could be performed. For the estimation of the relative risk of leaving a three-shift schedule job separate Cox regression models were evaluated with the baseline level of the psychological health and work and home variables as independents, adjusted for age. For these analyses we excluded those respondents who left their shift work job to receive a retirement pension. Those who changed to day work or stopped working were designated as cases. All data were analyzed using $\mathrm{SAS}^{48}$

\section{RESULTS}

As shown in Table 1, forward rotating three-shift workers were slightly older of age, had on average more years of three shift work experience, and were somewhat higher educated compared to backward rotating three-shift workers. No substantial differences between forward and backward rotating three-shift workers were observed with regard to work-related factors, such as psychological job demands, decision latitudle, physical demands, and coworker and supervisor social support and flexible working hours at baseline. However, the forwand rotating workers reported less overtime work. The backward rotating workers reported more fatigue, work-family conflict and were less often living with a partner at baseline although the difference with the forwards-rotating workers was not significant. For the other factors only small differences between the two groups, with a little less favorable levels in the forward rotating workers, were found

As shown in Table 2, a backward rotating schedule was prospectively related to increased need for recovery (Relative Risk (RR) 2.88; $95 \%$ Confidence interval (CI) 1.06-7.81) and general health (RR 3.21,95\% Cl 1.32-7.83) during the total abservation period of 32 months, as compared to a forward rotating three-shift system. Adjustment for age, educational level, years of shift work experience, presence of a long-term disease, psychological job demands, decision latitude, coworker and supervisor social support, physical demands and overtime work did not alter this relation considerably. Furthermore, a backward rotating three-shift system at baseline was associated with a substantially higher risk of work-family conflict ( $R R>8.94 ; 95 \% \mathrm{Cl} \mathrm{1.26-63.4)}$ and a poorer sleep quality ( $R \mathrm{R}>7.36 ; 95 \% \mathrm{Cl} 1.05-52.7)$ during the total observation period of 


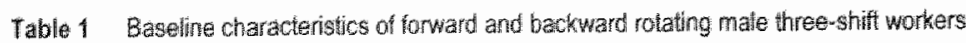

\begin{tabular}{|c|c|c|c|c|c|}
\hline Wartalde & Fonard & $S D$ & Backward & SD & P value difference \\
\hline$n$ & 95 & & 681 & & \\
\hline \multicolumn{6}{|l|}{ Demographics } \\
\hline $\mathrm{Ag} \in(\mathrm{yegrs})$ & 40.9 & 8.8 & 36,4 & 83 & $<0.0001$ \\
\hline \multicolumn{6}{|l|}{ Educational love } \\
\hline Louster & $79.4 \%$ & & $65.3 \%$ & & 0.92 \\
\hline Socondary & $17.4 \%$ & & $31.0 \%$ & & \\
\hline Higher & $3.3 \%$ & & $3.8 \%$ & & \\
\hline Years of work experience in same shifl & & & & & $<0.000 \%$ \\
\hline$\leq 5$ years & $44.7 \%$ & & $78.5 \%$ & & \\
\hline $6-15$ years & $17.0 \%$ & & $11.0 \%$ & & \\
\hline$>15$ years & $38.3 \%$ & & $11.5 \%$ & & \\
\hline \multicolumn{6}{|l|}{ Wokning conditions } \\
\hline Psychological job demands & 33.4 & 6.5 & 34.3 & 6.0 & 0.2 \\
\hline Decision latilude & 65.7 & 128 & 65.1 & 13.8 & 0.7 \\
\hline Coworker social support & 11.8 & 20 & 11.8 & 1.8 & 0.9 \\
\hline Supenisor social support & 9.1 & 2.7 & 9.7 & 28 & 0.05 \\
\hline Physically demanding work & $522 \%$ & & $47.5 \%$ & & 0.4 \\
\hline Overtime work & $25.5 \%$ & & $41,3 \%$ & & 0.004 \\
\hline Flaxible working hours & $3.2 \%$ & & $2.8 \%$ & & 0.8 \\
\hline \multicolumn{6}{|l|}{ Wowk and home inneraction } \\
\hline Dependert children & $50.5 \%$ & & $50.7 \%$ & & 0.99 \\
\hline Liwing with partner & $83.9 \%$ & & $75.0 \%$ & & 0.06 \\
\hline Insufficient leisure time & $38.0 \%$ & & $37.3 \%$ & & 0.9 \\
\hline Work-family contlict & $25,6 \%$ & & $34.4 \%$ & & 0.09 \\
\hline \multicolumn{6}{|l|}{ Psychological health } \\
\hline Fatigue cases & $22.0 \%$ & & $29.6 \%$ & & 0.13 \\
\hline Elewated need for necovery & $38.0 \%$ & & $36.0 \%$ & & 0.7 \\
\hline Poor steep qually & $36.6 \%$ & & $30.5 \%$ & & 0.3 \\
\hline Poor general health & $19.4 \%$ & & $17.2 \%$ & & 0.6 \\
\hline
\end{tabular}

32 months. Workers in a backward rotating shift schedule were also found to report more problems with insufficient leisure time over the total observation period of 32 months, although this difference was not significant.

The results of the cross-sectional and longitudinal analysis yielded considerable differences concerning the health outcomes. Therefore, additional analyses, adjusted for age, were performed to explore the possibility that three-shift workers experiencing health problems were more likely to leave their shift work job over time (Table 3). These analyses revealed that high levels of fatigue, need for recovery as well as a poor sleep quality, a reported poor general health status, insufficient leisure time and work-family conflict were associated with an increased risk of leaving a shift job over the total observation period of 32 months. 
Table 2 Relative risk for psychological heallh outcomes and work and home interaction for the backward versus forwards rotating three-shift warkers during 32 months follow up

\begin{tabular}{|c|c|c|c|c|c|c|}
\hline \multicolumn{2}{|l|}{ Variable } & $\begin{array}{l}\text { Incident } \\
\text { cases }\end{array}$ & $n$ & $\mathrm{RR}(85 \% \mathrm{Cl})$ & $\mathbb{R R}^{*}(95 \% \mathrm{CI})$ & $\mathrm{RR}^{\prime}(95 \% \mathrm{Cl})$ \\
\hline \multicolumn{7}{|c|}{ (Psychological) heaith outcomes } \\
\hline \multicolumn{2}{|c|}{ Fatique case } & 124 & 532 & $1.90(0.89-4.09)$ & $1.94(0.90-4.19)$ & $1.36(0.6)-3.06)$ \\
\hline \multicolumn{2}{|c|}{ Elevated need for recovery } & 112 & 485 & $2.88(1.06-7.81)$ & $3.08(1.13-8.43)$ & $2.99(1.06-8.44)$ \\
\hline \multicolumn{2}{|c|}{ Poor sleep quality } & 72 & 506 & $>7.36(1.05-52.70)^{\frac{1}{5}}$ & 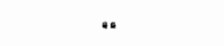 & * \\
\hline \multicolumn{2}{|c|}{ Poor general health } & 164 & 623 & $3.21(1.32-7.83)$ & $3.39(1.38-8.29)$ & $277(1.10-7.00)$ \\
\hline \multicolumn{7}{|c|}{ Work and home interaction } \\
\hline \multicolumn{2}{|c|}{ Insufficient leisure time } & 40 & 468 & $2.32(0.56-9.63)$ & $2.23(0.54-9.30)$ & $1.86(0.43-3.08)$ \\
\hline \multicolumn{2}{|c|}{ Work-familly conflict } & 64 & 493 & $>8.94(1.26-63.40)^{\mathrm{s}}$ & $*$ & $*$ \\
\hline \multicolumn{7}{|c|}{$\begin{array}{l}\text { "Adjusted for age, educational level, presence of a long-term disease } \\
\text { Adjusted for age, educational level, years of shift work experience, presence of a long-term disease, psychological job } \\
\text { demands, decision lalitude, coworker and supervisor social support, physical demands and overtime work } \\
\text { No cases in forward rotating group }\end{array}$} \\
\hline \multicolumn{7}{|c|}{$\begin{array}{l}\text { Table } 3 \text { Age adjusted relative risk of leaving ( } n=242 \text { ) versus remaining in three-shift work ( } n=776 \text { ) during } 32 \text { months of } \\
\text { follow up, according to baseline tevels of the main outcome variables }\end{array}$} \\
\hline \multicolumn{4}{|l|}{ Variable } & \multicolumn{3}{|c|}{ RR leaving shifft work job $(95 \% \mathrm{Cl})$} \\
\hline \multicolumn{4}{|c|}{ Fatigue case $(n=214)$} & \multicolumn{3}{|c|}{$1.76(1.36-2.29)$} \\
\hline \multicolumn{4}{|c|}{ Elevated need for recovery $(n=275)$} & \multicolumn{3}{|c|}{$1.60(1.23-2.07)$} \\
\hline \multicolumn{4}{|c|}{ Poor sleep quality $(n=229)$} & \multicolumn{3}{|c|}{$1.50(1.14-1.96)$} \\
\hline \multicolumn{4}{|c|}{ Poor general health $(n=132)$} & \multicolumn{3}{|c|}{$1.79(1.32-2.44)$} \\
\hline \multicolumn{4}{|c|}{ Insufficient leisure lime $(n=279)$} & \multicolumn{3}{|c|}{$1.41(1.09-9.84)$} \\
\hline \multicolumn{4}{|c|}{ Work-family conflict ( $n=249$ ) } & \multicolumn{3}{|c|}{$1.46(1.12-1.91)$} \\
\hline
\end{tabular}

\section{Discussion}

The present study examined associations between the direction of shift rotation and several (psychological) health related outcomes and work and home interaction among male three-shift workers. The cross-sectional analyses revealed little differences between three shift workers in forward as compared to backward rotating shift schedules. In the longitudinal analyses, however, we found that a forward rotating schedule was prospectively related to less psychological health related problems, in terms of need for recovery, sleep quality and general health, as compared with a backward rotating schedule. Furthermore, employees in a forward rotating schedule were less likely to report work-family conflict compared with employees in a backward rotating schedule.

Our findings of less favorable health outcomes in workers on a backwards-rotating schedule are in line with earlier studies regarding health outcomes and direction of 
rotation. ${ }^{16.21-23}$ in line with the arguments favoring forward rotation as reported by Rosa and stated in the introduction section. we also argue that forward rotating schedules, as opposed to backward rotating schedules, are healthier for shift workers, because they allow more time off between two blocks of similar shits and therefore provide employees wilh more opportumities to recover from their shift and perhaps prevent funther accumulation of fatigue. For the forward rotating schedules there is 16 hours more time to recover during the weekend days, as compared with the backward rotating schedules. However, once every complete cycle of shifts, the workers in a backward rotating schedule have an extra day off. Backward rotating schedules provide employees with a longer span of free time at the end of a complete shift cycle, but allow for less time for rest and sleep between two consecutive blocks of shifts as compared to forward rotating shift schedules. In spite of this, a considerable part of the working population remains working in backward rotating schedules. An important argument often encountered by shift workers is that a backward rotating schedule gives langer coherent periods of time off than a forward rotating schedule. where the free time "disappears" during the regular working day. ${ }^{40}$ Therefore, one might perhaps expect employees in a forward rotating schedule to report more work-family conflict. In contrast, however, we found the forward rotating workers to report less work-family conflict. Apparently, the "disappearing" time between consecutive shifts might be valuable for fine-tuning work and family obligations.

The results were different between the cross-sectional versus the longitudinal analyses. This might be due to the so-called healthy worker effect, that is, due to secondary selfselection, shift workers experiencing shift work related problems are more likely to leave shift work. This selection might be related to the years of shift work experience. However, adjustment for years of shift work experience did not change the reported relationships considerably. To explore whether such a selection process was present in our population we performed an additional analysis, examining whether the investigated outcomes, such as fatigue and work-family conflict, for example, proved to be risk factors for leaving three-shift work. These analyses revealed that the respondents experiencing psychological health problems or work-family conflict had a higher risk of leaving their shift work job. As far as we know our study is the first to find such a clear illustration of these self-selection processes among shift workers. Unfortunately, the number of employees does not allow studying risk factors for leaving three-shift work for backward and forward rotating shift workers separately. It is expected that the employees in a backward rotating schedule, associated with more health problems over time, would have a higher risk of leaving shift work when they encounter (psychological) health problems. On the other hand, forward rotating shift workers encountering psychological health problems might already have left their shift work job, before our first measurement.

The following issues should be kept in mind when interpreting the results. First, one of the main problems in shift work research is finding appropriate comparison groups with comparable types of jobs. Although we only included workers from companies with comparable job types, one cannot rule out that differences between jobs might have biased the results. However, as the working conditions, as reported by the workers, were not significantly different one should assume that this bias is only small. Furthermore, 
different changes in job content over time between the forward and backward shift workers might have biased the results. However, additional analyses revealed no notable differences between these two groups in the trends of job content over time at three consecutive time points in May 1998, May 1999 and May 2000 (specific analyses not shown). The very small influence of additional adjustment for work related factors provides further support for this assumption. Second, as considerable differences exist between three-shift work schedules and other shift work schedules, such as four- and five-shift work schedules, we consider an extrapolation of the results of the study toward workers in other schedules to be inappropriate. The same goes for women. In our study the number of female workers in shift work jobs was not sufficient to estimate the effects of rotation for this subgroup. Nevertheless, our results favoring a forward rotation do malch with results of studies on health effects and the direction of rotation in other shift work schedules.

To conclude, our study provides further evidence that optimization of the shift schedule, in terms of direction of shift rotation. might be used to decrease the adverse health impact of shift work. Future studies might irvestigate whether our findings for three-shift workers are applicable to other shift work schedules as well. Although one should keep in mind that working in shifts remains unhealthy and should therefore be prevented whenever possible, from a health point of view forward rotating shift schedules are preferable over backward rotating shift schedules, when day work is not feasible. Furthermore, this study provided a clear illustration of secondary selection processes taking place in shift workers, thereby emphasizing the complexity of valid sthift work research.

\section{ACKNOWLEDGEMENTS}

The Maastricht Cohort Study is part of the Netherlands concerted research action on "Fatigue at work" granted by the Netherlands Organization for Scientific Research. The present study was supported by grant no. 580-02.201 from the Netherlands Organization for Scientific Research.

\section{REFERENCES}

1. European Commission. Employment in Europe 2004 - recent trends and Prospects Luxembourg: Office for Official Publications of the European Communities; 2001.

2. European Foundation for the Improvement of Living and Working Conditions. Third European survey on working conditions 2000. Luxembourg: Office for Officiall Publications for the European Communities; 2001.

3. Baggild $H$, Knutsson A. Shift work, risk factors and cardiovascular disease. Scand J Work Environ Health 1999;25(2):85-99.

4. Knutsson $\mathrm{A}_{\mathrm{e}}$ Bøggild $\mathrm{H}$. Shiftwork and cardiovascular disease: review of disease mechanisms. Rev Environ Health 2000:15(4):359-72.

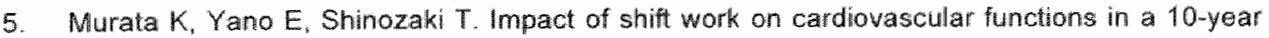
follow-up study. Scand J Work Environ Health 1999;25(3):272-7. 
6. Morkawa $Y$. Makagawa H. Mura K, Ishizaki M, Tabata M. Nishijo M, et al. Reilationship between shift work and onsef of hypentension ith a cohort of manual workers. Scand $J$ Work Endron Heath 1999,252$): 100-4$

7. Van Amelswort LG. Schouten EG. Maan AC, Swenne CA, Kok Fi. Changes in frequency of premature complexes and hear rate variability related to shift work. Occup Emviron Med 2001:58(10):678-81.

9. Angersbach D, Knauth P. Loskant H. Karwonen M, Undeutsch K, Rutenfranz J. A retrospective cohor study comparing complaints and diseases in day and shift workers. Int Arch Occuo Environ Health $1980 ; 45: 127-40$.

9. Tuchsen F, Jeppesen HJ, Bach E. Employment status, non-daytime wark and gastric ulcer in men. Int I Epidemiol $1994,23,365-70$.

10. Parkes: KR. Shift work and age as interactiwe predictors of body mass index among offshore workers. Scand J Work Enwiron Health 2002*28(1):64-71

11. War Amelswopr LGPM, Schouten EG, Kok FJ. Duration of shiftwork related to body mass index and waist to hip ratio. Int $J$ Obesity $1999 ; 23$ (9):973-8

12. Karlsson B, Knutsson A, Lindahl B. He there an association between shift work and having a metabolic symdrome? Results from a population based study of 27.485 people. Occup Environ Med 2001,58(11):747-52.

13. Akerstedt T. Work hours and sleepiness. Neuraphysial Olin 1995;25(6):367-75.

14. Jansen NWH, Kant IJ, Van Amelsvoort LPGM, Nijhuis FJM, Van den Brand PA. Need for recovery from work: Evaluating short-term effects of working hours, patterns and schedules. Ergonomics 2003:46(7):664-80

15. Akerstedt T, Fredlund P. Gilberg M, Jansson B. Work laad and work hours in relation to disturbed sleep and fatigue in a large representative sample. $₫$ Psychosom Res $2002,53(1): 585-8$

16. Barton J, Folkard S, Advancing versus delaying shift systems. Ergonomics 1993,36(1-3):59-64.

17. Harma M. New work imes are here are we ready? [Editorial]. Scand J Work Environ Health $1998: 24$ (Supp: 3):3-6.

18. Jansen NMH, Van Amelswoort LPGM, Kristensen TS, Van den Brandt PA, Kant IJ. Work schedules and fatigue: a prospecive cohort study, Occup Environ Med 2003;60(Suppl 1):447. 53.

19. Ahsberg $E_{\text {; }}$ Kecklund $G_{*}$ Akerstedit $\downarrow$, Gamberale $F$. Shiftwork and different dimensions of fatigue. Int J Ind Ergon 2000:26:457-65.

20. Koller Ku, Kundi M, Cervinka R. Field studies of shift work at an Austrian oil refinery. I: health and psychosocial wellbeing of workers who drop out of shiftwork. Ergonomics 1978;21:835-47.

21. Czeisler CA, Moor-Ede MC, Coleman RM. Rotating shift work schedules that disrupt sleep are improved by applying circadian principles. Science $4982: 217: 460-3$.

22. Knauth P. Dasigning better shift systems. Appl Ergon 1996;27,39-44.

23. Knauth $P$. Hornberger $S$. Changes from weekly backward to quicker fonward rotating shift systems in the steet industry. Int $\mathrm{J}$ ind Ergon $1998 ; 21(3-4) \cdot 267 \times 73$.

24. Knauth $P$. The design of shift systems. Ergonomics $1993 ; 36(1-3): 15-28$.

25. Wain Amelswoon LGPM. Schouten EG, Maarl AC, Swenne CA, Kok Fل. 24-Hour heart rate variability in shift workers: impact of shift schedule. J Occup Health 2001:43:32-8.

26. Orth-Gomer $K$. Intervention on coronary risk factors by adapting a shift work schedule to biologic inythmicity. Psychosom Med 1983;45:405-15.

27. Knauth $P$. Kiesswetter E. A change from weekly to quicker shiff rotatians: A field study of discontinuous threemshift workers. Ergonomics $1987: 30(9): 1311-21$.

28. Rosa RR. Examining work schedules for fatigue: it's not just hours of work. Hn: Hancock PA, Desmond PA, editors. Stress, workload and fatigue. Mahwah: Lawrence Erlbaum Associates $2001, p, 513-28$

29. Swaen GMH, Van Amelswoor LGPM, Bultmann U, Kant IJ. Fatigue as a risk factor for being injured in an occupational accident: results from the Maestricht Cohort Study. Occup Environ Med 2003;60(Suppi 1):i88-92

30. Wari Amelswoont LPGM. Kant 1W, Beurskens AJHM, Schröer CAP. Swaen GMH. Fatigue as a predictor of work disability. Occup Environ Med 2002,59:74:-3. 
31. Tucker P. Smith L, Macdonald I, Folkard S. Effects of direction of rotation in continuous and discontinuous 8 hour shift systems. Occup Environ Med 2000;57(10):678-84.

32. Barton $J$, Folkard $S$, Smith $L$, Poole CJM. Effects on health of a change from a delaying to an advancing shift system. Occup Environ Med 1994:51:749-55.

33. Walker J. Social problems of shiftwork. In: Folkard S, Monk TH, editors. Hours of work: temporal factors in work-scheduling. New York (NY): John Wiley \& Sons; 1985. p. 211-25.

34. Loudoun RJ, Bohle PL. Work/Non-work conflict and health in shiftwork: Relationships with family status and social support. Int J Occup Enwiron Health 1997;3(Suppl 2):571-7.

35. Jansen NWH, Kant IJ, Kristensen TS, Nijhuis FUN. Antecedents and consequiences of workfamily conflict: a prospective cohort study. J Occup Environ Med 2003;45(5):479-91.

36. Grandey $A A$, Cropanzano $R$. The Conservation of resources model applied to work-fiamily conflict and strain. J Vocat Behav 1999;54(2):350-70.

37. Kant IJ, Beurskens AJHM, Schroër CAP, Nijhuis FJN, Van Schayk CP, Van den Elzen HJ, et al. De Maastrichtse cohort studie naar langdurige psychische vermoeidheid in de arbeidssituatie [The Maastricht Cohort Study on prolonged mental fatigue and work]. Tijdschrift voor Bedrijfs- en Verzekeringsgeneeskunde 2000;8:226-32.

38. Kant IJ, Bültmann U, Schröer CAP, Beurskens AJHM, Van Amelswoort LPGM, Swaen GMH. An epidemiological approach to study fatigue in the working population: the Maastricht Cohort Study. Occup Environ Med 2003;60(Suppl 1):i32-9.

39. Van Veldhoven $M$, Meijman $T$. Het meten van psychosociale arbeidsbelasting [Questionnaire on psychological job demands and job stress]. Amsterdam: NIA-TNO; 1994.

40. Sluiter JK, Van der Beek AJ, Frings Dresen MH. The influence of work characteristics on the meed for recovery and experienced health: a study on coach drivers. Ergonomics $1999: 42(4): 573-83$.

41. Jansen NWH, Kant $\mathrm{IJ}$, Van den Brandt PA. Need for recovery in the warking population: description and associations with fatigue and psychological distress. Int J Behav Med $2002 ; 9(4): 322-40$.

42. Vercoulen $J H$, Swanink $C M$, Fennis JF, Galama JM, van der Meer $J M$, Bleijenberg $G$. Dimensional assessment of chronic fatigue syndrome. J Psychosom Res 1994;38(5):383-92.

43. Bülttmann $U$, De Vries $M$. Beurskens AJHM, Bleijenberg $G$, Vercoulen JHMM, Kant, IJ. Measurement of prolonged fatigue in the working population: determination of a cut off point for the checklist individual strength. J Occup Health Psychol 2000;5(4):411-6.

44. Aaronson NK, Muller M, Cohen PD, Essink Bot ML, Fekkes M, Sanderman $R$, et al. Translation, validation, and norming of the Dutch language version of the SF-36 Health Survey in community and chronic disease populations. J Clin Epidemiol 1998;51(11):1055-68

45. Karasek RA. Job content questionnaire and user's guide. Los Angeles (CA): Department of Industrial and Systems Engineering, University of Southern California; 1985.

46. Houtman 1. Reliablity and validity of the Dutch version of the Karasek Job content questionnaire. In: APA/NIOSH conference on work, stress and health; 1995; Washington (DC): American Psychological Association; 1995.

47. Gründemann RWM, Smulders PWG, De Winter CR. Handleiding Vragenlijst Arbeid en Gezondheid [Manual, questionnaire on work and health]. Lisse; Swets \& Zeitlinger; 1993.

48. SAS institute. SAS/STAT user's guide, volume 1, version 6. Cary (NC): SAS institute lnc: 1989.

49. Kristensen TS. Workplace intervention studies. Occup Med 2000;15(1):293.305. 


\title{
Prevalence of common infections among employees in different work schedules
}

\author{
Danielle CL Mohren" \\ Nicole WH Jansen ${ }^{*}$ \\ IJmert Kant" \\ Jochem MD Galama ${ }^{2}$ \\ Piet A van den Brandt' \\ Gerard MH Swaen ${ }^{\prime}$
}

\footnotetext{
${ }^{1}$ Department of Epidemiology, Maastricht University, Maastricht, The Netherlands

${ }^{2}$ Department of Medical Microbiology, University Medicall Center St. Radboud, Nijmegen, The Netherlands

Both authors made equal contributions to this article
} 


\section{ABSTRACT}

This study examined the prevalence of common infections among employees in different work schedules. Self-administered questionnaire data from the Maastricht Cohort Study on "Fatigue at Work" $(n=12,140)$ were used.

Job litle was used as a matching variable between day and shift workers to controf for their different work environment. We used a multilevel analysis of a two-level structure, in which the individual employees (level 1) were nested within job titles (level 2), adjusted for demographics, longstanding disease, health behavior, work-related factors fatigue and sleep quality. Results from the multilevel analyses showed that, compared to day work, shift work was associated with a higher risk for common infections, with the highest risk in three-shift workers. Compared to day work, shift work was further associated with differences in health, health behavior, sleep, fatigue and perceived job characteristics, factors that may influence the occurrence of infections and should be taken into account in future studies as well. 


\section{INTRODUCTION}

Common infections like common coll, flu-like illness, and gastroenteritis are endemic in the general population thereby causing considerable discomfort and absence from work. In a study by Feeney et al. it was found that respiratory disorders and gastroenteritis accounted for 50 to $60 \%$ of all spells of absence. In recent years, evidence has accumulated that stress influences the susceptibility to and duration of infections. Several psychosocial factors have been linked to an increased risk for infections. Daily hassles and major life events have been connected to a higher risk for upper respiratory tract infections. ${ }^{2 \cdot 6}$ Family functioning, measured with scales covering among others cohesion, adaptability and recent events within a family, ${ }^{7}$ has been associated with a higher risk for influenza-like illnesses. Also work-related stressors may play a role in the susceptibility to infections and several studies have demonstrated a link between the experience of work-related stressors and changes in immune activity. ${ }^{8-10}$ Psychological job demands for example, have been described as a possible risk factor for the common cold. ${ }^{11}$

Another work-related factor that is likely to be associated with common infections, constitutes shift work. Shift work can have a negative impact on the health and well being of workers. ${ }^{12}$ Problems related to shift work fall into three main areas. ${ }^{13}$ First, biological disruption of physiological processes, including the sleep-wake cycle ${ }^{14.15}$ can result from shift work. Second, the impairment of physical health and psychological well being $^{46}$ and third the disruption of social and domestic life ${ }^{17.18}$ have been associated with shift work as well. Studies have shown that shift workers have an increased risk of cardiovascular diseases, ${ }^{19-23}$ gastrointestinal diseases, ${ }^{12,24,25}$ and diminished well being. ${ }^{12}$ A few studies have reported depressed immune function in relation to shift work, which may explain an increased susceptibility to infections. ${ }^{26,27}$ Further, depression of immune function has been attributed to a disturbed circadian thythm ${ }^{28}$ caused by periodic shifting of the light-dark, wake-sleep-cycles. ${ }^{26}$ Shift work may be a major caulse of suboptimal sleep quality ${ }^{29}$ and has been related to a greater amount of insomnia, sleep deprivation, and daytime sleepiness. ${ }^{15}$ Cohen et al ${ }^{30}$ found that inefficient sleep is associated with an increased risk of colds. Moreover, we found that fatigue is associated with common infections. ${ }^{31}$ Fatigue can be regarded as a common complaint during infection, which afterwards can persist for months. On the other hand, it was found that fatigue can also precede a common infection.

The prevalence of infections may further be influenced by health behavior like smoking. drinking habits, and limited exercise. Increased smoking, drinking. ${ }^{32}$ and limited exercise $^{33}$ can influence the immune response. Both smoking and alcohol consumption are believed to suppress host resistance and thereby increase the risk of upper respiratory tract infections. ${ }^{34}$ Health behawior may also differ between day and shift workers and may possibly account for differences in infection rates. One of the most important physiological problems associated with shift work and the night shift in particular, is that working, eating and sleeping phases are changed. ${ }^{25}$ 
Strong differences beween day and shift workers have also been reported concerning other work conditions, such as, for example, decision latitude and conflicts at work, ${ }^{35}$ as well as womotional, physical and psychological job demands. ${ }^{36.37}$ This emphasizes the need to controf for differences in the work environment when examining work schedules. Approaches to take into account these confounders, are to include measures of perceived job characteristics in the analysis of shift work effects ${ }^{38}$ and/or use job title as a matching variable in the analyses.

We are currently interested in the associations between work schedules and the prevalence of infections. The present study is part of the large-scale Maastricht Cohort Study on "Fatligue at Work", in which work-related and nonwork-related factors as well as the occurrence of common infections were measured on an individual level by means of self-administered questionnaires. The aim of the present study was to investigate whether shift work is associated with a higher prevalence of common infections, such as common cold. flu-like illness, and gastroenteritis compared to day work, with day and shift workers matched on job title. We differentiated day workers from employees working three-shift, five-shift or irregular shift systems, while taking into account the role of demographics, health, health behavior, perceived job characteristics, sleep quality, and fatigue.

\section{METHODS}

\section{Maastricht Cohort Study}

At baseline the Maastricht Cohort Study surveyed a large helerogeneous population of employees working in 45 different companies and organizations. ${ }^{30,40}$ Temporary employees, as well as employees with an employment of less than $50 \%$, were excluded. A total of 12,161 employees completed the baseline questionnaire. Written consent was obtained from all participants. The overall response was $45 \%$. Twenty-one questionnaires were discarded because of technical reasons, ${ }^{\text {*1 }}$ resulting in a study population of 12,140 employees. Included were men and women, aged 18 to 65 years $(n=12,095)$.

The participants of the Maastricht Cohort Study received nime questionnaires at fourmonthly intervals, with a total observation period of three years (1998-2001). The results of the present study are based on the first (baseline) questionnaire (May 1998). At baseline, exposures (work-related factors, individual characteristics, domestic and social factors as well as information on job title) and outcomes were measured on an individual level using self-administered questionnaires.

\section{The study population}

For the present study we further excluded employees with multiple jobs $(n=497)$, since we have no information available on the content and work schedule of the other job. To study the effects of work schedules, employees involved in day work, three-shift, five- 
shift or irregular shift work were selected. All employees involved in other work schedules or those who did not provide information on their work schedule were excluded, resulting in a final study population of 8255 employees.

The questions "What is your job in the company/organization?" and "What is your most important task?" were used to assess an employees" job title in the current job. The responses to these open-ended questions were used by trained coders to assign a job title, with a five-digit code, based on The Netherlands Standard Classification of Occupations 1992. ${ }^{42}$ From the employees, 88 did not indicate their function or most important task. These employees were excluded from further analyses. At baseline in 1998, the Maastricht Cohort Study captured 687 different job titles. Job title was used to match the employees in the different work schedule groups. For example, employees working three-shift systems were matched with a reference group of day workers with similar job titles. For each distinguished job title, there was a minimum of two employees in each work schedule. For the comparison of three-shift workers with day workers, 47 job titles were identified ( $n=753$ for three-shift workers, $n=1114$ for day workers). Examples of job titles represented in both day work and three-shift systems were: production planner, operator, engine/bench fitter. For comparing five-shift workers and matched day workers, 58 job tilles were identified ( $n=947$ for five-shift workers, $n=1609$ for day workers). Examples of job titles represented in bath day work and five-shift systems were: machine operator, contraller or tester electric-machinery "maintenance electrician. As regards irregular shift workers and matched day workers, 28 job titles were identified ( $n=329$ for irregular shift workers, $n=573$ for day workers). Examples of job titles represented in both day work and irregular shift systems were mailman, enrolled nurse, care taker of the mentally handicapped or elderly.

\section{Work schedules}

Regarding work schedules, employees were asked whether they were involved in irregular shifts, two-shift, three-shift, four-shift, or five-shift work, exclusively evening or night work, or whether they worked daytime only. In our study, the term shift work is used for a work schedule that includes night work. In the present study only day workers, three-shift, five-shift or irregular shift workers were included for investigating differences between the schedules. The direction of the shifts (clockwise, counterclockwise) varied between the companies. In the present study three-shift work involves three alternating teams, with a semi-continuous schedule, in which a weekly interruption of the production. mainly in the weekends, takes place. Five-shift work involves full continuous shift work, spread over seven days including five alternating teams. Concerning working hours a week, five-shift work generally comprises 33 to 34 hours a week, whereas three-shift work comprises 38 to 40 hours a week. Employees working irregular shifts are involved in frequently deviating work hours, which can vary substantially every week. In the present study for irregular shifts we included only those employees reporting frequent night work within their shift. 


\section{Infections}

The four-month prevalence of infections was also determined using self-administered questionnaires. Three common infections: common cold, flu-like illness, and gastroenteritis were inventoried as separate items in the questionnaires asking employees about the occurrence of common infections in the past four months. For clarification, a brief description of the infection was included in the question. This description mainly contained the typical symptoms of the infection. For common cold these symptoms were: clogged or running nose, a sore throat, coughing, and silight or no fever (temperature less than $38^{\circ} \mathrm{C}$ ), for flu-like illness: fever (temperature $38^{\circ} \mathrm{C}$ or more), with at least four of the following six complaints, muscular pain, fatigue, sore throat, clogged or running nose, coughing, headache. For gastroenteritis these symptoms included: slight or no fever, gastritis, nausea, vomiting and/or diarrhea.

\section{Work environment}

In this study we included measures regarding the experience of several demands at work. Decision latitude was assessed with the Dutch version of the Job Content Questionnaire using the scale Decision Latitude. ${ }^{43.44}$ The level of psychological job demands was measured with the Dutch version of the Psychological Job Demands scale of the Job Content Questionnaire. ${ }^{43,44}$ The level of emotional demanding wark was measured using a five item scale consisting of two items of the Questionnaire Experience and Assessment of Work (VBBA) ${ }^{45}$ two items of the Questionnaire on Work and Health (VAG) ${ }^{46}$ and one self-formulated item. Physical demands were measured using a dichotomous item of the Dutch questionnaire on Work and Health (VAG). ${ }^{46}$

\section{Demographics and health variables}

Information on age, gender, the presence of a long-term disease, smoking and drinking habits, was obtained through self-report in the baseline questionnaire. Information on the quality of sileep was obtained through one item asking employees "Did you sleep well in the past four months?". This item was sicored on a four point scale (never, sometimes, usually, always). The Checklist Individual Strength (CIS) was used to measure prolonged fatigue. ${ }^{47}$ The CIS is a 20 -item questionnaire developed to measure several aspects of prolonged fatigue. The $\mathrm{ClS}$ is a selfmeport instrument consisting of four factors: subjective experience of fatigue, concentration, motivation, and physical activity level. Higher scores indicate a higher degree of fatigue, more concentration problems, reduced motivation or less activity. A composite CIS-total score, ranging from 20 to 140 , can be constructed by adding the individual's scores on the four factors. The Cronbach's alpha of the total scale is 0.93 . The cutoff point for case classification used in the present study was CIS total > 76. This cutoff point was established in a separate pilot study by means of defined samples with differences in fatigue levels. ${ }^{48}$. All those employees scoring $>76$ were considered to be probable fatigue cases. ${ }^{41}$ 


\section{Statistical methods}

We calculated crude and adjusted odds ratios (ORs) and $95 \%$ confidence intervals (Cl) for associations between each of the three common infections (common cold, flu-like illness, and gastroenteritis) and each work schedule. The ORs were adjusted in several steps for demographics, longstanding disease, health behavior, psychological job demands (continuous variable), decision latifude (continuous variable), emotional demands (continuous variable), physical demands, and fatigue (continuous variable) and sleep quality. Each shift work type (three-shift, five-shift and irregular shift work) was compared with a reference group of day workers with respect to the prevalence of common infections. We used a multilevel analysis of a two-level structure, in which the individual employees (level 1) were nested within job titles level 2). Additionally T-tests and Chi-square tests were used to test univariate differences between employees in the different shift work types versus day workers. All procedures were performed using SPSS for Windows release 9.0.0., SAS release 8.02, and GLIMMX, a SAS Macro for the multilevel analyses.

\section{RESULTS}

Table 1 shows descriptive characteristics of the study population before matching on job titte. The percentage of women involved in three- and five-shift work was significantly lower compared to day work, whereas the percentage of women was significantly higher in irregular shift work compared to day work. Shift workers were on average younger of age compared to day workers. Smoking was significantly more prevalent in shift workers as compared to day workers, with the highest percentage of smokers (46.7\%) observed in three-shift workers. Differences in alcohol use were also found between day and shift workers. The highest percentage of employees who reported to exercise never or onlly once a week was found in three-shift workers. With regard to job characteristics substantial differences emerged between day and shift workers. For example, the percentage of employees reporting their work to be physically demanding was substantially and significantly higher in all types of shift work compared to day work. Overall, the prevalence of employees reporting a long-term disease did not substantially differ between the work schedules, although the prevalence of a long-term disease was somewhat lower in five-shift work $(p<0.05)$ compared to day work. We found significant differences in sleep quality between employees in shift work and day work. Three-shift workers reported the highest percentage of poor sleep quality in the past four months. Compared to day work, the prevalence of fatigue was substantially higher in most shift work groups, with three-shift workers reporting the highest prevalence $(32.2 \%)$.

Table 2 shows the prevalence at baseline of common infections among employees working in different work schedules. The occurrence of common cold is highest among three-shift workers $(57.5 \%)$ and irregular shift workers $(55.5 \%)$. Flu-like illness is also most frequently reported by three-shift workers $(31.2 \%)$ and irregular shift workers $(30.5 \%)$. Finally " the highest prevalence for gastroenteritis was found among three-shift workers $(18.2 \%)$. 
Table 1 Descriptive characteristites study population

\begin{tabular}{|c|c|c|c|c|c|}
\hline & & Day work & Three-shift work & Five-sinft work & Ireguilar shift weon \\
\hline & n (number of organizations) & $5899(45)$ & $878(19)$ & $1058(11)$ & $420(25)$ \\
\hline \multirow[t]{2}{*}{ Demographics } & Gender $1 \%$ lemale & 32.6 & $11.6^{+64}$ & $6.4^{4}$ & $39.5^{+13}$ \\
\hline & Age mearl & 42.38 & $35.72^{* *}$ & $37.90^{*}$ & $37.87^{* n+4 x}$ \\
\hline \multirow[t]{10}{*}{ Health bohavior } & Smoking $\%$ & $22 . \overline{5}$ & $46.7^{1 \cdot 54}$ & $35.3^{+2-6}$ & $37.1 \times+\infty$ \\
\hline & Alcohol use \% (glassens / wh) & & tition & $*$ & 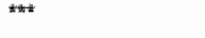 \\
\hline & none & 24.4 & 37.1 & 28.8 & 34.3 \\
\hline & $1-14$ & 642 & 52.5 & 59.9 & 57.6 \\
\hline & $15-21$ & 8.6 & 7.1 & 80 & 5.5 \\
\hline & $\geq 22$ & 2.8 & 3.3 & 3.3 & 2.6 \\
\hline & Exercise $\%$ & & 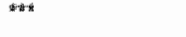 & $\|$ & \\
\hline & 0-1 limes / wk & 30.5 & 44. & 36.3 & 32.6 \\
\hline & $2-7$ times / wh & 62.4 & 50.3 & 576 & 58.1 \\
\hline & $>7$ times / wk & 7.1 & 5.5 & 6.1 & 9.3 \\
\hline \multirow{4}{*}{$\begin{array}{l}\text { Work-related } \\
\text { factors }\end{array}$} & Physically demanding work $\%$ & 11.8 & $51.6 *$ & $34.8^{8 * x \cdot k}$ & $71.9^{2.4 x}$ \\
\hline & $\begin{array}{l}\text { Psychological job demands } \\
(12-48)^{*}\end{array}$ & 32.73 & $34.69^{2 *}$ & $32.47^{\text {six }}$ & $34.34^{\text {natat }}$ \\
\hline & Decision latitude $(24.96)$ & 73.19 & $64.15^{* *}$ & $67.73^{4}$ & $68.79^{\mathrm{i} \cdot \mathrm{x} \cdot \mathrm{b}}$ \\
\hline & Emolional demands $(0.5)^{1}$ & 0.90 & 1.610 & $1.18^{*}$ & $1.93^{2+x}$ \\
\hline \multirow[t]{7}{*}{ Health } & Long-term disease \% & 24.7 & 26.2 & $217^{*}$ & 25.7 \\
\hline & Good steep in past four months & & $x \rightarrow$ & 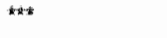 & $4:$ \\
\hline & never & 2.5 & 5.4 & 2.7 & 3.4 \\
\hline & sometines & 12.9 & 28.5 & 21.0 & 19.2 \\
\hline & usually & 56.7 & 46.8 & 53.0 & 52.9 \\
\hline & always & 27.9 & 19.2 & 23.3 & 24.5 \\
\hline & Fatigue $(\mathrm{CIS}>76) \%$ & 20.7 & $322^{* * *}$ & $250^{2+4}$ & 21.2 \\
\hline
\end{tabular}

Significant difference with day work: " $p<0.05, * 0<0.01$ *** $p<0.001$

1 Reference group for all three lypes of shitt work

Scale uange

Because of the large differences observed between day and shift workers with regard to the perceived work-related demands, job title was used as a matching variable in multilevel analysis. Table 3 shows the ORs for the three distinguished common infections by shift type, using multilevel GLIMMIX models in which the individual employees were nested within job titles. Three-shiff work was significantly associated with all three common infections (OR 1.42; Cl 1.14-1.76 for common cold, OR $1.72 ; \mathrm{Cl}$ $1.34-2.20$ for flu-like illness, OR $1.83 ; \mathrm{Cl} 1.40-2.38$ for gastroenteritis). In general. for irregular shift workers similar but lower associations were observed. Five-shift work was only significantly associated with gastroenteritis (OR 1.64; Cl 1.29-2.08). No significant differences were found for the prevalence of common cold and flu-like illness, when comparing five-shift workers with day workers.

Table 2 Prevalencs of common infections among different work schedules

\begin{tabular}{|c|c|c|c|c|}
\hline & Day work & Three-shift work & Fine-shift work & Irregular shifi work \\
\hline A (number of organizations) & $5899(45)$ & $878(19)$ & $1058(11)$ & $420(25)$ \\
\hline Common cold $\%$ & 53.0 & $57.5^{*}$ & 51.0 & 55.5 \\
\hline Flu-lke mess & 22.4 & $31.2^{* * * *}$ & 221 & $30.5^{\text {**ad }}$ \\
\hline Gastroenteritis & 118 & $18.2^{* * *}$ & $15.4^{4}$ & $15.1^{*}$ \\
\hline
\end{tabular}

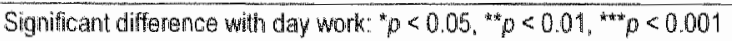


Adjusting for demographics and health factors (age. gender and long-term disease) and for health behavior (smoking, drinking habits, and exercise) resulted in weaker associations for all work schedules, except for the association beween five-shift work and common cold. Compared to day work, fiwe-shift work was then associated with a lower risk for common cold (OR 0.79; Cl 0.66-0.95). Subsequently, the ORs for common infections were additionally adjusted for several work-related demands, which resulted in changes of the ORs for the association between work schedules and common infections as well. Most ORs decreased, whereas the OR regarding the association between irregular shift work and flu-like illness increased (OR $1.52 ; \mathrm{Cl} 1.06-2.18$ ). Also, the OR for the association between five-shift work and glastroenteritis increased (OR $1.38 ; \mathrm{Cl} 1.03$ 1.85). In the final analyses, the ORs were additionally adjusted for sleep quality and fatigue levels, which resulted in only slight changes of the ORs for all three common infections. Statistically significant ORs remained for the associations between five shift work and common cold (OR 0.79; Cl 0.64-0.98), five-shift work and gastroenteritis (OR $1.42 ; \mathrm{Cl} 1.05-1.91$ ), and irregular shift work and flu-like illness (OR $1.63 ; \mathrm{Cl} 1.13-2.36$ ).

Finally, to study the role of fatigue and sleep quality in the relationship between work schedules and common infections separately, we conducted an additional analysis, in which we adjusted the ORs only for demagraphics, the presence of a longstanding disease, fatigue and sleep quality. These anallyses (specific data not shown) revealed that sleep quality and fatigue influenced the strength of the associations as well, although in general to a lesser extent as compared to the effect of perceived job demands.

Table 3 Odd Ratios and $95 \%$ Confidence Intervals for common infections by shift type Multilevel GLIMMIX Models

\begin{tabular}{|c|c|c|c|c|c|c|c|c|c|c|}
\hline \multicolumn{11}{|l|}{ Common cold } \\
\hline & OR & $95 \% \mathrm{Cl}$ & OR & $95 \% \mathrm{Cl}$ & ORt & $95 \% \mathrm{Cl}$ & ORt & $95 \% \mathrm{Cl}$ & OR & $95 \% \mathrm{Cl}$ \\
\hline Three-shift work & 1.42 & $1.44-1.76$ & 1.16 & $0.91-1.48$ & 1.14 & $0.88-1.46$ & 1.03 & $0.78-1.35$ & 1.03 & $0.78-1.36$ \\
\hline Five-shift work & 1.00 & $0.85-1.19$ & 0.83 & $0.69-0.99$ & 0.79 & $0.66-0.95$ & 0.77 & $0.63-0.95$ & 0.79 & $0.64-0.98$ \\
\hline Irregular shift & 1.09 & $0.83-1.44$ & 1.02 & $0.76+1.37$ & 1.01 & 0.751 .36 & 0.92 & $0.66-1.27$ & 0.95 & $0.68-1.32$ \\
\hline \multicolumn{11}{|l|}{ Flume illiness } \\
\hline & $\mathrm{OR}$ & $95 \% \mathrm{Cl}$ & $O R^{\prime}$ & $95 \% \mathrm{C}$ & OR: & $95 \% \mathrm{Cl}$ & OR: & $95 \% \mathrm{Cl}$ & ORF & $95 \% \mathrm{Cl}$ \\
\hline Three shift work & 1.72 & $1.34-2.20$ & 1.52 & $1.16-2.00$ & 1.41 & $1.07-1.67$ & 1.23 & $0.90 \times 1.68$ & 1,23 & $0.90-170$ \\
\hline Five-sinitu work & 1.06 & $0.84 m 1.34$ & 0.92 & $0.72-1.17$ & 0.88 & $0.69-1.12$ & 0.82 & $0.64-1.06$ & 0.82 & $0.83-1.07$ \\
\hline Irregular shift & 1.51 & $1.11-2.05$ & 1.40 & $1.01-1.95$ & 1.39 & $0.96 \times 1.94$ & 1.52 & $106-218$ & 1.89 & $1.13-2.36$ \\
\hline \multicolumn{11}{|l|}{ Giastroenteritis } \\
\hline & OR & $95 \% \mathrm{Cl}$ & $\mathrm{OR}^{\circ}$ & $95 \% \mathrm{Cl}$ & OR: & $95 \% \mathrm{Cl}$ & OR: & $95 \% \mathrm{Cl}$ & OR. & $95 \% 6$ \\
\hline Three-shift work & 1.83 & $1.40-238$ & 125 & $0.92 \cdot 1.70$ & 1.15 & $0.84-1.59$ & 1.05 & $0.73 \cdot 1.51$ & 1.06 & $0.73+1.54$ \\
\hline Five-ghift work & 1.64 & $1.29-208$ & 1.39 & $1.08-1.80$ & 1.34 & $1.03-1.74$ & 11.38 & $1.03-1.85$ & 1.42 & $9.65-1.91$ \\
\hline Imegular shitt & 1.40 & $0.95-206$ & 1.28 & $0.85-1.93$ & 1.22 & $0.80-1.86$ & 1.15 & $0.73-1.81$ & 1.17 & $0.73 \cdot 1.88$ \\
\hline
\end{tabular}

For every shift type, the reference group consisted of employees in day work with comparable occupatons

"Corrected for age, gender, longstanding disease

$\uparrow$ Additionaily corrected for smoking, drinking habits and exercise

t Additionaly corrected lor psychological job demands, decision latitude, physical demandis, and errotional demands

s. Additionally corrected lor sleep quality and fatigue 


\section{DIscussion}

In this study we found that the prevalence of three common infections (common cold, flum like illness, and gastroenteritis) differed significantly between employees involved in different work schedules. Three-shift workers reported the highest prevalence for all three infections. Taking into account the high prevalence of common intections and the fact that work schedules are not the primary "etiological agent", the observed associations are quite large, moreover when considering the loss of productive work hours when infections result in employee absenteeism.

Because differences in work-related factors are often large between day and shift. workers, in this study job title was used as a matching variable. Employees with similar job titles in different work schedules were matched to account for differences in the work environment. The crude ORs in the multilevel analyses revealed that shift work was clearly associated with a higher odds of common infections compared to day work. Three-shift work was strongly associated with all three infections. Compared to five-shift workers, three-shift workers have a working week comprising more hours. In addition. three-shift workers generally only have two (weekend) days available to recuperate before they switch to a new shift cycle. Others have observed that recovery from a shift did not occur by the end of the first rest day but might have occurred only by the end of the second rest day. ${ }^{49}$ The traditional weekly change of shifts, as for example seen in three-shift work, is often reported to be the worst solution. ${ }^{50,51}$

To elucidate possible underlying mechanisms relating work schedules to common infections, we adjusted in several steps conseculively for demographics, health, health behavior: job characteristics, sleep quality and fatigue. Adjustments for demographics, health status and health behavior resulted in lower odds for the association between work schedules and infections. This emphasizes the importance of correction for the above mentioned factors, since they are related both to infections and work schedules.

Subsequenily, we corrected for severall work-related demands. Although job title was used as a matching variable to take into account possible differences in demands, we still observed a change in the association between work schedules and infections after adjustment for work-related demands. Though the day and shift workers were in comparable job titles, there were still differences with regard to the perceived demands of the individual worker. Compared to day workers, shift workers may perceive these job characteristics as more demanding possibly since they are fighting their sleep. Another possibility is that job demands in simillar jobs actually are more demanding "when performed in shift work. We are aware that adjustment for job characteristics may constitute over control and thus could lead to underestimation of risks, because these jab characteristics may be part of the causal pathway linking work schedules to common infections. Therefore, we assume that the relatively crude results, only adjusted for age, gender and long-term disease, are more likely to represent the actual effect of shift work on the prevalence of common infections. The analyses with adjustments for job characteristics, however, provided important additional information to disentangle possible mechanisms linking work schedules to common infections. This is in line with 
other studies showing an association between work-related stressors and immune function. $8.41,52,53$

Further, evidence supports the view that lack of sleep lowers resistance to infection and that during periods of sleep deprivation. respiratory tract infections occur more frequently. ${ }^{28}$ Shift work has been clearly related to disturbed sleep. ${ }^{15,54}$ First, their unusual work hours prevent shift workers from sleeping at the normal time. Second, when shift workers do have an opportunity to sleep, they have to do so in an environment that is geared towards the awakened state. Third, night work and day sleep affect the circadian rhythm. ${ }^{55}$ In a study by Härmä et al. ${ }^{45}$ for example, sleep complaints were more common in two- and three-shift workers as well as in irregular shift workers compared to day workers. In our study, shift work was also associated with poorer quality of sleep. In addition, shift workers had a significantly higher prevalence of fatigue. Higher fatigue levels are related to common infections as well. ${ }^{39}$ When contralling for sleep quality and fatigue levels, only minor changes appeared in the association between work schedules and common infections. A possible explanation for these small effects could be that perceived work demands next to sleep quality and fatigue, play a dominant role in the mechanism to explain the association between work schedules and common infections. Thus, because we corrected for perceived demands in our analysis before we corrected in the last step for sleep quality and fatigue, a large part of the association may already have been explained by the level of perceived work demands. Additional analyses in which we correcled for fatigue and sleep quality, but not for work demands, resulted in general in a decrease of the association between work schedules and common infections. These changes were smaller as compared to the effects of adjusting for work-related demands. Because perceived work demands are related to fatigue in other studies, ${ }^{56}$ we feel that sleep disturbances and fatigue could constitute another pathway linking work schedules to common infections. Because sleep deprivation may result in increased susceptibility, shift workers may experience more infections compared to day workers. Altered light-dark cycles, which occur during shift work, are associated with disruptions of normal sleep patterns. ${ }^{57}$ Common perceptions that lack of sleep lowers resistance to infections and that infections develop during or after periods of sleep loss suggest that sleep deprivation is likely to impair immune function. ${ }^{58}$ Disorganization or disturbance of the sleep-wake system interferes with the immunological, neuroendocrine, and thermal systems and contributes to pathological processes. Disruption of these systems is evident in diseases, such as infections. ${ }^{59}$

The data presented in the study have been collected in a large-scale cohort study among employees from 45 different companies. Despite the almost inevitable shortcoming of large cohort studies using questionnaires, "this study gave us the opportunity to study the relationship between common infections and different types of work schedules in a nonexperimental setting with participants observed in a natural enviromment with all the normal every day hassles. The items in the questionnaire concerning the common infections cover representative symptoms for common cold, flu-like illness and glastroenteritis. However, self-reports of gastroemteritis may also include reports of gastrointestinal disturbances in addition to actual infections, which are common complaints among shift workers. We are aware of the fact that self-reported illnesses 
may lead to under or over reporting. A study on the comparison between self-assessed and observer-assessed presence of colds, however, has demonstrated strong convergence between self-assessments of colds and physician ratings. ${ }^{60}$ With regard to work schedules, selection into shift work and outflow of less healthy shift workers moving from shift to daytime work might lead to an underestimation of the effects of shift work ${ }^{19.23}$

Future studies could aim at the incidence of common infections among employees in different work schedules. Furthermore, if might be relevant to study effects of the direction of shift rotation in relation to the occurrence of infections, because it is argued that sysitems with a forward rotation may result in fewer problems for the shift worker than systems with a backward rotation. ${ }^{61}$ A forward rotating system is considered to be healthier because in the absence of external cues the sleep-wake and other circadian rhythms rum with a period of approximately 25 hours so sleep occurs later and later. ${ }^{61.62}$

In summary, the present study showed that shift work is associated with a higher prevalence of common cold, flu-like illness, and gastroenteritis compared to day work. Shift work was further associated with differences in health, health behavior, sleep, fatigue and perceived job characteristics, which constitute factors that should be taken into account in future studies examining the relationship between work schedules and health outcomes. More insight in these factors can be a starting point for interventions, when it is not feasible to change work schedules.

\section{ACKNOWLEDGEMENTS}

The Maastricht Cohort Study is part of the Netherlands concerted research action on "Fatigue at work" granted by the Netherlands Organization for Scientific Research. This study was supported by grants from the Netherlands Organization for Scientific Research (NWO grants no. 580-02.254 and no. 580-02.201). The authors would like to thank LGPM van Amelswoort, PhD, for his valuable advice concerning the statistical analyses.

\section{REFERENCES}

1. Feeney $A$. North $F$. Head J Canner R, Marmot M. Socioeconomic and sex differentials in reason for sickness absence from the Whitehall II study. Occup Enwiron Med 1998:55:91-8.

2. Graham NM, Douglas RM. Ryan P. Stress and acute respiratory infection. Am J Epidemiol $1986,124(3), 389-401$

3. Cobb IM, Steptoe A. Psychosocial stress and sulsceptibility to upper respiratory tract illmess in an adult population sample. Psychosom Med 1996;58(5):404-12.

4. Cohen S. Tyrrell DA, Smith A.P. Psychological stress and susceptibility to the common cold. N Engl J Med 1991:325(9):606\%12

5. Cohen S, Frank E, Doyle Wu, Skoner DP, Rabin BS, Gwaltney JM, Jr. Types of stressors thath increase susceptibility to the common cold in healthy adults. Health Psychol 1998:17(3):21423. 
6. Takkouche B, Regueira C, Gestal Otero JJ. A cohort study of stress and the common cold. Epidemiology 2001;12(3):345-9.

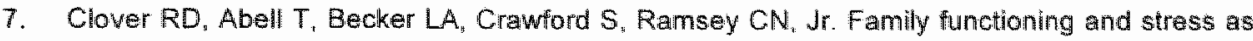
predictors of influenza $B$ infection. J Fam Pract 1989;28(5);535-9.

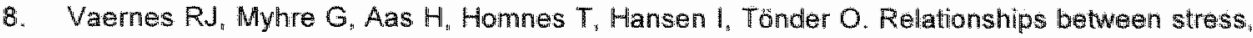
psychological factors, health, and immune levels among military aviators. Work Stress $1991 ; 5(1): 5-16$.

9. Endresen IM, Ellertsen B. Endresen C. Hjelmen AM, Matre, R, Ursin, H. Stress at work and psychological and immunological parameters in a group of Norwegian lemale bank employees. Work Stress 1991;5(3):217-27.

10. Ursin $H$, Mykletun $R$, Tönder $O$, Vaernes $R$, Relling $G$, Isaksen $E_{\text {s }}$ et al. Psychological stressfactors and concentrations of immunoglobulins and complement components in humans. Scand J Psychal 1984;25(4):340-7.

11. Mohren DCL, Swaen GMH, Borm P.JA, Bast A, Galama JMD. Psychological job demands as a risk factor for common cold in a Dutch working population. J Psychosom Res 2001;50:21-7.

12. Costa $G$. The impact of shift and night work on health. Appl Ergon 1996,27(1):9-16.

13. Smith L. Macdonald I, Folkard S. Tucker P. Industrial shift systems. Appl Ergon 1998:29(4):273-80.

14. Akerstedt T. Psychological and psychophysiological effects of shift work. Scand J Work Environ Health 1990;16(Suppl 1):67-73.

15. Härmä M, Tenkanen L, Sjobblom T, Alikoski T, Heinsalmi P. Combined effects of shift work and life-style on the prevalence of insomnia, sleep deprivation and daytime sleepiness. Scand J Work Environ Health 1998;24(4):300-7.

16. Bohle $P$, Tilley AJ. The impact of night work on psychological well-being. Ergonomics 1989;32(9):1089-99.

17. Monk TH, Folkard S. Making shift work tolerable. LondonMashington: Taylor \& Francis; 1992.

18. Walker J. Social probtems of shiftwork. In: Folkard S, Monk TH, eds. Hours of work. Temporal factors in work-scheduling. New York: John Wiley \& Sons:" 1985. p. 211-25.

19. Boggild $H$, Knutsson A. Shift work, risk factors and cardliovascular disease. Scand J Work Environ Health 1999:25(2):85-99.

20. Knutsson $A_{4}$ Akerstedt $T$, Jonsson $B G$, Orth-Gomér $K$. Increased risk of ischaemic heart disease in shift workers. Lancet 1986;8498(2):89-92.

21. Tenkanen $L$, Sjöblom $T$, Kalimo R, Alikoski T, Härmá M. Shift work, occupation and coronary heart disease over 6 years of follow-up in the Helsinki Heart Study. Scand $』$ Work Environ Health $1997 ; 23(4): 257-65$.

22. Kristensen TS. Cardiovascular diseases and the work environment. A critical review of the epidemiologic literature on nonchemical factors. Scand J Work Environ Heallh 1989:15(3):16579

23. Van Amelswoort LPGM. Cardiovascular risk profile in shift workers. Cardiac control, biological and lifestyle risk factors. Wageningen: Wageningen University: 2000 .

24. Gordon NP, Cleary PD. Parker CE, Czeisler CA. The prevalence and health impact of shiftwork. Am J Public Health 1986;76(10):1225-8.

25. Harrington JM. Shift work and health. A critical review of the literature on warking hours. Ann Acad Med Singap 1994:23(5):699-705.

26. Curti R, Radice L. Cesana GC, Zanettini R, Grieco A. Work stress and immune system: Lymphocyte reactions during rotating shift work. Preliminary results. Med Lav 1982:73(6):5649.

27. Kobayashi F. Furui $H$, Akamatsu $Y$, Watanabe T. Horibe H. Changes in psychophysiological functions during night shift in nurses. Influence of changing from a full-day to a half-day work shift before night duty. Int Arch Occup Enwiron Health 1997;69(2):83-90.

28. Brown R, Pang G, Husband AJ, King MG. Suppression of immumity to influenza virus infection in the respiratory tract following sleep disturbance. Reg Immunol 1989;2(5):32 1-5.

29. Regestein QR, Monk TH. Is the poor sleep of shift workers a disorder? Am J Psychiatry 1991:148(11):1487-93. 
30. Cohen S, Doyle WJ. Skoner DP, Rabin BS, Gwaitney JM, Jr. Social ties and susceptibility to the common cold. JAMA 1997;277(24):1940-4.

31. Mohren DCL; Swaen GMH, Kant U, Borm PJA, Galama JMD. Assaciations between common infections and fatigue in a Dutch working population: Results of the Maastricht Cohort Study on Fatigue at Work. Eur J Epidemiol in press 2002.

32. Kiecolt Glaser JK, Glaser R. Methodological issues in behavioral immunology research with humans. Brain Behav Immun 1988:2(1):67-78.

33. Nieman DC. Exercise, upper respiratory tract infection, and the immune system. Med Sci Sports Exere 1994:26(2):128-39.

34. Cohen $S$, Tyrrell DA, Russell MA, Jarvis MJ. Smith A.P. Smoking alcohol consumption, and susceptibility to the common cold. Am J Public Health 1993;83(9):1277-83.

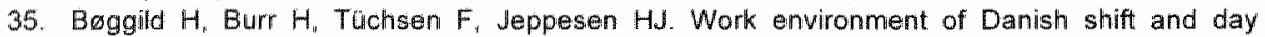
workers. Scand J Work Enwiron Health 2001;27(2):97-105.

36. Jansen NWH, Kant Id, Nifhuis FJN, Van den Brandt PA. Work schedules as risk factors for need for recovery and fatigue: Results from the Maastricht Cohort Study after one year followup. Shiftwork International Newsletter $2001,18(1): 52$

37. Jansen $N$ WW, Kant IJ. Need for recovery related to working time arrangements: results from the Maastricht Cohort Situdy on fatigue at work, Int J Behav Med 2000;7(Suppl 3):S9.

38. Parkes KR. Shittwork, job type, and the work environment as joint predictors of health-related outcomes. J Occup Health Psychol 1999:4(3):256-68.

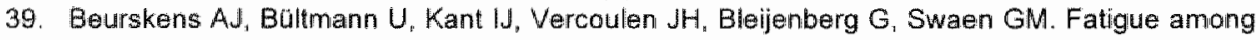
working people: validity of a questionnaire measure. Occup Environ Med 2000;57(5):353-7.

40. Kant IJ, Beurskens AJHM, Schröer CAP, Nijhuis FJN, Van Schayck CP, Van den Elzen HJ, et al. De Maastrichtse Cohort Studie naar langdurigle psychische vermoeidheid in de arbeidssituatie [The Maastricht Cohort Study on fatigue at work]. TBV 2000;8(8):226-32.

41. Bültmann $U$. Kant $I J$, Kasl $S$, Beurskens $A$, Van den Brandt $P$. Fatigue and psychological distress in the working population: Psychometrics, prevalence, and correlates. J Psychosom Res 2002;52(6):445-52.

42. Central Bureau of Statistics. Standaard Beroepenclassificatie 1992 [The Netherlands Standard Classification of Occupations 1992]. 's-Gravenhage: SDU/uitgeverij; 1993

43. Houtman I. Reliability and validity of the Dutch version of the Karasek Job Content Questionnaire. In: NIOSH/APA conference on Stress, Work, and Health. Washington DC: APA: 1995.

44. Karasek RA. The Job Content Questionnaire and User's Guide (version 1.1). Los Angeles: Department of Industrial and Systems Engineering, University of Southern California; 1985.

45. Van Veldhoven M, Meijman TF. Het imeten van psychosociale arbeidsbelasting met een vragenlijst: de vragenlijst beleving en beoordeling van de arbeid (VBBA) [The measurement of psychosocial job demands with a questionnaite (VBBA)]. Amsterdam: NIA; 1994.

46. Gründemann RWM, Smulders PWG, De Winter CR. Handleiding Vragenlijst Arbeid en Gezondheid [Manual, Questionnaire on work and health]. Lisse: Swets \& Zeitlinger; 1993.

47. Vercoulen $J H$, Swanink CM, Fennis JF, Galama JM, Van der Meer JW, Bleijenberg G. Dimensional assessment of chronic fatigue syndrome. $J$ Psychosom Res 1994;38(5):383-92.

48. Bultmann U, De Vries $M$. Beurskens $A J H M$, Bleijenberg $G$, Vercoulen JHMM, Kant IJ. Measurement of long-term fatigue at work in the Maastricht Cohort Study: Determination of a cutoff point J Occup Health Psychol 2000:5(4):411-6.

49. Totterdell P, Spelten $\mathbb{E}$, Smith L, Barton J, Folkard, S. Recovery from work shifts: How long does it take? J Appl Psychol 1995;80(1):43-57

50. Knauth P. The design of shift systems. Ergonomics 1993:36(1-3):15-28.

51. Knauth P. Designing better shift systems. Appl Ergon 1996;27(1):39-44.

52. Endresen IM, Vaernes $\mathbb{R}_{1}$ Ursin $H_{1}$, Tönder $O$. Psychological stress-factors and concentration of immunoglobulins and complement components in Norwegian nurses. Work Stress 1987:1:36576.

53. Kawakami $\mathbb{N}$, Tanigawa $T$. Araki $S$, Nakata A, Sakurai $S$, Yokoyama $K$, et al. Effects of job strain on helper-inducer (CD4+CD29+) and suppressor-inducer (CD4+CD45RA+) $T$ cells in Japanese blue-collar workers. Psychother Psychosom 1997:66(4):192-8. 
54. Akerstedt $T$. Is there an optimal sleep-wake pattern in shift work? Scand $J$ Work Environ Health $1998: 24$ (Suppl 3):18-27.

55. Rutenfranz $J$, Colquhoun WP, Knauth $P$, Ghata JN. Biomedical and psychosocial aspects of shift work. A review. Scand J Work Enwiron Health 1977;3(4):165-82.

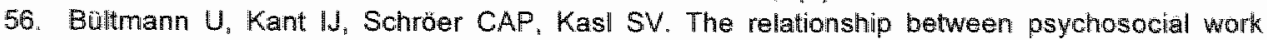
characteristics and fatigue and psychological distress. Int Arch Occup Environ Health 2002; 75: $259-66$.

57. Toth LA, Regh JE. Effects of sleep deprivation and other stressors on the immune and inflammatory responses of influenza-infected mice. Life Sci 1998;63(8); 701-9.

58. Tath LA. Sleep, sleep deprivation and infectious disease: Studies in animals. Adv Neuroimmunol 1995;5:79-92.

59. Moldofsky H. Sleep and the immune system. Int J Immunopharmac 1995;17(8):649.54.

60. Macintyre $S$, Pritchard $C$. Comparisons between the self-assessed and observer-assessed presence and severity of colds. Soc Sci Med 1989;29(11):1243-8.

61. Barton J, Folkard S. Advancing versus delaying shift systems. Ergonomics 1993;36(1-3):59-64.

62. Van Amelswoort LPGM, Schouten EG, Maan AC, Swenne KA, Kok FJ. 24-Hour heart rate variability in shift workers: Impact of shift schedule. J Occup Health 2001:43:32-8. 


\section{Antecedents and consequences of work-family conflict: A prospective cohort study}

Nicole WH Jansen ${ }^{1}$

IJmert Kant"

Tage S Kristensen ${ }^{2}$

Frans JN Niijhuis ${ }^{3}$

\footnotetext{
Department of Epidemiology, Maastricht University, Maastricht, The Netherlands ${ }^{2}$ National Institute of Occupational Health, Copenhagen, Denmark

${ }^{3}$ Department of Health Organization, Policy and Economics, Maastricht University, Maastricht, The Netherlands
} 


\section{ABSTRACT}

This study examined both risk factors for the onset of work-family conflict and consequences in terms of need for recovery and prolonged fatigue for men and women separately. Two-year follow-up data from the Maastricht Cohort Study on "Fatigue at Work" ( $n=12,095)$ were used. At baseline, the prevalence of work-family conflict was $10.8 \%(9.0 \%$ in women; $11.1 \%$ in men), the cumulative incidence at one year follow-up was $5.1 \%$. For men, several work-related demands, shift work "job insecurity, conflicts with coworkers or supervisor, having full responsibility for housekeeping, and having to care for a chronically ill child or other family member at home were risk factors for the onset of work-family conflict, whereas decision latitude and coworker and supervisor sociall support protected against work-family conflict. In women, physical demands, overtime work, commuting time to work, and having dependent children were risk factors for work-family conflict, whereas domestic help protected against work-family conflict at one year follow-up. Work-family conflict was further shown to be a strong risk factor for the onset of elevated need for recovery from work and fatigue. 


\section{INTRODUCTION}

The increasing participation of women in the workforce, ${ }^{1-3}$ the greater numbers of working single parents and dual-earner families, ${ }^{4}$ as well as the upcoming 24-hour society are just a few examples of trends providing employees with challenges in juggling work and family life in today"s society. Multiple role pressures experienced by women and men render work-family conflict virtually inevitable. ${ }^{5}$ Work-family conflict is defined as a form of interrole conflict in which the role pressures from the work and family domains are mutually incompatible in some respect. ${ }^{*}$ Work-familly conflict is a perception of insufficient energy and/or time to successfully perform work and fanily roles. ${ }^{7}$ Research suggests that conflict between work and family is reciprocal in nature in that work can interfere with family and family can interfere with work. ${ }^{8.9}$ In some studies, gender differences with regard to the experience of work-family conflict are reported. ${ }^{10-12}$

Different work-related factors and factors in the private situation have been associated with work-family conflict. Examples of work-related factors associated with work-family conflict are having a fultime job, ${ }^{13}$ work schedule inflexibility, ${ }^{14}$ shift work, ${ }^{4,15,16}$ a high quantitative workload, ${ }^{2}$ and lack of supervisor social support. ${ }^{13,17}$ Examples of nonworkrelated factors associated with work-family conflict are the presence of children at home, ${ }^{18,19}$ having a partner who works overtime frequently, ${ }^{2}$ and reporting stressful nonwork events or demands. "Whereas there is extensive literature on antecedents of work-family conflict, most studies, however, have relied on cross-sectional analyses, thus prohibiting assertions on causality of relations between antecedents and workfamily conflict. The very same is true for studies on the consequences of work-family conflict. Allen et al. ${ }^{9}$ noted in their review several (mental) health-related outcomes associated with work-family conflict. Consequences associated with work-family conflict were, for example, job dissatisfaction, job burnout, psychological distress, depression, life dissatisfaction, and marital dissatisfaction. However, because imost research on the consequences of work-family conflict also has been cross-sectional in nature, the direction of influence is difficult to interpret. Hence, a strong need exists for longitudinal studies to examine prospective relationships between antecedents and consequences of work-family conflict. $9.20-22$

In the present study, we aimed to address this need for longitudinal studies on antecedents and consequences of work-family conflict by using data of the Maastricht Cohort Study, a prospective cohort study on fatigue at work among Dutch employees. Because work-family conflict is associated with insufficient energy, it is likely that consequences of work-family conflict can be found in the development of elevated need for recowery from work and fatigue. Need for recovery represents short-term effects of a day of work ${ }^{23,24}$ and was defined as the need to recuperate from work-induced fatigue. primarily experienced after a day of work. ${ }^{25}$ Need for recovery from work can be recognized in the off-work situation by feelings of "wanting to be left alone for a while", or "having to lie down for a while". 24 Repeated insufficient recovery from work is related to health problems $s^{23,26}$ and is assumed to be related to fatigue. In our study, fatigue is seen as a subjective sensation with cognitive and behavioral components. Furthermore, we will only deal with fatigue persistent over a period of several days, also called prolonged 
fatigue. Prolonged fatigue is not easily reversible in the short-term and is not taskspecific ${ }^{27}$ This prolonged fatigue affects the individual's performance in the work and home setting and may lead to sick leave and work disability. ${ }^{28.29}$ Both need for recovery from work and prolonged fatigue are thought to have a multifactorial etiology, in which work-related, nonwork-related factors, and individual characteristics are inwolved.

To structure the complex relationship between predictors and outcomes of work-family conflict, the Conservation of Resources (COR) theory ${ }^{30.31}$ could constitute an appropriate framework. The COR theory was already applied to work-family conflict in an earlier study by Grandey and Cropanzano. ${ }^{7}$ In general, the COR model proposes that individuals strive to obtain, retain, protect, and foster those things that they value. These valued entities are termed resources and include objects, conditions, personal characteristics, and energies. ${ }^{31,32}$ According to COR theory, psychological stress occurs when individuals are threatened with resource loss, lose resources, or fail to gain resources after resource investment. ${ }^{30}$ As more conflict and/or demands are experienced in one domain, fewer resources are available to fulfill one's role in another domain. ${ }^{7}$ Experiencing high levels of conflict or demands at work might tap available resources and leave fewer resources available for family demands ${ }^{7}$ and vice versa. Thus, both demands at work and at home that draw on employee's resources can result in loss, whereas supportive elements may add to employees' resources and constitute resource gains. Hence, work-family conflict might be considered a reaction to the situation where the resources of the employee are being threatened, depleted or even lost. In line with work-family conflict being associated with insufficient energy and time resources, we hypothesized that important work-related factors, such as overtime work, psychological job demands and physical demands, but also demands in the private situation, would predict the onset of work-family conflict over time. We further hypothesized that supportive elements at work and at home, such as supervisor social support and domestic help, are protective against work-family conflict. The COR model proposes that conflict results in stress because resources, of time and energy, for example, are lost in the process of juggting both work and family roles. ${ }^{7}$ If work.family conflict sustains, that is, when depleted resources are maintained and/or when there is a lack of resource gain, then adverse consequences with regard to mental health might develop. We hypothesized that consequences of work-family conflict would then be the development of elevated need for recovery from work and fatigue.

The aims of the present study were to: (1) describe characteristics, prevalence and cumulative incidence of work-family conflict among employees in the Maastricht Cohort Study: (2) investigate antecedents at baseline in the work and private situation as risk factors for work-family conflict after one year follow-up; (3) examine whether work-family conflict constitutes a risk factor in the development of elevated need for recovery and/or fatigue in the working population; and (4) explore possible gender differences in the above relationships. 


\section{Methods}

\section{Sampling and procedures}

The present study is based on two-year follow-up data from the Maastricht Cohort Study on "Fatigue at Work", a prospective study on fatigue in the working population. 33,34 Employees were followed by means of self-administered questionnaires, which they received every four months. Once a year employees received an extensive questionnaire with items on work-related factors, demographics, nonwork-related factors, and health factors, as well as on work-family conflict, need for recovery and fatigue. Twice a year employees received a short questionnaire that captured mainly outcome measures. In May 1998, a total of 26,978 employees from 45 companies and organizations received a letter at home, inviting participation, and the self-administered baseline questionnaire. A reminder was sent out after two weeks. After six weeks, a brief nonresponse questionnaire was sent to a random subsample of 600 nonrespondents. Nonresponse analyses yielded no significant differences between respondents and nonrespondents regarding demographic characteristics. Nonrespondents were somewhat less, likely to report difficulties in work execution, fatigue complaints, and sick leave.

Altogether, 12,161 employees completed and returned the baseline questionnaire (response rate of $45 \%$ ). Sixty-six questionnaires were excludied from analysis because of technical reasons or because inclusion criteria were not met. Included were employees aged 18-65 years with a minimum employment of $50 \%$. The baseline (TO) cohort consists of $8840(73 \%)$ men and $3255(27 \%)$ women. All employees who returned the baseline questionnaire (TO) received the two short questionnaires, T1 in September 1998 (response rate $87.6 \%, n=10,592$ ) and $\mathrm{T} 2$ in January 1999 (response rate $84.9 \%$. $n=10,270$ ), as well. Employees returning the baseline questionnaire and at least one of the short questionnaires (T1 and/or T2) received the extensive questionnaire T3 in May 1999 (response rate $79.8 \%, n=9655$ ). Employees returning the $T 3$ questionnaire also received the shorl questionnaires $T 4$ in September 1999 (response rate $74.0 \%, n=8956$ ) and $T 5$ in January 2000 (response rate $71.9 \%, n=8692$ ). Employees who returned the questionnaire at T3 and at least one of the consecuitive short questionnaires (T4 and/or T5) also received the extensive questionnaire T6 in May 2000 (response rate 66.7\%, $n=8070$ ). Further information about the procedure and baseline characteristics has been reported elsewhere. ${ }^{34-36}$

For describing characteristics, prevalence and cumulative incidence of work-family conflict and to examine antecedents in the onset of work-family conflict after one year follow-up, we used the baseline questionnaire (TO, May 1998) and the questionnaire at one year follow-up (T3, May 1999; see Figure 1). Excluded were those employees who reported themselves absent from work because of illness or reported working under modified conditions related to former sickness absence at To and T3. In the Netherlands, many employees, mainly women, often change from fullime to parttime jobs during their career because of an inability to combine work and farmily life adequately. ${ }^{37}$ Because employees with small parttime jobs may have already anticipated or adapted to work- 
family conflict, we further selected employees with minimum working hours of 26 hours per week to describe characteristics and to study antecedents at baseline in the onsel of work-family conflict at one year follow-up specifically, resulting in $n=1098$ for women and $n=5785$ for men.

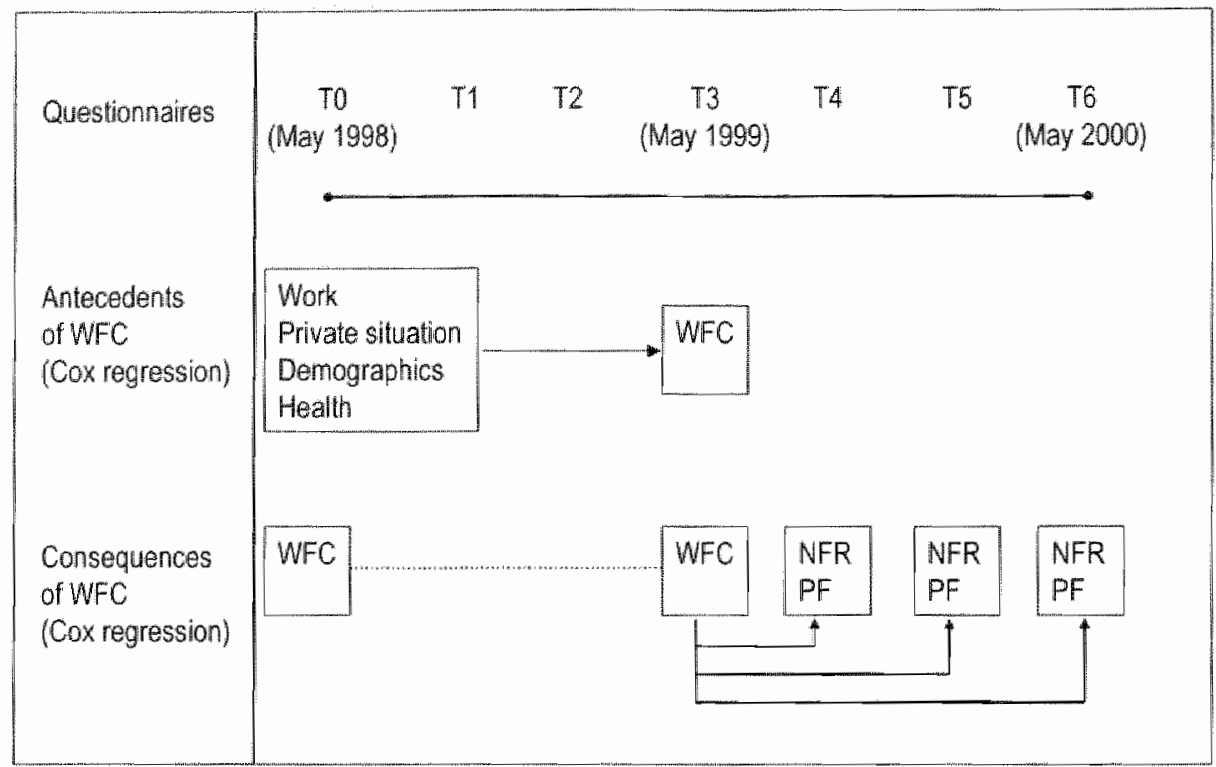

Figure 1 Questionnaines, analyses, and main variables used in the present study, as part of the Maastricht Cohort Study

WFC = Work-family conflact; NFR = Need for pecovery from work; PF = Prolonged fatigue

To examine consequences of work-family conflict in terms of elevated need for recovery and fatigue, we used the questionnaires at TO and T3 to assess the duration of workfamily conflict, and the questionnaires at T4 (September 1999), T5 (January 2000) and T6 (May 2000) to determine whether employees became "need for recovery-and/or fatigue-cases" at one of these consecutive time points (see Figure 1). We excluded those employees who reported themselves absent from work because of illness or reported working under modified conditions related to former sickness absence at TO and $\mathrm{T} 3$. The study population on whom two year follow-up data were available was composed of 6714 employees, of which $5015(74.7 \%)$ were men and $1699(25.3 \%)$ were women.

\section{Measures}

Work-ramily conflict

To assess work-family conflict the following question was used: "Are you able to adequately combine work and family life?". The response to this self-formulated item was yes/no. Work-family conflict was measured at To, T3, and T6. The convergent validity of this measure was tested by comparison with a shortened version of the Survey Work- 
home Interference Nijmegen (SWING) ${ }^{38,39}$ a questionnaire designed to measure types of work-home interference, which was included at T6. This version captured negative interference from work to home (six items; Cronbach's alpha 0.81) as well as negative interference from home to work (five items; Cronbach's alpha 0.74 ) measured on two domains, strain and time aspects. Items were scored on a fourpoint scale ranging from "seldom or never" to "very often". The Cochran-Armitage test for trend revealed that our measure of work-family conflict showed a significant trend $(p<0.001)$ with all items of the SWING on directions and domains of work-home interference, indicating that our operationalization was sufficiently broad to represent an overall measure of work-family confilict.

\section{Work characteristics}

A Dutch version of the Job Content Questionnaire was used to measure psychological job demands, decision latitude, and social support at work. ${ }^{40-42}$ Psychological job demands were assessed by the sum of five items (Cronbach's alpha 0.69). Decision latitude (Cronbach's alpha 0.81) was measured by the sum of two subscales: skill discretion and decision authority. Siocial support was assessed by two scales, each consisting of four items: supervisor support (Cronbach's alpha 0.85) and coworker support (Cronbach's alpha 0.75). The response options varied from "strongly disagree" to "strongly agree" on a four-point scale. For each scale, the total score was calculated by adding the responses to the items. Emotional demands at work were measured by the sum of five items, ranging from 0 to 5 (Cronbach's alpha 0.60). The questions were derived from a Dutch questionnaire on Work and Health, ${ }^{43}$ the Dutch Questionnaire on the Experience and Assessment of Work, ${ }^{44}$ and one self-formulated item. To study the prevalence of work-family conflict in different work categories (Table 1), the total scores of psychological job demands and decision latitude scales were grouped into tertilles, resulting in low, medium, and high levels of psychological job demands and decision latitude. For both supervisor social support and coworker support, the distribution of the total scores did not allow to group into tertiles. Therefore, these scalles were dichotomized at the median. Total scores of emotional demands were divided into three groups, resulting in no, low and high emotional demainds. To assess whether employees perceived their work as physically demanding, one item of the Dutch questionnaire on Work and Health (VAG) ${ }^{43}$ was used. Two items from the Dutch Questionnaire on the Experience and Assessment of Work ${ }^{44}$ were used to measure conflicts with coworker, and conflicts with supervisor. Job insecurity was queried with one item. The response to each item was yes/no. In addition, employees provided information about their working hours per week ( $>40$ hours, $36-40$ hours, $26-35$ hours, and $\leq 25$ hours), flexible working hours, regular overtime work, work schedules (day work versus shift work), and commuting time to work ( $<30$ minutes, 30 to 60 minutes, $>60$ minutes).

\section{Characteristics of the private situation}

A total of seven items were used to assess characteristics of the private situation. The first item concerned family status (living alone, cohabiting with partner, living with parents). "Demands at home" were measured by four items (Having dependent children. Caring for somebody with a chronic disease/handicap at home, Caring for family/friend outside home, Responsibility for housekeeping). "Support at home" was measured by 
one item on domestic help. Another item assessed the presence of life events, such as divorce, accident, or severe illness during the past year. All items were self-formulated and the response to each item was yes/no.

\section{Need for recovery from work}

Need for recovery from work was assessed with a scale from the Dutch Questionnaire on the Experience and Assessment of Work (VBBA). ${ }^{26}$ The scale contains 11 dichotomous items representing short-term effects of a day of work. All items were recoded in such a way that higher scores indicate more complaints, that is, a higher need for recovery. The recoded scores are presented in a range from 0 to 100 . The Cronbach's alpha of the scale is $0.78 .^{25}$ Examples of items in the scale are "I find it hard to relax at the end of a working day" and "My job causes me to feel rather exhausted at the end of a working day. ${ }^{26}$ There is no existing cutoff point to classify cases with very high scares on the scale. In the present study, the upper quartile was used to define a contrast between employees with a high versus low-medium need for recovery.

\section{Fatigue}

The Checklist Individual Strength (CIS) was used to measure prolonged fatigue. ${ }^{45}$ The CIS (Cronbach's alpha total scalle 0.93 ) is a 20 -item questionnaire developed to measure several aspects of prolonged fatigue. Whereas the items of the Need for Recovery scale are concerned with the recuperation period after one day of work and represent shortterm effects, the items of the CIS represent prolonged fatigue, asking employees how they felt during the past two weeks. The CIS is a self-report instrument consisting of four factors: subjective experience of fatigue, concentration, motivation, and physical activity level. Items of the CIS are scored on seven-point Likert scales. Higher scores indicate a higher degree of fatigue, more concentration problems, reduced motivation or less activity. A composite CIS-total score, ranging from 20 to 140 , is constructed by adding the individual's scores on the four factors. A CIS-total cutoff point of $>76$ was derived for use in the working population, with employees scoring $>76$ designated as probable cases of prolonged fatigue. Details about the prevalence and cutoff point for fatigue have been reported elsewhere. ${ }^{33.36}$

\section{Demographic and health factors}

Employees provided information on gender, age, educational level, and the presence of a long-term disease through self-report in the questionnaires.

\section{Statistical anallysis}

All analyses were conducted for men and women separately because of earlier reported gender differences with regard to work-family conflict. ${ }^{10-12}$ Multivariate survival analyses using Cox regression were conducted to examine the role of both antecedents and consequences of work-familly conflict (see Figure 1). Explorative data analysis using curves of hazard in time for studying the time course of both the antecedents and consequences revealed that, in general, the effects of antecedents and consequences of work-family conflict were vanished after one year. Therefore, a follow-up period of one year was chosen for both antecedents and consequences. Multivariate survival analyses 
using Cox regression were performed in two steps to examine the role of antecedents, measured at baseline in 1998 (TO), in the onset of work-familly conflict after one year follow-up in 1999 (T3). In these analyses, all employees reporting conflict between work and family life at baseline (TO) were excluded. In a first step, relative risks (RRs) and $95 \%$ confidence intervals $(95 \% \mathrm{Cls})$ were calculated for work-family conflict, adjusted for age, presence of a long-term disease, and educational level. Because work-family conflict was associated with need for recovery and fatigue (Table 1), and the probability that those employees who are already fatigued will have a higher risk of work-family conflict, we additionally adjusted the RRs for the continuous baseline need for recovery and fatigue scores in a second step. Finally sigmificant work-related factors and factors in the private situation predicting work-family conflict were entered in a multivariate model to evaluate the simultaneous effect of these variables for men and women separately. To investigate whether work-family conflict predicted the onset of elevated need for recovery or fatigue, multivariate survival analyses using Cox regression were performed, in which we modeled the time to first "need for recovery-caseness" and "fatigue-caseness" at T4, T5, or T6. To investigate whether the duration of work-family conflict influenced the strength of the associations, we distinguished those employees reporting work-family conflict both at baseline (TO) and at one year follow-up (T3), from those reporting work-familly conflict for the first time at T3. In both conditions, the reference group consisted of employees reporting no work-family conflict at both time points. In these analyses, either need for recovery cases or fatigue cases at T3 (1999) were excluded, when that variable was considered the dependent variable. RRs and $95 \%$ Cis were calculated for need for recovery and fatigue, adjusted for age, presence of a long-term disease at T3 and educational level (TO) in the first step. In the second step. we additionally adjusted the RRs for psychological job demands, decision latitude, social support from coworkers and supervisors, emotional and physical demands, work schedule and overtime work at T3. In the third step the RRs and 95\% Cls were additionally adjusted for responsibility for housekeeping and having dependent children at T3. Further statistical procedures included Chi-square tests and independent samples T-tests. The significance level for all statistical tests was fixed at $p<0.05$. Data were analyzed using SPSS $9.0^{46}$ and SAS. ${ }^{4 \%}$

\section{RESULTS}

\section{Work-family conflict: characteristics, prevalence and incidence}

The prevalence of work-family conflict was $10.8 \%(n=7.41), 9.0 \%$ in women $(n=99)$ and $11.1 \%$ in men ( $n=642)$. The prevalence of work-family conflict among cohabiting employees with care for homeliving children was $11.8 \%(n=421), 10.3 \%$ in women $(n=28)$ and $11.9 \%$ in men $(n=393)$. The prevalence of work-family conflict among cohabiting employees without care for home living children was $8.5 \%(n=194), 8.2 \%$ in women $(n=44)$ and $8.6 \%$ in men $(n=150)$. The prevalence of work-family conflict among employees living alone was $11.7 \%(n=78), 10.2 \%$ in women $(n=19)$, and $12.3 \%$ in men $(n=59)$. The cumulative incidence of work-family conflict at one year follow-up (T3) was 
Table 1 Prevalence of work-family conflict in different work and home categories for men $(n=5785)$ and women $(n=1098)$ separalidy at baseline me asurement (May 1998)

\begin{tabular}{|c|c|c|c|c|c|}
\hline & & \multicolumn{4}{|c|}{ Work-family confict (\%) } \\
\hline & & Men & p value & Women & $\rho$ walue \\
\hline \multirow{6}{*}{$\frac{\text { Totai study }}{\text { Age (years) }}$} & & 11.1 & & 9.0 & \\
\hline & $\leq 25$ & 17.7 & 0.000 & $\$ 13$ & 0.149 \\
\hline & $26-35$ & 15.2 & & 7.9 & \\
\hline & $36-45$ & 11.8 & & 11.2 & \\
\hline & $46-55$ & 8.0 & & 6.5 & \\
\hline & $\geq 56$ & 6.4 & & $-*$ & \\
\hline \multirow[t]{7}{*}{ Highest educational level } & Primary school & 12.4 & 0.001 & 13.3 & 0.017 \\
\hline & Lower wocallional & 14.9 & & 15.0 & \\
\hline & Lower secondary & 8.8 & & 89 & \\
\hline & intemediate vocational & 11.1 & & 4.9 & \\
\hline & Secondary schoal & 8.0 & & 10.8 & \\
\hline & Higher wocalional & 9.9 & & 8.1 & \\
\hline & Uniwersity & 12.0 & & 15.0 & \\
\hline \multirow[t]{2}{*}{ Work schedule } & Day work & 8.0 & 0.000 & 7.8 & 0.005 \\
\hline & Shift work & 18.7 & & 13.9 & \\
\hline \multirow[t]{2}{*}{ Overtime wark } & Yes & 12.6 & 0.000 & 10.7 & 0.071 \\
\hline & No & 9.6 & & 7.5 & \\
\hline \multirow[t]{3}{*}{ Psychological job denands } & High & 16.4 & 0.000 & 15.3 & 0.000 \\
\hline & Medium & 9.4 & & 8.9 & \\
\hline & LOW & 7.1 & & 3.2 & \\
\hline \multirow[t]{3}{*}{ Decision latitude } & High & 98 & 0.000 & 7.2 & 0.002 \\
\hline & Medium & 8.5 & & 6.8 & \\
\hline & Low & 15.6 & & 13.4 & \\
\hline \multirow[t]{3}{*}{ Emotional demands } & High & 17.7 & 0.000 & 12.5 & 0.012 \\
\hline & Medium & 11.0 & & 7.6 & \\
\hline & No & 7.2 & & 6.7 & \\
\hline \multirow[t]{2}{*}{ Social support colleagues } & High: & 9.1 & 0.000 & 79 & 0.019 \\
\hline & Low & 14.9 & & 12.5 & \\
\hline \multirow[t]{2}{*}{ Social stupport supervisor } & High & 8.0 & 0.000 & 6.2 & 0.000 \\
\hline & Low & 15.0 & & 13.3 & \\
\hline \multirow[t]{2}{*}{ Dependent children } & Yes & 12.1 & 0.005 & 11.0 & 0.166 \\
\hline & No & 9.7 & & 83 & \\
\hline \multirow[t]{3}{*}{ Responsibillyy hou sekeeping } & No & 10.4 & 0.146 & 1.3 & 0.001 \\
\hline & Yes, completely & 13.4 & & 12.8 & \\
\hline & Yes, shared & 11.2 & & 7.5 & \\
\hline \multirow[t]{2}{*}{ Presence of long-term disease } & Yes & 128 & 0.037 & 12.7 & 0.023 \\
\hline & No & 10.6 & & 7.9 & \\
\hline \multirow[t]{2}{*}{ Need for recovery 'case' } & Yes & 23.2 & 0.000 & 24.2 & 0.000 \\
\hline & No & 7.4 & & 5.1 & \\
\hline \multirow[t]{2}{*}{ Falligue 'case' } & Yes & 23.1 & 0.000 & 21.2 & 0.000 \\
\hline & No & 8.5 & & 6.5 & \\
\hline
\end{tabular}

* Wo dalia available 
$5.1 \%(n=315)$ in the total study population, $4.6 \%$ in women $(n=46)$ and $5.2 \%$ in men $(n=269)$.

Table 1 is based on the study population at To (May 1998) and presents the prevalence of work-family conflict in different work and home categories and demographic factors for men and women separately. For men, prevalences of work-family conflict varied according to different categories of age, and educational level. In men, the prevalence of work-family conflict was highest in shift workers, overtime workers, and in men with high psychological job demands, high or low levels of decision latitude and high emotional demands. Men with high supervisor and coworker social support reported lower prevalences of work-familly conflict. Finally, the prevalence of work-family conflict was also higher among men with dependent children, those reporting a long-term disease, and those designated as probable need for recovery and fatigue cases. For women, the prevalence of work-family conflict varied in different levels of education. In women, the prevalence of work-family conflict was higher in shift workers, and in women with high psychological job demands, high or low levels of decision latitude, high emotional demands, and low supervisor and coworker socilal support. Further, the prevalence of work-family conflict was higher among women with full responsibility for housekeeping, those reporting a long-term disease and women designated as probable fatigue and need for recovery cases.

\section{Work-related antecedents of work-family conflict}

As presented in Table 2, substantial prospective associations between work-related factors and work-family conflict were abserved. Work-related factors at baseline predicting work-familly conflict after one year follow-up in men were psychological job demands "physical demands, emotional demands, conflicts with coworkers, conflicts with supervisor, shift work and job insecurity, after adjustment for agle, the presence of a longterm disease, and educational level. Men with more decision latitude, higher coworker sociall support, and higher supervisor social support had a significantly lower risk of developing work-family conflict after adjustment for age, presence of a long-term disease, and educational level. Most RRs were reduced in magnitude after additional adjustment for baseline need for recovery and fatigue scores, although similar trends were observed. The onset of work-family conflict in women was predicted by physical demands, frequent overtime work and commuting time to work after controlling for age, presence of a long-term disease, and educational level. Furthermore, il seemed that shift work could constitute a risk factor for work-family conflict in women as well, although this association just failed to reach statistical significance. Additional adjustment for baseline need for recovery and fatigue scores generally resulted in weaker associations. All other investigated work-related antecedents were nonsignificantly associated with the onset of work-family conflict in women, probably because of the small incidence of workwamily conflict among women after one year follow-up. 
Table 2 Work-releted risk factors for work-tamily conflict after one year follow-wp lor men (n=5143) and women (n) $=999$ separately

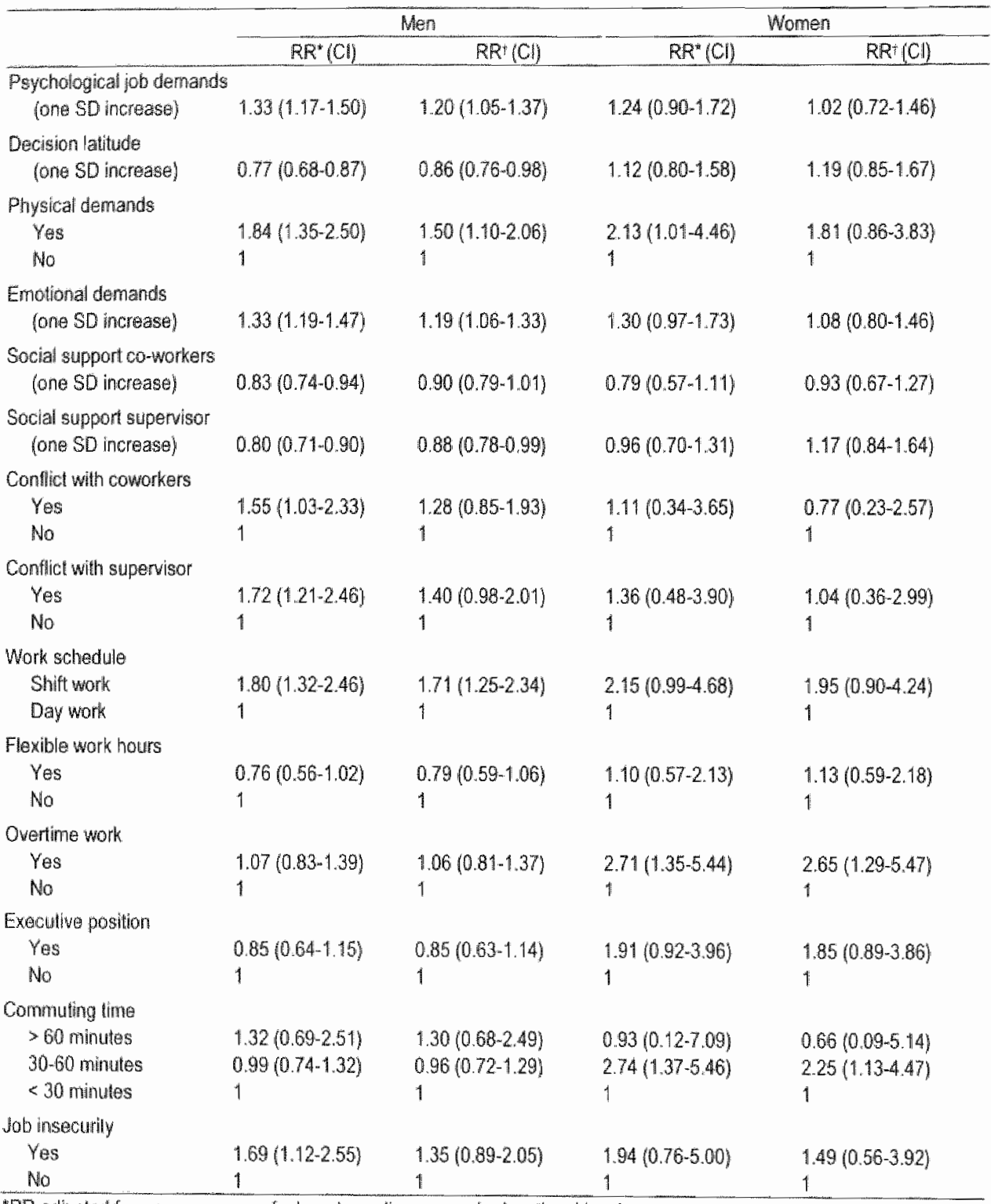

*RR adjusted for age, presence of a long-term disease, and educational level

IRR additionally adjusted for baseline need for recowery and fatigue levels

\section{Characteristics private situation as antecedents of work-family conflict}

Prospective associations between characteristics of the private situation and the onset of work-family conflict are shown in Table 3. In men, having full responsibility for housekeeping and caring for a chronically ill or handicapped child or family member at 
home predicted the ansel of work-family conflict, after controlling for age, presence of a long-term disease, and educational level. When we additionally controlled for baseline need for recovery and fatigue scores, all RRs were reduced in magnitude, though similar trends were observed. In women, having dependent children predicted the onset of work-family conflict, whereas domestic help was associated with less work-family conflict, after adjusting for age, presence of a long-term disease, and educational level.

Table 3 Characteristics of priwate situation as risk factors for work family conflict aftom one year bollow-up for nom $(n=5143)$ and women $(n=999)$ separately

\begin{tabular}{|c|c|c|c|c|}
\hline & \multicolumn{2}{|c|}{ Men } & \multicolumn{2}{|c|}{ Women } \\
\hline & $\mathrm{RR}^{*}(\mathrm{Cl})$ & $\mathrm{RR}^{\mathrm{I}}(\mathrm{Cl})$ & $\mathrm{RR}^{*}(\mathrm{C})$ & $\mathrm{RR}(\mathrm{CH}$ \\
\hline \multicolumn{5}{|l|}{ Family status } \\
\hline Living alone & $1.40(0.92-2.12)$ & $1.31(0.87-1.99)$ & $(0.8010 .34-2.08)$ & $0.81(0.31-2.11)$ \\
\hline Living with parents & $0.83(0.42-1.66)$ & $0.90(0.45-1.81)$ & $1.16(0.33-4.06)$ & $1,13(0.32-3,98)$ \\
\hline Cohabiting with partner & 1 & i & H & 1 \\
\hline \multicolumn{5}{|l|}{ Dependent children: } \\
\hline Yes & $1.06(0.82-1.36)$ & $1.04(0.31-1.34)$ & $1.98(1.00-3,93)$ & $2.09(1.04 \times 4.20)$ \\
\hline No & 1 & 1 & 1 & 1 \\
\hline \multicolumn{5}{|l|}{ Responsibility housekeeping } \\
\hline Yes, completely & $1.65(1.09-2.48)$ & $1.55(1.02-2.33)$ & $0.97(0.27-3.45)$ & $1.06(0.30-3.76)$ \\
\hline Yes shared & $1.13(0.86-1.48)$ & $1.10(0.84-1.45)$ & $0.89(0.26-3.04)$ & $0.98(0.29-3.34)$ \\
\hline Ho & 1 & 1 & 1 & 1 \\
\hline \multicolumn{5}{|l|}{ Domestic help } \\
\hline Yes & $1.23(0.86-1.76)$ & $1.16(0.8)-1.65)$ & $0.41(0.19-0.96)$ & $0.42(0.18 n .97)$ \\
\hline No & 1 & 1 & 1 & 1 \\
\hline \multicolumn{5}{|l|}{$\begin{array}{l}\text { Care chronically ill person at } \\
\text { home }\end{array}$} \\
\hline Yes, partner & $1.29(0.82-2.00)$ & $1.18(0.76-1.84)$ & $0.39(0.05-2.90)$ & $0.34(0.04-2.52)$ \\
\hline Yes, child(ren) & $1.69(1.04-2.74)$ & $1.61(0.99-262)$ & $1.08(0.75-7.99)$ & $0.86(0.11-6.50)$ \\
\hline Yes, family & $2.04(1.13-3.67)$ & $2.04(1.13-3.67)$ & -4 & + \\
\hline No & $\|$ & 4 & 1 & 1 \\
\hline \multicolumn{5}{|l|}{$\begin{array}{l}\text { Responsible care family friend } \\
\text { outside home }\end{array}$} \\
\hline Yes, completely & $0.67(0.09 .48)$ & $0.58(0.09-4.18)$ & + & -1 \\
\hline Yes, shared & $1.61(0.90-2.89)$ & $1.5680 .87-280)$ & $0.98(0,23 \times 4,20)$ & $0.68(0.16-2.94)$ \\
\hline No & 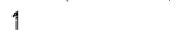 & i & 1 & 1 \\
\hline \multicolumn{5}{|l|}{ Lhe events past year } \\
\hline Yes & $0.92(0.71 \times 1.20)$ & $0.87(0.66-1.13)$ & $1.23(0.65-2.31)$ & $1.14(0.60-2.15)$ \\
\hline Mo & 1 & 1 & 1 & 1 \\
\hline
\end{tabular}

:RP adusted for age, presence of a long-terridisease and sducational level

TRR adiditionaly adjusied for baseiline need for recovery and fatigue levels

* po results avallable because of too lew incident work family conflict cases among women

\section{Multivariate model of antecedents of work-family conflict}

For men, all work-related factors and factors in the private siluation from Tables 2 and 3 that significantly predicted work-family conffict when controlled for age, the presence of a long-term disease and educational level were entered simultaneously in a multivariate model using Cox regression analysis to investigate the simultaneous effects of these 
antecedents. In this analysis we adjusted for age, long-term disease, educationall level and baseline need for recovery and fatigue scores. This multivariate model revealed that psychological job demands (one SD increase) (RR 1.15; Cl 1.00-1.32), shift work (RR 1.59; CI 1.13-2.23) and caring for a chronically ill or handicapped family member at home (RR 2.02, Cl 1.08-3.75) significantly predicted work-family conflict after one year follow-up. For women, the multivariate model revealed that overtime work (RR $2.66 ; \mathrm{Cl}$ $1.25-5.67$ ) and commuting time to work from 30 to 60 minutes (RR 2.91; Cl 1.43-5.89) still significanlly predicted work-family conflict, whereas domestic help at baseline protected against work-family conflict (RR 0.27; $\mathrm{Cl} 0.10-0.72$ ) after one year follow-up.

Table 4 Work-family conflict as a risk lactor for need for recowery and fatigue after one year follow-up

\begin{tabular}{|c|c|c|c|c|c|c|}
\hline & \multicolumn{3}{|c|}{$\begin{array}{l}\text { Need for recovery } \\
\text { Total study population }\end{array}$} & \multicolumn{3}{|c|}{$\begin{array}{l}\text { Faligue } \\
\text { Total study population }\end{array}$} \\
\hline & RRI (C) & $\mathrm{RRt}(\mathrm{Cl})$ & $\mathrm{RPS}(\mathrm{Cl}$ & $\mathrm{RR}(\mathrm{Cl})$ & RRI $(C)$ & $\mathrm{RR}$ (CI) \\
\hline \multicolumn{7}{|l|}{ WFC" } \\
\hline Yes & $1.64(1.24-2.17)$ & $1.39(1.05-1.85)$ & $1.38(1.04-1.84)$ & $1.77(1.43-2.20)$ & $1.45(1.16-1.81)$ & $1.44(1.15-1.80)$ \\
\hline \multirow[t]{3}{*}{ No } & 1 & 1 & 1 & 1 & 1 & 1 \\
\hline & \multicolumn{3}{|c|}{ Men } & \multicolumn{3}{|c|}{ Men } \\
\hline & $\mathrm{RPH}(\mathrm{Cl})$ & $\mathrm{PR}(\mathrm{Cl})$ & $\operatorname{RR}^{* *}(\mathrm{Cl})$ & FRH (CU) & $\mathrm{RR}(\mathrm{Cl})$ & $\mathrm{RR}^{*+1 \mathrm{Cl}}$ \\
\hline \multicolumn{7}{|l|}{ WFC: } \\
\hline Yos & $1.58(1.15-2.17)$ & $1.31(0.95-1.81)$ & $1.30(0.94 \times 1.80)$ & $1.80(1.422 .28)$ & $1.4 .4(1.13-1.84)$ & $1.43(1.12-1.83)$ \\
\hline \multirow[t]{3}{*}{ No } & 1 & 1 & in & 1 & 1 & 1 \\
\hline & \multicolumn{3}{|c|}{ Women } & \multicolumn{3}{|c|}{ Women } \\
\hline & $\mathrm{RR}^{\prime}(\mathrm{C})$ & $\mathrm{RP}(\mathrm{Cl})$ & $\mathrm{RR}^{\mathrm{*}+\mathrm{Cl}}(\mathrm{Cl}$ & $\mathrm{RR}(\mathrm{C})$ & $\mathrm{RPR}(\mathrm{C})$ & $\mathrm{RR}^{\mathrm{nat}}(\mathrm{C})$ \\
\hline \multicolumn{7}{|l|}{ WFC } \\
\hline Yes: & $1.88(1.04 \times 3.39)$ & $1.81\{0.98-3.35\}$ & $1.79(0.97-3.32)$ & $1.61(0.95-2.73)$ & $1.43(0.83-2.45)$ & $1.43(0.83-2.46)$ \\
\hline No & 1 & 1 & 1 & 1 & 1 & 1 \\
\hline \multicolumn{7}{|c|}{ Work-family conffict } \\
\hline \multicolumn{7}{|c|}{ 1 RR adfusted for age. gender and the presence of a long-term disease at T3, and educational level at To } \\
\hline \multicolumn{7}{|c|}{$\begin{array}{l}\text { Additionaly adjusted for psychological job demands, decision latitude, social support from co-workers, social support } \\
\text { from superwisor, emotional and physical demands, work schedule, working hours per week and overtime work at T3 }\end{array}$} \\
\hline \multicolumn{7}{|c|}{ Additionally adiusted for responsibility housekeeping and having dependant children at T3 } \\
\hline \multicolumn{7}{|c|}{ II RR adjusted for age and presence of a long-tem disease at $T 3$ and educational level at To } \\
\hline \multicolumn{7}{|c|}{$\begin{array}{l}\text { Additionally adjusted ly lor psychological job demands, decision latitude, social support from co-workers, social support } \\
\text { from supervisor, emotional and physical demands, work schedule, working hours per week and owertime work at T3 }\end{array}$} \\
\hline
\end{tabular}

\section{Work-family conflict as a risk factor for need for recovery and fatigue}

To examine prospective associations between work-family conflict and need for recovery from work and fatigue (Table 4), either need for recovery cases or fatigue cases at T3 (May 1999) were excluded, when that variable was considered the dependent variable. Table 4 shows, irrespective of the duration of work-family conflict, that employees reporting work-family conflict at $T 3$ had a significantly higher risk for developing an elevated need for recovery and fatigue, when controlling for age, gender, the presence of a long-term disease, and educational level. When we additionally controlled for workrelated factors and factors in the private situation, all RRs were reduced in magnitude, though they remained statistically significant and similar trends were observed. 
Differences between men and women were observed. For example, men who were not able to adequately combine work and family life had a RR of $1.58(\mathrm{Cl} 1.15-2.17)$ for developing elevated levels of need for recovery, after controlling for age, the presence of a long-term disease, and educational level, whereas women had a RR of $1.88(\mathrm{Cl} 1.04-$ 3.39) for developing elevated need for recovery.

\section{Duration of work-family conflict as a risk factor for need for recovery and fatigue}

When selections were made concerning the duration of work-family conflict in time, the size of the group of women became very small. Therefore, results regarding the duration of work-family conflict will be presented for men only (Table 5). As shown in Table 5 , reporting work-family conflict at $T 3$ only (May 1999) was associated with a higher risk of fatigue ( $R R \quad 1.56 ; \mathrm{Cl} 1.11-2.20$ ), when controlled for age, the presence of a long-term disease and educational level as compared with men not reporting work-family conflict. Additionally controlling for work-related factors and factors in the private situation yielded nonsignificant results. When work-family conflict was reported both at TO and T3, men had a substantially higher risk of developing elevated need for recovery and fatigue after adjusting for age, presence of a long-term disease and educational level. When additionally controlled for work-related factors and factors in the private situation, all RRs were reduced in magnitude, though similar trends were observed.

Table 5 Duration of work-family conflict as a risk factor for need for recovery and fatigue in men

\begin{tabular}{|c|c|c|c|c|c|c|}
\hline & \multicolumn{3}{|c|}{ Need for recovery } & \multicolumn{3}{|c|}{ Fatigue } \\
\hline & RRI (Cl) & RR: (Cl) & $\mathrm{RRS}(\mathrm{CI})$ & RRI (Cl) & $\mathrm{RP}^{*}(\mathrm{CH})$ & $\mathrm{RR}^{S}(\mathrm{Cl})$ \\
\hline \multicolumn{7}{|c|}{ WFC al T3 only } \\
\hline Yes & $\begin{array}{l}1.43 \\
(0.92-2.21)\end{array}$ & $\begin{array}{l}1.25 \\
(0.80-1.94)\end{array}$ & $\begin{array}{l}1.24 \\
(0.80 \cdot 1.93)\end{array}$ & $\begin{array}{l}1.56 \\
(1.11-2.20)\end{array}$ & $\begin{array}{l}1.33 \\
(0.94-1.88)\end{array}$ & $\begin{array}{l}1.33 \\
(0.94-1.88)\end{array}$ \\
\hline No & 1 & 1 & 1 & 1 & 1 & 1 \\
\hline \multicolumn{7}{|c|}{ WFC at To and T3 } \\
\hline Yes & $\begin{array}{l}1.95 \\
(1.24-3.06)\end{array}$ & $\begin{array}{l}1.54 \\
(0.95-2.38)\end{array}$ & $\begin{array}{l}1.52 \\
(0.96-2.40)\end{array}$ & $\begin{array}{l}2.21 \\
\{1.60 \cdot 3.05\}\end{array}$ & $\begin{array}{l}1.65 \\
(1.18-2.31)\end{array}$ & $\begin{array}{l}1.64 \\
(1.17-2.29)\end{array}$ \\
\hline No & 1 & 1 & 1 & 1 & 1 & 1 \\
\hline
\end{tabular}

" Work-familly conflict

$\rightarrow \mathbb{R R}$ adjusted for age, gender and the presence of a long-term disease at T3 and educational level at To

- Additionaly adjusted for psychological job demands, decision latitude, sociall support from co-wotkers, social support from supervisior, emotional and physical demands, work scherdule, working hours per week, owertime work al 13

sdd Ationally adjusted * for responsibility housekeeping and having dependent chaldren al T3

\section{DISCusSION}

The present study showed prospective relationships between antecedents and consequences of work-family conflict over time. In our study, the prevalence of workfamily conflict at baseline was $10.8 \%$. Frone et al. ${ }^{48}$ found a work-family conflict of $41 \%$ and also Kinnunen \& Mauno ${ }^{13}$ reported a prevalence of work-family conflict of about $40 \%$. A comparison of these proportions, however, is hindered because of different operationalizations of work-family conflict, different settings, and different gender 
distributions. The cumulative incidence of work-family conflict at one-year follow-up was $5.1 \%$ in the total study population, indicating that work-family conflict can have a relatively long duration in time. We observed a slightly higher prevalence and incidence of work-family conflict among men compared with women, which could seem counter intuitive. Besides the explanation that these findings could be the result of selection of respondents and nonrespondents, in which employees with high work-family conflict or tired employees did not answer the questionnaires, these results could also be the result of selection into the job because women with high family demands could be out of the labor market or have adjusted their job to their family demands to prevent future development of work-family conflict. An example of adjustments in the job can be found in the Dutch situation where the majority of women work partime ${ }^{49}$ or change from fulltime to parttime work during their career, ${ }^{37}$ thus providing them more possibilities for preventing work-family conflict compared with men mostly inwolved in fullime jobs. Therefore, we selected in the present study only employees with minimum working hours of 26 hours per week. After this selection on working hours, the majority of women in the cohort still reported lower working hours per week as compared to the men, mastly involved in 36 to 40 hours per week. Hence, the women in our study may still be somewhat at "advantage", because these lower working hours might enable women to better finetune work and family responsibilities.

Clear antecedents were observed in the onset of work-family conflict, with substantive gender differences in the antecedent variables. Generally, we found support for the COR theory in that demands drawing on employees" resources resulted in work-family conflict, whereas supportive elements that might add to employees' resources protected against work-family conflict. In men, psychological job demands, physical demands, emotional demands, conflicts with coworkers or supervisor, shift work, job insecurity, having full responsibility for housekeeping, and caring for a chronically ill or handicapped child or other family member at home increased the risk for future work-family conflict, whereas decision latitude and coworker and supervisor social support had a protective effect against future work-family conflict. For women, it was found that an extension of the working day, in terms of overtime work and a higher commuting time to work, was especially related to a higher risk of work-family conflict. Also, physical demands, and having dependent children were risk factors in the onset of work-family conflict in women. whereas domestic help protected against work-family conflict. Other studies ${ }^{16.19}$ reported that the presence of children at home was associated with work-family conflict as well. The low number of women reporting work-family conflict after one year follow-up might account for the absence of other significant risk factors for work-family conflict in women. The observed differences in the antecedents of work-family conflict between men and women may also partly depend on different types of jobs, and hence different characteristics of the men's and the women's jobs.

In line with work-family conflic consisting of combined work and home demands, it is. probabile that different combinations of antecedents might strengthen or weaken the effects on work-family conflict. We constructed an overall multivariate model of antecedents, showing that psychological job demands, shift work and caring for a chronically ill or handicapped family member at home still significantly predicted work- 
family conflict after one year follow-up in men. In women, overtime work and commuting time to work were still significantly associated with higher work-family conflict and domestic help with lower work-family conflict after one year follow-up.

Individual characteristics, such as coping strategies, were not included in the present study. Frone et al. ${ }^{50,51}$ reported that intrapersonal characteristics (eg. personality or coping styles) might be important moderators in the relation between work-family conflict and employee health. Probably personal characteristics could also play a role in the relationship between antecedents and the devellopment of work-family conflict. As proposed by the COR model as well, employees with more personal resources, such as self-esteem and adequate coping. might be better able to offset the loss of other resources. ${ }^{7}$ Including personal characteristics in future studies would provide a further refinement of the findings in the present study.

Work-family conflict constituted a strong risk factor for the onset of elevated need for recovery and fatigue. With regard to the consequences of work-family conflict, again substantive gender differences were observed, with the relative risk of need for recovery from work being higher among women. Furthermore, when we took the duration of workfamily conflict into account, the risk of future elevated need for recovery or fatigue substantially increased, like a dose-response relationship. In line with COR theory, an explanation could be that people who are strained by multiple roles may have already often stretched the limits of many of their resources, in terms of time and energy, and thus may be unable to ameliorate the loss because their resource reservoir is already fully taxed ${ }^{52}$ and therefore elevated need for recovery and fatigue levels might ensue. Although confidence intervals overlap, the relationship between work-family conflict and need for recovery from work may be stronger for women than for men. Therefore, it cannot be excluded, as Eckenrode and Gore earlier stated, ${ }^{11}$ that gender is a moderator variable in the relationship between work-family conflict and employee health. A possible explanation for these gender differences can be found in research on gender-role socialization, showing that men are socialized to give higher priority to the breadwinner role, whereas women are socialized to give higher priority to homemaker and motherhood roles. ${ }^{53}$ Other studies have demonstrated that women still retain a greater psychological and behavioral involvement in family work, ${ }^{54,55}$ and that work-family conflict might be more detrimental for employed women, because they have primary responsibility for family roles. ${ }^{56}$ Moreover. Frankenhaeuser et al. ${ }^{57}$ found that female managers were less able to unwind and rellax after work, reflecting their heavy workload, for example, the demands they experience from duties at home, often in conflict with demands related to their paid job. This inability to relax and unwind constitutes a phenomenon, quite similar to the concept of need for recovery, which was also found to be highest in women in the present study.

Although we found work-family conflict to be a clear risk factor in the onset of elevated need for recovery and fatigue, it is equally plausible that work-family conflict is an outcome, rather than a risk factor for need for recovery and fatigue, which was also reflected by the cross-sectional association between work-family conflict and need for recovery and fatigue. Kelloway et al. ${ }^{22}$ for instance, observed that perceptions of work- 
family conflici might have resulted from rather than predicted stress reactions. Hence, it is important for future studies to keep in mind a possible bi-directional causation between work-family conflict and mental health related outcomes such as need for recovery and fatigue.

Work-family conflict was measured with one item asking employees whether they were able to adequately combine work and family life. Obviously, one-item measures raise concern about likelier lower reliability and validity, and this should be kept in mind when interpreting the results. However, because our measure of work-family conflict showed a significant trend with all items of the SWING on directions and domains of work-home interference, we assume that our item was sufficiently broad to represent an overall measure of work-family conflict. In our study only self-report measures were used. Therefore, concern could be raised regarding the possibility of common method variance. However, since we used a longitudinal approach, in which we excluded prevalent cases of the different outcome measures at baseline, the risk of common method variance will be at least somewhat reduced.

In conclusion, the results from this prospective study provide evidence for the predictive effects of both work-related factors and factors in the private situation on work-familly conflict. Work-family conflict itself has also important mental health implications, such as the development of an elewated need for recovery from work and prolonged fatigue. Important issues for future research are to study the direction of work-familly conflict prospectively and to further elucidate different domains of work-family conflict, such as time-based, strain-based and behavior-based conflict. ${ }^{6}$ Within the antecedents of workfamily conflict clear risk factors for work-family conflict were observed. The results offer usefull indications for the development of preventive measures, which can be employed by policy makers in order to try to prevent the development of work-family conflict among employees, such as for instance paying attention to social support at work and limiting overtime hours especially in women. This study extends earlier research in providing longitudinal evidence for the importance of an adequate balance of work and family life among employees in order to prevent or reduce the consequences of work-familly conflict in lerms of high need for recovery from work and prolonged fatigue.

\section{ACKNOWLEDGEMENTS}

The Maastricht Cohort Study is part of the Netherlands concerted research action on "Fatigue at work" granted by the Netherlands Organization for Scientific Research. The present study was supported by grant no. 580-02.201 from the Netherlands Organization for Scientific Research.

\section{REFERENCES}

1. Beatty $C A$. The stress of managerial and professional women: Is the price too high? J Organ Behav 1996:17(3):233-5\%. 
2. Geurts $S$. Rutte $C$, Peeters M. Aintecedents and consequences of work-home interference among medical residents. Soc Sci Med 1999;48(9):1135-48

3. Central Bureau of Statistics. Tijdreeks beroepsbevolking naar geslachi vanaf 1970 ITimo series working population according to gender as from 1970]. Voorburg/heerlen: Cantral Bureau of Statistics; 2002 .

4. Burke RJ Same antecedents and consequences of Work-Family conflict. Soc Behav Pers $1988 ; 3(4): 287-302$

5. Greenhaus JHt. The intersection of work and fanily roles: Individual, interpersonal, and organizational issues. J Soc Behav Pers 1988;3(4):23-44.

6. Greenhaus $J H$, Beutell NJ. Sources and conflict between work and family roles. Acad Manage Rew $1985 ; 10(1): 76-88$.

7. Grandey AA Cropanzano R. The Conservation Of Resources model applied to work-family conflict and straim. J Wocat Behav 1999;54(2):350-70.

8. Frone MR, Russell M, Cooper ML. Antecedents and autcomes of work-family conflict: Testing a model of the work-family interface. J Appl Psychol 1992;77(1):65-78.

9. Allen TD, Herst DEL. Biluck CS, Sutton M. Consequences associated with work-to-family conflict: A review and agenda for future research. J Occinp Health Psychol 2000;5(2):278-308.

10. Duxbury LE, Higgins CA. Gender differences in work-family conflict. J Appl Psychol $1991 ; 76(1): 60-73$

11. Eckenrode J, Gore S. Stress and coping at the boundary of work and family. In: Eckenrode J, Gore $S_{2}$ editors. Stress between work and family. New York: Plenum; 1990, p. 1-16.

12. Gutek BA, Searle S, Klepa L. Rational versus gender role explanations for work-family conflict. $₫$ Appl Psychol 1991;76(4):560-8.

13. Kinnunen U, Mauno S. Antecedents and outcomes of work-family conflict among employed women and men in Finland. Hum Relat 1998;51 (2):157-77.

14. Pleck JH, Staines GL, Lamg L. Comflict between work and family life. Mon Labor Rev $1980 ; 103(3): 29-32$.

15. Loudoun RJ, Bohle PL. Work/Non-work conflict and health in shiftwork: Relationships with family status and social support. Int J Occup Environ Health 1997;3(Suppl 2):571-7.

16. Shamir B. Some antecedents of work-nonwork conflict. J Vocat Behav 1983;23(1):98-111.

17. Thomas LT, Ganster DC. Impact of family-supportive work variables on work-family conflict and strain: A controll perspective. J Appl Psychol 1995,80(1):6-15.

18. Greenhaus JH, Kopelman RE. Conflict between work and nonwork roles: Implications for the career planning process. Human Resource Planning 1981:4(1):1-10.

19. Voydanoff P. Work role characteristics, familly structure demands, and work/family conflict. J Marriage Fam 1988:50:749-61.

20. Bamett RC. Toward a review and reconceptualization of the work/family literature. Genet Soc Gen Psych Monograph 1998:124(2):125m:82.

21. Grant Vellone EJ, Donaldson SI. Consequences of work-family conflict on employee wellibeing over time. Work Stress $2001 ; 15(3): 214-26$

22. Kelloway EK, Gottleb BH, Barham L. The source, nature, and direction of work and family conflict: A llongitudinal investigation. J Occup Health Psychol 1999;4(4):337-46.

23. Meijman T. Mentale belasting en werkstress. Een arbeidspsychologische benadeiring. [Mental strain and workstress. An $1 / 0$ psychology approach]. Assen/Maastricht: Vam Gorcum; 1989

24. Sluiter JK. Frings.Dresen MHW, Van der Beek AJ, Meijman TF. The relation between work induced neuroendocrine reactivity and recovery, subjective need for recovery, and health status. J Psychosom Res 2001;50:29-37

25. Jansen NWH, Kant W, Van den Brandt PA. Need for recovery in the working papulation: description and associations with fatigue and psychological distress. Int I Behav Med $2002,9(4): 322-40$

26. Slutter JK, Van der Beek AJ, Frings-Dresen MHW. The infuence of work characteristics oin the need for recovery and experienced health: A study oin coach drivers. Ergonomics $1999 ; 42(4), 573-83$ 
27. Meijman T, Schaufeli $W$. Psychische vermoeidheid en arbeid; Ontwikkelingen in de A\&Opsychologie [Mental fatigue and work. Developments in Work and Organizational Psychology]. Psycholoog 1996;31)6!236-41.

28. Sehirder CAP. De toename wan arbeidsongeschiktheid wegens psychische aandoeningen [The increase of work disability due to mental disorders]. TBV 1997;5(1):16-23.

29. Van Amelsvoort LPGM, Kant IJ, Beurskens AJHM, Schröer CAP, Swaen GMH. Fatigue as a predictor of work disability. Occup Environ Med 2002:59:71:2-3.

30. Hobfoll SE Conserwation of Resources. A new attempt at conceptualizing stress. Am Psychol $1989 ; 44(3): 513-24$.

31. Hobfoll SE, Shirom A. Conservation of Resources Theory. Applications to stress and management in the workplace. In: Golembiewski RT, editor. Handbook of organizational behawior. New York: Dekker, 2001, p. 57-80.

32. Hobfoll SE. The influence of culture, community, and the nested-self in the stress process: Advancing Conservation of Resources theory. Appi: Psychol: Int Rev 2001:50(3):337-70.

33. Bültmann U, De Vries $M$, Beurskens AJHM, Bleijenberg $G$, Vercoulen JHMM, Kant $Y$. Measurement of prolonged fatigue at work in the Maastricht Cohort Study: Determination of a cuttoff point. J Occup Health Psychol 2000;5(4):411-6.

34. Kant IJ, Beurskens A.JHM Schröer CAP, Nijhuis FJN, Van Schayck CP. Van den Elzen HW, et al. De Maastrichtse Cohort Studie naar langdurige psychische vermoeidheid in de arbeidssituatie [The Maastricht Cohort Study on fatigue at work]. TBV 2000;8(8):226-32.

35. Kant IJ, Bültmann U, Schröer CAP, Beurskens A.JHM, Van Amelswoort LPGM. Swaen GMH. An epidemiological approach to study fatigue in the working population: The Maastricht Cohort Study. Occup Environ Med in press.

36. Bültmann U, Kant IJ, Kasl S, Beurskens A, Van den Brandt P. Fatigue and psychological distress in the working population: Psychometrics, prevalence, and correlates. J Psychosom Res 2002;52(6):445-52.

37. Koopmans I, Stavenuiter MMJ. Meer werken "minder zorgen. Arbeid en zorg in wetgeving en CAO's [More working, less caring. Work and care in legislation and collective labor agreements]. Breukelen: NYFER; 1999.

38. Wagena E, Geurts S. SWING: Ontwikkeling en validering van de 'Survey Werk-thuis Interferentie-Nijmegen" [SWING: development and validation of the "Survey Work-home Interference Nijmegen"]. Gedrag Gezond 2000;28(3):138-57.

39. Van Der Hulst M, Geurts S. Associations between overtime and psychological health in high and low reward jobs. Work Stress 2001:15(3);227-40.

40. Houtman I. Reliability and validity of the Dutch versian of the Karasek Job Content Questionnaire. In: NIOSHIAPA conference on Stress, Work, and Health; Washington, DC: APA: 1995.

41. Karasek RA. The Job Content Questionnaire and User's Guide (version 1.1). Los Angeles: Department of Industrial and Systems Engineering. University of Southern California; 1985.

42. Niedhammer I, Goldberg M, Leclerc A, Bugel I, David S. Psychosocial factors at work and subsequant depressive symptoms in the Gazel cohort. Scand $J$ Work Environ Health $1998 ; 24(3): 197-205$

43. Gründemann RWM, Smulders PWG, De Winter CR. Handleiding Vragenlijst Arbeid en Gezondheid [Manual, Questionnaire on work and health]. Lisse: Swets \& Zeitlinger; 1993.

44. Van Veldhoven $M$. Meijman TF. Het meten van psychosociale arbeidsbelasting met een vragenlijst: de vragenlijst belewing en beoordeling van de arbeid (VBBA) [The measurement of psychosocial job demands with a questionnaire (VBBA)l. Amsterdam: NIA; 1994.

45. Vercoulen $J H$, Swanink CM, Fennis JF, Galama JM, Van der Meer JW, Bleijenberg G. Dimensional assessiment of chronic fatigue syndrome. J Psychosom Res 1994;38(5):383-92.

46. SPSS. Base 9.0 for Windows User's Guide. Chicago: SPSS Inc,; 1998

47. SAS Institute. SAS version 6.12. Cary, North Carolina: SAS Institute; 1989

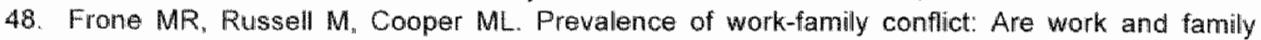
boundaries asymmetrically permeable? J Organ Behav 1992;13:723-9 
49. Gjerdingen D, McGovern P. Bekker M, Lundberg U, Willemsen T. Women's work roles and their impact on health, well-being, and career: Camparisons between the United States, Sweden and The Netherlands. Women Health 2000;3:(4):4-20.

50. Frone MR, Russell M, Cooper ML. Relation of work-family conflict to heaith outcomes: A fouryear longitudinal study of employed parents. J Occup Organ Psych 1997;70(4):325-35.

51. Frone $M^{\prime} R_{n}$ Russell M. Barnes GM. Work-family conflict gender, and health-related outcomes: a study of employed parents in two community samples. J Occup Health Psychal 1996; 1 (1):5769.

52. Wells UD, Hobfoll SE, Lavin J. Resource loss, resource gain, and communal coping during pregnancy among women with multiple roles. Psychol Women Quart 1997;21(4):645-62.

53. Major B. Gender, entitlement, and the distribution of family labor. J Soc Issues $1993 ; 49: 141$ m 59 .

54. Lewis $\mathrm{S}, \mathrm{Cooper} \mathrm{CL}$. The work-family research agenda in changing contexts. J Occup Health Psychol 1999;4(4):382-93.

55. Greenhaus J, Parasuraman S. Research on work, family and gender: Current status and future directions. In: Powell GN, editor. Handbook of gender in organizations. Newbury Park, CA: Sage; 1999.

56. Frone MR. Work-Family conflict and employee psychilatric disorders: The Nationial Comorbidity Survey. J Appl Psychol 2000;85(6):888-95.

57. Frankenhaeuser $M$, Lundberg $U$, Fredrikson $M_{*}$ Melin $B$, Tuomisto $M_{i}$ Myrsten $A$ - $L$, et al. Stress on and off the job as related to sex and occupational status in white-collar workers. $J$ Organ Behav 1989; 10(4);321-46. 


\section{Impact of working time arrangements on work-home interference among Dutch employees}

Nicole WH Jansen

IJmert Kant ${ }^{1}$

Frans JN Nijhuis ${ }^{2}$

Gerard MH Swaen"

Tage S Kristensen ${ }^{3}$

\footnotetext{
${ }^{1}$ Department of Epidemiology, Maastricht Uniwersity, Maastricht, The Netheriands

${ }^{2}$ Department of Health Organization. Policy and Economics, Maastricht University, Maastricht, The Netherlands

${ }^{3}$ National Institute of Occupational Health, Copenhagen, Denmark
} 


\section{ABSTRACT}

Objectives: (1) To examine the effects of different types of working time arrangements on work-home interference, while taking into account other work-related factors, aspects of the private situation and health status, (2) to explore gender differences in the above relation, and (3) to examine reciprocal effects between working hours and work-home interference.

Methods: Data of three consecutive questionnaires from the Maastricht Cohort Study on "Fatigue at work" were used with eight months of follow-up ( $n=6947$ at baselline).

Results: Working time arrangements were clearly related to work-home interference in men and women, even after controlling for confounding factors. As compared to day work, shift work at baseline was associated with higher work-thome interference over time. Within day work, fultime work was prospectively related to higher work-home interference as compared to parttime work. In fulltimers, overtime work, hours of overtime work, a change in number of working hours, and commuting time to work at baseline were related to higher work-home interference over time. whereas compensation of overtime work, familiarity with work roster, the ability to take a day off and a decrease in working hours at own request were associated with less work-home interference. In parttimers, overtime work and commuting time at baseline were related to higher work-home interference over time, whereas compensation of overtime work flexible working hours and the ability to take a day off were protective against work-home interference. Also reciprocal relations between work-home interference and working hours were found.

Conclusions: Working time arrangements are clearly related to work-home interference. Because reciprocal effects were shown as well, important selection processes may exist. Nevertheless, specific characteristics of working time arrangements could constitute useful tools with regard to the reduction of work-home interference. 


\section{INTRODUCTION}

Many employees are concerned about their ability to adequately combine their increasing demands at work and at home." and conflict between work and family is a salient issue nowadays. Work-family conflict is defined as a form of interirole conflict in which the role pressures from the work and family domains are mutually incompatible in some respect, ${ }^{2}$ where workers have insufficient energy and/or time to successfully perform work and family roles. ${ }^{3}$ Reported prevalences of work-family conflict range from about $10 \%$ to about $41 \%{ }^{5,6}$ Conflict between work and family is mutual in nature ${ }^{7,8}$ in that work can interfere with family (work-home interference), for example when family appointments have to be cancelled because of frequent overtime work, and family can interfere with work (home-work interference), for example when workers have little energy at work because of high demands at home. Allen et al. ${ }^{8}$ noted important consequences associated with conflict from work to family, such as job dissatisfaction, job burnout, psychological distress, depression, and life and marital dissatisfaction. Work-family conflict has been reported to be a risk factor for elevated need for recovery from work and fatigue as well. ${ }^{4}$ Severall studies have reported gender differences with regard to the experience of work-family conflict. ${ }^{9-11}$

At a time characterized by increasing numbers of dual-earner families and single-parents and the evolving 24-hour society, there is a strong need for facilities that are better amenable to combining work and family. One starting point for these facilities may be found in working time arrangements, because the amount of time demanded by work and the pattern and timing of work within the day constitute very obvious and important ways how occupational life affects family life. ${ }^{12}$ Moreover, working time arrangements are dynamic and modifiable factors, because they can be subject to change. Studies have indeed reported that work time is positively related to work interference with family or general work-family conflict ${ }^{11,13-15}$ and that long working hours may have negative consequences for employees who struggle to balance the demands of work and home life. ${ }^{14.96}$ Because working time arrangements are clearly work-related factors, in this study the direction of interference from work to home will be studied exclusively.

With regard to working time arrangements, a distinction can be made between work schedules (shift work versus day work) on the one hand and actual working hours (fultime versus partime) on the other. Shift work as compared to day work has been reported to be a risk factor for general work-family conflict. "For day workers specifically. subgroups may be defined with increased risks of work-home interference. One distinction can be made between fulltime and parttime workers. The Netherlands is known for the high prevalence of parttime work. In $2000.18 .9 \%$ of the male and $67.3 \%$ of the female active workforce worked less than 35 hours a week. ${ }^{17}$ Dutch women often change from fullime to parttime jobs or even leave the labor market altogether at one point during their career, especially following the birth of a first child, because of an incapability to combine work and family life adequately. ${ }^{18}$

To structure the relatianship between working time arrangements and work-home interference, the Conservation of Resources (COR) theory ${ }^{1920}$ could constitute an 
appropriate framework, which was already applied to work-family conflict in earlier studies, ${ }^{3,4}$ The COR model proposes that individuals strive to obtain, retain, protect, and foster those things that they value. These valued entities are termed resources, and include objects, conditions, personal characteristics and energies. ${ }^{202}$ According to COR theory, psychological stress accurs when individuals are threatened with resource loss, lose resources, or fail to gain resources following resource investment. ${ }^{10}$ As more conflict and for demands are experienced in one domain, fewer resources are available to fulfill one's role in another domain. ${ }^{3}$ For example, frequent overtime work might tap available resources and leave fewer resources availabile for family demands. In the case of frequent overtime work, work-home interference might be a reaction to the situation where the resources of the employee are being threatened, depleted or even lost because of the longer time spent at work and the prolonged effort investment. In line with COR theory, other aspects of working time arrangements, for example reflecting control over and predictability of working hours, may add to employees' resources and constitute resource gains. We hypothesized that demanding characteristics of working time arrangements, such as shift work and overtime work, would predict the onset of workhome interference over time, whereas supportive or facilitating elements, such as the ability to take a day off when wanted, would be protective against work-home interference.

Working time arrangements are mainly structural components of work. Both structural and content components, such as job demands, however, are critical to an understanding of the impact of work on employees and their families. ${ }^{22}$ Job demands often differ between shift workers and day workers ${ }^{23-25}$ and between fulltimers and parttimers. $^{26}$ Employees with longer working hours may experience more interference due to higher job demands compared to those averaging lower working hours. Because job demands are in themselves important factors affecting employees' resources, they should be controlled for when studying effects of working time arrangements on workhome interference. The same goes for characteristics of the private situation, where for example the degree of responsibility for childcare or housekeeping may moderate the relationship between working time arrangements and work-home interference. Further; health status could be a pottential confounder in the relation between working time arrangements and work-home interference because, in line with COR theory, health status will determine part of the energy levels, or resources, employees have left for juggling demands between work and family life.

It is likely that different components of working time arrangements may have a different time course of cause and effect. When the exposure is relatively sitable over time, for example in the case of shift work, both cross-sectional and longitudinal designs might be suitable. Cross-sectional studies provide insight into the accumulated effects of working time arrangements at the time of study and may reflect the length of exposure. Longitudinal studies, on the other hand, provide insight into the time sequence between working time arrangements and the onset of work-home interference and study exposure before effect. Most studies so far have rellied on cross-sectional associations between working time arrangements and work-home interference. Both cross-sectional and longitudinal studies can be limited when it comes to selection effects and the impact of 
changes in exposure taking place before or during the time of study. Sometimes the effect may already be present at baseline measurement. Finally, also reciprocal effects might occur, that is, employees experiencing high work-home interference may adjust their working hours over time as a means to reduce interference.

The current study was designed to expand the understanding of the role of working time arrangements in work-home interference by using a cross-sectional as well as a longitudinal design. The aims of this study were (1) to study the effects of various aspects of working time arrangements on work-home interference, while taking into account work-related factors, characteristics of the private situation and health status, (2) to explore gender differences in the relation between working time arrangements and work-home interference, and (3) to examine reciprocal effects between working hours and work-home interference.

\section{METHODS}

\section{Study population}

This study is based on data from the Maastricht Cohort Study on "Fatigue at Work" in the Dutch working population. ${ }^{27,28}$ Employees were followed by means of nine consecutive self-administered questionnaires, which they received at four-monthly intervals. In May 1998, a total of 26,978 employees from 45 companies received a letter at home, inviting participation, and the self-adiministered baseline questionnaire. A reminder was sent out after two weeks. Altogether, 12,161 employees completed and returned the baseline questionnaire (response rate of $45 \%$ ). Sixty-six questionnaires were excluded from analysis due to technical reasons or because inclusion criteria were not met. The baseline (TO) cohort consisted of $8840(73 \%)$ men and $3255(27 \%)$ women and captured both blue-collar and white-collar workers. Detailed information on sectors and trades represented in the Maastricht Cohort Study and on nonresponse has been reported elsewhere. ${ }^{25,27}$

The scale we used to measure work-home interference was first included at 24 months of follow-up (T6, May 2000) and then agairy at 32 months of follow-up (T8, January 2001), implying a period of eight months' follow-up for the present study. At T6, the baseline measurement for the current study, the cohort consisted of 8007 employees, $5814(72.6 \%)$ men and $2193(27.4 \%)$ women. All employees who returned the questionnaire at $T 6$ received the questionnaires at $T 7$ (September 2000; response rate $63.3 \%, \mathrm{n}=7662$ ) and $\mathrm{T} 8$ (January 2001 ; response rate $61.9 \%, \mathrm{n}=7482$ ). In the analyses we excluded those employees who reported themselves absent from work due to illness or reported working under modified conditions related to former sickness absence at the time of completing the questionnaire. These selection criteria resulted for the crosssectional analyses on working time arrangements and work-home interference at T6 in a study population of 6947 employees, $5140(74 \%)$ men and 1807 (26\%) women. For analyzing prospective relationships between working time arrangements and work-home interference after eight months of follow-up, these selection criteria resulted in a study population of 5308 employees, $4033(76 \%)$ men and $1275(24 \%)$ women. 


\section{Measures}

\section{Work-home interference}

To assess work-home interference we used a shortened version (Cronbach's alpha 0.81) of the scale work-home interference from the Survey Work-home Interference Nijmegen (SWING), ${ }^{2930}$ a questionnaire designed to measure directions and domains of workhome interference. Examples of items are "How often do you have to cancel appointments with your partner, family or friends because of obligations at work? ${ }^{\text {th }}$ and "How often do your working hours cause difficulties in meeting the demands at home?". All six items were scored on a four-point scale ranging fram "seldom or never" to "very often". The total score on the scale work-home interference ranged from 6 to 24 . The upper tertile of the scale (total score $\geq 11$ ) was used to define a contrast between employees with high versus low-medium work-home interference.

\section{Working time arrangements}

The questionnaire included 32 questions on working time arrangements. Employees first provided information about the work schedule (day work versus shift work). In this study the term shift work captures three-shift, four-shift, five-shift and irregular shift work; all including frequent night work. Emplayees also provided information on holding multiple jobs and working hours per week (recoded to $\geq 36$ hours, 26-35 hours, and $\leq 25$ hours): frequent overtime work, number of overtime hours a week, compensation of overtime (money, time, money and/or time, no compensation), flexible working hours, familiarity with work roster one month in advance, the ability to take a day off when wanted. whether employees had changed their working hours during the past year and whether or not this change was at own request. Finally, commuting time to work ( $<30$ minutes, $\geq$ 30 minutes) was queried. Except where otherwise noted, the response to each item was yes/no.

\section{Work-related factors}

A Dutch version of the Job Content Questionnaire was used to measure psychological job demands and decision latitude. ${ }^{31 \cdot 33}$ Psychological job demands were assessed by the sum of five items (Cronbach's alpha 0.69). Decision latitude (Cronbach's alpha 0.81) was measured by the sum of two subscales: skill discretion and decision authority. The response options varied from "strongly disagree" to "strongly agree" on a four-point scale. Emotional demands at work were measured by the sum of five items, ranging from 0 to 5 (Cronbach's alpha 0.60). The questions were derived from a Dutch questionnaire on Work and Health, ${ }^{34}$ the Dutch Questionnaire on the Experience and Assessment of Work, ${ }^{35}$ and one self-formulated item. To assess whether employees perceived their work as physically demanding, one item of the Dutch questionnaire on Work and Health $(\text { VAG) })^{34}$ was used.

\section{Private situation}

Employees were asked if they had dependent children at home (yes/no) and about their responsibility for housekeeping (coded as no, yes shared, yes completely). 


\section{Demographic and health-related factors}

Employees provided information on gender, age, educational level and presence of a long-term disease through self-report in the questionnaires.

\section{Statistical analysis}

Logistic regression analyses, stratified for gender, were conducted to study the crosssectional relationship between working time arrangements and work-home interference. The distribution of the scale work-home interference was skewed to the left. Poisson regression analyses were conducted to study prospective relations between working time arrangements at baseline and the continuous score of work-home interference at eight months of follow-up. To study reciprocal effects, multivariate survival analyses using Cox regression were performed, in which we modeled the time to a change of working hours at T7 and T8. All regression analyses were adjusted for age, presence of a long-term disease, educational level, psychological job demands, decision latitude, emotional and physical demands, having dependent children and housekeeping responsibillity. Where the numbers of workers did not allow stratifying for gender, we adjusted in the regression analyses for gender as well. Other statistical procedures included Chi-square tests and independent samples T-tests. Data were analyzed using SPSS for Windows release 11.0.1 and SAS release 8.02 .

\section{RESULTS}

As shown in Table 1, work-home interference clearly differed across demographic factors, working time arrangements and characteristics of the private situation. Employees reporting high work-home interference were more frequently male ( $\rho<$ 0.0001 ). Both in men and women, higher percentages of employees with elevated workhome interference were found among those aged 36-45 years, fulltime workers, those with frequent owertime work, shift workers, and among those with dependent children at home. Nonsignificant differences in work-home interference were observed between employees with different levels of housekeeping responsibility and between those with and without multiple jobs.

Logistic regression analyses showed that shift work was associated with higher workhome interference in men (OR 2.44; $\mathrm{Cl} 1.98-3.00$ ) and women (OR 2.14; $\mathrm{Cl} 1.30-3.51$ ) as compared to day work. Employees with multiple jolss averaged $12.5 \mathrm{~h} / \mathrm{wk}$ (SD 12.2) in the additional job. Holding multiple jobs, however, was not associated with more workhome interference in men (OR 1.08; $\mathrm{Cl} 0.77-1.50$ ) or women (OR 1.14; Cl 0.64-2.04). Similar findings were found in the Poisson regression analyses ( $n=5308$ ) where shift work at baselline was associated with somewhat higher work-home interference after eight months follow-up $(\beta=0.129 ; \mathrm{SE}=0.012 ; p<0.0001)$, even when additionally adjusted for baseline work-home interference levels $(\beta=0.048 ; S E=0.010 ; p<0.0001)$. 
Table 1 Cheractenstics of the surfy populaton with regard to high work-home interterence (upper tervie)

\begin{tabular}{|c|c|c|c|c|c|c|}
\hline & \multicolumn{3}{|c|}{ Men } & \multicolumn{3}{|c|}{ Women } \\
\hline & Total $n$ & $\begin{array}{l}\text { High work home } \\
\text { intenerence } 1 \%\end{array}$ & p yalue & Totail n & $\begin{array}{l}\text { Hoh work-home } \\
\text { intererence }(\%)\end{array}$ & p value \\
\hline Giender & 540 & 35.8 & & 1807 & 28.2 & \\
\hline Age (brs) & & & $<0,0001$ & & & 0.114 \\
\hline$\leq 25$ & 19 & 26.3 & & 42 & 26.2 & \\
\hline $26-35$ & 777 & 37.7 & & $50:$ & 26.1 & \\
\hline $36-45$ & 1869 & 39.5 & & 759 & 30,0 & \\
\hline $46-55$ & 2011 & 33.6 & & 419 & 29.8 & \\
\hline$\geq 56$ & 455 & 27.3 & & 80 & 17.5 & \\
\hline Working hous & & & 0.137 & & & $<0.0001$ \\
\hline Low partirne $(\leq 25$ m/wk) & 82 & 25.6 & & 785 & 21.1 & \\
\hline High partime (26.35 hwk) & 540 & 35.2 & & 405 & 321 & \\
\hline Fultime $(236$ how & 4489 & 36.1 & & 607 & 34.8 & \\
\hline Frequent overtine work & & & $<0.0001$ & & & $<0.0001$ \\
\hline Yes & 2261 & 49.7 & & 654 & 39.3 & \\
\hline No & 2834 & 24.8 & & 1139 & 21.7 & \\
\hline Work sonedile & & & $<0,0001$ & & & $<0.0001$ \\
\hline Shiff work & 1283 & 43.8 & & 337 & 36.2 & \\
\hline Day work & $3766^{\circ}$ & 33.0 & & 1408 & 26.1 & \\
\hline Multiple jobs & & & 0.347 & & & 0.236 \\
\hline Yes & 203 & 38.9 & & 79 & 34,2 & \\
\hline Mo & 4915 & 35.7 & & 1723 & 28.0 & \\
\hline Dependent children & & & $<0.0001$ & & & 0.043 \\
\hline Yes & 2867 & 38.9 & & 886 & 30.4 & \\
\hline No & 2236 & 31.80 & & 909 & 26.1 & \\
\hline Responsible for housekeeping & & & 0.619 & & & 0.799 \\
\hline Yes, completely & 464 & 34.5 & & 884 & 28.2 & \\
\hline Yes, shared & 2427 & 36.4 & & 852 & 28.6 & \\
\hline No & 2208 & 35.3 & & 57 & 24.6 & \\
\hline
\end{tabular}

All further results for actual working hours, that is fulltime versus parttime work, and other characteristics related to working hours are based on day workers only, that is, we excluded those employees with multiple jobs, shift workers, and those involved in night work and evening work, resulting in a study population of 4945 employees, 3606 (72.9\%) men and $1339(27.1 \%$ ) women. For men, we distinguished fultime ( $\geq 36 \mathrm{~h} / \mathrm{wk}$ ) from parttime work ( $<36 \mathrm{~h} / \mathrm{wk}$ ), whereas in women the numbers allowed to distinguish fulltimers from low ( $\leq 25 \mathrm{~h} / \mathrm{wk}$ ) and high parttimers $(26-35 \mathrm{~h} / \mathrm{wk})$. In men, fulltime work, as compared with partime work, was not associated with higher work-home interference (OR 1.26; $\mathrm{Cl} 0.87-4.82$ ). In women, a low parttime job protected against work-home interference (OR 0.29 ; Cl 0.190 .44 ), whereas a high partime job was not associated with lower work-home interference (OR 0.71 ; $\mathrm{Cl} 0.48-1.04$ ) compared with fulltime work.

Table 2 shows cross-sectional associations between characteristics of working time arrangements and work-home interference for male fullimers and parttimers separately. In male fulltimers, frequent overtime work, number of overtime hours, and an increase of working hours during the past year were associated with more work-home interference, whereas compensation of overtime, flexible working hours, familiarity with work roster in advance and the ability to take a day off were associated with less work-home interference. In general, the associations between aspects of working time arrangements 
Table 2 Cross-sectional asscciations between working time arrangements and work-home interference (upper tertite) in fullime and parttime working men in day work

\begin{tabular}{|c|c|c|}
\hline & Fulltime work $(\geq 36$ hiwk) $(n=3402)$ & Partinne work ( 36 howk $(n=204)$ \\
\hline & $O R^{*}(95 \% C l)$ & $O P^{*}(95 \% \mathrm{Cl})$ \\
\hline \multicolumn{3}{|l|}{ Frequent owertime work } \\
\hline Yes & $2.99(2.48-3.60)$ & $2.36(0.995 .60)$ \\
\hline No & 1 & t \\
\hline \multicolumn{3}{|c|}{ Hours of overtime work a week } \\
\hline$<5$ & 1 & j \\
\hline$\geq 5$ & $2.17(1.73-2.71)$ & $0.52(0.06-4.67)$ \\
\hline \multicolumn{3}{|c|}{ Compensation owertime hours } \\
\hline Time & $0.57(0.38-0.85)$ & $0.46(0.07-3.12)$ \\
\hline Time andior money & $0.70(0.50-0.97)$ & $0.11(0.05-2.46)$ \\
\hline Money & $0.46(0.27-0.77)$ & a. \\
\hline No & 1 & 1 \\
\hline \multicolumn{3}{|l|}{ Flexible warking hours } \\
\hline Yes & $0.82(0.68 \cdot 0.98)$ & $1.06(0.67-1.67)$ \\
\hline No & 1 & 1 \\
\hline \multicolumn{3}{|c|}{ Work roster known 1 month in advance } \\
\hline Yes & $0.62(0.51-0.76)$ & $0.61(0.22-1.73)$ \\
\hline No & 1 & 1 \\
\hline \multicolumn{3}{|c|}{ Able to take a day off when wanted } \\
\hline Yes & $0.45(0.35-0.58)$ & $0.97(0.33-2.82)$ \\
\hline No & 1 & 1 \\
\hline \multicolumn{3}{|l|}{ Decrease working hours } \\
\hline Yes & $1.12(0.68-1.83)$ & $0.38 \cdot(0.13-1.14)$ \\
\hline No & 1 & 1 \\
\hline \multicolumn{3}{|c|}{ Decrease working hours at own request } \\
\hline Yes & $0.37(0.10-1.43)$ & \\
\hline No & $i$ & .* \\
\hline \multicolumn{3}{|l|}{ Increase working hours } \\
\hline Yes & $2.17(1.66-2.82)$ & $2.25(0.40-12.65)$ \\
\hline No & 1 & 1 \\
\hline \multicolumn{3}{|c|}{ Increase working hours at own request } \\
\hline Yes & $0.92(0.54 .9 .66)$ & \\
\hline No & 1 & $"$ \\
\hline \multicolumn{3}{|l|}{ Commuling time to work } \\
\hline$<30$ mirutes & 1 & 1 \\
\hline$\geq 30$ mirutes & $1.00(0.84-1.19)$ & $1.16(0.54 \cdot 2.64)$ \\
\hline
\end{tabular}

* Adjusted for age, presence of a long-lerm disease, educational level, psychological job demands, decision latitude. emotional and physical demands, having dependent children and responsibility for housekeepingt

* Data not awailable, because of too smail sample size

and work-home interference were less strong among male parttimers, probably partly due to the smaller numbers of partime working men.

Table 3 presents cross-sectional associations between characteristics of working time arrangements and work-home interference for women. In both fultime and low parttime workers, overtime work was associated with more work-home interference. Number of overtime hours was associated with more work-home interference and famillarity with the work roster in adwance with less work-home interference in high parttime workers. A decrease of working hours was associated with more work-home interference in fulltime 
Table 3 Cross-zoctinal associations between working tume arangements and work home interference (upper ferthe) among futhime, high parthime and low parttime working women in day work

\begin{tabular}{|c|c|c|c|}
\hline & $\begin{array}{l}\text { Fulltime work } \\
(\geq 36 \text { howly }(n=494)\end{array}$ & $\begin{array}{l}\text { High partime work } \\
(26-35 \text { h/wh) }(n=280)\end{array}$ & $\begin{array}{l}\text { Low partime work } \\
(\leq 25 \mathrm{n} / \mathrm{wk})(n=559)\end{array}$ \\
\hline & $\mathrm{OR}^{*}(95 \% \mathrm{CH}$ & $\mathrm{OR}^{*}(95 \% \mathrm{Cl})$ & $\mathrm{OR}^{*}(95 \% \mathrm{C})$ \\
\hline \multicolumn{4}{|l|}{ Frequent overtime work } \\
\hline Yes & $1.89(1.2-3.19)$ & $1.72(0.88-3.35)$ & $1.96(1.16-3.33)$ \\
\hline No & 1 & 1 & 1 \\
\hline \multicolumn{4}{|c|}{ Hours of overtime work a week } \\
\hline$<5$ & 1 & 1 & 1 \\
\hline$\geq 5$ & $1.78(0.88-3.60)$ & $4.30(1.34-13.84)$ & $2.27(0.72-7.12)$ \\
\hline \multicolumn{4}{|c|}{ Compensation overtime hours } \\
\hline Time & $0.75(0.29-1.91)$ & $0.35(0.10-1.23)$ & $1.28(0.40-4.13)$ \\
\hline Time andior money & $0.92(0.31-2.74)$ & $0.33(0.05-2.04)$ & $0.42(0.10-1.69)$ \\
\hline Money & $2.42(0.44-13.26)$ & $0.40(0.04-4.56)$ & $1.67(0.32-8.70)$ \\
\hline No & 1 & 1 & 1 \\
\hline \multicolumn{4}{|l|}{ Flexible working hours } \\
\hline Yes & $1.40(0.97 \cdot 2.03)$ & $0.63(0.34-1.19)$ & $0.97(0.64-1.47)$ \\
\hline No & 1 & $\|$ & 1 \\
\hline \multicolumn{4}{|c|}{ Work roster known 1 month in advance } \\
\hline Yes & $0.54(0.26-1.14)$ & $0.43(0.19-0.99)$ & $0.71(0.32-1.59)$ \\
\hline No & 1 & 1 & 1 \\
\hline \multicolumn{4}{|c|}{ Ablle to take a day off when wanted } \\
\hline Yes & $0.85(0.47-1.54)$ & $0.51(0.24-1.08)$ & $0.84(0.47-1.49)$ \\
\hline No & 1 & 1 & 1 \\
\hline \multicolumn{4}{|l|}{ Decrease working hours } \\
\hline Yes & $4.92(1.40-17.23)$ & $0.99(0.44-2.25)$ & $0.59(0.24-1.45)$ \\
\hline No & 1 & 1 & 1 \\
\hline \multicolumn{4}{|l|}{ Increase working hours } \\
\hline Yes & $1.52(0.75-3.06)$ & $1.04(0.442 .45)$ & $1.30(0.61-2.77)$ \\
\hline No & 1 & 1 & 1 \\
\hline \multicolumn{4}{|l|}{ Commuting time to work } \\
\hline$<30$ minutes & 1 & 1 & 1 \\
\hline$\geq 30$ minutes & $1.38\{0.83-2.31\}$ & $1.23(0.61-2.46)$ & $2.83(1.54-5.20)$ \\
\hline
\end{tabular}

*Adjusted for age. presence of a long-term disease, educational level, psychological job demands, decision latitude, amothonal and physical dernands, responsibility for housekeping, and having cependeni children

workers. High commuting time to work was associated with more work-home interference in low parttime workers.

Poisson regression analysis was conducted to study the prospective relationship between working time arrangements at baseline and the continuous score of work-home interference after eight months of follow-up in day workers (Table 4). Excluded were those employees who had multiple jobs or who were involved in shift work, evening or night work at T6, resulting in a study population with eight months of follow-up of 4336 employees, $3193(73.6 \%)$ men and $1143(26.4 \%)$ women. These analyses were performed without stratification for gender, because this would result in loo low numbers. Fulltime work at baseline was associated with higher work-home interference after eight months of follow-up. Additional adjustments for baseline work-home interference levels revealed less strong associations. For fultime workers specifically, all characteristics of working time arrangements, except for flexible working hours and an increase of working 
hours at own request, were associated with work-home interference. When additional adjustments for baseline work-home interference levels were made, the associations were less strong. In parttimers, frequent overtime work and high commuting time to work at baseline were associated with more work-home interference after eight months of follow-up, whereas compensation of overtime, flexible working hours and the ability to take a day off when wanted were associated with less work-home interference. After additionally adjusting for baseline work-home interference levels, overtime work was still associated with more work-home interference, whereas the ability to take a day off when wanted and increased working hours per week during the past year were associated with less wark-home interference.

Table 4 Working time arrangements at baseline as risk factors for work-home interference (continuous score) affer eight monhth of follow-up in day workers

\begin{tabular}{|c|c|c|c|c|c|c|}
\hline \multirow[b]{4}{*}{ Fulltime vs partime work } & \multicolumn{6}{|c|}{ Day work $(n=4336)$} \\
\hline & \multicolumn{3}{|c|}{ Model I $^{*}$} & \multicolumn{3}{|c|}{ Model 2 } \\
\hline & $\beta$ & SE & p value & $\beta$ & $\mathrm{SE}$ & P value \\
\hline & 0.059 & 0.015 & 40.0001 & 0.015 & 0.011 & 0.180 \\
\hline & \multicolumn{6}{|c|}{ Fulltime work $(\geq 36 \mathrm{~h} / \mathrm{wk})(\mathrm{n}=3422)$} \\
\hline & \multicolumn{3}{|c|}{ Madel $1^{*}$} & \multicolumn{3}{|c|}{ Madel 2} \\
\hline & $\beta$ & SE & $P$ value & $\beta$ & $S E$ & p value \\
\hline Frequent overtime work & 0.126 & 0.011 & $<0.0001$ & 0.039 & 0.009 & $<0.0001$ \\
\hline$\geq 5$ hours of owertime wark a week & 0.030 & 0.009 & 0.001 & 0.004 & 0.008 & 0.641 \\
\hline Overtime hours compensated & -0.064 & 0.018 & $<0.000$ & -0.017 & 0.014 & 0.247 \\
\hline Flexible working hours & -0.001 & 0.009 & 0.939 & 0.006 & 0,007 & 0.438 \\
\hline Work rositer known 1 month in adwance & -0.059 & 0.013 & $<0.0001$ & -0.009 & 0.010 & 0.374 \\
\hline Able to take a day off when wanted & -0.068 & $0: 015$ & $<0.0001$ & -0.012 & 0.012 & 0.313 \\
\hline Decrease working hours & 0.067 & 0.029 & 0.022 & 0.046 & 0.023 & 0.047 \\
\hline Decrease working hours al own request & -0.152 & 0.073 & 0.038 & -0.062 & 0.063 & 0.320 \\
\hline Increase working hours & 0.083 & 0.016 & $<0.0001$ & 0.018 & 0.012 & 0.145 \\
\hline Increase working hours at own request & -0.012 & 0.037 & 0.751 & 0.013 & 0.029 & 0.668 \\
\hline \multirow[t]{4}{*}{$\geq 30$ minutes commuting time to work } & 0.033 & 0.010 & 0.001 & 0.011 & 0.008 & 0.178 \\
\hline & \multicolumn{6}{|c|}{ Partlime work ( $<36$ h/wk) $(n=914)$} \\
\hline & \multicolumn{3}{|c|}{ Model 1: } & \multicolumn{3}{|c|}{ Model 21} \\
\hline & $\beta$ & SE & pwalue & $\beta$ & SE & p walue \\
\hline Frequent overtime work & 0.140 & 0,021 & $<0.0001$ & 0.071 & 0.017 & $<0.0001$ \\
\hline 25 hours of overlime work a week & 0.067 & 0.041 & 0.100 & 0.014 & 0.034 & 0.688 \\
\hline Overtime hours compensated & -0.088 & 0.042 & 0.035 & -0.037 & 0.035 & 0.287 \\
\hline Flexible whorking hours & -0.030 & 0.015 & 0.047 & 0.020 & 0.012 & 0.088 \\
\hline Work roster known 1 month in advance & -0.049 & 0.027 & 0.075 & 0.009 & 0.022 & 0.676 \\
\hline Able to take a day off when wanted & .0 .095 & 0.024 & $<0.0001$ & .0 .040 & 0.019 & 0.033 \\
\hline Decrease working hours & .0 .004 & 0.028 & 0.889 & 0.009 & 0.022 & 0.676 \\
\hline Decrease working hours at own request & -0.077 & 0.105 & 0.460 & 0.160 & 0.097 & 0.099 \\
\hline Increase working hours & -0.001 & 0.032 & 0.973 & -0.056 & 0.025 & 0.027 \\
\hline Increase working hours at own request & -0.047 & 0.073 & 0.518 & 0.006 & 0.065 & 0.924 \\
\hline$\geq 30$ minutes commuting time to work & 0.064 & 0.023 & 0.005 & 0.049 & 0.018 & 0.301 \\
\hline
\end{tabular}

"Adjusted for gender, age, presence of a long-term disease, educational leve: psychological job demands, decision latilude, emolional and physical demands, responsibility for houselkeeping and having depuendent childran

idditionally adjusted for continuous baseline work-home interference lewels 
To test whether the findings remained similar when the different characteristics of working time arrangements were included altogether in the Poisson regression analyses, we constructed a multivariate model with fulltime versus parttime work, overtime work, flexible working hours, commuting time, familiarity with work roster, ability to take a day off, agie, gender, presence of a long-term disease, educational level, psychological job demands, decision latitude, physical and emotional demands, responsibility for housekeeping and having dependent children. This model revealed for the characteristics of working time arrangements at baseline, that fullume work $(\rho<0.01)$, overtime work ( $p<0.0001)$, $\geq 30$ minutes commuting time to work $(\rho<0.0001) \%$ familiarity with work roster in advance $(\rho<0.0001)$, and the ability to take a day off when wanted $(p<0.0001)$ still remained associated with work-home interference in the expected direction after eight months of follow-up. When additionaliy controlled for baseline work-home interference levels, only overtime work $(p<0.0001)$ remained aissociated with work-home interference.

To study reciprocal effects between working hours and work-home interference, we examined whether high work-home interference (upper tertile) at T6 among fulltime workers ( $236 \mathrm{~h} / \mathrm{wk}$ ) predicted a change of working hours over eight months of follow-up. Cox regression analyses were performed, in which we modeled the time to a change of working hours at T7 and T8. Employees involved in shift work and/or in multiple jobs and those who reported themselves absent from work due to illness or reported working under modified conditions related to former sickness absence at T6 were excluded, resulting in $n=3828$. We were unable to study whether the change in working hours at $T 7$ or T8 was an increase or decrease in working hours. Therefore, we studied fulltime workers exclusively, where a change of working hours over time most likely reflects a decrease in hours. Multivariate Cox regression analyses showed that high work-home interference at baseline went together with an increased probability of changing working hours over time both in men (RR 1.36; $\mathrm{Cl} 1.08-1.72$ ) and women (RR 2.04; $\mathrm{Cl} 1.18$ 3.52).

\section{Discussion}

Working time arrangements were clearly related to work-home interference both in the cross-sectional and longitudinal analyses, with differences emerging between men and women, between day and shift workers, as well as between fultimers and partimers. These differences remained even after adjusting for work-related factors, characteristics of the private situation and health status, which constitutes evidence for true prospective relations between working time arrangements and work-home interference. Adjustments for these factors showed a large impact on the relation between working time arrangements and work-home interference, pointing to the necessity of taking job content, private situation and health status into account in this area of research and which is fully in line with propositions of the Conservation of Resources theory. Furthermore, reciprocal effects between working hours and work-home interference were observed. Shift work was a risk factor for work-home interference after eight months follow-up. Because shift work involves working and living patterns diverging from 
community thythms of social, recreational and domestic activities, ${ }^{36}, 37$ conflict between work and family would be more likely to arise among shift workers as compared to day workers. Holding multiple jobs, in contrast, was not related to higher work-home interference. An explanation could be that having multiple jobs actually represents a very crude measure, due to the fact that the group of employees with multiple jobs caln consist of workers with very different working hours and job content in the additional job. Another explanation is that a selection took place in which only those who were better able to combine work and family life held multiple jobs.

An adequate comparison of the results regarding the effects of fultime and partime work on work-home interference with other studies is difficult or sometimes hindered because of different definitions and operationalizations used for working hours and work-home interference. Fulltime work was prospectively related to higher work-home interference as compared to parttime work. Although other studies also found long work hours to be associated with work-home interference or general work-family conflict, ${ }^{11,13-15}$ we were able to study specific aspects of working time arrangements in relation to work-home interference. In fulltimers, overtime work was prospectively related to higher work-home interference. Prolongation of the work day could, in line with the COR theory, deplete time and/or energy resources available for family activities, which was also shown in the cross-sectional analyses, where particularly for women with a low partime job, overtime work and high commuting time fostered work-home interference. Possibly, these women had already anticipated work-home interference and selected partime work as an option to reduce it. Due to the prolonged working day, their carefully selected fit between work and family was compromised and work-home interference became more likely to develop.

Both an increase and decrease of working hours during the past year was related to higher work-home interference among fulltime workers in the prospective analyses. Possible explanations could be that the employees who changed their working hours have not yet adapted to their new working hours, or that the change in working hours was still not enough to adequately combine work and family life. Furthermore, it may be possible that the private situation has become more demanding for employees who had started working fewer hours during the past year. When we specifically studied whether or not the change in hours was the worker's own choice, it was found that working fewer hours at own request during the past year was prospectively related to less work-home interference among fulltime workers. The opportunity to take a day off when wanted, indicating autonomy or control over working hours, could provide employees with more possibilities to combine work and family life and was in line with our hypotheses found to be protective against work-home interference. Flexible working hours were not consistently associated with less work-home interference. In a study by Smith Major at al., "14 the relation between long work hours and time-based work interference with family was not moderated by schedule flexibility as well. One explanation could be that flexible working hours do not provide a solution for employees with structural time conflicts between work and family, because the actual hours that need to be spend at work still remain similar. Flexible hours may provide a solution when employees encounter occasional time conflict situations however. 
Several methodological and conceptual issues should be addressed. A first issue concerns the time window of relations between working time arrangements and workhome interference. Both cross-sectional and longitudinal analyses yielded significant associations with work-home interference. From the prospective analyses it appears, however, that working time arrangements do not necessarily have an immediate effect on work-home interference, but may also develop gradually. In this study we used an eight-month follow-up period. Although working time arrangements were clear risk factors for work-home interference after eight months of follow-up, it is likely, however. that different aspects of working time arrangements, such as shift work or overtime work, may have a different time course of cause and effect. In our study for shift workers a steady state situation may have already been developed with regard to work-home interference. Still, significant effects of shift work were observed, which could also be due to other changes in the work or home situation that we did not control for. For future studies it is valuable to study different time windows for the relationship between working time arrangements and work-home interference. Second, the employees in our study were already in the middle of an ongoing process both with regard to working time arrangements and combining work and family. In this respect, the term baseline is not a true reference condition, because employees experiencing work-home interference may have already chosen day work instead of shift work, or parttime work and less overtime work, as an option to reduce work-home interference. The reciprocal effects between work-home interference and working hours clearly pointed in this direction. Consequently, a selection bias may have taken place before our baseline measurement and/or during follow-up, reducing all observed associations. This could also be an explanation for the lower proportion of women reporting work-home interference, because it could be argued that this selection might be stronger among women, since women have culturally accepted ways of coping with work-home interference, for example working parttime as an option that permits more time for their families. Compared to other European countries, Dutch women are less inclined to put out a great part of childcare to someone outside of the household and as a consequence, their situation on the labor market is usually adapted to the situation at home. "Indeed, we observed that fulltime working women with high work-home interference had a substantially higher probability of changing their working hours over time, compared to those reporting lower work-home interference. For men, similar findings were observed, although the associations were less strong. Third, from a methodological point of view it was important to exclude those employees absent from work at the time of completing the questionnaires, because these employees might have interpreted the questions on combining work and family differently. However, excluding employees absent from work may have resulted in an underestimation of risks, because these employees could be more likely to stay away from work due to problems in combining work and family. Fourth, in this study we used self-reported data only, although the measurement of working time arrangements can be considered as fairly objective. Nevertheless, common method variance may have caused an overestimation of the strength of the observed associations between working time arrangements and work-home interference. Finally, to date there are no existing cutoff points for classifying employees with marked workhome interference as measured with the SWING. Therefore, in this study we used the upper tertile to define a contrast between employees with and without marked work- 
home interference. It should be kept in mind that using this upper tertile actually reflects a moderate contrast only, since the work-home interference scale was skewed to the left.

From the present study we conclude that working time arrangements may have beneficial as well as adverse effects on work-home interference under certain specific conditions. Demanding aspects of working time arrangements, such as for example overtime work and shift work, went together with higher work-home interference. whereas characteristics of working time arrangements reflecting control and predictability were protective against work-home interference. Because working time arrangements are in essence dynamic and modifiable factors, that can be subject to change when necessary or requested, they constitute important tools for reducing work-home interference. Furthermore, experiencing high work-home interference at baseline was an important predictor for changing working hours over time. This further points to the importance of working time arrangements for an adequate work-family balance, not only on an individual level, but also on a societal level with respect to consequences of workhome interference in terms of labor force participation.

\section{ACKNOWLEDGEMENTS}

The Maastricht Cohort Study is part of the Netherlands concerted research action on "Fatigue at work" granted by the Netherlands Orglanization for Scientific Research. The present study was supported by grant no. 580-02.201 from the Netherlands Organization for Scientific Research.

\section{REFERENCES}

1. Ester P, Vinken H. Vam later zorg. Verwachtingen van Nederlanders over arbeid, zorg en vrijetijd in de 2 te eeum [Of later concern. Expectations of the Dutch population about work, care, and leisure in the 21 st century]. Den Haag: Service Centrum Uitgevers: 2000

2. Greenhaus JHA, Beutell MJ. Sources and conflict between work and family roleg. Acad Manage Rev 1985;10(1):76-88.

3. Grandey AA, Cropanzano $R$. The Conservation Of Resources model applied to work-family conflict and strain. J Vocat Behaw 1999:54(2):350-70.

4. Jansen NWH, Kant Wh Kristemsen TS, Nijhuis F.JN. Antecedents and consequences of workfamily conflict: a prospective cohort study. J Occup Enviran Med 2003:45(5):479.91.

5. Frone MR. Russell M. Cooper ML. Prevalence of work-family conflict: Are work and family boundaries asymmetrically permeable? J Organ Behaw 1992"13:723-9.

6. Kinnunen U. Mauno S. Antecedents and outcomes of work-family conflict among employed women and men in Finland. Hum Relat 1998:51(2):157-77.

7. Frone MR, Russell M. Cooper ML. Antecedents and outcomes of work-family conflict: Testing a model of the work-family interface. J Appl Psychol 1992;77(1):65-78.

8. Allen TD, Herst DEL, Bruck CS, Sutton M. Consequences associated wilh work-to-family conflict: A review and agenda for future research. J Occup Health Psychal 2000,5(2):278-308,

9. Duxbury LE, Higgins CA. Gender differences in work-family conflict. A Appl Psychol $1991: 76(1): 60-73$.

10. Eckenrode J, Gore S. Stress and coping at the boundary of work and family. In: Eckenrode w, Gore S, editors. Stress between work and family. New York: Plenum: 1990. p. 1-16. 
11. Gutek BA, Searle S, Klepa L. Rational versus gender role explanations for work-family conflict. J Appl Psychol 1991;76(4):560-8.

12. Kanter RM. Work and family in the United States: A critical review and agenda for research and policy. New York: Russell Sage Foundation, Social Science Frontiers; 1977.

13. Grzywacz JG. Marks NF. Reconceptualizing the work-family interface: An ecological perspective on the correlates of positive and negative spillover between work and family. I Occup Heallh Psychol 2000;5(1):111-26.

14. Smith Major $V$, Klein KJ, Ehrhart MG. Work time, work interference with family, and psychological distress. J Appl Psychol 2002;87(3):427-36.

15. O' Driscoll MP, Ilgen DR, Hildreth K. Time devoted to job and off-job activities, interrole conflict, and affective experiences. J Appl Psychol 1992;77(3):272-9.

16. Hochschild AR. The time bind: When work becomes home and home becomes work. New York: Metropolitan Books; 1997.

17. Central Bureau of Stakistics. Statistisch Jaarboek 2003 [Statistical yearbook 2003]. Voorburg/Heerlen: Centraal Bureau voor de Statistiek; 2003

18. Koopmans I, Stavenuiter MMMJ. Meer werken, minder zorgen. Arbeid en zorg in wetgeving en CAO's [More working, less caring. Work and care in legislation and collective labor agreements]. Breukelen: NYFER; 1999.

19. Hobfoll SE Conservation of Resiulrces. A new attempt at conceptualizing stress. Am Psychol $1989 ; 44(3): 513-24$.

20. Hobfoll SE, Shirom A. Conservation of Resources Theory. Applications to stress and management in the workplace. In: Golembiewski RT, editor. Handbook of organizational behavior. New York: Dekker; 2001. p. 57-80.

21. Hobfoll SE. The influence of culture, community, and the nested-self in the stress process: Advancing Conservation of Resources theory. Appl Psychol: Int Rev 2001:50(3):337-70.

22. Barmett RC. Toward a rewiew and reconceptualization of the workffamily literature. Genet Soc Gen Psych Monograph 1998;124(2):125-82.

23. Bøggild $H$, Burr $H$, Tüchsen $F$, Jeppesen $H J$. Work environment of Danish shift and day workers. Scand J Work Environ Health 2001;27(2):97-105.

24. Jansen NWH, Kant IJ, Van Amelswoort LPGM, Nijhuis FJN, Van dlen Brandt PA. Need for recovery from work: Evaluating short-term effects of working hours, patterns and sichedules. Ergonomics 2003:46(7):664-80.

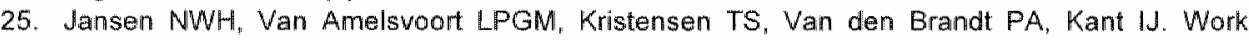
schedules and fatigue: a prospective cohort study. Occup Environ Med 2003;60(Suppl 1):44753.

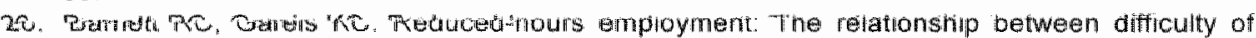
trade-offs and quality of life. Work Occupat 2000;27(2):168-87.

27. Kant W, Bültmann L', Schröer CAP. Beurskens AJHM, Van Amelsvoort LPGM. Swaen GMH. An epidemiological approach to study fatigue in the working population: The Maastricht Cohort Study. Occup Environ Med 2003;60(Suppl 1):i32-9.

28. Kant IJ "Beurskens AJHM, Schröer CAP, Nijhuis FJN, Van Schayck CP, Van den Elzen HJ, et al. De Maastrichtse Cohort Studie naar langdurige psychische vermoeidheid in de arbeidssituatie [The Maastricht Cohort Study on fatigue at work]. TBV 2000;8(8):226-32.

29. Wagena E, Geurts S. SWING: Ontwikkeling en validering van de 'Survey Werk-thuis Interferentio-Nijmegen' [SWING; development and validation of the 'Survey Work-home Interference Nijmegen']. Gedrag Gezond 2000;28(3):138-57.

30. Van der Hulst M, Geurts S. Associations between overtime and psychological health in high and low reward jobs. Work Stress 2001:15(3):227-40.

31. Houtman 1. Reliability and validity of the Dutch version of the Karasek Job Content Questionnaire. In: NIOSH/APA conference on Stress, Work, and Heaith; 1995; Washington. DC: 1995.

32. Karasek RA. The Job Content Questionnaire and User's Guide (version 1.1). Los Angeles: Department of Industrial and Systems Engineering, University of Southern California; 1985. 
33. Niedhammer I. Goldberg $M$, Leclerc A. Bugel I. David S. Psychosocial factors at work and subsequent depressive symptoms in the Gazel cohort. Scand J Work Environ Health $1998 ; 24(3): 197-205$.

34. Gründemann RWM. Smulders PWG, De Winter CR. Handleiding Vragenlijst Arbeid an Gezondheid [Manual, Questionnaire on work and health]. Lisse: Swets \& Zeitlinger; 1993.

35. Van Veldhoven $M$, Meijman TF. Het meten van psychosociale arbeidsbelasiting met een vragenlijst: de vragenlijst beleving en beoordeling van de arbeid (VBBA) [The measurement of psychosocial job demands with a questionnaire (vBBA)]. Amsterdam: NIA; 1994.

36. Loudoun RJ, Bohle PL. Work/Non-work conflict and health in shiftwork: Relationships with family status and social support. Int J Occup Environ Health 1997;3(Suppl 2):S71-7.

37. Walker J. Social problems of shiftwork. in: Folkard S, Monk TH, editors. Hours of work. Temporal factors in work-scheduling. New York: John Wiley \& Sons: 1985, p. 211-25.

38. Fokkema $T$. Combining a job and children: Contrasting the heaith of married and divorced women in the Netherlands? Soc Sci Med 2002;54(5):741-52. 


\section{Work-family conflict as a risk factor for sickness absence}

Nicole WH Jansen ${ }^{1}$

I.Jmert Kant ${ }^{1}$

Ludovic GPM van Amelsvoort

Tage S Kristensen?

Gerard MH Swaen ${ }^{1}$

Frans JN Nijhuis ${ }^{3}$

"Department of Epidemiology, Maastricht University, Maastricht, The Netherlands

2 National Institute of Occupational Health, Copenhagen, Denmark

${ }^{3}$ Department of Health Organization. Policy and Economics, Maastricht University, Maastricht, The Netherlands 


\section{ABSTRACT}

Objectives: The aims of the present study were 1) to study both cross-sectional and prospective relationships between work-family conflict and sickness absence from work; and 2) to explore possible differences in the direction of conflict (work-home interference versus home-work interference) and sickness absence.

Methods: Data from the Maastricht Cohort Study were used with six months of follow-up ( $n=6087$ at baseline measurement). Work-family conflict was measured with the Survey Work-Home Interference Nijmegen (SWING). Sickness absence was assessed objectively through individual record linkage with the company registers on sickness absence.

Results: In the cross-sectional analyses, high levels of work-family conflict, work-home interference and home-work interference were all associated with a higher odds of being absent at the time of completing the questionnaire, after controlling for age, and the presence of a long-term disease. For women, the prospective associations between work-family conflict, the directions of conflict, and time to onset of first sickness absence spell were in the expected direction, yet failed to reach statisticall significance, probably due to the low numbers of women. One standard deviation increase on the scale of home-work interference was in men associated with a shorter time to first sickness absence spell. The difference in average number of absent days between cases and noncases of work-home interference was statistically significant for men and most pronounced in women. where the average number of absent days over six months of follow-up was almost four days higher in women with high work-home interference as compared with women with low-medium work-home interference.

Conclusions: A clear relation between work-family conflict and sickness absence was demonstrated, with differences in the impact of direction of work-family conflict on sickness absence. The effects of work-family conflict may be stronger for women than men. Sickness absence should be added to the list of adverse outcomes for employees struggling to combine their work and family life. 


\section{INTRODUCTION}

Rapid changes in the domains of work and caring tasks have resulted in more and more people struggling to combine work and family matters. Not only the division of household and labor has changed substantially with increasing numbers of working single parents and dual-earner families, ${ }^{1,2}$ but there are also developments in the work enwironment providing employees with challenges to combine their work and family life. European surveys have for example shown steady increases in work intensity and job demands in the past decade, ${ }^{3.4}$ causing intensified demands during the working day, which for workers may result in having too little energy left for dealing with family matters. Moreover, many work situations require long working hours or frequent overtime work due to tight deadlines, understaffing or emergency contingencies ${ }^{5}$ posing high extensive demands for the worker, which may result in a time conflict for combining work and family life. In an earlier study we found that over $10 \%$ of employees participating in a large cohort study ${ }^{\hat{A}, 7}$ in the Netherlands reported that they were not able to combine work and family life adequately. ${ }^{B}$ Work-family conflict is a form of interrole conflict in which the role pressures from the work and family domains are mutually incompatible in some respect. Participation in the work (family) role is made more difficult by virtue of participation in the family (work) role. ${ }^{9}$ Work-family conflict can be reciprocal in nature, in that work can interfere with family and family can interfere with work, ${ }^{10,11}$ The term work. family conflict will in this study be used to point to general conflict between work and family where the directions of conflict are not separated. The term work-home interference will be used to refer to the direction of interference from work to home, whereas home-work interfierence will indicate the direction of interference from home to work. Consequences associated with work to family conflict reported in a review by Allen et al. ${ }^{11}$ were for example job dissatisfaction, job burnout, psychological distress, depression, life dissatisfaction, and marital dissatisfaction. Furthermore, work-family conflict has been found to be a risk factor for elevated need for recovery from work and fatigue. 8

There are several indications that work-family conflict is associated with sickness absence as well. When the demands of work and family are incompatible, and for example demands at home such as taking care for sick children can neither be delayed nor ignored, employee absence is likely ${ }^{12}$ and may constitute a way to (temporarily) cope with the situation. Steers and Rhodes ${ }^{13}$ reported in their review on influences on employee attendance that family responsibilities may put constraints on the ability to attend work, even when attendance motivation is high. Several studies have shown associations between the presence of children at home and absence from work 14,15 In a study by Goff et al. ${ }^{16}$ it was found that work-family conflict was related to sickness absenteeism, in terms of average number of hours absent from work. Barling et al. ${ }^{12}$ found that interrole conflict between work and family among employees with elder care was associated with partial absenteeism, such as arriving late, leaving early, and spending time taking on the telephone when at work. In a cross-sectional study on workfamily conflict among employees with care giving responsibilities for older family members, Gignac et al. ${ }^{17}$ reported that family interference with work was associated with increased absenteeism, in terms of work interruptions and number of times absent from 
work for at least three days. A disadvantage is that the vast majority of these studies relied on cross-sectional analyses, thus prohibiting assertions on the specific causality beween work-family conflict and sickness absence. Additionally, in these studies information on sickness absence was mostly obtained through self-reports, which may have drawbacks in terms of common method variance. If companies have reliabie registration systems of sickness absence episodes, the absence data gathered from company records should be considered the preferred outcome measure. ${ }^{18}$

Whereas cross-sectional analyses gain insight in the effects that are already present at baseline measurement, the present study will additionally focus on the prospective relationship between work-family confllict and sickness absence by using absence data through company recond linkage for the prospective analyses. However, because most studies on the relationship between work-family conflict and sickness absence have relied on cross-sectional analyses, the underlying mechanism linking work-family conflict to absenteeism is relatively unknown so far, as is insight in the time course of cause and effect. The Conservation of Resources theory could be an interesting framework when considering possible mechanisms relating work-family conflict to future absenteeism. According to the Conservation of Resources (COR) model, individuals attempt to obtain, retain, protect, and foster those things that they value. ${ }^{19,20}$ These valued entities are termed resources, and include objects, conditions, personal characteristics and energies. The COR theory predicts that psychological stress occurs when individuals are threatened with resource loss, lose resources, or fail to gain resources following resource investment. ${ }^{21}$ As more conflicts and/or demands are experienced in one domain, fewer resources are available to fulfill one"s role in another domain. ${ }^{22}$ Employees struggling to combine their work and family life probably have fewer resources left for work and family demands, which may express itself in increased sickness absence. In this way, sickness absence may constitute a response to the situation where the resources of the employee are being threatened, depleted or even lost. Hence, sickness absence should probably be seen as a type of coping behavior ${ }^{23}$ not as a simple expression of a person's health or disease status, but as a type of behavior, reflecting health but also the broader life circumstances of the person. ${ }^{23-25}$ in this respect, work-family conflict may largely influence absence behavior, because employees may well be using sickness absence spells as a coping strategy to deal with stressful roles both at home and at work. ${ }^{28}$ Therefore, in this respect the follow-up period between work-family conflict and absenteeism should probably be not too long because it is rather unlikely that work-family conflict will influence absence behavior after one or two years for example.

The aims of the present study are 1) to study both cross-sectional and prospective relationships belween work-family conflict and sickness absence from work; and 2) to explore possible differences in the direction of conflict (work-home interference versus home-work interference) and sickness absence. We hypothesized that employees experiencing work-family conflict will report themselves ill at an earlier stage as compared with employees without work-family conflict. We included different absence measures to explore the nature of the relationship between work-family conflict and sickness absence, in terms of time to first sickness absence spell, and absence duration. 
All analyses are conducted for men and women separately because of reported gender differences both in work-family conflict ${ }^{8,27-29}$ and employee absenteeism. ${ }^{\text {e.9.45.26.30-32 }}$

\section{METHODS}

\section{Study population}

This study is based on data from the Maastricht Cohort Study on "Fatigue al Work" in the working population. ${ }^{6.7}$ Employees were followed by means of nine consecutive selfadministered questionnaires, which they received at four-monthly intervals. In May 1998 , a total of 26,978 employees from 45 companies received a letter at home, inviting participation, and the self-administered baseline questionnaire. A reminder was sent out after two weeks. Altogether, 12,161 employees completed and returned the baseline questionnaire (response rate of $45 \%$ ). Sixty wix questionnaires were excluded from anallysis due to technical reasons or because inclusion criteria were not met. The baseline (TO) cohort consisted of $8840(73 \%)$ men and $3255(27 \%)$ women. Information on nonresponse has been reported elsewhere. ${ }^{7,33}$

The scale used to measure work-family conflict was first included at 24 months of followup (T6, May 2000). Therefore, T6 will constitute the baseline measurement for the current study. At T6 in May 2000, the cohort consisted of 8007 employees, $5814(72.6 \%)$ men and $2193(27.4 \%)$ women. For the cross-sectional analyses at T6, several exclusion criteria were applied. We excluded those employees holding multiple jobs because we lack information about both the content of and absence behavior in the second job. Employees working less than 26 hours per week were excluded because workers with partime job may show different absence behavior as compared to fullime workers. Pregnant women were also excluded to avoid counting absence spells specifically related to pregnancy leave. These selection criteria resulted in a study population of 5072 men and 1015 women for the cross-sectional analyses.

Longitudinal data derived from self-reports in the questionnaire at T6 and register-based information on sickness absence from the participating companies and organizations in the Maastricht Cohort Study were collected between 1998 and 2001. Tiwently-two out of the 45 participating companies in the Maastricht Cohort Study supplied sickness absence data for the year 2000 . Sick leave data were available for $n=7483$ at T6. For the prospective analyses, the same exclusion criteria were applied as for the cross-sectional analyses and we additionally excluded those employees who reported themselves absent from work due to illness or reported working under modified conditions related to former sickness absence at T6, to study incident sickness absence exclusively. Further excluded were women who were on the sick list because of pregnancy or maternity leave, as well as recipients of unemployment benefits or disablement insurance benefits. After application of the above described exclusion criteria, the study population captured 3789 employees, of which 3358 were men and 431 were women. The large decrease in the number of women was mainly due to the exclusion of those employees working less than 26 hours per week. 


\section{Measures}

\section{Sickness absence}

For the present study sickness absence data from the six-months directly following the questionnaire in May 2000 were used, indicating a follow-tip period from June 2000 through November 2000. All information regarding time to onset of first sickness absence spell (irrespective of duration), and total number of days absent from work over the six months of follow-up was measured through record linkage on an individual level with the company registers on sickness absence. Apart from these sickness absence data based on the company records, employees were asked in the questionnaire to indicate whether they were absent at the time of completing the questionnaire. This latter information could be used to study the cross-sectional association between work-family conflict and sickness absence, and to exclude the employees absent from work at the tirne of completing the questionnaire for the prospective analyses.

\section{Work-family conflict}

To assess general work-family conflict we used a shortened version of the Survey Workhome Interierence Nijmegen (SWING), ${ }^{3 /, 35}$ a questionnaire designed to measure directions and domains of work-home interference (Cronbach's alpha 0.80). All 11 items were scored on a four-point scale ranging from "seldom or never" to "very often". The total score ranged from 11 to 44 . Principal components analyses generally revealed two factors for the SWING, the first representing work to home interference items, the second factor representing home to work interference items. Work-home interference was assessed with the subscale of the shortened SWING consisting of six work to home interference items (Cronbach's alpha 0.81), for example "How often does your work take up time you would rather spend with your partner, family or friends?". The total score ranged from 6 to 24. Home-work interference was measured with the subscale of the shortened SWING representing five home to work interference items (Cronbach's alpha 0.74), with a total score ranging from 5 to 20 . Examples of items of the home-work interference scale are "How often do you have little pleasure in your work, because you worry about your home situation?" and "How often do obligations at home cause you difficulty to be at work on time?". To date, there are no existing cutoff points for classifying employees with elevated work-family conflict. One option to define a contrast between employees with high versus low-medium work-family conflict is to use for example the upper lertile to classify those with high work-family conflict. However, classification of cases according to percentile scores resulted in substantial differences in degrees of severity of conflict on the three scales (work-family conflict, work-home interference, home-work interference). Therefore, as an alternative, we chose to fix the cutoff point with respect to the degree of severity on the total score of the separate scales to define a contrast between employees with high versus low-medium levels of conflict, that is all those scoring on average at least "sometimes" or more (that is "often", or "very often") on the total scale were designated as cases. This resulted in a cutoff point of $\geq 22$ for the work-family conflict scale, $\geq 12$ for the work-home interference scalle and $\geq 10$ for the home-work interference scale. 


\section{Confounding factors}

Several potential confounding factors should be controlled for when studying the relationship between work-family conflict and sickness absence. such as age and the presence of a long-term disease. Because of earlier reported gender differences both with regard to work-family conflict and absenteeism, all analyses will be conducted for men and women separately. Educational level was included as a control variable because of differences in absenteeism with different levels of educational. Educational level was recoded in three categories that is low, medium and high educational level. Because sickness absence behavior may differ between shift workers and day workers ${ }^{32}$ work schedule was also included as a control variable. We distinguished day work from shift work, where shift work captures three-shift, four-shift, five-shift and irregular shift work; all including frequent night work. The presence of dependent children at home was. also included as a control variable, because having dependent children at thome has been associated with increased absenteeism. ${ }^{\text {e.9. }}$ "4,15 Additonally characteristics of the work environment were included as potential confounders, which have been shown to be associated with sickness absence as well. ${ }^{36.38}$ The Dutch version of the Job Content Questionnaire was used to measure psychological job demands, decision latitude and social support at work. ${ }^{39-41}$ Psychological job demands were measured by the sum of five items (Cronbach's alpha 0.69). Decision latitude (Cronbach's alpha 0.81) was measured by the sum of two subscales: sikill discretion and decision authority. Social support was measured with two scales, each capturing four items: supervisor support (Cronbach's alpha 0.85) and coworker support (Cronbach's alpha 0.75). The response options varied from "strongly disagree" to "strongly agree" on a four-point scale. Emotionall demands at work were measured by the sum of five items, ranging from 0 to 5 (Cronbach's alpha 0.60 ). The questions originated from a Dutch questionnaire on Work and Health, ${ }^{42}$ the Dutch Questionnaire on the Experience and Assessment of Work, ${ }^{43}$ and one selfformulated item. These potential confounding factors were all assessed through selfreport in the questionnaire.

\section{Statistical analysis}

Logistic regression analyses were performed to study the cross-sectional relation between general work-family conflict and sickness absence at the time of completing the baseline questionnaire. Adjustments were made in three steps. In the first step, odds ratios (ORs) and $95 \%$ confidence intervals $(95 \% \mathrm{Cls})$ were calculated for work-family conflict (cases versus noncases), adjusted for age, and presence of a long-term disease. In the second step additional adjustments were made for work schedule (day work versus shift work), educational level, and having dependent children. In the third step, additionall adjustments were made for psychological job demands, decision latitude, emotional and physical demands, social support from supervisor and social support from coworkers. Multivariate survival analyses using Cox regression were conducted to examine prospective effects of work-family conflict, work-home interference and homework interference at baseline, in which we modeled the time to first sickness absence spell from work ower the six month period directly following the questionnaire at May 2000. In these analyses, all employees reporting sick at the time of completing the questionnaire and those who had not completely resumed work after a period of sick 
leave were excluded to study incident absenteeism only. For the Cox regression analyses, adjustments were made in three steps. In a first step, relative risks (RRs) and $95 \%$ confidence intenals $(95 \% \mathrm{Cls})$ were calculated for cases versus noncases of workfamily conflict, and the directions of work-family conflict, adjusted for age, and presence of a long-term disease. In a second step additional adjustments were made for work schedule, educational level, and having dependent children. In the third step, adidional adjustments were made for psychological job demands, decision latitude, emotional and physical demands, social support from supervisor and social support from coworkers. Because the distribution of total number of days absent over six months was skewed to the left like a Poisson distribution, Poisson regression analyses were used to test differences in number of sickness absence days between employees with different levels of work-family conflict. work-home interference and home-work interference. Other statistical procedures included Chi-square tests and independent samples T-tests. Data were analyzed using SPSS $11.0^{44}$ and SAS. 45

\section{RESULTS}

Table 1 presents descriptive characteristics of the study population at baseline measurement (May 2000). As shown in Table 1, employees with high work-family conflict were slightly younger compared with those experiencing lower levels of work-familly conflict. The proportion of employees who reported having a long-term disease, having dependent children living at home, as well as the proportion of employees involved in shift work was significantly higher in employees experiencing high work-family conflict as compared with employees with lower work family conflict levels.

Table 1 Descriplive characteristics study population (May 2000)

\begin{tabular}{|c|c|c|c|}
\hline & \multicolumn{3}{|c|}{ Work-family conffict } \\
\hline & Cases & Noncasesi & $p$ value \\
\hline$n$ & 593 & 5494 & \\
\hline Mall & 84.1 & 83.2 & 0.571 \\
\hline Ago mean (SD) & $42.36(7.93)$ & $43.93(8.49)$ & $<0,000$ \\
\hline Educationallevel \% & & & 0.007 \\
\hline Low & 20.2 & 18.2 & \\
\hline Mediun & 36.9 & 43.7 & \\
\hline High & 42.9 & 38.1 & \\
\hline Longwerm distase to & 31.1 & 20.0 & $<0.000$ \\
\hline Dependent children \% & 59.6 & 51.0 & $<0.000$ \\
\hline Work sichedule \% & & & $<0.000$ \\
\hline Day work & 67.1 & 82.1 & \\
\hline Shifl work & 32.9 & 17.9 & \\
\hline Psychologicat job demands meian (SD) & $35.85(5.55)$ & $32.27(5.32)$ & $<0.000$ \\
\hline Decision lalitude mean (SD) & $69.96(12.60)$ & $73.14(10.08)$ & $<0.000$ \\
\hline Emolional demands mean (SD) & $1.71(1.51)$ & $0.94(1.16)$ & $<0.000$ \\
\hline Physical demands $\%$ & 30.9 & 19.3 & $<0.000$ \\
\hline Social support supervisor mean (SD) & $9.47(2.67)$ & $10.46(2.21)$ & $<0.000$ \\
\hline Social support coworker mean (SD) & $11.48(1.76)$ & $11.85(1.49)$ & $<0.000$ \\
\hline Absent from work at time of completing questionnaire \% & 120 & 5.3 & $<0.000$ \\
\hline
\end{tabular}

* Tolal score SWING $\geq 22$

Tolal score SWNG $<22$ 
Differences in educational level were also observed. As compared with employees experiencing lower levels of work-family conflict, employees reporting high work-family conflict also experienced higher levels of psychological job demands and emotional demands, and lower levels of decision latitude, social support from supervisor and social support from coworkers. The proportion of employees experiencing high physical demands was also higher among employees with higher levels of work-family conflict as compared with employees with lower levels of work-family conflict. Finally, the proportion of employees being absent from work at the time of completing the baseline questionnaire for the present study was substantially higher in employees reporting high work-family conflict.

Table 2 shows cross-sectional associations between work-family conflict and the direction of conflict, and sickness absence at the time of completing the baseline questionnaire. High levels of work-family conflict, work-home interference and homework interference were all associated with a higher odds of being absent at the time of completing the questionnaire, after controlling for age, and the presence of a long-term disease. The highest associations were found in women. As regards the specific direction of conflict, the highest associations were found for home-work interference and sickness absence at the time of completing the baseline questionnaire. Except for the cross-sectional association between work-home interference and sickness absence, all ORs remained statistically significant after additional adjustments for work schedule, educational level and having dependent children at home.

Table 2 Cross-sectional association between work-familly contlict, work-home interference, nome-worll interference and absenteeism (cases versus noncases)

\begin{tabular}{|c|c|c|c|c|}
\hline & \multicolumn{4}{|c|}{ Men } \\
\hline & $\mathrm{n}$ & $\mathrm{OR}^{*}(95 \% \mathrm{Cl})$ & ORt (95\% Cl) & ORt $(95 \% \mathrm{Cl})$ \\
\hline \multicolumn{5}{|c|}{ Work-family conflict } \\
\hline Cases & 499 & $1.73(1.18-2.54)$ & $1.60(9.08-2.37)$ & $1.14(0.75-1.73)$ \\
\hline Noncases & 4573 & 1 & 1 & 1 \\
\hline \multicolumn{5}{|c|}{ Work-home interference } \\
\hline Cases & 1339 & $1.35(1.00-1.82)$ & $1.27(0.93 \times 1.73)$ & $0.92(0.66-1.30)$ \\
\hline Noncases & 3737 & 1 & 1 & 1 \\
\hline \multicolumn{5}{|c|}{ Home-work interference } \\
\hline Cases & 219 & $2.51(1.54-4.08)$ & $2.44(1.50 \times 3.99)$ & $1.87(1.12-3.13)$ \\
\hline \multirow[t]{3}{*}{ Noncases } & 4855 & 1 & 1 & 1 \\
\hline & \multicolumn{4}{|c|}{ Women } \\
\hline & n & $\mathrm{OR}^{*}(95 \% \mathrm{Cl})$ & $O R(95 \% \mathrm{Cl})$ & OR $(95 \% \mathrm{CH})$ \\
\hline \multicolumn{5}{|c|}{ Workffamily conflict } \\
\hline Cases & 94 & $3.72(1.93-7.18)$ & $325(1.66-6.37)$ & $2.21(1.07-4.57)$ \\
\hline Noncases & 921 & 1 & 1 & 1 \\
\hline \multicolumn{5}{|c|}{ Work -home interference } \\
\hline Cases & 265 & $1.83 \cdot(1.07 \cdot 3.14)$ & $1.56(0.89-2.74)$ & $1.00(0.54-1.83)$ \\
\hline Noncases & 748 & 1 & 1 & 1 \\
\hline \multicolumn{5}{|c|}{ Home-work interference } \\
\hline Cases & 31 & $7.34(2.81-19.16)$ & $7.15(2.72-18.82)$ & $4.97(1.81-13.68)$ \\
\hline Noncases & 984 & 1 & 1 & 1 \\
\hline
\end{tabular}

* Adifusted for age and long term disease

Additionally adjusted for educational level, wok schedule, and having dependert children:

¿Additionally adjusted for psychological job demands, decision latitude, emotional and physical demands, social supoon from superwisor and social support from coworkers 
Similar results were obtained after additionally controlling for work-related demands and social support, although all ORs were reduced in magnitude.

For the prospective analyses we examined the effects of work-family conflict and the directions of conflict on time to onset of first sickness absence spell, irrespective of sickness absence duration. We first studied the effects of one SD increase on the total scores of the separate scales to use the full continuous spectrum of the scales (specific data not shown). In men, higher home-work interference was prospectively associated with a shorter time to onset of the first sickness absence spell (RR 1.11; CI 1.04-1.17) after controlling for age and the presence of a long-term disease. This result remained statistically significant when additionally controlling for work schedule, educational level, and having dependent children (RR 1.10; $\mathrm{Cl} 1.04-1.17$ ) and even when additionally controlling for work-related demands and social support (RR $1.08 ; \mathrm{Cl} 1.01-1.15$ ). For women, the RRs for general work-family conflict and work-home interference were in the expected direction, yet just failed to reach statistical significance (RR 1.09; Cl 0.93-1.27 and $\mathrm{RR} 1.11 ; \mathrm{Cl} 0.95-1.30$ respectively) after controlling for age and the presence of a long-term disease, and also when additionally controlling for educational level, work schedule and having dependent children at home (RR 1.10; $\mathrm{Cl} 0.93-1.30$ and RR 1.13; $\mathrm{Cl}$ 0.96-1.33 respectively) and for work-related demands and social support (RR $1.08 ; \mathrm{Cl}$ $0.90-1.30$ and $\mathrm{RR} 1.12 ; \mathrm{Cl} 0.94-1.34$ respectively).

Table 3. Work-familly conflict, work-hame interference and home-work inlerterence as risk factors for a shorter time lo onset of first sickness absence speill

\begin{tabular}{|c|c|c|c|c|}
\hline \multirow{3}{*}{ Work-family conflict } & \multicolumn{4}{|c|}{ Men } \\
\hline & \multicolumn{2}{|c|}{$n \operatorname{RR}^{*}(95 \% \mathrm{Cl})$} & \multirow[t]{2}{*}{$\mathrm{RR}(95 \% \mathrm{Cl})$} & \multirow[t]{2}{*}{$\operatorname{RR}^{*}(95 \% \mathrm{Cl})$} \\
\hline & & & & \\
\hline Cases & 310 & $0.91(0.73-1.14)$ & $0.96(0.76-1.20)$ & $0.87(0.69-1.11)$ \\
\hline Noncases & 3036 & 1 & 1 & 1 \\
\hline \multicolumn{5}{|c|}{ Work-home interference } \\
\hline Casas & 866 & $0.90(0.78-1.05)$ & $0.94(0.81-1.10)$ & $0.88(0.74-1.03)$ \\
\hline Noncases & 2478 & 1 & 1 & 1 \\
\hline \multicolumn{5}{|c|}{ Home-work interterence } \\
\hline Cases & 129 & $1.08(0.78 \cdot 1.49)$ & $1.07(0.77-1.48)$ & $0.97(0.70-1.36)$ \\
\hline \multirow[t]{3}{*}{ Noncases } & 3218 & 1 & 1 & 1 \\
\hline & \multicolumn{4}{|c|}{ Women } \\
\hline & $n$ & $\operatorname{RR}^{*}(95 \% \mathrm{Cl})$ & RR: $(95 \% \mathrm{Cl})$ & RRE $195 \% \mathrm{Cl}$ \\
\hline \multicolumn{5}{|c|}{ Work-family conflict } \\
\hline Cases & 36 & $1.48(0.87-2.53)$ & $1.55\{(0.89-2.68\}$ & $1.67(0.932 .97)$ \\
\hline Noncases & 394 & 1 & 1 & 1 \\
\hline \multicolumn{5}{|c|}{ Work-home interference } \\
\hline Cases & 94 & $1.34(0.93-1.95)$ & $1.41(0.96-2.07)$ & $1.40(0.92-2.11)$ \\
\hline Noncases & 335 & 1 & 1 & 1 \\
\hline \multicolumn{5}{|c|}{ Home-work interference } \\
\hline Cases & 15 & $1.34(0.55-3.30)$ & $1.33(0.54-3.27)$ & $1.28(0.51-3.19)$ \\
\hline Noncases & 415 & 1 & 1 & 1 \\
\hline
\end{tabular}

"Adusted for age, and long tem disease

1 Additionally adjusted for educitional levef, work schedule, and having dependent children

t Additionally adjusted for psychological job demands, deciston latitude, emotional and physical demands, social support from supervisor and social support from coworkers 
Table 3 presents prospective relations between cases versus noncases of work-family conflict, the directions of conflict and time to onset of first sickness absence spell in the six months directly following the questionnaire in May 2000. For men, only nonsignificant associations were found. For women, the RRs for the relation between work-family conflict, the directions of conflict, and time to onsel of first sickness absence spell were in the expected direction, yet failed to reach statistical significance, which is probably due to the low numbers of women in the case groups.

Table 4 shows substantial differences in the average number of absent days from work over six months of follow-up among employees with different levels of general workfamily conflict, and the directions of work-family conflict. The difference in average number of absent days between cases and noncases of work-home interference was statistically significant both for men and women. The results were most pronounced for women, where the average number of absent days over six months of follow-up was almost four days higher in women with high work-home interference as compared with women with low-medium work-home interference.

Table 4 Average number of days absent from work over six months of follow-up among cases and noncases of work-family confict, work-home interference, and home-work interference

\begin{tabular}{|c|c|c|c|c|c|c|c|c|}
\hline & \multicolumn{4}{|c|}{ Men } & \multicolumn{4}{|c|}{ Women } \\
\hline & $n$ & Mean & SD & $p$ value & $\mathrm{n}$ & Mean & $\mathrm{SD}$ & $p$ walue \\
\hline Total study & 3358 & 5.44 & 17.47 & & 431 & 6.93 & 18.87 & \\
\hline \multicolumn{9}{|c|}{ Work-family conflict } \\
\hline Case & 310 & 4.90 & 16.85 & 0.336 & 36 & 9.78 & 20.64 & 0.162 \\
\hline Noncase & 3036 & 5.51 & 17.57 & & 394 & 6.69 & 18.72 & \\
\hline \multicolumn{9}{|c|}{ Wark-home interference } \\
\hline Case & 866 & 6.07 & 19.05 & 0.049 & 94 & 9.94 & 24.58 & 0.008 \\
\hline Noncase & 2478 & 5.24 & 16.93 & & 335 & 6.01 & 16.83 & \\
\hline \multicolumn{9}{|c|}{ Home-work interference } \\
\hline Case & 129 & 5.14 & 15.30 & 0.733 & 45 & 6.47 & 15.09 & 0.881 \\
\hline Noncase & 3218 & 5.47 & 17.58 & & 415 & 6.96 & 19.02 & \\
\hline
\end{tabular}

Poisson regression analyses were used to test differences in number of absent days belween cases and noncases

\section{Discussion}

As far as we know, this is the first prospective study showing an association between work-family conflict, directions of conflict, and sickness absence, even after adjusting for several important confounding factors, such as demographic factors, health and characteristics of the work environment and private situation. The results of this study showed both cross-sectional and prospective relations between work-family conflict and sickness absence. Because cross-sectional associations do not allow assertions on the specific causality of associalions between work-family conflict and sickness absence, the prospective analyses provided actual evidence that work-family conflict or the specific directions of conflict can be considered predictors of sickness absence. Especially the cross-sectional associations were very pronounced. This may indicate that a large part of the effect of work-family conflict on sickness absence may already have been present at 
baseline measurenent. Because of these high cross-sectional associations, the results from the longitudinal analyses may be underestimated. Additionally, if those employees who experience great work-family conflict have already left the labor market, the effect of work-family conflict on employee absenteeism could be underestimated even further.

In the present study we used different sickness absence measures to study the relationship between work-family conflict and sickness absence, It appears that employees experiencing high work-family conflict report themselves ill at an earlier poinl in time as compared with employees with low-medium levels of conflict, which would indicate that sickness absence in this respect might best be viewed as a behavioral expression. When studying the impact of work-family conflict on time to onset of first sickness absence spell as recorded by the employer, we disregarded the duration of sickness absence spells. Because employees experiencing high work-family conflict may use sickness absence from work as a temporary solution to cope with the demands at home and at work, distinguishing between short and long sickness absence spells would have constituted a refinement of the findings in the present study. Furthermore, differences between employees with high versus low-medium work-family conflict were observed with respect to the average number of days absent over the six months followup period. This provides indications that sickness absence as a consequence of workfamily conflict probably should not be viewed as a behavioral expression alone, but that other mechanisms play a role as well. One mechanism, in line with the Conservation of Resources theory, may be found in depleted energy resources among those workers strained by multiple roles, which may eventually result in longer sickness absence spells.

From both the cross-sectional and longitudinal analyses it appeared that the relationship between work-family conflict and sickness absence might be stronger for women as compared with men. It is often argued that because women are usually assigned primary responsibility for family matters, they are absent more often for reasons such as the care of sick children for example. ${ }^{A 6}$ in our earlier analyses regarding antecedents of workfamily conflict, we found that the onset of work-family conflict is also different for men and women $^{8}$ and that men and women further anticipate and adapt to work-family conflict situations in different ways, for example by adjusting working hours. ${ }^{\text {th }}$

The direction of conflict, in terms of work-home interference and home-work interference may constitute a further refinement of the relationship between general work-family conflict and sickness absence. In the cross-sectional analyses, both directions of conflict were associated with sickness absence. In the prospective analyses significant results were observed for the associations between work-home interference and average number of absence days over six months of follow-up both in men and women. Nonsignificant results were obtained with respect to time to sickness absence when comparing cases and noncases in the prospective analyses for men and women. For women, all associations were in the expected direction, but failed to reach statistical significance probably due to the small number of women in the case groups. When we studied the effects of ane standard deviation increase on the continuous scale, a statistical significant result was observed for the effect of home-work interference on a shorter time to sickness absence in men. One possible explamation for the discrepancy 
between the two prospective analyses in men may be that the relationship between work-family conflict, its directions, and time to sickness absence is not linear, but curvilinear in nature. Therefore, the approach where we studied the effects of one SD increase on the total scale is likely to reflect the effects of work-family conflict better from a methodological viewpoint.

When interpreting differences in sickness absence with regard to the direction of workfamily conflict, one should consider the distribution of scores, the applied cutoff point and subsequent prevalence of the different concepts. To date, there is no cutoff point for distinguishing employees with high work-family conflict. Hence, it is very difficult to distinguish between those with high versus low-medium work-family conflict, which hinders accurate classification of cases versus noncases allso in the present study. To be able to at least distinguish between those employees with higher versus lower levels of work-family conflict, we applied an arbitrary cutoff point. All those scoring on average at least "sometimes" or more (that is "often", or "very often") on the total scalle were designated as cases. This is actually quite a conservative contrast between cases and noncases. When the cutoff point was put on those scoring on average often or very often, it is likely that even higher effects of work-family conflict on sickness absence would have been observed. We also examined the effects of one standard deviation increase on the total score of the work-family conflict, work-home interference and homework interference scales, enabling us to use the full continuous spectrum of the scales and thereby avoiding the disadvantages of using an arbitrary cutoff point. These analyses showed more or less similar trends.

While the scales of work-family conflict and work-home interference were somewhat skewed, the scale home-work interference was extremely skewed to the left, indicating that the vast majority of employees reported the lowest score possible on home-work interference. This may reflect that home-work interference is not really prevalent in our study, which is in line with a study by Gutek, Searle and Klepa ${ }^{29}$ showing that men and women reported relatively little family interference with work. Other studies have also reported that work negatively influencing home is more prevalent than home negalively influencing work. ${ }^{48.49}$ More specifically, a study by Frone, Russell and Cooper ${ }^{50}$ demonstrated that the prevalence rate of work to family conflict was almost three times larger as compared with the prevallence rate for family to work conflict. So far, however, it remains unclear whether the lower prevalence of home-work interference is based on a conceptual difference, or rather reflects the severity of conflict. The possibility exists that those employees reporting high home-work interference actually experience more severe levels of conflict between work and family life as compared with those employees with high work-home interference. If the latter is true, it cannot be concluded that the effects of home-work interference on sickness absence are stronger than the effects of work-home interference, since the contrast between cases and noncases is different. An indication for this reasoning was found in Table 2 and 3 where the contrast between cases and noncases of home-work interference appears to be much higher. Additionally, the results may also be indicative that the subscale home-work interference of the SWING was unable to assess home-work interference properly and that the psychometric properties of this scale should be further improved. 
In the analyses several adjustments were made to investigate whether the effects of work-family conflict on sickness absence could be fully ascribed to work-family conflict or should be attributed to other confounding factors, known to be associated with sickness absence. Therefore, we adjusted in several steps for demographic factors, health and characteristics of the work environment and private situation. Although the ORs and RRs were reduced after controlling for characteristics in the work environment and the private situation, generally similar trends remained. The observed effects on sickness absence after controlling for confounding factors could then be fully ascribed to work-family conflict. However, in line with the Conservation of Resources theory, it could also be argued on the other hand that controlling for work-related factors and characteristics of the private situation consitutes over-control because these factors, such as for example shift work and physical demands, are also important risk factors in the onset of workfamily conflict among employees. ${ }^{B}$ Hence, an underestimation of the effects of workfamily conflict on sickness absence may have resulted. Furthermore, by controlling for all these confounding factors, many different variables are introduced in the regression analyses, capturing more missing values, which may result in a decrease of power to detect statistical significant differences between cases and noncases of work-family conflilict.

While the psychometric properties of the SWING, and especially the home-work interference subscale, require further attention, several strengths of the present study should be mentioned as well. The results of our study were based on data from a largescale prospective cohort study, enabling us to study the prospective relationship between work-family conflict and absence behavior among employees over a six months follow-up period. Sickness absence was assessed directly following work-family conflict measurement, where sickness absence was measured through linkage on an individual level with the company records on sickness absence, providing us with objective sickness absence data. Only for the cross-sectional analyses did we use sickness absence data that were derived from the questionnaire alone. Although measured by self-report, we argue that in this case no recall bias has occurred, since workers were asked for sickness absence at the time of completing the questionnaire.

Both the high cross-sectional associations between work-family conflict and sickness absence at baseline measurement and the fact that prospective associations appeared within six months of follow-up indicate that the effects of work-family conflict on sickness absence may occur rather quick over time. Therefore, prevention of sickness absence due to work-family conflict should probably focus on avoiding work-family conflict rather than intervening on employees already reporting work-family conflict. One possibility is to focus on the risk factors in the onset of work-family conflict, which were described in earlier studies and which may be different for men and women. For men, various workrelated demands, shift work, job insecurity, conflicts with coworkers or supervisor, having full responsibility for housekeeping and having to care for a chronically ill child or other family member at home were risk factors for the onset of work-family conflict, whereas decision latitude, coworker and supervisor social support protected against work-family conflict. In women, physical demands, overtime work, commuting time to work and having dependent children were risk factors for the onset of work-family conflict, whereas 
domestic help protected against work-family conflict at one year follow-up. By reducing the impact of some of these risk factors and paying more attention to those factors that are protective against work-family conflict, sickness absence due to work-family conflict might also decrease.

Future research should further focus on the underlying mechanisms relating work-family conflict to increased sickness absence to unravel potential attitudinal and health related mechanisms. Furthermore, future studies should further investigate the impact of workfamily conflict on differences in sickness absence duration, distinguishing between short and long sickness absence spells. From the present study we conclude that a clear relationship between work-family conflict and sickness absence was demonstrated, and that therefore sickness absence may be added to the list of adverse outcomes for employees struggling to combine their work and family life.

\section{ACKNOWLEDGEMENTS}

The Maastricht Cohort Study is part of the Netherlands concerted research action on "Fatigue at Work" granted by the Netherlands Organization for Scientific Research. The present study was supported by grant no. 580-02.201 from the Netherlands Organization for Scilentific Research.

\section{REFERENCES}

1. Burke RJ. Some antecedents and consequences of Work-Family conflict. J Soc Behav Pers $1988 ; 3(4): 287-302$

2. Reemers AMW. Arbeidsdeelname valn paren [Labor force participation of couples]. SociaallEconomische Maandstatistiek 2003;2:12-5.

3. Paoli P, Merllié D. Third European Survey on Working Conditions. Dublin: European Foundation for the Improvement of Living and Working Conditions; 2001

4. Landsbergis PA. The changing organization of work and the safety and health of working people: A commentary. J Occup Environ Med 2003;45(1):61-72.

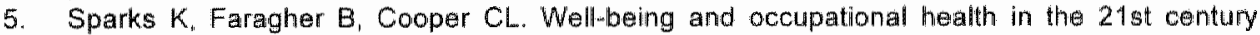
workplace. J Occup Organ Psych 2001;74(4):489-509.

6. Kant IJ, Beurskens AJHHM, Schröer CAP, Nijhuis FJN, Van Schayck CP. Van den Elzen HJ, et al. De Maastrichtse Cohort Studie naar langdurige psychische vermoeidheid in de arbeidssituatie [The Maastricht Cohort Study on fatigue at work]. TBV 2000;8(8):226-32

7. Kant UJ, Bültmann U! Schröer CAP, Beurskens. AJHM, Van Amelsvoort LGPM, Swaen GMH. An epidemiological approach to study fatigue in the working population: The Maastricht Cohort Study. Occup Enwiron Med 2003;60 (Suppl 1):i32-9.

8. Jansen NWH, Kant $I J$, Kristensen TS. Nijhuis FJN. Antecedents and consequences of workfamily conflict: a prospective cohort study. J Occup Environ Med 2003:45(5):479-91.

9. Greenhaus $\mathrm{JH}$, Beutell NJ. Sources and conflict between work and family roles. Ackad Manage Rev 1985:10(1):76-88.

10. Frone MR, Russell M, Cooper ML. Antecedents and outcomes of work-family conflict: "Testing a model of the work-family interface. J Appl Psychol 1992;77(1):65-78.

11. Allen TD, Herst DEL, Bruck CS, Sutton M. Consequences associated with work-to-family conflict: A review and agenda for future research. J Occup Health Psychol 2000;5(2):278-308.

12. Barling J, MacEwen KE, Kelloway EK, Higginbottom SF. Predictors and outcomes of eldercare-based interrole conflict. Psychol Aging 1994:9(3):391-7 
13. Steers RM, Rhodes SR. Major influences on employee attendance: A process model. I Appl Psychol 1978;63(4):391-407.

14. Brooke PP. Price $U$. The determinants of employee absenteeism: An empirical test of a causal model J Occup Psychol 1989;62:1-19.

15. Van den Heuvel A. Absence because of family responsibilities: An examination of explanatory factors. J Fam Econ lissues 1997;18(3):273-97.

16. Goff SJ, Mount MK Jamison RL. Employer supported child care, workffamily conflict, and absenteeism: A field study. Pers Psychol 1990;43(4):793-809.

17. Gignac MAM, Kelloway EK, Gottlieb $B H$. The impact of caregiving on employment: $A$ mediational model of work-family conflict. Can J Aging 1996;15(4):525-42.

18. Van Poppel MNM. De Vet HCW. Koes BW, Smid T, Bouter LM. Measuring sick leave: a comparison of self-reported data on sick leave and data from company records. Otcup Med 2002;52(8):485-90.

19. Hobfoll SE. Shirom A. Cionservation of Resources Theory. Applications to stress and management in the workplace. In: Gollembiewski RT, editor. Handbook of organizational behavior. New York: Dekker: 2001. p. 57-80.

20. Hobfoll SE. The influence of culture, community, and the nested-self in the stress process: Advancing Conservation of Resiources theory. Appl Psychol: Int Rev 2001;50:337-70.

21. Hobfoll SE. Conservation of Resources. A new attempt at conceptualizing stress. Am Psychol 1989;44(3):513-24.

22. Grandey AA, Cropanzano $R$. The Conservation Of Resources model applied to work-family conflict and strain. J Vocat Behav 1999;54(2):350-70.

23. Kristensen TS. Sickness absence and work strain among Danish slaughterhouse workers: An analysis of absence from work regarded as coping behaviour. Soc Sci Med 1991;32(1):15-27.

24. Nielsen ML, Kristensen TS, Smith-Hansen L. The Intervention Project on Absence and Wellbeing (IPAW): Design and results from the baseline of a 5-year study. Work Stress 2002:16(3):191-206.

25. Kivimäki $M$, Vahtera J, Thomson $\mathrm{L}$, Griffits $A, \operatorname{Cox} T$, Pentfi J. Psychosocial factors predicting employee sickness absence during economic decline. J Appl Psychol 1997;82(6):858-72.

26. Feeney $A$, North F, Head J, Canner R, Marmot M. Socioeconomic and sex differentials in reason for sickness absence from the Whitehall II study. Occup Environ Med 1998;55:91-8.

27. Duxbury LE. Higgins CA. Gender differences in work-family conflict. J Appi Psychol 1991;76(1):60-73.

28. Eckenrode J, Gore S. Stress and coping at the boundary of work and family. In: Eckenrode J, Gore S, editors. Stress between work and family. New York: Plenum; 1990. p. 1-16.

29. Gutek $B A$, Searle $S$, Klepa $L$. Rational versus giender role explanations for work-familly conflict. J Appl Psychol 1991;76(4):560-8.

30. Mastekaasa A. Parenthood, gender and sickness absence. Soc Sci Med 2000;50(12):1827-42.

31. Cuelenaere $B$, Jetten $B$, Van Kooten $G$. Verschillen in ziekteverzuim tussen mannen en vrouwen? Verklaringen onderzocht [Differences in sickness absence between men and women? Studying explamations]. Tijdschr Arbeidsvraagstukken 1996;12(1):43-55.

32. Smulders PGW. Personal, nonwork and work characteristics in male and female absence behavior. J Occup Behav 1983:4:285-95.

33. Jansen NWH, Van Amelsvoort LPGM, Kristensen TS, Van den Brandt PA, Kant W. Work schedules and fatigue: a prospective cohort study. Occup Environ Med 2003;60(Suppl 1):147. 53.

34. Wagena $E$, Geurts S. SWING: Ontwikkeling en validering van de 'Survey Werk-thuis Interferentie-Nilmegen' [SWING: development and validation of the 'Survey Work-home Interference Nijmegen']. Gedrag Gezond 2000;28(3):138-57.

35. Van der Hulst $M$, Geurts S. Associations between overtime and psychological health in high and low reward jobs. Work Stress 2001;15(3):227-40.

36. Smulders PGW. Nijhuis. FJN. The Job Demands-Job Control model and absence behaviour: Results of a 3-year longitudinal study. Work Stress 1989;13:115-31.

37. Alexanderson $K$. Sickness absence: a review of performed studies with focused on levels of exposures and theories utilized. Scand J Soc Med 1998;26(4):241-9 


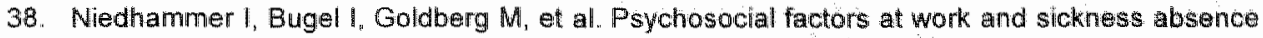
in the Gazel cohort: a prospective study. Occup Environ Med 1998;55(11):735-41.

39. Houtman 1. Reliability and validity of the Dutch version of the Karasek Job Content Questionnaire. In: NIOSHAPA conference on Stress, Work, and Health; 1995; Washington, DC: 1995

40. Karasek RA. The Job Content Questionnaire and User's Guide (version 1.1). Los Angeles: Department of Industrial and Systems Engineering, University of Southern California; 1985.

41. Niedhammer I, Goldberg M, Leclerc A, Bugel I, David S. Psychosocial factors at work and subsequent depressive symptoms in the Gazel cohort. Scand J Work Environ Health $1998 ; 24(3): 197-205$.

42. Gründemann RWM. Smulders $P W G$, De Winter $C R$. Handleiding Vragenilist Arbeid on Gezondheid [Manual, Questionnaire on work and health]. Lisse: Swets \& Zeitlinger; 1993.

43. Van Veldhoven M, Meijman TF. Het meten van psychosociale arbeidsbelasting met een vragenlijst: de vragenlijst beleving en beoordeling van de arbeid (VBBA) [The measurement of psychosocial job demands with a questionnaire (VBBA)]. Amsterdam: NIA; 1994.

44. SPSS. Base 9.0 for Windows User's Guide. Chicago: SPSS Inc.; 1998.

45. SAS Institute. SAS version 6.12. Cary, North Carolina: SAS Institute; 1989.

46. VandenHeuvel $A$, Wooden M. Do explanations of absenteeism differ for men and women? Hum Relat 1995;48(11):1309-29.

47. Jansen NWH, Kant IJ, Nijhuis FJN, Swaen GMH, Kristensen TS. Impact of working time arrangements an work-home interference among Dutch employees. Submitted for publication.

48. Geurts $S A E$. Diemerouti $E$. Work/non-work interface: a review of theories and findings. In: Schabracq MJ, Winnubst JAM, Cooper CL, editors. Handbook of work and health psychology. Chichester: John Wiley \& Sons Itd.; 2003. p. 279-312.

49. Kinnunen U, Mauno S. Antecedents and outcomes of work-family conflict among employed women and men in Finland. Hum Relat 1998;51(2):157-77.

50. Frone $M_{\text {R }}$ Russell $M$, Cooper ML. Prevalence of work-family conflict: Are work and family boundaries asymmetrically permeable? J Organ Behav 1992;13:723-9. 

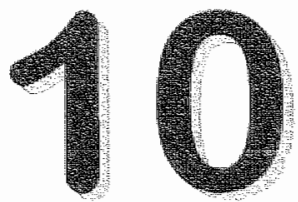

Epilogue 
The goal of this Epilogue is to describe and discuss the overall value of our studies and findings above and beyond the studies conducted. Furthermore, strengths and weaknesses of our studies and implications for the prevention of fatigue and work-family conflict are described and propositions are made for moving the focus from effects on the individual level to the family and societal level.

\section{MaIN findings}

In the Introduction chapter of the present thesis a conceptual model on the relationships between working time arrangements, work-family conflict and fatigue was postulated, in which it was hypothesized that working time arrangements could affect fatigue related outcomes on the one hand and work-family conflict on the other. Furthermore, it was hypothesized that work-family conflict could be a risk factor for fatigue as well. The proposed relationships were largely confirmed in the separate studies. This thesis clearly showed that working hours and schedules are associated with both need for recovery from work and fatigue, with different associations for men and women. A higher number of working hours per day and per week generally went together with more need for recovery from work. Other studies have also revealed that long working hours are associated with poor psychological health. ${ }^{1,2}$ Men and women with frequent overtime work, for example, had about two-fold higher odds of elevated need for recovery as compared with those without frequent overtime work. When overtime work was experienced as troublesome, men had over six-fold higher adds and women over sevenfold odds of elevated need for recovery. Work schedules were significantly associated with need for recovery as well. For instance, female three-shift workers had over fourfold higher odds and male three-shift workers had over three-fold higher odds of elevated need for recovery as compared with female and male day workers. Fatigue was also significantly more prevalent among three-shift workers $(28.6 \%)$ and five-shift workers $(23.7 \%)$ as compared with day workers $(18.1 \%)$, which is in line with other studies demonstrating that shift workers generally report more fatigue than day workers. ${ }^{3.4}$ In the time course of fatigue there were only minor differences between employees in different work schedules. Although fatigue did not significantly increase over time in neither shift nor day workers, shift work clearly sustained the higher levels of fatigue that already existed between day and shift workers. Apart from the effects of working time arrangements on fatigue related outcomes, we also observed that the prevalence of common cold, flu-like illness and gastroenteritis significantly differed between employees involved in different work schedules. So far, the most unfavorable results were consistently observed in different types of shift work. As regards the direction of shift rotation, employees working in a backward rotating schedule had about a three-fold higher risk of elevated need for recovery and poor general health as compared with employees in a forward rotating schedule in three-shift workers. Furthermore, employees in a forward rotating schedule were less likely to report work-family conflict over time.

Various characteristics of the work environiment and private situation were prospectively related to an increased risk of general work-family conflict. With regard to working time arrangements specifically, shift work as compared to day work was associated with 
higher work-home interference ower time. In fultimers, overtime work, hours of overtime work, a change in number of working hours, and commuting time to work at baseline were related to higher work-home interference over time, whereas compensation of overtime work, familiarity with work roster, the ability to take a day off and a decrease in working hours at own request were associated with less work-home interference. In partimers, overtime work and commuting time at baseline were related to higher workhome interference over time, whereas compensation of overtime work, flexible working hours and the ability to take a day off were protective against work-home interference.

Although work-family conflict has already been associated with several (mental) health outcomes in other, mainly cross-sectional, studies, ${ }^{5}$ this thesis provided longitudinal evidence that employees reporting general work-family conflict had about a one and a half times higher risk of elevated need for recovery and fatigue, compared with those not reporting work-family conflict at baseline. Furthermore, work-family conflict was prospectively associated with sickness absence as well.

Apart from the hypothesized relationships between the three main variables that were largely confirmed, also important reciprocal relations were observed between the main variables. As regards a reciprocal relationship between work schedules and fatigue, fatigue is often cited as a major ciause of shift work intolerance, ${ }^{6}$ but this thesis provided actual evidence that employees reporting fatigue or work-family conflict had about one and a half times as high probability of quitting shift work. Additionally, employees experiencing high levels of work-home interference had a substantial higher probability of changing working hours over time. For example, women experiencing elevated workhome interference had a two-fold higher probability of changing their working hours over the eight months follow-up period. Finally, indications were also observed for a reciprocal relation between work-family conflict and fatigue.

The conceptual model that was introduced in Chapter 1 was reformulated to more clearly reflect the existence and importance of reciprocal relationships as well. This revised model is shown in Figure 1.

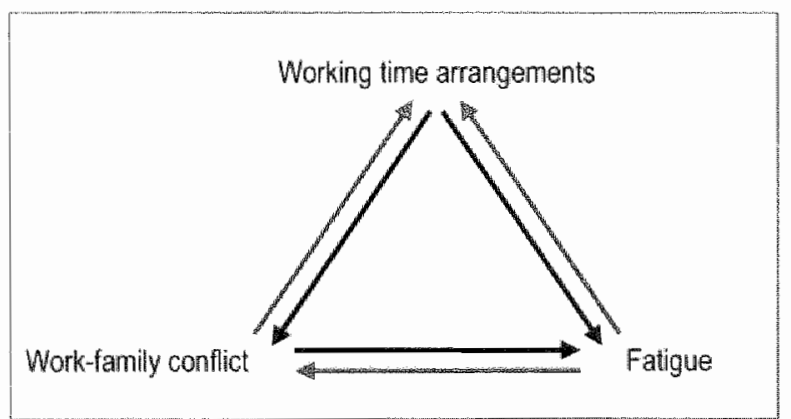

Figure I Conceptual model of proposed and observed relationships between working time arrangements "work-family conflict" and fatigue 


\section{STRENGTHS AND WEAKNESSES}

In this section the strong and weak points of our studies will be discussed, and topics needing further study will be highlighted. Because it was recognized that the three main variables used in this thesis, that is working time arrangements, work-family conflict and fatigue, as well as their mutual relationships can be very dynamic in nature, several requirements for the study design and population will be evaluated and supplemented where necessary.

\section{Operationalization and measurement main variables}

\section{Working time arrangements}

Information on working time arrangements was primarily obtained through self-report in the questionnaires. Because we were especially interested in the normal average working hours of participants per day and per week, we asked the participants in the cohort study about their usual working hours as opposed to contractual working hours. The information on work schedules was additionally checked with the company records as well. Robinson and Bostrom ${ }^{7}$ analyzed data on work hours using diaries and selfreports. They found that recall methods are accurate for those working up to 50 hours a week, but that there was a tendency to inflate work schedules among those reporting longer workweeks. May be with the exception of reporting very high working hours a week in some cases, we would argue that working time arrangements generally can be considered to reflect fairly objective exposures, in the sense that they are less dependent on specific individual's cognitions and emotions. ${ }^{8}$

In this thesis we did not incorporate the impact of domestic work hours on fatigue-related outcomes and work-family conflict. With the increase in dual-earner couples and the number of women entering the workforce, further study is required on the impact of domestic work hours an employee well being. A high domestic workload may exacerbate any negative effects from working hours. Combining both time spent at work and at home would provide more detailed insight in the complex relationship between time aspects and work-family conflict. In the analyses on the relationship between working time arrangements and work-family conflict we were able, however, to control for the responsibility for housekeeping and care for dependent children at home. This enabled us to lake into account some aspects of domestic workload. Generally, controlling for these factors resulted in only minor changes of the relationship between working time arrangements and work-home interference. An explanation for this finding could be that because we corrected for perceived job demands in the analyses before we corrected for characteristics of the private situation, a large part of the association may alleady have been explained by perceived job demands. On the other hand, our outcome work-home interference was directed at measuring the direction of work to home interference explicitly and earlier studies have reported that work-pelated factors are primary sources in explaining work to home interference, whereas family factors would be primary sources of family to work interference. ${ }^{10-12}$ 


\section{Fatigue}

Lewis and Wessely ${ }^{13}$ argued that fatigue should not be regarded as a discrete disorder. but as a continuum ranging from mild, frequent complaints seen in the community to the severe, disabling fatigue characteristics of burnout, overstrain or chronic fatigue syndrome. To be able to cover this fatigue spectrum at least to some extent, we included two different fatigue related outcome measures. Need for recovery was defined as the need to recuperate from work-induced fatigue, primarily experienced atter a day of work, and was measured by the Need for Recovery scale from the Dutch questionnaire on the Experience and Assessment of Work. ${ }^{145}$ Fatigue is seen as a subjective sensation with cognitive and behavioral components, persistent over a period of several days, also called prolonged fatigue. Prolonged fatigue is not easily reversible in the short-term and not task-specific, ${ }^{16}$ and the compensating mechanisms that were usefull in reducing acute fatigue are no longer effective. ${ }^{17}$ Prolonged fatigue was measured with the Checklist Individual Strength (CIS). ${ }^{4: 8}$ Whereas the items of the Need for Recovery scale are concerned with the recuperation period after one day of work and represent shortterm effects, the items of the CIS represent prolonged fatigue, asking employees how they felt during the past two weeks.

Although overlapping between the two fatigue-related outcomes clearly existed, notable distinctions were also observed. When regarding caseness, $25 \%$ of the emplayees with significant need for recovery reported significant need for recovery alone, without fatigue and psychological distress. From the Principal components analyses, it appeared that need for recovery did not fully capture the spectrum of prolonged fatigue as measured by the CIS. Although overlapping existed with regard to the subjective experience of fatigue, to be classified as prolonged fatigued, employees should additionally report decreased concentration, motivation, and decreased physical activity. These aspects were not captured by the items of the Need for Recovery scale, which are primarily related to the time spent after work in terms of recuperation need. The actual temporal relationship between need for recovery and prolonged fatigue, however, would be an interesting topic for further research.

In general , one might wonder whether fatigue should be taken as a serious concern for employees. In this thesis "fatigue cases were classified according to the cutoff point of scoring $>76$, a cutoff point which was established in a separate pilot study by means of defined samples with differences in fatigue levels. ${ }^{19}$ Because those employees who are designated as probable fatigue cases, have been shown to be at greater risk for acute common infections, ${ }^{20}$ accidents, ${ }^{21}$ sickness absenteeism, ${ }^{22}$ and work disability, ${ }^{23}$ fatigue itself should be considered an important precursor of further adverse outcomes and therefore deserves careful and serious consideration. For need for recovery from work a health based cut-off point is not established yet. A study by De Croon et al., ${ }^{24}$ however, did already reveal that high levels of need for recovery (upper tertile) increased the risk of subsequent sickness absence as well.

\section{Work-family conflict}

Work-familly conflict is a form of interrole conflict in which the role pressures from the work and familly domains are mutually incompatible in some respect, where workers 
have insufficient energy and/or time to successfully perform work and family roles. ${ }^{25}$ Work-family conflict represents a different type of concept as compared to mental health outcomes such as need for recovery and prolonged fatigue. Work-family conflict should probably be regarded as a cognitive construct, a reaction to the situation where the resources of the employee are being threatened, depleted or even lost. Both factors in the work environment and characteristics of the private situation were predictive of workfamily conflict among employees. Work-family conflict was obviously regarded as a serious concern by employees themselves, because work-family conflict influenced their behavior in terms of changing work schedules or working hours when they ancountered serious work-family conflict. Furthermore, work-family conflict was predictive for mental health, in terms of need for recovery and fatigue, and for sickness absence as well.

In this thesis the term work-family conflict was used to indicate general conflict between work and family where the directions of conflict are not separated. The term work-home interference was used to refer to the direction of interference from work to home, whereas home-work interference indicated the direction of interference from home to work. In additional analyses (specific data not shown) we found that $81 \%$ of all employees reporting general work-family conflict, as measured with the one item measure asking employees if they are able to adequately combine work and familly life, was also classified as a "case" (upper tertile) on the total Survey Work-home Interference Nijmegen ${ }^{26}$ capturing both work-home interference and home-work interference items, supporting the notion that our one item measure on work-family conflict was sufficiently broad to represent an overall measure of work-family conflict as well.

It is important for future studies to additionally consider how work positively affects family and how family can facilitate one's functioning at work as well. Another topic that could result in a further refinement of the findings in this thesis can be found in the impact of the organizational climate on work-family conflict. For example, when the organizational climate is not supportive to take a day off in hectic periods, this might result in an underestimation of the association between working time arrangements and work-family conflict. Taking into account the role of corporate cultures in future studies could constitute a further refinement of our findings. Further, individual characteristics such as coping strategies were not included in the present study. Frone et al. ${ }^{11.27}$ reported that intrapersonal characteristics (e.g. personality or coping styles) might be important moderators in the relation between work-family conflict and employee healih. Probably personal characteristics could also play a role in the relationship between antecedents and the development of work-family conflict. As proposed by the Conservation of Resources model as well, employees with more personal resources, such as self-esteem and adequate coping, might be better able to offsel the loss of other resources ${ }^{25}$ Including personal characteristics in future studies would prowide a further refinement of the findings of our studies as well. 


\section{Time window, follow-up and sampling frequency}

The time window with the three-year follow-up period and frequent sampling in the largescale Maastricht Cohort Study (1998 - 2001) enabled us to study almost all proposed relations between various characteristics of working time arrangements, work-family conflict and fatigue adequately.

The frequent sampling during the Maastricht Cohort Study was vital for gaining further insight in the time course between cause and effect and to study reciprocal effects between the exposure and outcome measures. Except for the analyses of shift work schedules where many of the effects were already present at baseline, the three-year follow-up period for most variables was long enough for effects to appear. For investigating the antecedents and consequences of work-family conflict, the time window and sampling frequency during the Maastricht Cohort Study turned out well, because we were able to catch at least part of the dynamic nature of work-family conflict, more insight in the time course of cause and effect and even found reciprocal effects in this respect. For many of the studied relationships a one year follow-up period was chosen. The analyses showed for example that the effects of work-family conflict on fatigue disappeared within one year. The frequent sampling during the cohort study further enabled to investigate dose-response relationships between work-family conflict and fatigue and to gain insight into the effects of prolonged exposure. We found that reporting work-family conflict at two consecutive points in time went together with an even higher risk of prolonged fatigue and need for recovery from work.

The frequent sampling during the cohort study was essential to study the impact of changes in the main variables. in this respect, we looked for instance at the effects of a change from shift work to day work on fatigue levels of employees. Compared to those remaining in shift work, employees who changed from shift to day work reported substantially higher fatigue levels on average six months prior to changing to day work. On average two months prior to changing to day work employees scored also higher on fatigue, although the fatigue levels were somewhat lower compared to six months prior to change. Possibly at this point, employees had already decided to change work schedules or had already found a future job in day work, resulting in lower fatigue levels due to the prospect of leaving their shift work job. From just after the change up till on average six months after the change to day work emplayees reported no significant differences in fatigue levels compared to those remaining in shift work. These findings indicate that the effects of a change in work schedules on fatigue can appear relatively fast.

Furthermore, it should be taken into account that also within the observed time interval changes may occur in both the exposure and outcome variables. For example, the relationship between work-familly conflict and fatigue was studied using a one-year follow-up period. In these analyses the assumption is made that work-family conflict represents a stable exposure measure predicting fatigue over time. The possibility exists of course that the experience of work-family conflict may fluctuate over time. However: indications were observed that work-family conflict might have a relatively long duration 
over time, because the prevalence of work-family conflict was $10.8 \%$ and the cumulative incidence at one year follow-up was $5.1 \%$.

Future studies on the relationship between working time arrangements, fatigue-related outcomes and work-family conflict will also need the relatively frequent sampling over time, to adequately track and take into account the dynamic nature of these variables, as well as the dynamic nature of their mutual relationships. Future studies on work schedules and fatigue might further aim at the onset of the different levels in fatigue observed among employees involved in different work schedules "ideally requiring a cohort of employees starting to work in a shift work job. The same goes for studies on work-family conflict, where it, for example, would be interesting to follow employees who are about to start a family and to investigate developments in the balance between work and family over time.

\section{Selection effects}

Without doubt, selection effects will be encountered when studying the relationship between working time arrangements, work-family conflict and fatigue. Especially with regard to shift work, it is well known that different selection processes take place. ${ }^{20}$ Due to self-selection and pre-job medical examinations, primary selection processes could have led to differences between the day and shift workers. ${ }^{29}$ The lower mean age and the larger dropout of the shift workers compared to the day workers in our study already pointed in the direction of selection. These selection processes also certainly apply to work-family conflict. As regardis primary selection processes, many employees who anticipate work-family conflict in the future may already choose a job in day work instead of shift work or parttime work as a means for reconciling work and family life. Additionally, over the course of time employees may develop preferences for a change in working time arrangements in their current job as well. For example, employees experiencing high work-familly conflict may start to work fewer hours, or quit shift work, as an option of coping with work-family conflict or fatigue. Future studies should also take into account these reciprocal effects when studying the relationship between working time arrangements and various outcomes. Because of these different selection processes an underestimation of the observed levels of fatigue and work-family conflict may have resulted.

\section{Subgroup analyses for gender}

In this thesis several gender differences were observed. Women experiencing high workhome interference had a higher probability of changing working hours over time. For men, a lower risk was observed. This could be an explanation for the counterintuitive finding that the prevalence of work-family conflict was higher in men as compared to women. Women have the more culturally accepted ways of coping with work-family conflict, such as working parttime as an option that permits for more time with their families. Interestingly, also important differences in need for recovery between men and women with regard to working hours were observed. Differences in need for recovery between men and women were highest in the groups of employees with partime jobs. It 
was found that men with a small partime job ( $\leq 25$ hours per week) generally reported higher levels of need for recovery compared to fulltime workers, whereas women with a small partime job generally reported lower need for recovery levels compared to fultime workers. Compared to men working $>25$ hours a week, the men working $\leq 25$ hours had a substantally higher prevalence of a long-term disease. In women, the presence of a long-term disease was not significantly related to their specific working hours. These examples point to the importance of conducting subgroup analyses, particularly with regard to gender, because men and women may anticipate and respond at a different stage to for example work-family conflict.

\section{PREVENTION AND REDUCTION OF FATIGUE AND WORK-FAMILY CONFLICT}

Our studies provided firm evidence for the hypothesis that working time arrangements may have a profound impact on fatigue-related outcomes and work-family conflict among employees. The effects of several aspects of working time arrangements on fatigue have similar or even greater magnitude as regards the effects of aspects of workload for example, ${ }^{30}$ a topic generally considered of great concern nowadays warranting for active interference as well. Because working time arrangements can be subject to change when necessary or requested, however, they could perhaps constitute clear starting points and utilizable tools for the prevention and reduction of fatigue and/or work-family conflict among employees.

With regard to the prevention of fatigue and work-family conflict among employees, occupational health services for example could pay more attention in risk evaluations to the role and impact of working time arrangements. While shift work schedules already receive attention in these risk evaluations, the scope of working time arrangements should be extendled and more detailed. The impact of long working hours, overtime work and commuting time for example should be incorporated and emphasized as well. Moreover, the impact of working time arrangements should always be evaluated in combination with other factors in the work environment, such as psychological job demands, physical and emotional demands for instance, that are very interrelated with the effects of working time arrangements.

Occupational physicians and general practitioners are frequently visited by employees reporting fatigue complaints ${ }^{31}$ and/or problems in combining work and family life. As regards the treatment of fatigue and work-family conflict it is imperative for general practitioners and occupational physicians to include the role of working time arrangements in their case histories, where it is important to specify working hours, work schedules, and overtime work. Particular attention should be paid to changes in these variables, and whether these changes were forced by the employer or whether the employee requested an adjustment of working time arrangements him/herself, where the latter could indicate an anticipation of or adaptation to work-family conflict and fatigue problems. It should further be realized that employees presenting work-family conflict problems also often have fatigue complaints and vice versa. Occupational physicians and general practitioners should additionally consider that the interplay between working 
time arrangements, work-family conflict and fatigue may often be different for men and women. For instance, as opposed to men, for women overtime was prospectively associated with an increased risk of work-family conflict, whereas for men psychological job demands were prospectively related to increased work-family conflict but not in women. These findings imply that a different approach regarding prevention or treatment of fatigue-related outcomes and/or work-family conflict for men and women may sometimes be warranted as well.

Whereas working time arrangements can be subject to change when necessary or requiested, it should be reminded that there are responsibilities involved for at least three parties in this respect, that is, employees themselves, employers, and the government. The accents in responsibilities may vary with different aspects of working time arrangements.

As regards the effects of working time arrangements, the most adverse effects were consistently found for shift work, which should be avoided whenever possible. Shift work schedules however, can only be changed by the employer or through government interference. Apart from choosing not to take a job involving shift work or leaving shift work altogether, the employee actually has no influence on the work schedule, which leaves him or her fully dependent on the employer or the works council in this respect.

Not all shift work types are similar in the opportunities they leave for rest and recovery between two consecutive shifts. When it is not feasible to change from shift work to day work, it is recommendable for employers to consider optimization of shift work types, in terms of the direction of shift rotation, as an option to decrease the adverse health impact of shift work. Although future studies should investigate whether our findings on the direction of shift rotation among three-shift workers are applicable to other shift work schedules as well, our findings strongly indicated that a backwards rotating shift schedule, indicating a shift system which first moves from night shift to evening shift and then to morning shift, was prospectively related to increased need for recovery, poorer sleep quality and general health, as compared to employees in a forward rotating schedule. Furthermore, employees in a forward rotating schedule were less likely to report work-familly conflict over time. In a study by Orth-Gomér among policemen ${ }^{32}$ it was also shown that the sense of general well being, in terms of longer and better sleep, was improved with a forwards rotating schedule as compared to a backwards rotating schedule. Therefore, optimization of shift work schedules in terms of forward rotation should be considered one solution to diecrease the adverse effects of working in shifts.

Shift work schedules were consistently shown to be associated with higher need for recovery, fatigue and work-family conflict on a group level. It should be noted, however, that the impact of shift work schedules on these outcomes might be different on an individual level, when one considers individual motivations to work in a certain work schedule or certain number of working hours. For example, tolerance to night work appears to increase when individuals have made the decision to work at night, rather than when night work automatically forms part of a rotating-shift schedule. ${ }^{33}$ This points to the importance of the convenience of the work hours for personal, usually domesticrelated commitments. 
Shared responsibilities can be more clearly found with regard to the antecedents of work-family conflict. Undoubtedly, the employee has an important own responsibility with regard to fine-funing hisher work and family matters. Generally we observed that a prolongation of the working day, for example by working hours, overtime work and commuting time, went together with increased work-family conflict. Where commuting time could be considered an employee's own responsibility, limiting overtime work is part of both employee and employer responsibilities, that is, the employee should not take up too much overtime work and the employer should allow the employee to limit or refuse overtime work. Although often mentioned as a solution for work-family conflict matters, in our study flexible working hours did as yet not provide a consistent structural solution for reducing work-family conflict. While this might appear counterintuitive, one explanation could be that flexible working hours do not provide a solution for employees with structural time conflicts between work and family, because the actual hours that need to be spend at work still remain the same. Employees assigned to a particular schedule may find that its flexibility does not meet with their own needs and life style. However, flexible working hours might provide a solution when employees encounter occasional time conflict situations or for employees who have the opportunity to customize their flexible work schedules to actually match their own requirements."

There are several ways in which employers could further enable their employees to combine work and familly life satisfactorily. Control over working hours and predictability of working hours in our study proved to be protective against work-home interference. In practice, this means that employees who are able to take a day off when wanted or who are familiar with their work roster in advance might be better able to fine tune work and family matters. Additionally it appeared to be very important for workers to have the ability to adjust their working hours. In this respect, the Adaptation of Working hours Act (Wet Aanpassing Arbeidsduur) from July 2000, providing employees with the right to modify their working hours, could be important in enabling employees to actually adjust their working hours.

\section{MOVING THE FOCUS FROM THE INDIVIDUAL LEVEL TOWARDS THE FAMILY AND SOCIETAL LEVEL}

The present thesis focused on outcomes for the individual employee. The thesis demonstrated strong relations between working time arrangements; work-family conflict and fatigue, and hence provided clear utilizable starting points for prevention and/or reduction of fatigue and work-familly conflict among employees. In this final section we would like to expand the focus from the individual level a step further towards the family and societal level in order to indicate that the abserved relations may not only be important for and applicable to the individual worker, but may even extend to the family and societal level as well.

Because the mutual relations between the three main variables proved to affect the individual worker profoundly, it is very likely that there will also be effects on family well being. For example, if an employee is preoccupied with work and spends so much time 
working, families may be put under strain as well. Hammer et al. ${ }^{34}$ for instance found that the partner's conflicts (which they termed cross-over effects) explained a significant amount of the variance in an individual's work-family conflict, and they adwocate moving the focus of future research to the couple. ${ }^{35}$

Moreover, when employees feel that an adequate balance between work and family life cannot be realized, this may have consequences for both family decisions and labor force participation. There is an overall decline in average household size in Europe, primarily because of declining fertility rates and an increasing number of childess families in many countries. ${ }^{36}$ Parents or potential parents who perceive their preferred work-family balance to be unachievable may alter their family behavior and choose to have children at a later age, not as many as desired, or decide to have no children at all. ${ }^{36.37}$ On the other hand, labor market behavior may be changed. As we already observed, employees may start to work fewer hours or change work schedules when they encounter conflict between work and family life. Moreover, many parents are not part of the labor force, either for the short term or on a long-term basis. This may on the one hand be because they prefer fulltime care for theif children, whatever their employment opportunities, whereas others want to increase their working hours, but refrain from doing so because resource constraints in terms of time and perhaps access to services hamper their labor force participation. ${ }^{37}$

Adema, Gray and Pearson ${ }^{37}$ described that if demographic trends and current fertility rates were to continue, futture working age populations will be smaller (and older) relative to populations of nonworking age than they are today with clear implications for future labor supply, health, retirement and other public policies. Thus, the importance of an adequate work-family balance also lies in the fact that it may greatly influence societal goals and contributes to the sustainable development of countries. ${ }^{37}$

Therefore, it would be very valuable to study nat onlly the consequences of work-family conflict on family well being and family composition within one certain country, but to make cross-national comparisons as well, because countries often greatly differ in the facilities they provide to reconcile work and family life. Where it is relatively easy to adjust working hours, by starting to work partime for example, to better fine tune work and home responsibilities in the Netherlands, this may not be so easy in other countries. Denmark, for example, has known a decrease in the proportion of parttime workers in the period of 1990 to $2000 .^{38}$ As an explanation Burr et al. ${ }^{38}$ reported that Danish labor market agreements do not make parttime work easily accessible on the one hand, and that the Danish welfare system provides day care to almost all children from two to six years of age on the other. While public expenditure on childcare is very high in Denmark, ${ }^{37}$ in other countries like the Netherlands, public policies on childcare facilities are less advanced so far, and employers are seen as important actors in the development of work-and-caring facilities. ${ }^{39}$

The conceptual model that was postulated in this chapter might constitute a valuable starting point when moving the focus towards the familly and societal level as well. In studying the interplay between work-family conflict, family well being and composition, 
and labor force participation, it is highly likely that working time arrangements again will prove to play a key role for change.

\section{REFERENCES}

1. Borg $V$ "Kristensen TS. Psychosociall work einvironment and mental health among trayelling salespeople. Work Stress 1999;13(2):132-43.

2. Sparks $K$, Cooper $C$, Fried $W$. Shirom A. The effects of hours of work on health: A metaanalytic review. J Occup Organ Psych 1997;70(4):391-408.

3. Akerstedt T. Psychological and psychophysiological effects of shift work. Scand $J$ Work Environ Health 1990,16(Suppl 1 ):67-73.

4. Akerstedt T. Sleepiness as a consequence of shift work. Sleep 1988;11(1):17-34.

5. Alleri TD, Herst DEL, Bruck CS, Sutton M. Consequences associated with work-to-family conflict: A revilew and agenda for future research. J Occup Health Psychol 2000,5(2):278-308.

6. Harrington JM. Shift work and health. A critical review of the literatule on warking hours. Ann Acad Med Singap 1994;23(5):699-705.

7. Robimson JP, Bostrom A. The overestimated workweek? What time diary measures suggest. Mon Labor Rev 1994;117:11-23.

8. Frese M, Zapf D. Methodological issues in the study of work stress: Objective ws subjective measurement of work stress and the question of longitudinal studies. In: Cooper CL, Payne $R$, editors. Causes, Coping and Consequences of Stress at Work. Chichester: Wiley; 1988. p. $375-411$

9. Sparks K, Faragher B, Cooper CL. Well-being and occupational health in the 21 sit century workplace. J Occup Organ Psych 2001;74(4):489-509.

10. Frone MR, Russell M, Cooper ML. Antecedents and outcomes of work-family conflict: Testing a model of the work-family interface. $₫$ Appl Psychol 1992;77(1):65-78.

11. Frone MR, Russell M. Cooper ML. Relation of work-familly conflict to health outcomes: A fouryear longitudinal study of employed parents. J Occup Organ Psych 1997;70(4),325-35.

12. Crouter $A C$. Spillower from family to work: The neglected side of the work-family interface. Hum Relat 1984;37(6) $425-41$.

13. Lewis $G$. Wessely $S$. The epidemiology of fatigue: more questions than answers $J$ Epidemiol Community Health $1992 ; 46(2): 92-7$.

14. Van Veldhowen M, Mejman TF. Het meten van psychosociale arbeidsbelasting met een wragenlijst: de wragenlijst beleving en beoordeling van de arbeid (VBBA) IThe measurement of psychosociall job demands with a questionmaire (NBBA)]. Amsterdam: NIA: 1994.

15. Sluter JK, Van der Beek AJ. Frings-Dresen MHW. The influence of work characteristics on the need for recovery and experienced health: A study on coach drivers. Ergonomics $1999: 4: 2(4): 573-83$

16. Mejman T. Schaufel W. Psychische vermoeidheid en arbeid; Ontwikkelingen in de A\&Opsychologie [Mental faligue and work. Developments in Work and Organizational Psychology]. Psycholoog 1996;31(6):236-41.

17. Meijman TF. Over vermoeidheid arbeidspsychologische studies naar belewing van belastingseffecten. [Fatigue: studies on the perception of workload effects]. Amsterdam: University of Arnsterdam: 1991

18. Vercoulen JH. Swanink CM, Fennis JF, Galama JM. Van der Meer JW, Bleijenberg G. Dimensional assessment of chronic fatigue syndrome. I Psychosom Res 1994;38(5):383-92.

19. Bullmann U, De Vries M, Beurskens A.HM, Bileijenberg $G$, Vercoulten JHMM, Kant Measurement of prolonged fatigue at work in the Maastricht Cohort Study: Determination of a cut off point. J Occup Health Psychol 2000,5(4):411-6.

20. Mohren DCL, Swaen GMH, Kant $\| J$, Borm PJA, Galama JMD. Associations between infections and fatigue in a Dutch working population: Results of the Maastricht Cohort Study on Fatigue at Work. Eur J Epidemiol 2001;17(12):1081-7. 
21. Swaen GMH, Van Amelsvoort LGPM, Bültmann U. Kant IJ. Fatigue as a risk factor for being injured in an occupational accident. Results from the Maastricht Cohort Study. Occup Environ Med 2003; 60(Supp 1)::8:83.

22. Janssen N, Kant IJ, Swaen GMH, Janssen PPM, Schröer CAP. Fatigue as a predictor of sickness absence: results from the Maastricht cohort study on fatigue al work. Occup Environ Med 2003: 60('Suppl 1):i71-7.

23. Van Amelsvoort LPGM, Kant IJ, Beurskens AJHM, Schröer CAP, Swaen GMH. Fatigue as a predictor of work disability. Occup Environ Med 2002,59(10):712-3.

24. De Croon EM, Sluiter JK, Frings-Dresen MHHW. Need for recovery after work predicts sickness absence: A 2-years prospective cohort study in truck drivers. I Psychosom Res in press.

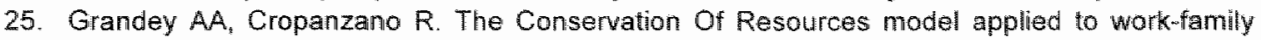
conflict and strain. J Vocat Behav 1999:54(2):350-70.

26. Wagena $E$, Geuirts S. SWING: Ontwikkeling en validering van de "Survey Werk-thuis Interferentie-Nijmegen' [SWING: development and validation of the 'Survey Work-home Interference Nijmegen']. Gedrag Gezond 2000;28(3):138-5.7.

27. Frone MR, Russell M, Barnes GM. Work-family conflict, gender, and health-related outcomes: a study of employed parents in two community samples. J Occup Health Psychol 1996;1(1):57 69.

28. Kristensen TS. Cardiovascular diseases and the work environment. A critical review of the epidemiologic literature on nonchemical factors. Scand J Work Environ Health 1989;15(3):16579.

29. Van Amelsvoort LPGM. Cardiovascullar risk profile in shift workers. Cardliac control, biologicall and lifestyle risk factors. Wageningen: Wageningen University; 2000

30. Bültmann U, Kant IJ, Van den Brandt PA, KasI SV. Psychosocial work chararteristics as risk factors for the onset of fatigue and psychological distress: Prospective results from the Maastricht Cohort Study. Psychol Med 2002;32(2):333-45.

31. Andrea $H$, Kant IJ, Beurskens AJHM, Metsemakers JFM, Van Schayck CP. Associations between fatigue attributions and fatigue, health and psychosocial work characteristics: a study among employees visiting a physician in relation to fatigue. Occup Environ Med 2003; 60(Suppl 1):199-105.

32. Orth-Gomer K. Intervention on coronary risk factors by adlapting a shift work schedule to biologic rhythmicity. Psychosom Med 1983;45(5):405-15.

33. Barton $\downarrow$. Choosing to work at night: a moderating influence on individual tolerance to shift work. J Appl Psychal 1994;79(3):449-54

34. Hammer LB, Allen E, Grigsby TD. Work-family conflict in dual-earner couples: Within-individual and crossover effects of work and family. J Vocat Behav 1997;50(2):185-203

35. Fouad NA. Tinsley HE. Work-Family Balance. J Vocat Behav 1997;50(2):141-4.

36. Van Doorne.Huiskes J, Den Dulk $L$, Schippers J. Work-farmily arrangements in the context of welfare states. In: Den Dulk L, Van Doorne-Huiskes J. Schippers J, editors. Work-familly arrangements in Europe. Amsterdam: Thela Thesis; 1999.

37. Adema W, Gray D. Pearson M. Babies and basses. Reconciling work and family life (volume 1): Australia , Denmark and the Netherlands. Paris: OECD; 2002.

38. Burr $H_{2}$ Bjorner JB, Kristensen TS, Tüchsen F, Bach E. Trends in the Danish work environment 1990-2000 and their associations with labor force changes. Submitted for publication.

39. Den Dulk L. Werkgevers en de zorgende werknemer: hoe Nederlandse, Italiaanse, Britse en Zweedse organisaties de combinatie arbeid en zorg faciliteren. Gedrag Gezond $2002 ; 15(4): 225 * 39$. 


\section{SUMMARY}

Considerable changes in working time arrangements have taken place in the twentieth century. Working time is no longer automatically organized on a weekly or anrual basis, but a more flexible approach is being adopted. Not only are working hours spread over all days of the week and all hours of the day "there are also flexible patterns within time schedules, with many European workers reporting fluctuating weekly and daily work schedules. Many work situations also require frequent overtime work due to tight deadlines, understaffing or emergency contingencies. Working time arrangements can be distinguished in several categories. One distinction is between day work, generally indicating working hours between seven am and seven pm, and shift work. Shift work can be defined as work, which includes working outside the normal working hours. Most shift work includes working nights. Shift work schedules can further be divided in discontinuous (two-shift), semi-continuous (three-shift), continuous (four-, five- and sixshift), and irregular work schedules. Although shift work has frequently been shown to have detrimental effects on the health of employees, shift work is still becoming increasingly prevalent in contemporary life. Nowadays, about one in five workers in Europe are employed in shift work involving night work. The reorganization of working time arrangements in recent decades is partly due to advances in technology and industry, but is mainly driven by employer's demands for greater flexibility in work schedules to cover extended operating or opening hours, predictable peaks in labor demand at different parts of the day, week, or year as well as less predictable requirements for additional cover due to market uncertainty.

Working time arrangements may impact on several domains. One of these domains can be found in fatigue, because working time arrangements will provide employees to a large extent with the actual time and timing to recover from their working day. Insufficient recovery from work may result in increased fatigule. A second domain where working time arrangements may impact can be made up by the reconciliation of work and family life. Rapid changes in the domains of work and caring tasks have resulted in more and more people struggling to combine work with family matters. The developments with regard to working time arrangements, where overtime work for instance poses high extensive demands for the worker, may result in a time conflict for tuning work and family life. Furthermore, trends with reglard to the job content, posing intensified demands for example with regard to working with tight deadlines, may result for workers in having too few energy left for dealing with familly matters.

In this thesis the main focus will be on the effects of various aspects of working time arrangements on fatigue related outcomes and on the (in)ability of employees to adequately combine work. Working time arrangements are in essence modifiable factors that can be subject to change when necessary or requested. Therefore, the central aims of this thesis were to study the relationship between working time arrangements and work-family conflict, and to examine the relationship between working time arrangements and fatigue. Furthermore, because those employees who report work-family conflict might be at greater risk for future fatigue, the relationship between work-family conflict and fatigue was subject of study as well. 
Chapter 1, the Introduction, describes recent trends and changes in working time arrangements, job content, the division of household and labor, possible consequences of these developments, and as such presents the rationale and aims of the thesis. Furthermore, Chapter 1 describes the design of the Maastricht Cohort Study on "Fatigue at Work", a large-scale prospective cohort study $(n=12,140)$, which constituted the sampling frame for all studies described in this thesis. In this cohort study, employees from 45 different companies were followed for three years (1998-2001) by means of nine self-administered questionnaires at four-monthly intervals. Once a year employees received an extensive questionnaire with items on work and nonwork related factors, demographics and health factors, as well as on fatigue and work-familly conflict. Twice a year employees received a short questionnaire that captured mainly outcome measures.

To address the specific aims of the thesis that were formulated in the Introduction, we first wanted more insight in the relationship between the different fatigue-related outcomes that were included in the cohort study. Chapter 2 provides a description of need for recovery from work in the working population, that is the need to recuperate from work-induced fatigue, experienced after a day of work, in which comparisons are made with other concepts such as fatigue and psychological distress. A cross-sectionall study was carried out. Some degree of need for recovery was found in nearly all employees. Need tor recovery from work was associated with demographic, work-related and health factors. Principal Components Analysis revealed obvious separation between need for recovery items and both fatigue items and psychological distress items, supporting the notion that need for recovery, fatigue, and psychological distress represent different underlying concepts. Although need for recovery, fatigue, and psychological distress were frequently comorbid, they also clearly occurred as separate entities.

To study the relationship between working time arrangements and fatigue-related outcomes several studies (Chapters 3, 4, and 5) were conducted. Chapter 3 addresses the cross-sectional relation between working time arrangements and need for recovery from work, and describes associations between need for recovery and working hours, working patterns and work schedules. Poisson regression analyses and multivariate logistic regression analyses revealed that higher working hours a day and working hours a week generally went together with more need for recovery from work. Overtime work was particularly associated with higher need for recovery from work in both genders. Both male and female three-shift or irregular shift workers had higher adds of elevated need for recovery compared to day workers. When additionally controlling for workrelated factors, need for recovery levels among shift workers substantially lowered. This study clearly showed that working hours and schedules are associated with need for recovery from work, with different associations for men and women. Especially the associations between work schedules and need for recovery from work were very interrelated with other work-related factors. Future studies could further investigate the possibilily that shift work might function as a proxy of other work-related factors that explain the different levels in need for recovery from work, or that job demands are perceived higher among shift workers and may therefore lead to more need for recovery from work. 
Chapter 4 presents the results of a study in which employees with similar job titles but on different work schedules (day work, three-shift, five-shift, and irregular shift work) were compared with regard to fatigue status and the course ffatigue over 32 months of follow-up. This chapter further describes fatigue levels among shift workers prior and after changing to day work. The prevalence of faligue was $18.1 \%$ in day workers, $28.6 \%$ in three-shift, $23.7 \%$ in five-shift, and $19.1 \%$ in irregular shift workers. For three-shift and five-shift workers substantial higher fatigue levels were observed compared to day workers at baseline measurement. In the course of fatigue over the 32 months of followup there were only small and insignificant differences between employees in different work schedules. However, among employees fatigued at baseline, fatigue levels decreased faster over time among five-shift workers compared to fatigued day workers. Shift workers changing to day work reported substantially higher fatigue levels prior to change, compared to those remaining in shift work. Substantial differences in fatigue existed between day and shift workers. However, as no considerable differences in the course of fatigue were found, these differences have probably developed within a limited time span after starting in a shift work job. Further, evidence was found that fatigue could be an important reason for quitting shift work and moving to day work. Finally, in the relation between work schedules and fatigue, perceived job characteristics might play an important role.

Chapter 5 constitutes a refinement of the concept of work sichedules and addresses the effects of shift rotation in three-shift workers on amongst others need for recovery from work, fatigue and work-farmily conflict. Moreover, the impact of need for recovery, fatigue and work-family conflict as predictors of quitting shift work is addressed. In this study we found that a backward rotating schedule was praspectively related to increased need for recovery and poor general health as compared with employees in a forward rotating schedule. Adjustment for demographic and health variables "and characteristics of the work environment did not alter these relations considerably. Furthermore, a forward rotating schedule was prospectively related to less work-family conflict and better sleep quality over the 32 months of follow-up. Finally, high levels of fatigue, need for recovery as well as poor sleep quality, poor general health, insufficient leisure time and workfamily conflict at first measurement were associated with an increased risk of leaving shift work during follow-up. From this chapter we conclude that optimization of shift work schedules, in terms of shift rotation, seems a promising method to decrease the negative impact accompanying shift work. Future studies should investigate whether the present findings for three-shift workers are applicable to other shift work schedules as well. This chapter clearly illustrates the existence of secondary selection processes in shift workers, thereby emphasizing the complexity of valid shift work research.

Because fatigue is also related to common infections and since a few studies have already explored depressed immune function in relation to shift work, the relation between work schedules and the occurrence of common infections was studied as well. Chapter 6 examined the prevalence of common infections among employees in different work schedules. Job title was used as a matching variable between day and shift workers to contral for their different work environment. We used a multilevel analysis of a two-level structure, in which the individual employees were nested within job titles, 
adjusted for demographics, longstanding disease, health behavior, work-related factors, fatigue and steep quality. Results from the multilevel analyses showed that, compared to day work, shift work was associated with a higher risk for common infections, with the highest risk in three-shift workers. Compared with day work, shift work was further associated with differences in health, health behavior, sleep, fatigue and perceived job characteristics, factors that may influence the occurrence of infections and should be taken into account in future studies as well.

In several studies (Chapters 5, 7,8, and 9) the relationship between predictors and outcomes of work-family conflict was examined. Chapter 7 studied both risk factors for the onset of work-family conflict and consequences in terms of need for recovery and prolonged fatigue for men and women separately. Two-year follow-up data from the Maastricht Cohort Study were used. At baseline, the prevalence of work-family conflict was $10.8 \%(9.0 \%$ in women; $11.1 \%$ in men). The cumulative incidence at one year follow-up was $5.1 \%$. For men, several work-related demands, shift work, job insecurity, conflicts with coworkers or supervisor, having full responsibility for housekeeping, and having to care for a chronically ill child or other family member at home were risk factors for the onset of work-family conflict, whereas decision latitude and coworker and supervisor social support protected against work-family conflict. In women, physical demands, overtime work, commuting time to work, and having dependent children were risk factors for work-family conflict, whereas domestic help protected against work-family conflict at one year follow-up. Work-family conflict was further shown to be a strong risk factor for the onset of elevated need for recovery from work and fatigue.

Chapter 8 reports the relationship between various aspects of working time arrangements and work-home interference, that is, the direction of conflict from work to home. Chapter 8 further addresses whether employees experiencing work-home interference have a higher probability of changing work hours. Data of three consecutive questionnaires from the Maastricht Cohort Study were used with eight months of followup. Working time arrangements were clearly related to work-home interference in men and women, even after controlling for confounding factors. As compared to day work, shift work at baseline was associated with higher work-home interference over time. Within day work, fulltime work was prospectively related to higher work-home interference as compared to parttime work. in fulltimers, overtime work, hours of overtime work, a change in number of working hours, and commuting time to work at baseline were related to higher work-home interference over time, whereas compensation of overtime work, familiarity with work roster and the ability to take a day off were associated with less work-home interference. In partimers, overtime work and commuting time at baseline were related to higher work-home interference over time. whereas compensation of overtime work and the ability to take a day off were prolective against work-home interference. Also reciprocal relations between work-home interference and working hours were found. From this study we conclude that working time arrangements are clearly related to work-home interference. Because reciprocal effects were shown as well, important selection processes may exist. Nevertheless, specific characteristics of working time arrangements could constitute useful tools with regard to reduction of work-home interference. 
Chapter 9 describes the role of work-family conflict as a risk factor for sickness absence, where we studied both cross-sectional and prospective relationships between workfamily conflict and sickness absence from work, and explored possible differences in the direction of conflict (work-home interference versus home-work interference) and sickness absence. Data from the Maastricht Cohort Study were used with six months of follow-up. Sickness absence was assessed abjectively through individual record linkage with the company registers on sickness absence. In the cross-sectional analyses, high levels of work-family conflict, work-home interference and home-work interference were all associated with a higher odds of being absent at the time of completing the questionnaire, after controlling for age, and the presence of a long-term disease. For women, the prospective associations between work-family conflict, the directions of conflict, and time to onset of first sickness absence spell were in the expected direction. yet failed to reach statistical significance, probably due to the low numbers of women. One standard deviation increase on the scale of home-work interference was in men associated with a shorter time to first sickness absence spell. The difference in average number of absent days between cases and noncases of work-home interference was statistically significant for men and most pronounced in women, where the average number of absent days over six months of follow-up was almost four days higher in women with high work-home interference as compared with women with low-medium work-home interference. Hence, a clear relation between work-family conflict and sickness absence was demonstrated, with differences in the impact of direction of workfamily conflict on sickness absence. The effects of work-family conflict may be stronger for women than men. Sickness absence should be added to the list of adverse outcomes for employees struggling to combine their work and family life.

In Chapter 10, the Epilogue, the overall value of our studies and findings above and beyond the studies conducted are described and discussed. Our studies provided firm evidence for the hypothesis that working time arrangements may have a profound impact on fatigue-related outcomes and work-family conflict among employees. Moreover, important reciprocal relations between working time arrangements, work-fiamily conflict and fatigue were observed. Because working time arrangements can be subject to change when necessary or requested they could constitute clear starting points and utilizable tools for the prevention and reduction of fatigue and/or work-family conflict among employees. Strengths and weaknesses of the studies and implications for the prevention of fatigue and work-family conflict are also addressed in this chapter. With regard to the prevention of fatigue and work-family conflict among employees, occupational health services for example could pay more attention in risk evaluations to the role and impact of working time arrangements. While shift work schedules already receive attention in these risk evaluations, the scope of working time arrangements should be extended and more detailed. The impact of long working hours, overtime work and commuting time for example should be incorporated and emphasized as well. As regards the treatment of fatigue and work-family conflict it is imperative for general practitioners and occupational physicians to include the role of working time arrangements in their case histories, where it is important to specify working hours, work schedules, and overtime work. Particular attention should be paid to changes in these variables, and whether these changes were forced by the employer or whether the 
employee requested an adjustment of working time arrangements him/herself, where the latter could indicate an anticipation of or adaptation to work-family conflict and fatigue problems. Occupational physicians and general practitioners should additionally consider that the interplay between working time arrangements, work-family conflict and fatigue might often be different for men and women. Chapter 10 concludes with propositions for moving the focus from effects on the individual level to the family and societal level. The observed relations between working time arrangements, work-family conflict and fatigue, may not only be important for and applicable to the individual worker "but may even extend to the family and societal level as well. When employees feel that an adlequate balance between work and family life cannot be realized, this may have consequences for both family decisions and labor force participation. The conceptual model that was postulated in this thesis might constitute a valuable starting point when moving the focus towards the family and societal level as well. In studying the interplay between workfamilly conflict, family well being and composition, and labor force participation, it is highly likely that working time arrangements again will prove to play a key role for change. 


\section{SAMENVATTING}

In de twintigste eeuw hebben aanzienlijke veranderingen plaatsgevonden in de duur, het patroon en de inhoud van betaalde arbeid. Deze veranderingen zijn ten dele toe te schrijven aan de ontwikkelingen in de technologie en industrie, maar worden hoofdzakelijk ingegeven door een grotere vraag van werkgevers naar flexibiliteit in arbeidspatronen om langere bedrijfs- of openingsuren te kunnen realiseren, en voorspelbare en onvoorspelbare pieken in het productieproces mogelijk te maken op verschillende delen van de dag, de week of het jaar. Zo zijn met name in de Westerse wereld werktijden niet langer georganiseerd op een wekelijkse of jaarlijkse basis, maar is er sprake van een meer flexibele benadering, waarbij arbeidsuren verdeeld kunnen worden over alle dagen van de week en alle uren wan de dag. Dit leidt tot verschillende arbeidspatronen waarbij zelfs wekelijkse en dagelijkse fluctuaties mogelijk zijn. Het arbeidspatroon van werknemers kan in verschillende categorieën worden onderverdeeld. Een onderscheid is tussen dagdienst, dat in het algemeen duidt op werk tussen zeven uur 's ochtends en zeven uur 's avonds, en ploegendienst. Ploegendienst kan gedefinieerd worden als werk dat plaatsvindt buiten de normale werktijden. Bij de meeste ploegendiensten werkt men ook regelmatig 's nachts. Ploegendienst kan verder worden onderverdeeld in discontinue roosters (twee-ploegendienst), semi-continue roosters (drie-ploegendienst), volcontinue roosters (vier-, vijf-en zes-ploegendienst), en onregelmatige dienst roosters. Hoewel frequent is aangetoond dat het werken in ploegendienst nadelige gezondheidseffecten heeft, neemt het aantal werknemers dat werkzaam is in een of andere vorm van ploegendienst alleen maar toe. Tegenwoordig is een op de vijf werknemers in Europa werkzaam in ploegendienst met geregeld nachtdienst. Niet alleen het arbeidspatroon is aan verandering onderhevig, maar ook de arbeidsduur. Zo vragen krappe deadlines, onderbemanning of onvoorziene gebeurtenissen ook frequent overwerk. Het aantal uren dat werknemers werken (arbeidsduur) en het arbeidspatroon waarin ze werkzaam zijn, zijn de voornaamste onderdelen van de werktijdregeling. Deze werktijdregeling kan tussen bedrijven en individuen sterk verschillen. Daarnaast is ook de arbeidsinhoud (o.a. werkdruk, taakeisen en regelmogelijkheden) de laatste decennia aan veranderingen onderhevig.

Werktijdregelingen kunnen consequenties hebben op verschillende domeinen. Een van deze domeinen betreft vermoeidheid, aangezien werktijdregelingen in eerste instantie de duur en het tijdstip voor herstel van de werkdag bepalen. Onvoldoende herstel van werk kan resulteren in toenemende vermoeidheid. Een tweede domein heeft betrekking op het combineren van werk en privéleven. Snelle veranderingen op het gebied van werk en zorgtaken hebben erin geresulteerd dat meer en meer mensen moeite hebben om werk en privé adequaat te kunnen combineren. Frequent overwerk bijvoorbeeld, stelt hoge eisen aan de werknemer in de zin van verlengde werkdagen, hetgeen kan resulteren in een tijdsconflict met betrekking tot de afstemming van werk en privé. Daarnaast kunnen ontwikkelingen op het gebied van de arbeidsinhoud, bijvoorbeeld het werken onder hoge tijdsdruk, resulteren in minder energie om met zaken in de thuissituatie om te gaan.

In dit proefschrift ligt de nadruk op de effecten van allerlei aspecten van werktijdregelingen op vermoeidheidsgerelateerde uitkomsten en het (on)vermogen werk 
en prive adequat te combineren. Werktijdregelingen zouden namelijk belangrijke sitartpunten voor preventie van vermoeidheid en werk-thuis conflict kunnen zijn, aangezien werktijdregelingen in essentie modificeerbaar zijn, indien noodzakelijk of gewenst. De centrale vraagstellingen wan dit proefschrift zijn er op gericht om meer inzicht te verschaffen in de relatie tussen werktjdregelingen en vermoeidheid enerzijds en de relatie tussen werktijdregelingen en werk-thuis conflict anderzijds. Aangezien de mogelikheid bestaat dat werknemers die werk-thuis conflict ervaren eveneens een hoger risico op langdurige vermoeidheid hebben, is ook de relatie tussen werk-thuis conflict en vermoeidheid onderwerp van studie.

Hoofdstuk 1, de Inleiding, beschrift recente ontwikkelingen en veranderingen op het gebied van werktijdregelingen, arbeidsinhoud, en de verdeling van werk en privé, evenals mogelijke consequenties van deze ontwikkelingen en presenteert als zodanig de rationale en doelstellingen van dit proefschrift. Daarnaast wordt in Hoofdstuk 1 het design van de Maastrichtse Cohort Studie naar langdurige vermoeidheid in de arbeidssituatie toegelicht. De data van deze grootschalige prospectieve cohort studie $(n=12,140)$ wormen de basis voor alle in dit proefschrift beschreven studies. In deze cohort studie werden werknemers uit 4.5 verschillende bedrijven en instellingen gedurende drie jaar (1998-2001) opgevolgd met behulp van negen wragenlijsten, die zij ledere vier maanden ontvingen. Een maal per jaar kregen de deelnemers een uitgebreide wragenlijst met items over werk en niet werkgerelateerde factoren, demografische- gezondheidskenmerken, evenals over vermoeidheid en werk-thuis conflict. Twee maal per jaar ontvingen de werknemers een korte vragenlijst waarin hoofdzakelijk uitkomsten werden gemeten, zoals herstelbehoefte en vermoeidheid.

Om de verschillende vraagstellingen te kunnen beantwoorden, wilden we eerst meer inzicht in de relatie tussen de verschillende vermoeidheidsgerelateerde uitkomstmaten die in de cohort studie waren opgenomen. Hoofdstuk 2 geeft een beschrijving van het concept herstelbehoefte, dat wil zeggen de behoefte om te herstellen van werkgerelateerde vermoeidheid na een werkdag. In dit hoofdstuk worden vergeiljkingen gemeakt mel andere concepten, zoals vermoeidheid en psychische klachten. Hoofdstuk 2 betreft een dwarsdoorsnede onderzoek. Enige mate van herstelbehoefte werd waargenomen bij vrijwel alle werknemers. Herstelbehoefte was geassocieerd met demografische, werkgerelateerde en niet-werk gerelateerde factoren. Principale Componenten Analyse liet een duidelijke scheiding zien tussen herstelbehoefte items enerzijds en vermoeidheidsitems en items die betrekking hadden op psychische klachten anderzijds. Dit biedt ondersteuning voor de hypothese dat herstelbehoefte, vermoeidheid en psychische klachten andere onderliggende constructen weergeven. Hoewel herstelbehoefte, vermoeidheid en psychische klachten regelmatig tegelijkertijd voorkwamen bij werknemers, kwamen deze klachten ook afzonderlijk woor.

Verschillende studies zijn uitgevoerd om de relatie tussen werktijdregelingen en vermoeidheidsgerelateerde uitkomsten in kaart te brengen (Hoofdstuk 3, 4 en 5). Hoofdstuk 3 beschrijft de cross-sectionele relatie tussen arbeidsduur, arbeidspatroon en herstelbehoefte. Poisson regressie en multivariate logistische regressie analyses laten zien dat een hoge arbeidsduur per dag en per week over het algemeen gepaard gaat 
met een hogere herstelbehoefte. Met name frequent overwerk bleek geassocieerd met een hoge behoefte aan herstel bij mannen en wrouwen. Zowel mannelijke als vrouwelijke drie-ploegendienstmedewerkers en werknemers in onregelmatige dienst vertonen een grotere kans op een verhoogde herstelbehoefte in vergelijking met dagdienstmedewerkers. Additionele correctie voor de arbeidsinhoud in deze analyses resulteerde in een aanzienlijke verlaging van de herstelbehoefte niveaus. In dit hoofdstuk werd duidelijk aangetoond dat arbeidsduur en arbeidspatroon sterk geassocieerd zijn met herstellbehoefte, met verschillende resultaten voor mannen en vrouwen. Met name de associaties tussen arbeidspatronen en herstelbehoefte zijn echter sterk verweven met de arbeidsinhoud. Toekomstig onderzoek moet uitwijzen of ploegendienst feitelijk fungeert als een proxy voor arbeidsininoud, of dat de arbeidsinhoud door ploegendienstmedewerkers als zwaarder wordt ervaren en zodoende tot een hogere herstelbehoefte leidt.

Hoofdstuk 4 beschrijf een onderzoek naar het wórkomen en het beloop van vermoeidheid bij verschillende arbeidspatronen (dagidienst, drie-ploegendienst, vijfploegendienst, en onregelmatige dienst). Hiertoe werden werknemers met een zelfde beroep, maar werkzaam in een verschillend arbeidspatroon, gedurende 32 maanden opgevolgd. De prevalentie van vermoeidheid was $18.1 \%$ bij dagdienstmedewerkers, $28.6 \%$ bij drie-ploegendienstmedewerkers, $23.7 \%$ bij wijf-ploegendienstmedewerkers, en $19.1 \%$ bij werknemers in onregelmatige dienst. Bij de eerse meting werden aanzienlijk hogere vermoeidheidsniveaus gevondem bij drie- en vijf-ploegendienstmedewerkers in vergelijking met dagdienstmedewerkers. In het beloop van vermoeidheid over 32 maanden follow-up werden slechts geringe en miet significante werschillen waargenomen tussen werknemers in verschillende arbeidspatronen. Echter, bij werknemers die vermoeid waren bij de eerste meting, namen de vermoeidheidsniveaus sneller af in de loop der tijd bij vijf-ploegendienst medewerkers in vergelijking met vermoeide dagdienst medewerkers. Dezelfde studie toonde aan dat ploegendienstmedewerkers die veranderden naar een baan in dagdienst aanzienlijk hogere vermoeidheidsniveaus rapporteren vór de verandering naar dagdienst in vergelijking met werknemers die in ploegendienst werkzaam bliven. Aangezien geen substantiele verschilen in het beloop van vermoeidheid werden gevonden tussen werknemers in verschillende arbeidspatronen, is hel aannemelijk dat de verschillen in vermoeidheid die al bij de eerste meting aanwezig waren, zich ontwikkeld hebben in het tijdsbestek kort na aanvang van het werken in ploegendienst. Daarnaast werd bewijs gevonden dat vermoeidheid een belangrijke reden kan zijn om ploegendienst te verlaten en over te gaan tot uitsluitend werken in dagdienst. Tenslotte lijken werkkenmerken een belangrijke rol te spelen in de relatie tussen arbeidspatronen en vermoeidheid.

In Hoofdstuk 5 wordt een studie naar mogelijke effecten van ratatierichting bij drieploegendienstmedewerkers beschreven. Het hoofdstuk vormt daarmee een verfijning van het concept arbeidspatroon. In dit hoofdstuk wordt hel effect van rotatierichting op onder andere herstelbehoefte, vermoeidheid, en werk-thuis conflict beschreven. In dit onderzoek werd gevonden dat een achterwaartse rotatie prospectief geassocieerd is met een verhoogde herstelbehoefte en een slechtere algemene gezondheid in vergelijking met werknemers in een voorwaards roterend drie-ploegendienst rooster. Controle voor 
demografische en gezondheidsvariabelen, evenals kenmerken uit de werkomgeving. veranderde deze bevindingen niet substantjeel. Een voorwaarts roterend schema in drieploegendienst was prospectief geassocieerd met minder werk-thuis conflict en een betere slaapkwaliteit over 32 maanden follow-up. Ten slotte zijn hoge vermoeidheids-en herstelbehoefte niveaus evenals een slechte slaapkwaliteil bij de eerste meting geassacieerd met een hoger risico op hel werlaten van ploegendienst gedurende de follow-up. Uit de resultaten van dit hoofdstuk wordt geconcludeerd dat optimisatie van ploegendienstroosters, in termen van rotatierichting, een veelbelovende methode kan zijn om de negatieve effecten van het werken in ploegendienst te reduceren. Verder onderzoek dient uit te wijzen of deze bevindingen voor drie-ploegendienstmedewerkers ook van toepassing zijn op andere ploegendienstroosters. Dit hoofdstuk illustreert op duidelijke wijze het bestaan van secundaire selectieprocessen bij ploegendienst medewerkers en benadrukt daarmee de complexiteit van valide ploegendienst onderzoek.

Aangezien vermoeidheid ook gerelateerd is aan acute infecties en enkele studies reeds een onderdrukte immuunfunctie in relatie tot ploegendienst bestudeerd hebben, is er eveneens gekeken naar de relatie tussen arbeidspatroon en het optreden van acute infecties. In Hoofdstuk 6 wordt de prevalentie van acute infecties bestudeerd bij werknemers in verschillende arbeidspatronen. Om rekening te houden met verschillen in werkinhoud werden de dagdienst- en ploegendienst medewerkers gematched op beroep. Multilevel analyses zijn uitgevoerd, waarin de individuele werknemers (niveau 1) genest zijn in beroepen (niveau 2), waarbij in verschillende stappen gecorrigeerd is voor demagrafische factoren, langdurige ziekte, gezondheidsgedrag, werkgerelateerde factoren, vermoeidheid en slaapkwaliteit. De multilevel analyses lieten zien dat het werken in ploegendienst geassocieerd is met een hoger risico op infecties in vergelijking met het werken in dagdienst. Het hoogste risico werd waargenomen in drieploegendienst. Vergeleken met het werken in dagdienst, bleek het werken in ploegendienst verder geassocieerd met verschillen in gezondheid, gezondheidsgedrag, slaap, vermoeidheid, en ervaren werkkenmerken, hetgeen factoren zijn die mogelijk ook het optreden van infecties beïnvloeden en daarom ook in toekomstig onderzoek meegenomen dienen te worden.

Verschillende studies zijn uitgevoerd om meer inzicht te verkrijgen in voorspellers en uitkomsten van werk-thuis conflict (Hoofdstuk 5, 7, 8 en 9). Hoofdstuk 7 beschrijft zowel risicofactoren in het ontstaan van werk-thuis conflict en de gevolgen van werk-thuis conflict, in termen wan herstelbehoefte en langdurige vermoeidheid, voor mannen en vrouwen afzonderlijk. Hiertoe werden twee jaar follow-up gegevens van de Maastrichtse Cohort Studie geanalyseerd. Bij de eerste meting was de prevalentie van werk-thuis conflict $10.8 \%(9.0 \%$ bij vrouwen; $11.1 \%$ bij mannen). De cumulatieve incidentie bij 1 jaar follow-up was 5.1\%. Voor mannen waren verschillende werk-gerelateerde factoren, het werken in ploegendienst, toekomstonzekerheid, conflicten met collega's of de dagelijkse leiding, volledige verantwoordelijkheid voor het huishouden, evenals de zorg voor een chronisch ziek of gehandichapt kind of ander familielid, risicofactoren voor het optreden van werk-thuis conflict. Regelmogelijkheden in het werk en sociale steun van collega's of dagelijkse leiding beschermden daarentegen tegen werk-thuis conflict. Bij vrouwen 
bleken fysiek inspannend werk, frequent overwerk, een lange reistijd van en naar het werk, en de zorg voor thuiswonende kinderen, risicofactoren voor het ontstaan van werkthuis conflict. Daarentegen bleek het hebben van huishoudelijke hulp beschermend tegen werk-thuis conflict bij 1 jaar follow-up. Werk-thuis conflict zelf was een sterke risicofactor voor het optreden van een verhoogde herstelbehoefte en vermoeidheid.

Hoofdstuk 8 beschrijft een studie naar de relatie tussen verschillende aspecten van werktijdregelingen en werk-thuis interferentie. Data van drie opeenvolgende vragenlijsten van de Maastrichtse Cohort Studie zijn gebruikt met acht maanden follow-up. Werktijdregelingen bleken duidelijk gerelateerd aan werk-thuis interferentie bij mannen en vrouwen, zelfs na correctie voor bellangrijke confounders. In vergelijking met het werken in dagdienst, was ploegendienst geassocieerd met hogere werk-thuis interferentie in de prospectieve analyses. Binnen dagdienst, was fulltime werk prospectief geassocieerd met hogere werk-thuis interferentie in vergelijking met parttime werk. Binnen fulltime werkers bleek frequent overwerk, aantal uren overwerk, een verandering in arbeildsduur, en reistijd naar het werk geassocieerd met een hogere werkthuis interferentie over 8 maanden follow-up. Compensatie van overwerk, bekendheid met het werkrooster, en de mogelijkheid een dag wrij te nemen indien nodig, waren geassocieerd met minder werk-thuis interferentie daarentegen. Bij partime werkers was overwerk en reistijd bij de baseline meting geassocieerd met meer werkuthuis interferentie in de tijd, terwijl compensatie van overwerk flexible arbeidstijden en de mogelijkheid een dag vrij te nemen indien nodig, beschermden tegen werk-thuis interferentie. Daarnaast werden ook reciproke relaties tussen werk-thuis interferentie en arbeidsduur aangetoond. Deze studie toont aan dat werktijdregelingen duidelijk van inviloed zijn op werk-thuis interferentie. Aangezien ook reciproke relaties werden gevonden, zullen belangrijke selectieprocessen eveneens bestaan. Desalniettemin kunnen specifieke kenmerken van werktijdregelingen belangrijke en bruikbare middelen $z$ ijn met het oog op reductie van werk-thuis interferentie.

Hoofdstuk 9 beschrijft de rol van werk-thuis conflict als risicofactor woor zietkteverzuim. Hiertoe werden zowel de cross-sectionele als prospectieve relaties tussen werk-thuis conflict en ziekteverzuim bestudeerd. Bovendien zijn mogelike verschillen in de richting van conflict (werk-thuis unterferentie en thuis-werk interferentie) onderzocht. Ziekteverzuim werd objectief gemeten middels koppeling van de gegevens van de individuele werknemer met de bedrijfsgegevens over ziekteverzuim. In de crosssectionele analyses bleken hoge niveaus van algemeen werk-thuis conflict, werk-thuis interferentie en thuis-werk interferentie allen geassocieerd met een hogere kans op afwezigheid van het werk op het moment van invulien van de vragenlijst, na correctie voor leeftijd en het hebben van een langdurige ziekte. Voor vrouwen waren de prospectieve associaties tussen werk-thuis conflict, de richtingen van conflict, en de tijd tot eerste ziekmelding in de verwachte richting, maar bereikten, waarschijnlijk door de lage aantallen vrouwen, geen statistische significantie. Een toename van een standaard deviatie op de schaal thuis-werk interferentie was bij mannen geassocieerd met een kortere tijd tot eerste ziekmelding. Het verschil in gemiddeld aantal ziekteverzuimdagen tussen werknemers met en zonder werk-thuis interferentie was statistisch significant voor zowel mannen als vrouwen. Dit verschil was het meest uitgesproken bij vrouwen 
waar het gemidideld aantal ziekteverzumdagen over een half jaar follow-up bijna wier dagen hoger lag bili vrouwen met hoge werk-thuis interferentie in vergelijking met vrouwen met lagere werk-thuis interferentie. In deze studie werd een duidelijke relatie gevonden tussen werk-thuis conflict en ziektewerzuim, met verschillende bewindingen voor de richting wan werk-thuis conflict. De effecten van werk-thuis conflict op zilekteverzuim zijn wellicht sterker voor vrouwen dan voor mannen. Uit deze studie wordt geconcludeerd dat ziekteverzuim toegevoegd dient te worden aan de reeks vam negatieve consequenties voor werknemers die werk en privé niet goed kunnen combineren.

Hoofolstuk 10 vormt de Epiloog van dit proefschrift. In dit hoofdstuk worden de bevindingen uit de voorgaande hoofdstukken bediscussieerd. De studies bieden sterk bewijs voor de hypothese dat werktijdregelingen grote invloed hebben op vermoeidheidsgerelateerde uitkomsten en werk-thuis conflict. Dezelfde studies tonen verder aan dat er tussen werktijdregelingen enerzijds en vermoeidheid en werk-thuis conflict anderzijds ook duidellike reciproke relaties bestaan. Zo neigen vermoeide werknemers eerder tot verandering van werktijd dan niet vermoeide werknemers. Aangezien werktijdregelingen in principe modificeerbaar zijn, kunnen zij een belangrijk startpunt vormen voor de preventie en reductie van vermoeidheid en/of werk-thuis conflict. Sterke en zwakke punten van de verschillende studies en implicaties voor de preventie van vermoeidheid en werk-thuis conflict worden eveneens beschreven. Ten aanzien van de preventie van vermoeidheid en werk-thuis conflict wordt benadrukt dat arbodiensten in risico-evaluaties meer aandacht aan de rol van werktijden dienen te besteden, inclusief de rol van arbeidsiduur, patroon en overwerk. Ten aanzien van de behandeling van vermoeidheid en werk-thuis conflict is het belangrijik dat huisartsen en bedrijfsartsen de rol van werktijdregelingen in hun anamnese meenemen, waarbij het belangrijk is om arbeidsduur, arbeidspatroon en overwerk nauwgezet te specificeren. Hierbij verdienen veranderingen in arbeidsduur en/of patroon speciale aandacht. In kaart gebracht dient te worden of het een verandering betreft die door de werkgever werd opgelegd of dat het een verandering op eligen verzoek was. Het laatste zou kunnen wijzen op een anticipatie van of adaptatie aan werk-thuis conflict of vermoeidheidsklachten. Daarnaast dienen huisartsen en bedrijfsartsen erop bedacht te zijn dat het samenspel van werktijdregelingen, vermoeidheid en werk-thuis conflict voor mannen en vrouwen zeer verschillend kan zijn. Hoofdstuk 10 besluit met de propasitie dat de gevonden effecten van werktijdregelingen, werk-thuis conflict en vermoeidheid, niet alleen belangrijk en van toepassing zijn op de individuele werknemer, maar zich wellicht ook kunnen uitbreiden naar het gezin (o.a. gezinskeuze en arbeidsparticipatie) en uiteindelijk ook effecten kunnen hebben op de maatschappii als geheel (demografie en arbeidsparticipatie). Het conceptuele model dat in dit proefschrift werd uiteengezet. kan wellicht ook gebruikt worden voor hel bestuderen van effecten op het gezin en de maatschappij als geheel. Ook hierbij zal een belangrijke rol zijn weggelegd voor werkikijdregelingen. 


\section{DANKWOORD}

Veel mensen zijn betrokken geweest bij de totstandkoming van dit proefschrift. Al deze mensen will ik hartelijk bedanken. Een aantal mensen wil ik daarnaast in het bijzonder noemen.

Allereerst wil ik IJmert Kant, mijn copromotor, bedanken. Beste IJmert, jouw enthousiaste, betrokken en deskundige begeleiding in de afgelopen jaren waren een echte stimulans en steun voor mij, en dat alles in een samenwerking die ik als bijzonder plezierig heb ervaren. Fijn dat ik altijd bij je binnen kon vallen voor vragen of advies op welk gebied dan ook. UJmert "ik heb enorm veel van je geleerd, en daarvoor ben ik je erg dankbaar.

Vervolgens wil ik de beide promotoren, Piet van den Brandt en Frans Nijhuis, bedanken. Beste Piet, hartelijk bedankt voor je bijdrage aan de totstandkoming van dit proefschrift. Ik heb je kritische commentaar op mijn werk en je voortgangsbewaking erg gewaardeerd. Beste Frans, ook jouw bijdrage aan dit proefschrift stel ik erg op prijs. Op de achtergrond hield je de grote lijnen in de gaten en voorzag je me van waardevol advies.

I also whish to express special gratitude to professor Tage Kristensen from the National Institute of Occupational Health in Copenhagen, Denmark, who became actively involved in this project several years ago. Dear Tage, I am very thankful for your commitment and enthusiasm during the journey to thesis defense. As chief of the Danish jury, you always provided me with lots of constructive criticism and good feedback for improving my work, which was an important source of insight and inspiration for me!

De meer dan 12,000 werknemers die deelnamen aan de Maastrichtse Cohort Studie naar vermoeidheid in de arbeidssituatie verdienen een speciaal woord van dank. Met hun trouwe en langdurige deelname aan het onderzoek is de Maastrichtse Cohort Studie tot een prachtige bron van informatie geworden.

Gerard Swaen, bedankt voor alle mogelijkheden om met de resultaten van ons onderzoek op pad te gaan, je aanvullingen op de artikelen, maar ook voor het op zijn tijd organiseren van arbeidsepi-etentjes die bijdroegen aan een goede werksfeer. Ludovic van Amelsvoort, jij was lid van de projectgroep. Bedankt voor je leerzame adviezen op het gebied van plcegendiensten en ook op het statistisch vlak, en je gezelschap naar Zushi station. Jos Slangen, ik ben je erg dankbaar voor je belhulpzaamheid en grote inzet in de Maastrichtse Cohort Studie, maar natuurlijk ook voor het op peil houden wan de vitamine $C$ voorraad! Marliese Saya wil ik graag bedanken voor haar zorgvuldige hulp bij het lay-outen wan dit proefschrift. 'Oude en nieuwe' collega's wan Arbeidsepidemiologie, Sandra Beurskens, Samne Imbos en Saskia Duijts, dank voor de samenwerking binnen het Arbeidsepi-team.

De Maastrichtse PVA-AiO"s, Danielle Mohren, Ute Boiltmann, Nathalie Janssen, Marcus Huibers en Helene Andrea wil ik graag bedanken voor hun fijne samenwerking in de afgellopen jaren. Danielle, ik ben erg blij dat je mijn paranimf wilt zijn. Gedurende de rit naar de promotie toe hebben we heel wat meegemaakt. Wat hebben we gelachen 
(wellswaar soms pas achterafl) met onze handzame 'koffertjes' op weg naar Boston. op de step in Provincetown, Riz Raz in Kopenhagen, en met Bunzy Buddy die in minn computer een nieuw en permanent tehuis zocht. Bovenal waardeer ik het dat we ook naast de lach zoveel dingen samen konden delen in de afgelopen jaren.

Ute, thet was altijd fijn binnenvallen bij je, en over werk en privé bij te praten. Nathalie, bedankt voor alle gezellige etentjes, dat we nog maar veel restaurantjes gaan uitproberen samen! Marcus, bedankt voor je belangstelling en support in de eindspurt naar onze promoties in drie dagen tijd! Helene, bedankt voor je altijd vrolijke noot.

Verder wil ik de (oud)collega"s van de capaciteitsgroep Epidemiologie bedanken woor hun belangstelling en de prettige werksfeer. Boukje van Dijk, mijn kamergenoat bij Epidemiologie, dank je wel voor je gezelschap en belangstelling Cobie Martens, jij hielp Marliese en mij op gang met de lay-outerie, waarvoor hartelijk dank. Een woord van dank natuurlijk ook aan alle lunchwandelaars die dagelijks de Tour de Heugem afleggen en voor gezellige ontspanning zorgen. De leden van de Chicken-Club, bedankt voor alle uitjes en het vooruitzicht op modderbaden!

Familie en vrienden bedank ik voor hun interesse in mijn werk.

Robert, bedankt voor je hulp bij de vormgeving van de cover van het proefschrift. Sylvia, mijn paranimf van het thuisfront, je bent een fantastische zus en ik ben heel blij dat je me ook tijdens de promotie terzijde zult staan.

Lieve mam, je staat altijd voor ons klaar. Bedankt woor al je steun, begrip en vertrouwen. Dit proefschrift draag ilk op aan jou en pap.

Lieve Alexander, bedankt voor alles wat we samen delen!

Nicole Jansen

Reuver, Oktober 2003 


\section{ABOUT THE AUTHOR}

Nicole Jansen was born on October 24, 1974 in Reuver, the Netherlands. After completing secondary school (WO) at the Bisschoppelijk College Broekhin in Roermond in 1993, she studied Health Sciences at Maastricht University and graduated cum laude in Mental Health Sciences in 1998. In the same year, she graduated cum laude in Biological Psychology at the Faculty of Psychology of Maastricht University, From January 1999 till July 2003 she worked as a PhD student at the department of Epidemiology, Maastricht University, on a research project examining the effects of various working time arrangements on both fatigue and work-family conflict. This project is part of the Maastricht Cohort Study on "Fatigue at Work" and resulted in the present thesis. Since August 2003 Nicole works as a postdoctoral fellow at the department of Epidemiology of Maastricht University on a project examining the effectiveness of early treatment of employees with an increased risk of long-lerm sickness absenteeism. 